\title{
Uso de Estratégias Baseadas em Conhecimento para Algoritmos Genéticos Aplicados à Predição de Estruturas Tridimensionais de Proteínas
}

\author{
Lariza Laura de Oliveira
}

\author{
DISSERTAÇÃO APRESENTADA \\ $\mathrm{AO}$ \\ PROGRAMA INTERUNIDAdES EM BIOINFORMÁTICA \\ DA \\ UNIVERSIDAdE DE SÃo PAUlo \\ PARA \\ OBTENÇÃO DO GRAU \\ DE \\ Mestre EM CiÊNCIAS
}

Área de Concentração: Bioinformática

Orientador: Prof. Dr. Renato Tinós

Durante o desenvolvimento deste trabalho o autor recebeu auxílio financeiro da FAPESP 


\title{
Uso de Estratégias Baseadas em Conhecimento para Algoritmos Genéticos Aplicados à Predição de Estruturas Tridimensionais de Proteínas
}

\author{
Este exemplar corresponde à redação \\ final da dissertação devidamente corrigida \\ e defendida por Lariza Laura de Oliveira \\ e aprovada pela Comissão Julgadora.
}

Comissão Julgadora:

- Profa. Dr. Renato Tinós (Orientador) - FFCLRP-USP

- Prof. Dr. Paulo Sergio Lopes de Oliveira - Incor-HCFMUSP

- Prof. Dr. Alexandre Claudio Botazzo Delbem - ICMC-USP 


\section{Agradecimentos}

Meus sinceros agradecimentos aos professores Renato Tinós e Fernando L. Barroso da Silva pela orientação, incentivo, paciência, disponibilidade e ensinamentos durante a realização deste projeto.

Ao professor Luiz Otávio Murta Junior por ter gentilmente cedido um de seus servidores para a realização de nossos experimentos.

Aos professores Alexandre Claudio Botazzo Delbem, Paulo Sergio Lopes de Oliveira e Sergio Emanuel Galembeck membros da banca de qualificação, pelas contribuições feitas.

Agradeço aos meus pais que apoiaram e incentivaram minha decisão de iniciar o mestrado, bem como a paciência durante os períodos em que não foi possível visitá-los com muita frequência.

Agradeço ao meu namorado Hugo pelo apoio, companheirismo e paciência em todos os momentos, principalmente nos mais difíceis.

Aos amigos de laboratório e laboratórios vizinhos pelo convívio, troca de experiências acadêmicas e claro, principalmente, pela simples amizade.

Aos amigos que mesmo estando distantes fisicamente sempre estiveram próximos o bastante.

Por fim, agradeço a FAPESP, cujo apoio financeiro foi fundamental para a execução deste projeto. 


\section{Resumo}

Proteínas desempenham uma grande variedade de funções biológicas. O conhecimento da estrutura tridimensional proteica pode ajudar no entendimento da função desempenhada. De acordo com a hipótese de Anfisen, a estrutura terciária nativa de uma proteína pode ser determinada a partir da informação contida na sequência primária, o que permitiria que métodos computacionais poderiam ser usados para predizer estruturas terciárias quando a primária estiver disponível. No entanto, ainda não existe uma ferramenta computacional capaz de predizer a estrutura tridimensional para uma grande variedade de proteínas. Desse modo, o problema de Predição de Estruturas de Proteínas (PEP) permanece como um desafio para a Biologia Molecular. A conformação nativa de uma proteína é frequentemente a configuração termodinamicamente mais estável, ou seja, que possui menor energia livre. Assim, PEP pode ser vista como um problema de otimização, onde a estrutura com menor energia livre deve ser encontrada dentre todas as possíveis. Entretanto, este é um problema NP-completo, no qual métodos tradicionais de otimização, em geral, não apresentam um bom desempenho. Algoritmos Genéticos (AGs), devido às suas características, são interessantes para essa classe de problemas. O principal objetivo desse trabalho é verificar se a adição de informação pode ser útil aos AGs aplicados em PEP, valendo-se dede modelos moleculares simplificados. Cada indivíduo do AG representa uma solução que, neste caso, é uma possível conformação que será avaliada por um campo de força. Dessa forma, o indivíduo é codificado por um conjunto de ângulos de torção de cada aminoácido. Para auxiliar no processo de busca, bases de dados compostas de ângulos determinados por cristalografia e RNM são utilizadas. Com o objetivo de guiar o processo de busca e manter a diversidade nos AGs, duas estratégias são aqui testadas: Imigrantes Aleatórios e Imigrantes por Similaridade. A última delas foi criada baseando-se na similaridade da sequência primária. Além disso, é investigado neste trabalho o uso de um campo de força coarse-grained, que utiliza os átomos de carbono- $\alpha$ para representar a cadeia proteica, para avaliar os indivíduos do AG.

Palavras-chave: Algoritmos Genéticos, Predição de Estruturas de Proteínas, Modelo Coarse-Grained. 


\section{Abstract}

Proteins exhibit an enormous variety of biology functions. The knowledge of tertiary structures can help the understanding of the protein's function. According to Anfisen, the native tertiary structure of a protein can be determined by its primary structure information, what could allow that computational methods could be used to predict the tertiary structure when the primary structure is available. However, there is still not a computational tool to solve the structure prediction problem for a large range of proteins. In this way, Protein Structure Prediction (PSP) has been a challenge to Molecular Biology. The conformation of native protein is usually the thermodynamically most stable configuration, i.e., the one having the lowest free energy. Hence, PSP can be viewed as a problem of optimization, where the structure with the lowest free energy should be found among all possible structures. However, this is an NP-problem, where traditional optimization methods, in general, do not have good performance. Genetic algorithms (GAs), due to their characteristics, are interesting for this class of problems. In recent years, there is a growing interest in using GAs for the protein structure prediction problem. The main objective of this work is to verify the addition of useful information to GAs employed in PSP. Each individual of the GA represents a solution for the optimization problem which is, in this case, a possible conformation that will be evaluated by a force field function. Thus, an individual is encoded by a set of torsion angles of each amino acid. In order to reduce the search space, a database composed of angles, determined by crystallography and NMR, is used. With the aim to guide the final search process and maintain diversity in GAs, two strategies were employed here: Random Immigrants and Similarity-based Immigrants. The last strategy was based on similarity of primary amino acid sequence. Furthermore, in this work, a coarse-grained force field, which uses $\alpha$-carbon to represent the protein backbone was employed to evaluate the individuals of GA.

Keywords: Genetic Algorithms, Protein Structure Predition, Coarse-Grained Model. 


\section{Sumário}

Lista de Abreviaturas $\quad$ xi

Lista de Figuras

$\begin{array}{ll}\text { Lista de Tabelas } & \text { xvii }\end{array}$

1 Introdução 1

1.1 Motivação ........................... 2

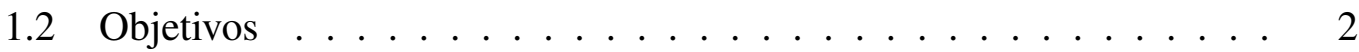

1.3 Organização do Trabalho . . . . . . . . . . . . . . . 3

2 Proteínas 5

2.1 Níveis Estruturais . . . . . . . . . . . . . . . . . . . 6

$2.1 .1 \quad$ Estrutura Primária $\ldots \ldots \ldots \ldots$

2.1.2 Estrutura Secundária . . . . . . . . . . . . . . 8

2.1.3 Estrutura Terciária . . . . . . . . . . . . . . 9

2.1.4 Estrutura Quaternária . . . . . . . . . . . . . . . . . 10

2.2 Motivos e Domínios . . . . . . . . . . . . . . . 10

2.3 Dobramento de Proteínas . . . . . . . . . . . . . . . . . . 11

2.4 Métodos Experimentais de Determinação de Estrutura Tridimensional de Proteína . . . . . . . . . . . . . . . . . . . . . 12

2.4.1 Ressonância Nuclear Magnética . . . . . . . . . . . . . 13

2.4.2 Cristalografia de Raios-X . . . . . . . . . . . . . 13

3 Predição de Estruturas de Proteínas $\quad 15$

3.1 Modelagem baseada em conhecimento . . . . . . . . . . . . . . 16

3.1.1 Modelagem baseada em homologia ou Modelagem Comparativa 16 
3.1.2 Threading.................... 17

3.2 Modelagem por Primeiros Princípios . . . . . . . . . . . . . 18

3.3 Sistemas de PEP que merecem destaque . . . . . . . . . . . . . 18

$3.3 .1 \quad$ ROSETTA . . . . . . . . . . . . . . 18

3.3.2 I-Tasser . . . . . . . . . . . . . . . . . . 19

3.4 Campos de Força . . . . . . . . . . . . . . . . . . . . 21

3.5 Algoritmos Genéticos . . . . . . . . . . . . . . . . . 21

3.5.1 O Algoritmo Genético Padrão . . . . . . . . . . . . . 22

3.6 Aplicações de AGs em PEP . . . . . . . . . . . . . . . . . 25

4 Metodologia $\quad 27$

4.1 Bases de Dados de Ângulos . . . . . . . . . . . . . . . . . . . 27

4.1.1 Base de Dados da Cadeia Principal . . . . . . . . . . . 28

4.1.2 Base de Dados da Cadeia Lateral . . . . . . . . . . . . . . 29

4.2 O AG implementado . . . . . . . . . . . . . . . . . . . . 29

4.2.1 Codificação do AG . . . . . . . . . . . . . . . 30

4.2 .2 Operadores utilizados . . . . . . . . . . . . . 31

4.2.3 Estratégias Baseadas em Imigrantes . . . . . . . . . . . 33

4.3 Funções de Avaliação . . . . . . . . . . . . . . . . . . . . . 35

4.3.1 Modelo CG . . . . . . . . . . . . . . . . . . 36

4.3 .2 Modelo full-atom . . . . . . . . . . . . . . . 41

4.4 Proteínas selecionadas . . . . . . . . . . . . . . . . . . 42

4.4.1 Proteína Receptora de Acetilcolina . . . . . . . . . . . . . . . 42

4.4 .2 Proteína MSI-594 . . . . . . . . . . . . . . . . . . 42

4.4 .3 Proteína DNA-ligante . . . . . . . . . . . . 43

4.4 .4 Proteína $G \ldots \ldots . \ldots . \ldots . \ldots . \ldots 43$

4.4.5 Proteína Fosfatase . . . . . . . . . . . . . . . . 44

5 Resultados e discussões $\quad 45$

5.1 Descrição dos experimentos . . . . . . . . . . . . . . 45

5.2 Experimentos com o modelo CG . . . . . . . . . . . . . 47

5.2.1 Experimento 1: Modelo CG sem predição de estrutura secundária . . . . . . . . . . . . . . . . . 4 47 
5.2.2 Experimento 2: Modelo CG com predição de estrutura secundária . . . . . . . . . . . . . . . 50

5.3 Experimentos com o modelo Full-atom . . . . . . . . . . 72

5.3.1 Experimento 3: Otimização da cadeia lateral . . . . . . . . 72

5.4 Análise dos resultados obtidos . . . . . . . . . . . . . 88

$5.4 .1 \quad$ Experimento $1 \ldots \ldots \ldots . \ldots \ldots$

5.4 .2 Experimento $2 \ldots \ldots \ldots \ldots$

5.4 .3 Experimento $3 \ldots \ldots \ldots$. . . . . . . . . . 90

5.4.4 Comparação entre os experimentos . . . . . . . . . . 9 91

6 Conclusões $\quad 95$

A Função de avaliação para o modelo full-atom 97

A.1 Energia do Comprimento de Ligação (ECL) . . . . . . . . . . . . . 98

A.2 Energia do Ângulo de Ligação (EAL) . . . . . . . . . . . . . . 100

A.3 Energia do Ângulo de Torção (EAT) . . . . . . . . . . . . . . . 101

A.4 Energia de Urey-Bradley (EUB) $\ldots \ldots$. . . . . . . . . . . 103

A.5 Energia Torção-Torção (ETT) . . . . . . . . . . . . . . . . . . . . . 104

A.6 Energia Imprópria $(\mathrm{EI}) \quad \ldots \ldots$

A.7 Energia de Van der Waals . . . . . . . . . . . . . . . . 105

A.8 Energia Eletrostática $(\mathrm{EE}) \ldots \ldots \ldots$

$\begin{array}{ll}\text { Referências Bibliográficas } & 107\end{array}$ 


\section{Lista de Abreviaturas}

AG

AGA6

AGAutoOrg

AGP

AGS6

CG

PEP

RMSD

RNM

Algoritmo genético

Algoritmo genético com $6 \%$ de imigrantes aleatórios

Algoritmo genético auto-organizável

Algoritmo genético padrão

Algoritmo genético com $6 \%$ de imigrantes por similaridade Coarse-grained

Predição de estruturas de proteínas

Root mean square deviation

Ressonância nuclear magnética 


\section{Lista de Figuras}

2.1 Ângulos de torção $\phi$ e $\psi$. R é a cadeia lateral do aminoácido. . . . . . 6

2.2 Diagrama de Ramachandran (adaptado de [Unizar, 2010]). . . . . . . 8

2.3 Exemplo de $\alpha$-hélice que constitui a estrutura nativa da proteína receptora de acetilcolina (PDB:1A11) . . . . . . . . . . . 9

2.4 Exemplos de folha- $\beta$ que constitue a estrutura do grampo $\beta$ (PDB:2EVQ). $\quad 9$

2.5 Exemplo de estrutura terciária da proteína G (PDB:2GB1). . . . . . . 10

2.6 Exemplo de estrutura quaternária que constitui a proteína hemoglobina $($ PDB: $2 \mathrm{~W} 6 \mathrm{~V}) \ldots \ldots \ldots \ldots$

2.7 Funil de energia livre que descreve o enovelamento protéico, adaptado de $[$ Dill, 2010]. . . . . . . . . . . . . . . . . . . 12

3.1 Algoritmo Genético: funcionamento básico. . . . . . . . . . . . 23

3.2 Funcionamento básico do crossover. . . . . . . . . . . . . . . . . 24

3.3 Funcionamento básico da mutação. . . . . . . . . . . . . . . . . . 24

4.1 Esquema do processamento da base de dados da cadeia principal. . . . 28

4.2 Codificação do AG para o caso mais geral (full-atom). . . . . . . . . . 31

4.3 Funcionamento do AG. . . . . . . . . . . . . . . . . . 33

4.4 Exemplo da energia potencial relacionada com o ângulo de ligação. 37

4.5 Energia dos ângulos diedrais. . . . . . . . . . . . . . . . 38

4.6 Gráfico típico para o termo de van der Waals do potencial de interação. 40

4.7 Representação da estrutura nativa da proteína 1A11 . . . . . . . . . . 42

4.8 Representação da estrutura nativa da Proteína 2K98. . . . . . . . . . . 43

4.9 Representação da estrutura nativa da proteína $1 \mathrm{ENH}$. . . . . . . . . . 43

4.10 Representação da estrutura nativa da proteína $2 \mathrm{~GB} 1$. . . . . . . . . . 44

4.11 Representação da estrutura nativa da proteína 2 W4P. . . . . . . . . . 44 
5.1 Média dos fitness mínimos (ou seja, obtidos pelo melhor indivíduo da população corrente) ao longo das gerações para a 2GB1 sem predição de estrutura secundária. . . . . . . . . . . . . . . . . . . . . . 49

5.2 Média dos fitness mínimos ao longo das gerações para a 2GB1 sem predição de estrutura secundária.

5.3 Estruturas preditas de menor energia e menor RMSD para a 2GB1sem predição de estrutura secundária. . . . . . . . . . . . . . 50

5.4 Média dos fitness mínimos ao longo das gerações para a 1A11 sem predição de estrutura secundária. . . . . . . . . . . . . . 51

5.5 Média dos RMSDs mínimos ao longo das gerações para a 1A11 sem predição de estrutura secundária. . . . . . . . . . . . . . . . . 52

5.6 Estruturas preditas de menor energia e menor RMSD para a 1A11. . . 52

5.7 Variação das taxas de imigrantes $\left(p_{i A}, p_{i S}\right.$ e $\left.1-p_{i}\right)$ para a $1 \mathrm{~A} 11 . \ldots 53$

5.8 Energia para a primeira execução do AGAutoOrg. . . . . . . . . . . . 53

5.9 RMSD para a primeira execução do AGAutoOrg. . . . . . . . . . . . 54

5.10 Média dos fitness mínimos ao longo das gerações para a 2K98. . . . . 56

5.11 Média dos RMSDs ao longo das gerações para a 2K98. . . . . . . . 56

5.12 Estrutura predita de menor e energia e menor RMSD para a 2K98. . . 57

5.13 Variação das taxas de imigrantes para a 2K98. . . . . . . . . . . . 57

5.14 Energia para a primeira execução do AGAutoOrg. . . . . . . . . . . . 58

5.15 RMSD para a primeira execução do AGAutoOrg. . . . . . . . . . . 58

5.16 Média dos fitness mínimos ao longo das gerações para a 1ENH. . . . 60

5.17 Média dos RMSDs mínimos ao longo das gerações para a 1ENH. . . . 60

5.18 Estruturas preditas de menor e energia e menor RMSD para a 1ENH. . 61

5.19 Variação das taxas de imigrantes para a 1ENH. . . . . . . . . . . . 61

5.20 Energia para a primeira execução do AGAutoOrg da 1ENH. . . . . . 62

5.21 RMSD para a primeira execução do AGAutoOrg da 1ENH. . . . . . . 62

5.22 Média dos fitness mínimos ao longo das gerações para a 2GB1 com predição de estrutura secundária. . . . . . . . . . . . . . . 64

5.23 Média dos RMSDs do melhor indivíduo ao longo das gerações para a 2GB1 com predição de estrutura secundária. . . . . . . . . . . . . 65

5.24 Estruturas preditas de menor e energia e menor RMSD para a 2GB1, com predição de estrutura secundária. . . . . . . . . . . . . . . 65 
5.25 Variação das taxas de imigrantes para a 2GB1. . . . . . . . . . . . 66

5.26 Energia para a primeira execução do AGAutoOrg. . . . . . . . . . . 66

5.27 RMSD para a primeira execução do AGAutoOrg. . . . . . . . . . . . 67

5.28 Média dos fitness mínimos ao longo das gerações para a 2W4P. . . . . 68

5.29 Média dos RMSDs mínimos ao longo das gerações para a 2W4P. . . . 69

5.30 Estruturas preditas de menor energia e menor RMSD para a 2W4P. . . 69

5.31 Variação das taxas de imigrantes para a 2W4P. . . . . . . . . . . 70

5.32 Energia para a primeira execução do AGAutoOrg. . . . . . . . . . . . 70

5.33 RMSD para a primeira execução do AGAutoOrg. . . . . . . . . . . 71

5.34 Média dos fitness mínimos ao longo das gerações para a 1A11 com modelo full-atom . . . . . . . . . . . . . . . . 74

5.35 Média dos RMSDs ao longo das gerações para a 1A11 com modelo full-atom. . . . . . . . . . . . . . . 75

5.36 Estruturas preditas de menor energia e menor RMSD para a $1 \mathrm{~A} 11 \mathrm{com}$ modelo full-atom . . . . . . . . . . . . . . . . . . . . 75

5.37 Média dos fitness mínimos ao longo das gerações para a 2K98 com modelo full-atom . . . . . . . . . . . . . . . . . . 76

5.38 Média dos RMSDs ao longo das gerações para a 2K98 com modelo full-atom. ........................ 77

5.39 Estruturas preditas de menor energia e menor RMSD para a $2 \mathrm{~K} 98 \mathrm{com}$ modelo full-atom . . . . . . . . . . . . . . . . . .

5.40 Média dos fitness mínimos ao longo das gerações para a 1ENH com modelo full-atom . . . . . . . . . . . . . . . . . . . . 78

5.41 Média dos RMSDs ao longo das gerações para a 1ENH com modelo full-atom . . . . . . . . . . . . . . . . . . 79

5.42 Estruturas preditas de menor e Energia e menor RMSD para a 1ENH com modelo full-atom. . . . . . . . . . . . . . . . . . . . 79

5.43 Média dos fitness mínimos ao longo das gerações para a 2GB1 para o modelo full-atom . . . . . . . . . . . . . . . . . . . . . . . 80

5.44 Média dos RMSDs ao longo das gerações para a 2GB1 para o modelo full-atom. ....................... 8

5.45 Estruturas preditas de menor e energia e menor RMSD para a 2GB1 com modelo full-atom. . . . . . . . . . . . . . . . . . 81

5.46 Variação das taxas de imigrantes para a 2GB1 . . . . . . . . . . . . 82 
5.47 Energia para a primeira execução do AGAutoOrg. . . . . . . . . . 82

5.48 RMSD para a primeira execução do AGAutoOrg. . . . . . . . . . . . 83

5.49 Média dos fitness mínimos ao longo das gerações para a 2W4P com modelo full-atom . . . . . . . . . . . . . . . . . . . 84

5.50 Média dos RMSDs ao longo das gerações para a 2W4P com modelo full-atom. . . . . . . . . . . . . . . . 84

5.51 Estruturas preditas de menor energia e menor RMSD para a 2W4P com modelo full-atom. . . . . . . . . . . . . . . 85

5.52 Variação das taxas de imigrantes para a 2W4P. . . . . . . . . . . 86

5.53 Energia para a primeira execução do AGAutoOrg. . . . . . . . . . . 86

5.54 RMSD para a primeira execução do AGAutoOrg. . . . . . . . . . . . 87

5.55 Tempo computacional gasto pelo o modelo CG para as proteínas 1ENH e 2 GB $1 \ldots \ldots \ldots \ldots \ldots$

5.56 Tempo computacional gasto pelo o modelo full-atom para as proteínas

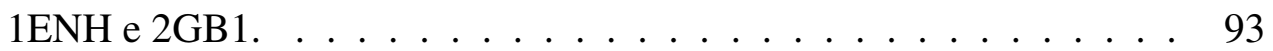

A.1 Codificação dos átomos do CHARMM22 . . . . . . . . . . . . . . . 98

A.2 Trecho do arquivo de parâmetros do CHARMM22, contendo alguns parâmetros do comprimento de ligação. . . . . . . . . . . . . . 99

A.3 Energia do Comprimento de Ligação. . . . . . . . . . . . . . . . . . 99

A.4 Fragmento do arquivo de parâmetros do CHARMM22 contendo alguns parâmetros do ângulo de ligação. . . . . . . . . . . . . . . . 100

A.5 Energia do Ângulo de Ligação. . . . . . . . . . . . . . . . . . . . 101

A.6 Fragmento do arquivo de parâmetros do CHARMM22 contendo alguns parâmetros de torção. . . . . . . . . . . . . . . . . . . . . . 102

A.7 Energia do ângulo de torção. . . . . . . . . . . . . . . . . . . 103

A.8 Fragmento do arquivo de parâmetros do CHARMM22 contendo alguns parâmetros de Urey-Bradley. . . . . . . . . . . . . . . . . . . . 104 


\section{Lista de Tabelas}

4.1 Parâmetros dos vários tipos diedrais [Yap et al., 2008]. . . . . . . . . 38

4.2 Parâmetros dos vários tipos diedrais [Brown et al., 2003] . . . . . . . 39

4.3 Mapeamento [Yap et al., 2008]. . . . . . . . . . . . . . . . . . . 40

4.4 Valores para S1 e S2 [Yap et al., 2008]. . . . . . . . . . . . . 40

5.1 Teste de Parâmetros: Energia mínima (do melhor indíviduo) em unidades de $\epsilon_{h} \ldots \ldots \ldots \ldots$. . . . . . . . . . . . . . . . 45

5.2 Experimentos realizados. . . . . . . . . . . . . . . . . 46

5.3 Valores da energia total para a 2GB1 sem predição de estrutura secundária (valores relativos a 10 execuções) . . . . . . . . . . . . . . . . 48

5.4 RMSD para a 2GB1 sem predição de estrutura secundária. . . . . . . 48

5.5 Teste Estatístico para a 2GB1. . . . . . . . . . . . . . . . . . . 48

5.6 Valores da energia total para a $1 \mathrm{~A} 11 \ldots \ldots \ldots$

5.7 RMSD para a $1 \mathrm{~A} 11 \ldots \ldots \ldots \ldots \ldots$

5.8 Teste estatístico para a 1A11. . . . . . . . . . . 51

5.9 Valores da energia total para a 2 K98 . . . . . . . . . . . 55

5.10 RMSD para a 2 K98. . . . . . . . . . . . . . . . 55

5.11 Teste estatístico para a 2K98. . . . . . . . . . . 55

5.12 Valores da energia total para a 1ENH. . . . . . . . . . . . 59

5.13 RMSD para a 1 ENH. . . . . . . . . . . . . . . . . . . 59

5.14 Teste estatístico para a 1ENH. . . . . . . . . . . . . . 59

5.15 Valores da energia total para a 2GB1 com PES. . . . . . . . . . . 63

5.16 RMSD para a 2GB1 com predição de estrutura secundária. . . . . . . 63

5.17 Teste estatístico para 2GB1 no Experimento 2. . . . . . . . . . 63

5.18 Valores da energia total para a 2W4P. . . . . . . . . . . . 67

5.19 RMSD para a 2 W4P. . . . . . . . . . . . . 68 
5.20 Teste estatístico para a 2W4P. . . . . . . . . . . . . . . 68

5.21 Termos de energia empregando o CHARMM22 para a 2GB1 . . . . . 72

5.22 Valores da energia total para otimização da cadeia lateral. . . . . . . . 73

5.23 Termos de Energia no experimento de otimização da cadeia lateral. . . 73

5.24 Valores da energia total para 1A11. . . . . . . . . . . . 74

5.25 RMSD para a 1 A11. . . . . . . . . . . . . . . . 74

5.26 Teste de Wilcoxon para a 1A11 com modelo full-atom. . . . . . . . 75

5.27 Energias para a 2K98 com modelo full-atom. . . . . . . . . . . 76

5.28 RMSD para a 2 K98 com modelo full-atom. . . . . . . . . . . . 76

5.29 Teste de Wilcoxon para a 2K98 com modelo full-atom. . . . . . . . . 77

5.30 Energias para a 1ENH com modelo full-atom . . . . . . . . . 78

5.31 RMSD para a 1ENH com modelo full-atom . . . . . . . . . . . 78

5.32 Teste de Wilcoxon para a 1ENH com modelo full-atom. . . . . . . . . 79

5.33 Energias para a 2GB1 com modelo full-atom. . . . . . . . . . 80

5.34 RMSD para a 2 GB1 com modelo full-atom . . . . . . . . . . . 80

5.35 Teste de Wilcoxon para a 2GB1 com modelo full-atom. . . . . . . . . 81

5.36 Energias para a 2W4P com modelo full-atom. . . . . . . . . . . 83

5.37 RMSD para a 2W4P com modelo full-atom . . . . . . . . . . . 83

5.38 Teste de Wilcoxon para a 2W4P com modelo full-atom. . . . . . . . . 85

5.39 Termos de Energia para a 1A11 pelo modelo CG. . . . . . . . . . . . 88

5.40 Máximo Score e e-value obtidos pelo Blast para as proteínas utilizadas. 89

5.41 Ranking dos algoritmos com CG que obtiveram menor energia mediana no Experimento 2. . . . . . . . . . . . . . . . . . 90

5.42 Ranking dos algoritmos com CG que obtiveram menor RMSD no Experimento $2 \ldots \ldots \ldots \ldots$

5.43 Ranking dos algoritmos com full-atom que obtiveram menor Energia no Experimento 3. . . . . . . . . . . . . . . . . . . . 91

5.44 Ranking dos algoritmos com full-atom que obtiveram menor RMSD no Experimento 3. . . . . . . . . . . . . . . . . . . . . 91 


\section{Capítulo 1}

\section{Introdução}

O problema de Predição de Estruturas Tridimensionais de Proteínas (PEP) através de métodos computacionais é um das questões centrais da Biologia Molecular, ainda sem uma solução completa [Pedersen e Moult, 1996; Unger, 2004; Zhang, 2008]. O conhecimento de estruturas tridimensionais é de vital importância para o entendimento das funções das diferentes proteínas, as quais são fundamentais para a maioria dos processos biológicos.

A conformação nativa de uma proteína é usualmente a termodinamicamente mais estável, ou seja, a de menor energia livre [Leach, 2001]. Assim, o problema de PEP através de computadores pode ser visto como um problema complexo de otimização, no qual dada uma sequência de aminoácidos, deve-se determinar qual é a estrutura nativa da proteína, dentre todas as estruturas possíveis.

PEP é um problema NP-completo [Liang e Wong, 2001]. Além disso, conta com a presença de um grande número de ótimos locais, parâmetros envolvidos e com a falta de conhecimento sobre as relações entre a função de avaliação (normalmente uma função da energia potencial da estrutura) e as variáveis do campo de força que estão sendo utilizadas no processo de otimização [Jiang et al., 2003]. Dessa forma, dois pontos cruciais que devem ser considerados para o problema de PEP são: a escolha do método de otimização e a escolha da função de energia.

Algoritmos Genéticos (AGs) podem ser considerados interessantes para problemas com tais características. De fato, tem havido interesse regular em aplicar AGs na determinação da estrutura tridimensional de proteínas [Bonetti, 2010; Cooper et al., 2003; De Lima et al., 2007; Do Ó, 2009; Faccioli et al., 2007; Gabriel, 2010; Hoque et al., 2011; Jiang et al., 2003; Nugent et al., 2011; Pedersen e Moult, 1996; Schulze-Kremer, 2003a; Unger, 2004; Unger e Moult, 1993; Zhang et al., 2010]. Uma das características interessantes dos AGs é que eles utilizam uma população de possíveis soluções, o que pode facilitar a fuga de ótimos locais, pelo menos no princípio do processo de otimização.

A utilização de AGs para o problema de PEP tem frequentemente adotado abordagens 
ab initio [Cooper et al., 2003; Do Ó, 2009; Schulze-Kremer, 2003a; Unger, 2004; Unger e Moult, 1993], que não fazem uso de características intrínsecas do problema, por exemplo, a similaridade com proteínas parecidas, cujas estruturas tridimensionais já tenham sido obtidas por técnicas experimentais. Este trabalho propõe o estudo e a utilização de AGs com a incorporação desse conhecimento para guiar o processo de otimização no espaço de busca do problema. As características do problema são investigadas para, principalmente, a composição da população inicial e de imigrantes, os quais são indivíduos inseridos periodicamente na população dos AGs e gerados conforme algum critério.

Empregar uma função de avaliação eficiente e com custo computacional reduzido também é um ponto fundamental em PEP. Neste trabalho, o modelo minimalista ou CG (coarse-grained), proposto para o problema de dobramento proteico em [Yap et al., 2008], é investigado para o problema de PEP utilizando AGs. Este modelo permite a reprodução de características do dobramento com um menor número de graus de liberdade, reduzindo o custo computacional e viabilizando testes que seriam muito custosos com Hamiltonianas mais complexas. Os resultados com este modelo são comparados com os obtidos pelo modelo full-atom CHARMM versão 22.

\subsection{Motivação}

O Projeto Genoma disponibilizou grandes quantidades de sequências de DNA e genomas completos de organismos. Contudo, esse material só é útil quando processado e analisado. É necessário saber onde estão os genes, quais proteínas eles codificam e qual função essas proteínas desempenham. Neste contexto, o número de sequências de proteínas conhecidas é muito maior que o número de estruturas tridimensionais conhecidas. No entanto, o processo de determinação experimental de proteínas nem sempre pode ser aplicado a todas as proteínas, o que torna necessário o desenvolvimento de abordagens computacionais. Além disso, investigar o desenvolvimento de novos operadores para os AGs pode ser interessante, uma vez que eles poderão futuramente ser empregados também em outros problemas.

\subsection{Objetivos}

Este trabalho tem como principal objetivo estudar a PEP computacionalmente, testando e pesquisando técnicas para inserção do conhecimento em AGs, valendo-se de um modelo CG. Deseja-se verificar o comportamento e a manutenção da diversidade com a inclusão desse tipo de informação. As técnicas criadas poderão ser empregadas em outros problemas que utilizem AGs. Cabe ressaltar que este trabalho não possui o objetivo de solucionar o problema de predição de estruturas de proteínas. O objetivo é investigar se a inserção de conhecimento através de imigrantes (soluções) construídas através de similaridade com estruturas conhecidas é útil em AGs aplicados a PEP. 
Verifica-se também se a associação dos imigrantes construídos com similaridade e dos imigrantes aleatórios é útil neste problema.

Além disso, como objetivo secundário, é investigado se um campo de força coarsegrained, o qual foi usado apenas para dobramento proteico, é útil para AGs aplicados ao problema de PEP.

\subsection{Organização do Trabalho}

Este trabalho está organizado em: Capítulo 2, no qual são fornecidos conceitos básicos sobre proteínas; Capítulo 3, que apresenta as principais abordagens e trabalhos relacionados à Predição de Estruturas de Proteínas; Capítulo 4, no qual é apresentada a metodologia utilizada neste trabalho; Capítulo 5, no qual são apresentados os resultados obtidos e Capítulo 6, que apresenta as conclusões obtidas. 
4 INTRODUÇÃO 


\section{Capítulo 2}

\section{Proteínas}

Proteínas são macromoléculas vitais para o funcionamento da maioria dos processos biológicos. Elas são responsáveis por executar importantes atividades codificadas por genes [Lodish et al., 2003]. Essas atividades, muitas vezes, exigem a ação conjunta de várias proteínas. Ao longo de bilhões de anos de evolução, as proteínas passaram por um processo de desenvolvimento e refinamento, tanto estrutural, quanto funcional [Alberts et al., 2006; Branden et al., 1991]. Essa evolução proporcionou a aquisição de atividades especializadas. Entre as principais funções biológicas das proteínas [Alberts et al., 2006], destacam-se: catálise, transporte, armazenamento, motilidade, defesa e regulação. A atividade funcional proteica é diretamente dependente de sua estrutura tridimensional. Assim, o conhecimento de estruturas proteicas é fundamental para o estudo de suas funções [Lehninger et al., 2005].

A organização espacial de proteínas é chamada de conformação [Lehninger et al., 2005]. Uma proteína pode ter várias conformações. Essa propriedade reflete características funcionais, por exemplo, a participação em reações e a interação com ligantes. Normalmente, as conformações predominantes são as termodinamicamente mais estáveis. Quando encontradas em alguma de suas conformações funcionais, as proteínas são chamadas de nativas.

As proteínas são compostas por aminoácidos unidos por ligações covalentes, chamadas ligações peptídicas. A ligação peptídica, que une os aminoácidos, é planar, ou seja, os átomos do grupo peptídico encontram-se no mesmo plano [Lehninger et al., 2005]. A ligação peptídica $C-N$ não consegue girar livremente, pois possui um caráter parcial de dupla ligação. Isso ocorre porque existe ressonância ou compartilhamento de pares de elétrons $\pi$ entre o nitrogênio da amida e o oxigênio da carbonila. As ligações $N-C_{\alpha}$ e $C_{\alpha}-C$ conseguem rotacionar, e os ângulos formados a partir de suas rotações são chamados, respectivamente de $\phi$ (fi) e $\psi$ (psi).

Dessa forma, o esqueleto polipeptídico é formado por uma série de planos capazes de rotacionar apenas em pontos comuns, ou seja, os átomos de $C_{\alpha}$, como ilustrado na Figura 2.1. 


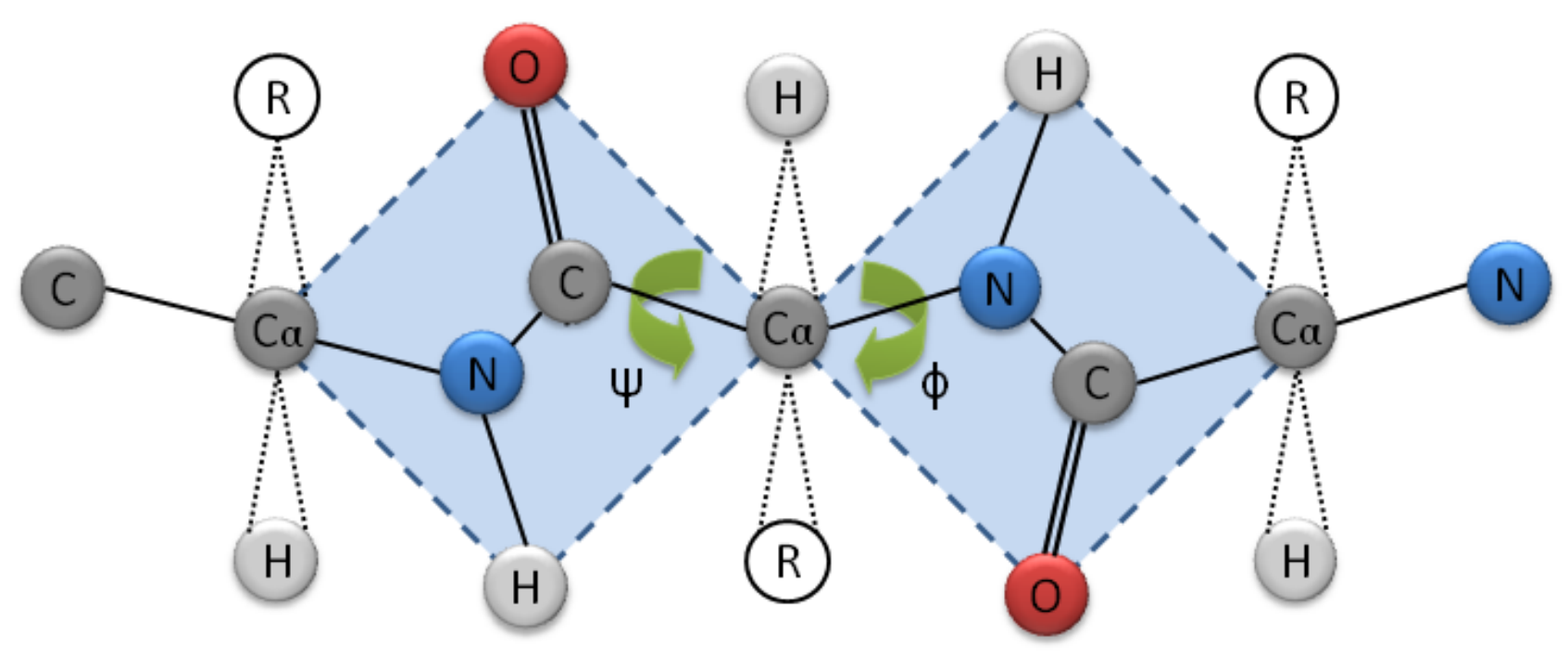

Figura 2.1: Ângulos de torção $\phi$ e $\psi$. Ré a cadeia lateral do aminoácido.

\subsection{Níveis Estruturais}

Proteínas são organizadas nos níveis estruturais: primário, secundário, terciário e quartenário. Estas e outras definições de organização estrutural, como domínios e motivos, além de uma breve discussão sobre o dobramento proteico, são fornecidas a seguir.

\subsubsection{Estrutura Primária}

A sequência de aminoácidos representa a estrutura primária das proteínas. Os aminoácidos diferem entre si pelas suas cadeias laterais, ou grupos $\mathrm{R}$, que podem variar conforme carga, tamanho, estrutura e polaridade. As diferentes propriedades das cadeias laterais dos aminoácidos são responsáveis por produzir uma diversa variedade de proteínas funcionalmente distintas [Leach, 2001]. De acordo com [Lehninger et al., 2005], os aminoácidos podem ser classificados, em função da cadeia lateral, em 5 grupos:

- Alifáticos e apolares: glicina (G), alanina (A), prolina (P), valina (V), leucina (L), isoleucina (I) e metionina (M);

- Aromáticos: fenilalanina $(\mathrm{F})$, tirosina $(\mathrm{Y})$ e triptofano $(\mathrm{W})$;

- Polares e não-carregados: serina $(\mathrm{S})$, treonina $(\mathrm{T})$, cisteína $(\mathrm{C})$, asparagina $(\mathrm{N})$ e glutamina (R);

- Positivamente carregados: lisina (K), histidina (H) e arginina (R);

- Negativamente carregados: aspartato (D) e glutamato (E).

Alguns aminoácidos possuem características especiais. Por exemplo, a glicina, que é o mais simples dos aminoácidos, não possui cadeia lateral, mas sim um hidrogênio 
em seu lugar. Essa propriedade faz com que a glicina não seja limitada estericamente [Voet e Voet, 2003]. Alguns autores [Alberts et al., 2006; Lehninger et al., 2005] consideram a glicina como sendo hidrofóbica, outros como [Branden et al., 1991] não a classificam como tal. Já a prolina possui uma cadeia cíclica diferente, com um grupo amino secundário (imino), o que reduz sua flexibilidade estrutural. Os aminoácidos metionina e cisteína possuem um enxofre em sua constituição. Essa propriedade faz com que duas cisteínas possam se unir através de ponte de dissulfeto formando uma cistina.

As diferenças entre os aminoácidos fazem também com que cada um possua uma curva de titulação característica. As curvas de titulação representam a variação do $\mathrm{pH}$ em função da adição de íons hidróxido $O H^{-}$, o que ocasiona a adição ou remoção de prótons $H^{+}$.

No caso da glicina, que é um aminoácido bastante simples, os únicos grupos tituláveis são o amino e o carboxila. Em pH muito baixo, a glicina encontra-se totalmente protonada. Ao longo da titulação, percebemos a existência de regiões da curva onde o $\mathrm{pH}$ varia pouco (região tamponante), ao passo que a adição de base aumenta rapidamente. Essas regiões representam a titulação de um grupo e seu ponto médio marca o $\mathrm{pK}^{1}$ do grupo. Assim, o grupo carboxila da glicina possui um $\mathrm{pK}$ de 2,34, enquanto que o grupo amino possui um pK de 9,6 [Lehninger et al., 2005]. Entre a titulação dos dois grupos, existe uma região da curva onde o $\mathrm{pH}$ varia rapidamente, enquanto a concentração de base permanece constante. $\mathrm{O}$ ponto médio dessa região representa o fim da titulação do grupo carboxila e o início da titulação do grupo amino. Este ponto é chamado de isoelétrico, uma vez que a carga líquida da molécula é igual a zero nesta situação.

Uma informação importante é que a presença de determinados grupos pode influenciar o pK de outros. Se isso não fosse verdade, todos os grupos carboxila, tanto de aminoácidos, quanto de outras moléculas, como ácidos carboxílicos por exemplo, seriam titulados com o mesmo pK, o que não ocorre. Em [Lehninger et al., 2005], o exemplo apresentado é o do ácido acético, cujo pKa de titulação do grupo carboxílico é igual a 4,74, diferente do pKa igual a 2,34 da glicina. Essa diferença é atribuída à presença do grupo amino positivo do aminoácido, que atua retirando o elétron do grupo carboxílico. Todos os aminoácidos que não possuem grupos tituláveis na cadeia lateral possuem uma curva de titulação semelhante à da glicina, com duas regiões de titulação. Já os que possuem grupos tituláveis na cadeia lateral apresentam uma curva de titulação mais complexa.

\footnotetext{
${ }^{1}$ Entende-se como $\mathrm{pK}$ a tendência de um grupo doar um próton. Quanto menor o pK, maior é essa tendência.
} 


\subsubsection{Estrutura Secundária}

A estrutura secundária de uma proteína é formada pela disposição espacial dos aminoácidos mais próximos entre si na estrutura primária. Alguns desses arranjos mais conhecidos são as folhas- $\beta$ e as $\alpha$-hélices. Esses arranjos não se formam por acaso, mas devido a estabilidade que ocasionam.

Teoricamente, os ângulos $\psi$ e $\phi$ podem variar entre $-180^{\circ} \mathrm{e}+180^{\circ}$, porém isso não é possível devido a interferências estéricas entre os átomos da cadeia. Os valores usualmente encontrados são mostrados no diagrama Ramachandran (Figura 2.2), no qual pode-se observar que as folhas- $\beta$ e as $\alpha$-hélices possuem combinações específicas de ângulos.

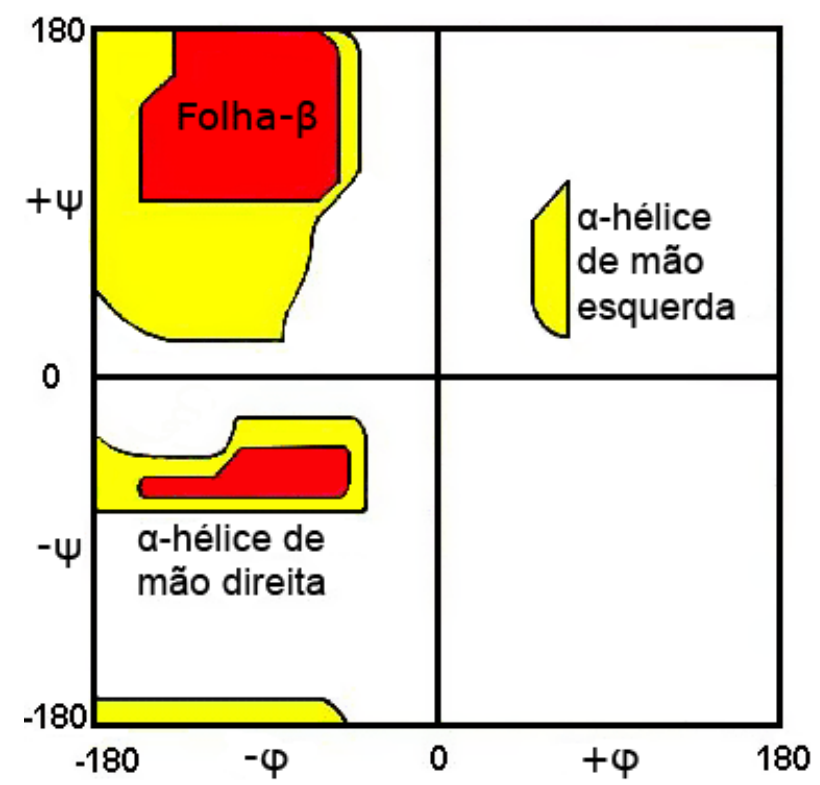

Figura 2.2: Diagrama de Ramachandran (adaptado de [Unizar, 2010]).

Nas estruturas helicoidais, a cadeia polipeptídica está enovelada em formato de hélice, em torno de um eixo imaginário, com suas cadeias laterais voltadas para o exterior da hélice (Figura 2.3). As $\alpha$-hélices são estruturas secundárias helicoidais mais comuns, onde cada volta da hélice possui 3,6 resíduos [Voet e Voet, 2003]. As hélices são estabilizadas por ligações de hidrogênio e interações de dispersão hidrofóbicas.

As figuras 2.3 e 2.4, que foram geradas através do aplicativo JMol [Herráez, 2006] usando estruturas depositadas no Protein Data Bank (PDB) ${ }^{2}$, mostram exemplos de $\alpha$-hélice e folha- $\beta$.

\footnotetext{
${ }^{2}$ Disponível em http://www.pdb.org
} 


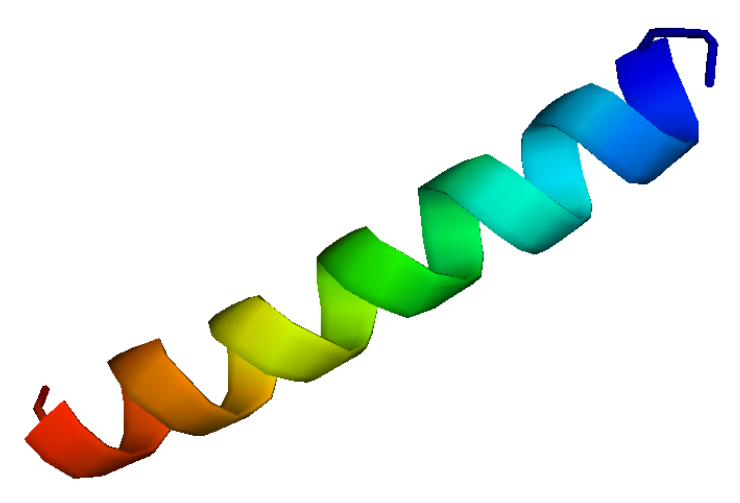

Figura 2.3: Exemplo de $\alpha$-hélice que constitui a estrutura nativa da proteína receptora de acetilcolina (PDB:1A11).

As folhas- $\beta$, por sua vez, são estruturas estendidas, onde as cadeias polipeptídicas podem se arranjar lado a lado, formando pontes de hidrogênio (Figura 2.4 ). As cadeias laterais ficam voltadas para o exterior. As folhas- $\beta$ podem ser paralelas ou anti-paralelas dependendo do sentido das cadeias.

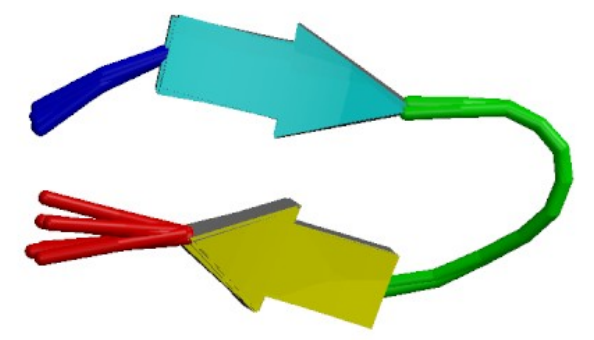

Figura 2.4: Exemplos de folha- $\beta$ que constitue a estrutura do grampo $\beta$ (PDB:2EVQ).

\subsubsection{Estrutura Terciária}

Estrutura terciária fornece a disposição espacial dos átomos dos aminoácidos que compõem a Estrutura Primária. É a forma tridimensional enovelada de uma proteína. A Figura 2.5 mostra um exemplo de estrutura terciária. Pode-se observar que nesta proteína existem $\alpha$-hélices e folhas- $\beta$. 


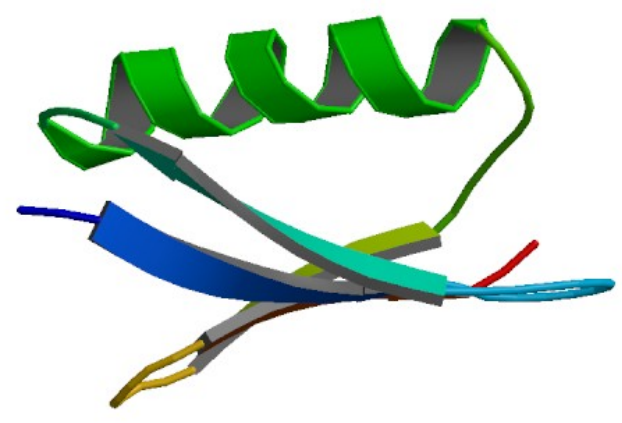

Figura 2.5: Exemplo de estrutura terciária da proteína $G(P D B: 2 G B 1)$.

\subsubsection{Estrutura Quaternária}

Algumas proteínas possuem mais de uma cadeia polipeptídica e a estrutura quaternária representa a disposição dessas cadeias dentro de estrutura proteica [Lehninger et al., 2005]. A Figura 2.6 mostra um exemplo de proteína com quatro cadeias polipeptídicas.

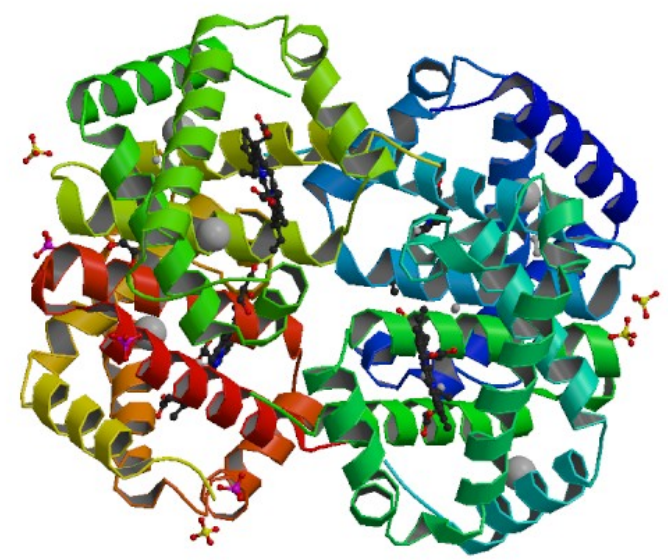

Figura 2.6: Exemplo de estrutura quaternária que constitui a proteína hemoglobina (PDB: 2W6V).

\subsection{Motivos e Domínios}

Motivos ou estruturas supersecundárias são arranjos estáveis formados por estruturas secundárias [Lehninger et al., 2005]. A forma mais comum é o motivo, que é composto por uma $\alpha$-hélice que faz uma conexão cruzada com duas folhas- $\beta$. Podemos citar outros motivos como: grampo $\beta$, canto $\alpha-\alpha$, barril $\beta$, entre outros. 
Domínios são unidades formando agregados globulares estáveis. A quantidade de resíduos necessários para que ocorra a formação dessas unidades não é consensual, sendo necessários mais de 100 resíduos segundo [Lehninger et al., 2005] e mais de 200 de acordo com [Voet e Voet, 2003].

Uma forma simples de se classificar domínios é considerando as estruturas secundárias que os formam. Assim domínios- $\alpha$ são formados por $\alpha$-hélices. Podemos citar também os domínios- $\beta$ e os domínios- $\alpha / \beta$.

\subsection{Dobramento de Proteínas}

Se considerarmos que para formar a estrutura tridimensional de uma proteína seja necessário explorar todo o espaço conformacional aleatoriamente até encontrar a conformação de menor energia, pode-se estimar o tempo necessário para tal tarefa. Considerando apenas os ângulos de torção $(\phi, \psi)$, de uma proteína com $n$ resíduos, que possui apenas 3 conformações estáveis, teríamos $3^{2 n} \approx 10^{n}$ conformações possíveis [Voet e Voet, 2003]. Assim, também de acordo com [Voet e Voet, 2003], se cada conformação for explorada em um tempo $t$ semelhante ao qual as ligações simples se orientam, ou seja, $t \approx 10^{13} \mathrm{~s}$, e considerando $n=100$ resíduos, seria necessário um tempo de cerca de 20 bilhões de anos. Essa questão foi levantada por Cyrus Levinthal em 1968 e é conhecida como "Paradoxo de Levinthal" [Levinthal, 1969]. A partir desse problema, Levinthal sugeriu que o dobramento possui algumas rotas preferenciais [Lehninger et al., 2005; Voet e Voet, 2003]. Desse modo, à medida que a proteína se aproxima da conformação nativa, por um conjunto de rotas, sua estabilidade aumenta.

Técnicas capazes de detectar mudanças estruturais, de forma rápida, são empregadas no monitoramento do dobramento. Podem ser citadas: espectro de dicroísmo circular (CD) e troca pulsada H/D [Voet e Voet, 2003].

Utilizando essas técnicas, para a maioria das proteínas pequenas e com um único domínio, verificou-se que as estruturas secundárias, como folhas- $\beta$ e as $\alpha$-hélices, formam-se logo no início do dobramento, em um processo chamado de fase explosiva, uma vez que ocorre rapidamente [Voet e Voet, 2003]. Posteriormente, o chamado "colapso hidrofóbico" reduz drasticamente o raio da proteínas, fazendo com que os grupos hidrofóbicos se juntem e expulsem, tanto quanto possível, as moléculas hidrofílicas ao redor [Voet e Voet, 2003]. O estado resultante desse colapso hidrofóbico é chamado de glóbulo fundido [Lehninger et al., 2005; Voet e Voet, 2003].

Termodinamicamente falando, o processo de dobramento proteico é frequentemente comparado a um funil (Figura 2.7), analogia geralmente chamada de teoria da paisagem [Lehninger et al., 2005; Voet e Voet, 2003]. As duas coordenadas horizontais da figura representam as combinações de ângulos de torção $(\phi, \psi)$. A coordenada vertical 
representa a energia livre que é minimizada durante o processo.

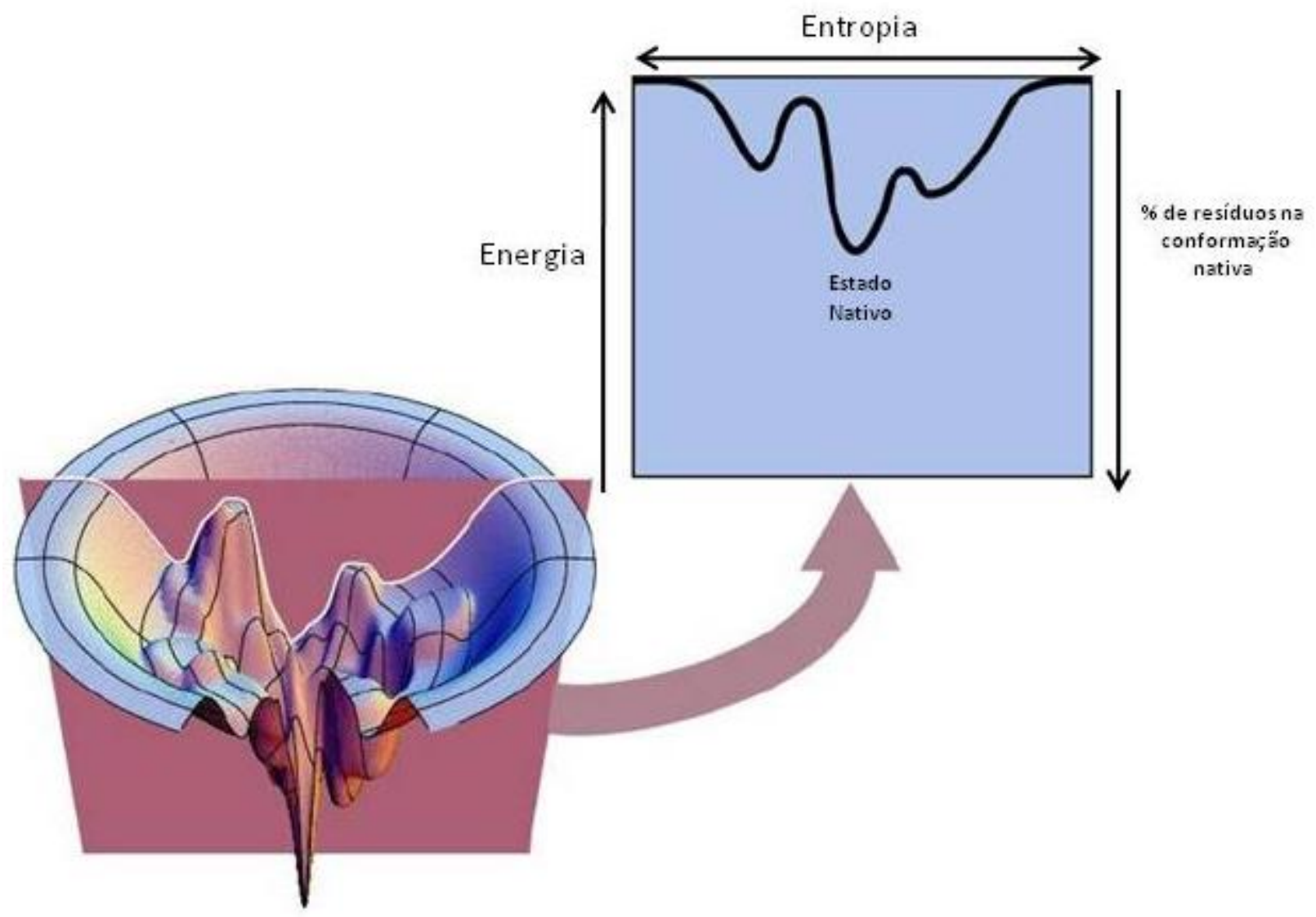

Figura 2.7: Funil de energia livre que descreve o enovelamento protéico, adaptado de [Dill, 2010].

O Problema de enovelamento proteico permanece como um problema de grande interesse para a Biologia Molecular. Uma solução completa para esse problema seria capaz de fornecer a estrutura tridimensional final obtida depois do enovelamento de uma proteína, descrevendo também todas as suas etapas. Este problema, no entanto, ainda não possui uma solução completa. Dessa forma, como o conhecimento das estruturas tridimensionais de proteínas é de grande importância para a investigação de processos biológicos, o problema de PEP pode ser visto como uma tentativa prática de se atingir o objetivo desejado [Khimasia e Coveney, 1997].

\subsection{Métodos Experimentais de Determinação de Estrutura Tridi- mensional de Proteína}

As estruturas proteicas conhecidas podem ser encontradas no PDB (Protein Data Bank), conforme já mencionado. De acordo com [Kleywegt, 2006] e [Davis et al., 2003], a utilização e seleção de estruturas do PDB deve ser realizada com cautela, uma vez que as estruturas determinadas experimentalmente estão sujeitas a alguns tipos de artefatos e problemas. Pode-se citar: baixa resolução, sobreposições, proble- 
mas de orientação, problemas nas conformações das cadeias principal e lateral, entre outros.

Atualmente, os principais métodos experimentais utilizados para determinar a estrutura tridimensional de uma proteína são: Cristalografia de Raios X e Ressonância Nuclear Magnética (RNM), os quais são discutidos a seguir.

\subsubsection{Ressonância Nuclear Magnética}

A RNM é utilizada na determinação de proteínas pequenas [Alberts et al., 2006]. Na RNM, a proteína em solução é colocada em um campo magnético e irradiada com ondas eletromagnéticas com frequências diferentes. Alguns átomos como: ${ }^{1} \mathrm{H},{ }^{13} \mathrm{C}$, ${ }^{15} N,{ }^{19} \mathrm{~F},{ }^{31} \mathrm{P}$ geram um sinal de RNM [Lehninger et al., 2005], que pode ser utilizado para determinar distâncias entre aminoácidos. Essa informação combinada com o conhecimento da sequência de aminoácidos é então empregada na determinação da estrutura. A grande vantagem dessa técnica em relação à Cristalografia é que ela é aplicada a moléculas em solução.

\subsubsection{Cristalografia de Raios-X}

Para se determinar estruturas a partir dessa técnica, é necessário cristalizar a proteína de interesse. A cristalização é quase que um processo empírico, através do qual tentase obter cristais, cujas proteínas contidas possuam a mesma conformação. Para tanto, o cristalógrafo precisa descobrir as condições necessárias para que isso ocorra, tais como: concentração e tipo de íons a serem adicionados, temperatura ideal, entre outras [Alberts et al., 2006]. Muitas proteínas não foram ainda determinadas devido à dificuldade de obter seu cristal [Lehninger et al., 2005].

Uma vez que um cristal é obtido, inicia-se a análise por difração de raio-X. Um feixe de raio-X atinge o cristal e seus átomos o desviam. O padrão de difração é então capturado por detectores e analisado com o auxílio de computadores.

A cristalografia de raios $\mathrm{X}$ tem sido empregada com sucesso em proteínas grandes, as quais não podem ser determinadas por RNM. 


\section{Capítulo 3}

\section{Predição de Estruturas de Proteínas}

Predizer a estrutura proteica tem sido alvo de cresceste interesse por parte de pesquisadores. Em parte porque determinar estruturas experimentalmente é um trabalho laborioso e com algumas limitações, nem sempre possível para todas as proteínas. Por outro lado, existem métodos de modelagem por similaridade que realizam predições bem sucedidas. Entretanto, esse método só é possível para proteínas que possuem estruturas similares já conhecidas. Desse modo, PEP permanece um desafio, uma vez que diversas estruturas não podem ser preditas e/ou determinadas eficientemente com os métodos existentes. Por essa razão, o número de sequências primárias conhecidas é bem maior que o número de estruturas tridimensionais.

Desde 1994, a avaliação bianual CASP (Comparative Assessment of Methods for Protein Structure Prediction) é realizada para avaliar os métodos de predição de estruturas de proteínas [Moult et al., 2009]. O principal objetivo dessa avaliação é verificar a qualidade e eficiência dos métodos de predição de estruturas existentes. São disponibilizadas diversas sequências proteicas alvo e ao final uma classificação é divulgada com o desempenho dos grupos participantes. As sequências alvo são divididas em duas categorias: template-based modelling e template free modelling. A primeira categoria compreende sequências que possuem estruturas tridimensionais relacionadas já conhecidas, enquanto que na segunda categoria, esse tipo de relacionamento não pode ser detectado [Moult et al., 2009].

Existem dois tipos básicos de abordagens para a o problema de PEP: os métodos $a b$ initio (primeiros princípios), que utilizam princípios físicos para predizer a estrutura da proteína e os baseados em homologia. O primeiro tenta predizer a estrutura tridimensional utilizando, geralmente, apenas a sequência de aminoácidos. Já o segundo, inclui técnicas como modelagem comparativa e threading, normalmente utiliza alinhamento de sequências para construir seus modelos [Contreras-Moreira et al., 2005]. As duas seções seguintes tratam essas duas abordagens mais detalhadamente. Na Seção 3.1 é apresentada a modelagem baseada em conhecimento, enquanto que na Seção 3.2, a modelagem por primeiros princípios é comentada. Na Seção 3.4 são apresentados os conceitos básicos de campo de força. Na seção 3.5 são apresentados os algo- 
ritmos genéticos; enquanto que na Seção 3.6 são apresentados alguns dos trabalhos relacionados de AGs para PEP.

\subsection{Modelagem baseada em conhecimento}

O banco de dados público de proteínas PDB (Protein Data Bank) é um repositório internacional de estruturas proteicas, que possibilita a busca por estruturas já conhecidas. A disponibilidade de estruturas nos bancos de dados tem favorecido a utilização de técnicas baseadas em conhecimento, as quais têm obtido sucesso para várias proteínas. O grande problema desse tipo de abordagem é que nem todas as proteínas possuem similar no PDB. Desse modo, a melhoria das abordagens que não utilizam esse tipo informação é uma questão de extrema importância.

Dentre as abordagens baseadas em conhecimento, podemos destacar modelagem baseada em homologia e threading.

\subsubsection{Modelagem baseada em homologia ou Modelagem Comparativa}

As proteínas existentes na natureza foram selecionadas ao longo do processo de evolução. Assim, as proteínas evolutivamente relacionadas possuem similaridade de estrutura primária, a qual é chamada homologia. De acordo com [Kaczanowski e Zielenkiewicz, 2010], proteínas homólogas quase sempre possuem estruturas tridimensionais semelhantes.

A modelagem baseada em homologia procura prever a estrutura da proteína de interesse utilizando as estruturas de proteínas homólogas já conhecidas como modelo [Leach, 2001]. Técnicas de alinhamento e conhecimento da atividade funcional ajudam a escolher as melhores proteínas-modelos.

De acordo com [Pevsner, 2009] e [Martí-Renom et al., 2003], a modelagem por homologia consiste nos seguintes passos:

1. Selecionar molde (template). Este primeiro passo consiste em selecionar proteínas homólogas para serem utilizadas como molde. Isso é feito através de ferramentas de alinhamento como, por exemplo, o BLAST. Em seguida, as regiões conservadas são identificadas. Mais de uma proteína-molde pode ser selecionada, o que geralmente pode aumentar a acurácia da modelagem. Os fatores que devem ser considerados, quando a escolha de uma proteína-molde, são: a família da proteína selecionada, para isso a construção de árvores filogenéticas e alinhamentos múltiplos podem ser úteis; as condições do meio tais como $\mathrm{pH}$, solvente e interações com ligantes; a qualidade da proteína molde (resolução).

2. Alinhar a proteína-molde com a proteína-alvo. Geralmente são utilizados métodos de alinhamento baseados em programação dinâmica, entre eles destacase software para alinhamento múltiplo CLUSTAL. Este segundo passo torna-se 
especialmente difícil quando existe pouca similaridade entre proteína-molde e proteína-alvo. Nestes casos, o número de gaps e erros no alinhamento aumenta significativamente e erros podem ser propagados para os modelos construídos.

3. Construir um modelo. Uma variedade de métodos podem ser empregados nesta etapas para construir o modelo 3D da proteína-alvo. Entre eles, destacam-se: modelagem de corpos rígidos, modelagem por pareamento de fragmentos ou reconstrução coordenada e modelagem por satisfação de restrições espaciais. A modelagem das regiões de dobras ou loops e das cadeias laterais é um problema a parte. As regiões de dobras são problemáticas, uma vez que são pouco conservadas em proteínas homólogas. Desse modo, a modelagem dessas regiões costuma aliar a utilização da similaridade com técnicas de modelagem ab initio.

4. Avaliar o modelo. Esta última etapa consiste na avaliação do modelo criado e pode ser feita através de diversos softwares disponíveis. Entre eles: PROCHECK, WHATCHECK, VERIFY3D, entre outros.

\subsubsection{Threading}

Proteínas não evolutivamente relacionadas (não homólogas) também podem ter estruturas similares, assumindo o mesmo tipo de dobramento. Baseando-se nos dobramentos proteicos conhecidos, os cientistas tem conjeturado que o número de possíveis dobramentos seja finito, para todas as proteínas existentes [Isaev, 2004]. Isso porque algumas proteínas com o mesmo dobramento conhecido não possuem relação evolutiva nem funcional.

Nessas situações, uma técnica bastante utilizada em PEP é a modelagem por threading, ou folding recognition, como também é conhecida. Essa abordagem considera que o número de dobramentos possíveis é finito e ao invés de procurar por todo o espaço conformacional, se limita a buscar pelo melhor dobramento possível, dentre as proteínas que possuem estrutura conhecida [Leach, 2001]. Para tanto, os métodos de threading alinham uma sequência proteica de busca diretamente nas estruturas tridimensionais conhecidas, buscando assim encontrar o dobramento da proteína de interesse.

Em [Zhang, 2008], um tipo de modelagem baseada em homologia (Template-based modeling), que utiliza threading, é descrita. Dada uma sequência de interesse, o processo pode ser resumido nas seguintes etapas: encontrar estruturas conhecidas "modelos" (templates) cujas sequências sejam relacionadas a da proteína alvo; alinhar a proteína alvo com as sequências de estruturas conhecidas; copiar as regiões com alinhamento satisfatório, respeitando condições de impedimento estérico, construir as regiões que não alinharam e adicionar as cadeias laterais. As duas primeiras etapas consistem na modelagem por threading. 


\subsection{Modelagem por Primeiros Princípios}

A modelagem ab initio, ou Primeiros Princípios, ou de novo, ou free modeling como tem sido referida no CASP, consiste em predizer a estrutura tridimensional de uma proteína partindo de sua sequência de aminoácidos. Para tanto, realiza uma busca no espaço conformacional a fim de encontrar a estrutura, ou estruturas mais apropriadas, as quais são assumidas como sendo as que possuem menor energia livre. Campos de força empíricos são frequentemente empregados nessa abordagem.

Há algum tempo, os campos de força eram vistos como sendo promissores para o problema de PEP. Hoje, no entanto, a modelagem ab initio, que utiliza apenas campos de força ocupa uma posição periférica no CASP [Gopal et al., 2009; Kryshtafovych et al., 2007]. De acordo com [Takeshi et al., 2008], apesar da grande quantidade de trabalhos na área empregando métodos $a b$ initio, ainda não existe uma técnica $a b$ initio completamente segura. No CASP 7, os melhores resultados na categoria free modeling foram obtidos através de abordagens mistas, combinando princípios físicos com técnicas baseadas em conhecimento [Zhang, 2008]. O conhecimento advindo de estruturas já conhecidas pode melhorar a eficiência de métodos ab initio. Dois importantes exemplos de preditores que utilizam técnicas ab initio combinadas com estratégias baseada em conhecimento são: ROSETTA [Das et al., 2007b] e I-TASSER [Zhang e Skolnick, 2004].

De maneira geral, podemos concluir que o problema de PEP tem sido alvo de interesse de diversos grupos de pesquisa. Esse interesse tem estimulado a competitividade e a melhoria dos softwares destinados a predição de estruturas. O CASP tem contribuído fortemente para esse aprimoramento.

\subsection{Sistemas de PEP que merecem destaque}

\subsubsection{ROSETTA}

O ROSETTA é um pacote de código aberto desenvolvido na Universidade de Washington, que possui um algoritmo para PEP de mesmo nome. O ROBETTA é um servidor responsável pela PEP e está disponível em http://robetta.org/submit.jsp. O ROBETTA faz parte de um projeto maior: o Rosetta@home que é um projeto de computação distribuída, que além da predição de estruturas também possui servidores para dobramento e doking [Das et al., 2007a].

O ROBETTA utiliza as abordagens ab initio e a modelagem comparativa para realizar suas predições. Em [Raman et al., 2009], o protocolo utilizado nas predições do CASP 8 é descrito para todas as proteínas-alvo o algoritmo tenta inicialmente gerar conformações modelo baseado em homologia. Quando a proteína-alvo não possui homólogas, o algoritmo Rosetta ab initio é empregado. O algoritmo Rosetta ab ini- 
tio possui um protocolo chamado de "reconstrói e refina", que simplificadamente é composto por uma etapa que emprega um modelo minimalista, chamada modelagem de baixa resolução, seguida de uma etapa que utiliza um modelo full-atom, chamada modelagem de alta resolução.

Na etapa de modelagem de baixa resolução, utiliza-se um campo de força reduzido, também chamado de baixa resolução. Essas regiões são construídas a partir de bibliotecas de fragmentos.

As bibliotecas de fragmentos são geradas a partir de uma ampla variedade de estruturas diferentes e não-homólogas [Simons et al., 1997b]. Os fragmentos gerados possuem tamanhos 3 e 9. De acordo com [Raman et al., 2009], fragmentos maiores são utilizados nas regiões de $\alpha$-hélice, enquanto que os menores são empregados nas folhas- $\beta$. A partir desses fragmentos estruturas moldes são montadas de acordo com similaridade local da sequência primária e avaliadas por funções de pontuação Bayesianas.

Já a etapa de alta resolução emprega um modelo full-atom e a minimização de energia é realizada com um algoritmo de Monte Carlo. Os principais componentes dessa função de energia são as interações de curto alcance, como, Van der Waals, ponte de hidrogênio e solvatação, mas também possui a energia eletrostática, que é uma interação de longo alcance.

\subsubsection{I-Tasser}

O I-Tasser (Iterative Threading Assembly Refinement) é uma plataforma para predição de estrutura e função de proteínas. A predição de estrutura tridimensional é realizada utilizando a abordagem de threading. A metodologia empregada pelo ITasser para PEP será brevemente descrita a seguir.

Conforme apresentado em [Roy et al., 2010], as etapas do método empregado pelo I-Tasser podem ser sintetizadas nos seguintes passos:

1. Threading. Esta etapa consiste, inicialmente, em alinhar a sequência proteica de busca (sequência primária) à uma base de dados, utilizando a ferramenta PSIBLAST para identificar possíveis relações evolutivas. Através de alinhamentos múltiplos, constrói-se um perfil (profile) para a sequência de busca e sua estrutura secundária é predita através do aplicativo PSIPRED. Em seguida, a sequência de busca, bem como o perfil gerado e a predição de estrutura secundária são utilizados por vários algoritmos de threading localizados no servidor LOMET ${ }^{1}$, de acordo com [Wu e Zhang, 2007], são eles:

- FUGUE. Descrito em [Shi et al., 2001], o qual emprega programação dinâmica.

\footnotetext{
${ }^{1}$ Disponível em http://zhanglab.ccmb.med.umich.edu/LOMETS/
} 
- PROSPECT2. Descrito em [Xu e Xu, 2000], utiliza uma função de pontuação (scoring) que combina penalizações obtidas no alinhamento com potencial de contato, propensão da estrutura secundária e mutação dos resíduos.

- HHSEARCH. Apresentado em [Soding, 2005], que emprega modelos ocultos de markov.

- SPARKS2 e SP3. Apresentados em [Zhou e Zhou, 2004, 2005] empregam programação dinâmica no alinhamento, sendo que o SPARKS2 emprega um potencial estatístico baseado em conhecimento.

- SAM-T02. Descrito em [Karplus et al., 2003] e baseado no alinhamento múltiplo do PSI-Blast, também utiliza modelo oculto de Markov.

- PPA-I. Trata-se uma abordagem baseada em alinhamento do tipo perfilperfil combinado com conhecimento da estrutura secundária [Wu e Zhang, 2007].

- PPA-II. Semelhante ao PPA-I, sendo que aqui o perfil é coletado do SAMT99 [Karplus et al., 1998].

- PANT. Este algoritmo conta com uma função de energia que emprega mutação dos resíduos, conhecimento e estrutura secundária e penalizações do alinhamento [Wu e Zhang, 2007].

Os algoritmos de threading são utilizados para produzir estruturas moldes (templates), as quais são selecionadas de acordo com uma série de pontuações baseadas em características estruturais. A qualidade desses moldes é avaliada conforme a significância estatística do alinhamento.

2. Montagem de conformações. Os fragmentos contínuos das regiões que obtiveram bom alinhamento nas estruturas moldes são utilizados para montar as conformações. Já as regiões que não possuem bons alinhamentos são construídas através de modelagem ab initio. O I-Tasser utiliza um modelo reduzido, que emprega o carbono- $\alpha$ para representar a proteína, juntamente com um algoritmo de Monte Carlo para realizar a otimização. As conformações geradas durante este processo são agrupadas através de clusterização para identificar estados de baixa energia e os centroides desses clusters são selecionados para a próxima etapa.

3. Seleção de Estruturas-Modelos e Refinamento. Nesta etapa, a montagem de conformações por fragmentos é executada novamente utilizando os centroides da etapa anterior. Esse segunda execução tem por objetivo refinar as estruturasmodelos (centroides) eliminando interferências estéricas. Após a nova execução, clusters são gerados novamente e as conformações de menor energia são selecionadas. Por fim, realiza-se uma otimização da energia das ligações de hidrogênio. 


\subsection{Campos de Força}

Encontrar uma função matemática capaz de calcular a energia livre de uma estrutura proteica é um dos principais problemas que dificultam a obtenção de resultados melhores no problema de PEP. Para calcular a energia potencial de uma molécula, campos de força podem considerar todos os átomos da proteína em seus cálculos, sendo, neste caso, chamados full-atom. Existem vários pacotes de simulação molecular que utilizam campos de força full-atom. Podemos citar os campos de força: GROMOS [Scott et al., 1999], AMBER [Pearlman et al., 1995], OPLS [Jorgensen e Tirado-Rives, 1988] e CHARMM [Brooks et al., 1983a]. Outros campos de força não consideram todos os átomos e são chamados coarse-grained (CG), como, por exemplo, o MARTINI [Marrink et al., 2007].

A escolha do campo de força adequado também esbarra na questão complexidade do modelo versus custo computacional. Neste trabalho, optamos por investigar a PEP usando AGs e um modelo CG. Este tipo de modelo, também chamado reduzido, utiliza átomos unificados (beads) dos aminoácidos para representar a cadeia principal de uma proteína. Esses modelos têm sido cada vez mais utilizados para o estudo do enovelamento proteico [Yap et al., 2008]. Eles permitem a reprodução de características da dinâmica do dobramento proteico com um menor número de graus de liberdade. No entanto, ainda não foram muito explorados para PEP. Em um segundo momento, utilizamos também um modelo full-atom devido à necessidade de maior detalhamento.

\subsection{Algoritmos Genéticos}

Nas décadas de 1950 e 1960, grupos de pesquisadores independentes começaram a utilizar sistemas evolutivos biológicos como inspiração para seus algoritmos de otimização [Mitchell, 1996]. Surgiram, nessa época, os principais algoritmos da computação evolutiva.

Os AGs, tais como são conhecidos hoje, foram introduzidos na década de 1960 por John Holland e popularizados por um de seus alunos, David Goldberg, na universidade de Michigan [Haupt e Haupt, 1998]. Diferentemente das estratégias evolutivas e da programação evolucionária, que também se desenvolviam nessa época, o AG de Holland foi, desde o início, projetado com propósito mais geral e não para problemas específicos.

Com o passar do tempo e o desenvolvimento da computação evolutiva como um todo, as fronteiras entre AGs, estratégias evolutivas e programação evolucionária se tornaram mais tênues. Desse modo, autores têm usado o termo "Algoritmo Genético" para designar algoritmos bem diferentes do original criado por Holland [Mitchell, 1996]. 


\subsubsection{O Algoritmo Genético Padrão}

Otimização é o processo que consiste em tentar encontrar a melhor solução para determinado problema entre as várias soluções possíveis [Haupt e Haupt, 1998]. Em problemas complexos de decisão, onde uma série de variáveis estão envolvidas, deve-se selecionar um objetivo capaz de quantificar a qualidade da decisão [Luenberger e Ye, 2008]. O objetivo escolhido pode então ser maximizado ou minimizado de acordo com as características do problema, fornecendo uma boa combinação de variáveis, considerando as limitações do método utilizado.

As principais diferenças entre AGs e os métodos de otimização tradicionais são ressaltadas em [Goldberg, 1989] e sintetizadas a seguir:

- AGs utilizam uma população de soluções candidatas e não apenas com uma única solução em seu processo de busca. Essa propriedade reduz a probabilidade do algoritmo ficar preso em um ótimo local, principalmente no início do processo de otimização.

- AGs utilizam regras de transição probabilísticas e não determinísticas.

- AGs podem utilizar uma representação da solução candidata, não precisando trabalhar com a solução propriamente dita.

- AGs utilizam a informação fornecida por uma função objetivo para guiar o processo de busca, ao invés de derivadas ou outro tipo de conhecimento.

Encontrar a melhor solução para um problema complexo nem sempre é uma tarefa possível, uma vez que podem existir várias soluções permitidas, além de inúmeros ótimos locais. No AG padrão, as possíveis soluções de um dado problema são representadas como um conjunto de indivíduos (ou cromossomos), a chamada população. Uma população está sujeita às leis da evolução, sendo que em cada geração, ou passo do algoritmo, operadores de seleção escolhem as soluções mais aptas e operadores de transformação geram novos indivíduos.

A solução $\mathbf{x}_{i}$ representada pelo cromossomo $i=1, \ldots, N$ é avaliada através de uma função de avaliação, ou fitness, $f\left(\mathbf{x}_{i}\right)$, que mede o nível de adequação do cromossomo.

A Figura 3.1 mostra o funcionamento básico do AG Padrão. 


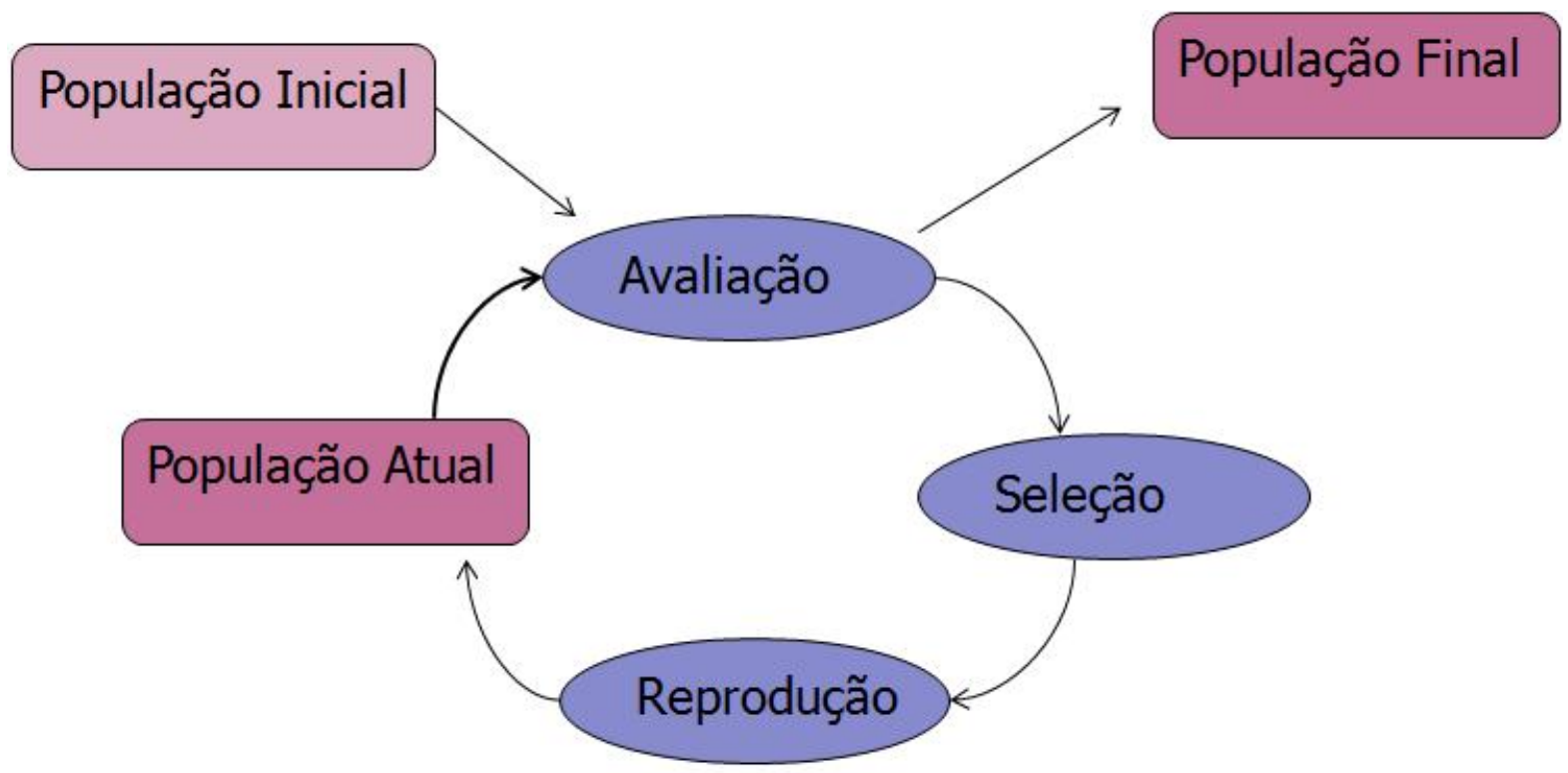

Figura 3.1: Algoritmo Genético: funcionamento básico.

Alguns operadores de seleção comuns são:

- Roleta:

O método da roleta consiste em selecionar um indivíduo com uma probabilidade proporcional ao seu fitness relativo. Define-se fitness relativo como sendo a razão entre o fitness do $i$-ésimo indivíduo e a somatória dos fitness de toda a população em uma dada geração.

- Torneio:

Um número $M_{t}$ de indivíduos é sorteado, sendo selecionado aquele indivíduo com melhor fitness para compor a próxima população. Este operador costuma ser empregado por proporcionar um controle da pressão seletiva, diferentemente do método anterior.

- Elitismo:

O Elitismo garante que o melhor indivíduo de uma dada geração seja automaticamente selecionado para a próxima geração.

Os principais operadores de transformação são:

- Crossover:

No crossover, dois indivíduos da população corrente são escolhidos através de um critério de seleção e têm alguns de seus genes permutados. O número de indivíduos escolhido para crossover em uma época é definido através de uma taxa $p_{c}$, chamada de taxa de crossover. A Figura 3.3 mostra o crossover de um ponto no caso binário. 


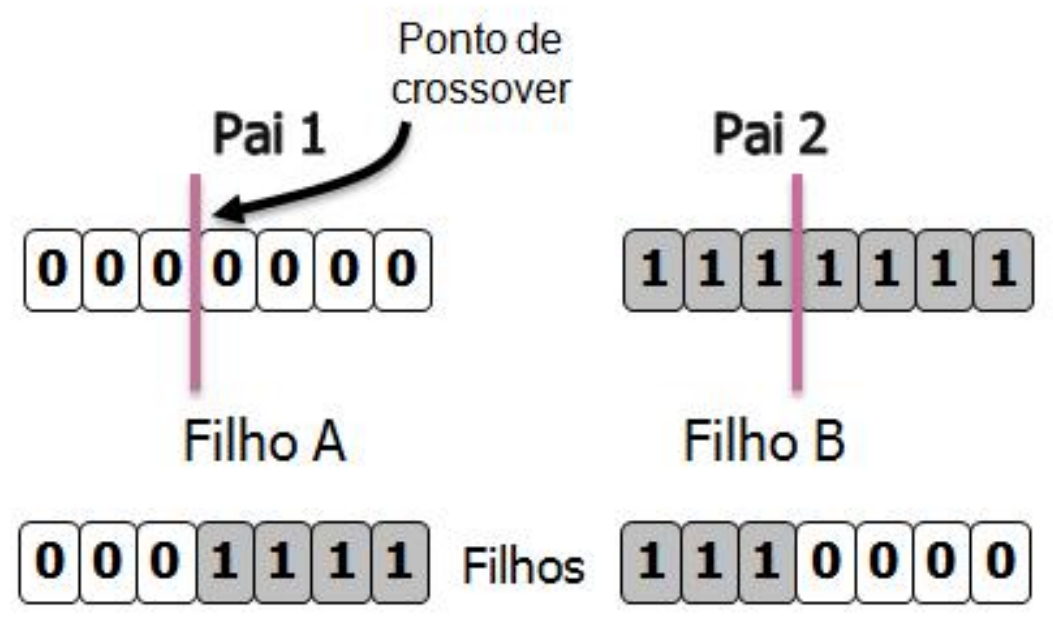

Figura 3.2: Funcionamento básico do crossover.

- Mutação:

Na mutação, indivíduos têm alguns de seus genes, escolhidos aleatoriamente, alterados através de uma regra pré-definida. Por exemplo, no caso binário, o valor do gene é invertido quando ele sofre mutação. O número de genes alterados por mutação é definido através de uma taxa $p_{m}$, chamada de taxa de mutação.

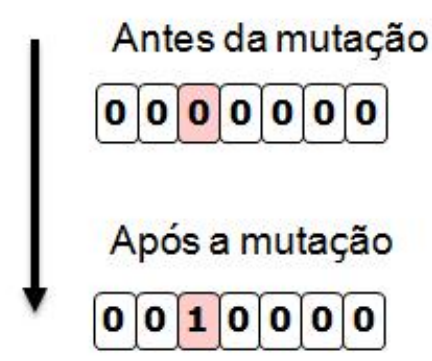

Figura 3.3: Funcionamento básico da mutação.

O pseudo-código do AG padrão pode ser visto no Algoritmo 3.1 


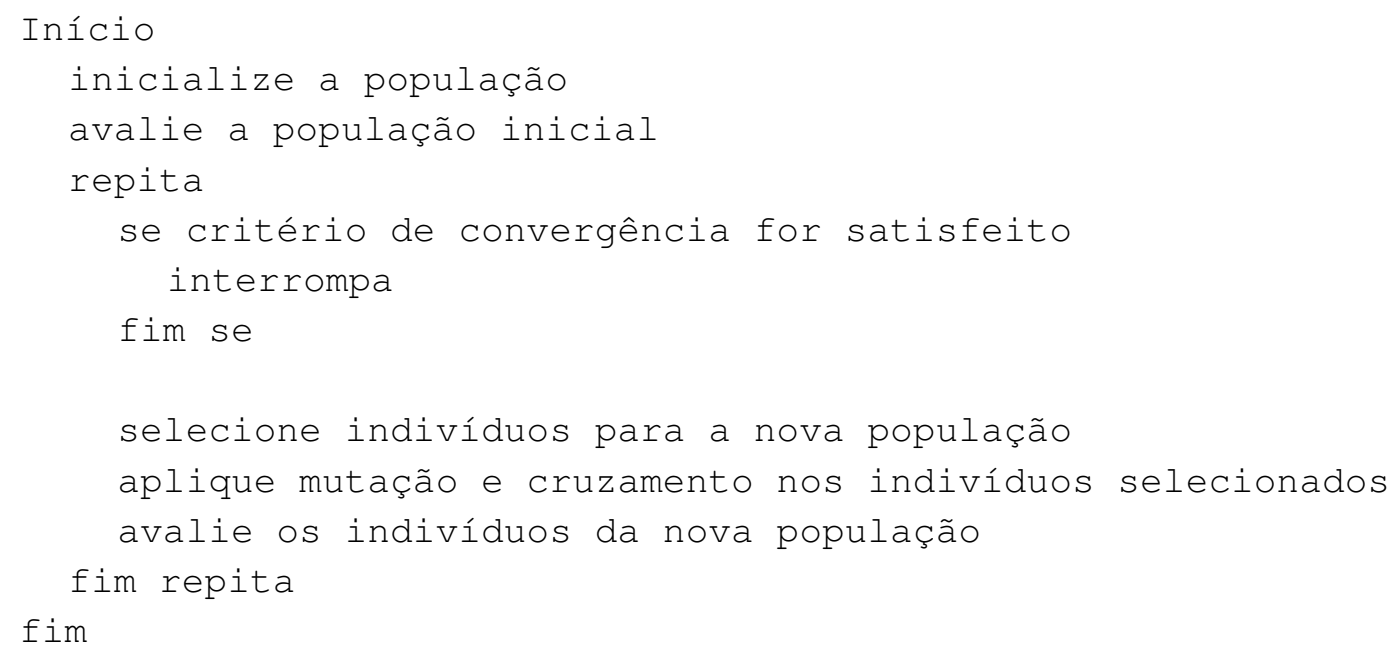

Algoritmo 3.1: Pseudo-código para AG Padrão

\subsection{Aplicações de AGs em PEP}

Os Algoritmos Evolutivos (AEs), com destaque para os Algoritmos Genéticos, têm sido utilizados nos últimos anos para o problema de PEP, principalmente em abordagens ab initio. Existem vários trabalhos que tratam este tema, sendo aqui selecionados alguns deles.

Em [De Lima, 2006], foram estudadas diversas técnicas de AEs para o problema de PEP, sendo empregadas as abordagens mono-objetivo e multi-objetivo. Como conclusões o trabalho mostrou que os AEs possuem potencial preditivo para o problema de PEP, porém eles ainda não são capazes de solucionar o problema com precisão. A abordagem utilizada também apresentou dificuldades nas predições de folhas- $\beta$, fato comum na grande maioria dos preditores.

Já em [Faccioli et al., 2007], empregou-se lógica Fuzzy em AEs multi-objetivo. Foi empregada uma abordagem baseada em homologia, para ajustar as regras Fuzzy. Desse modo, tenta-se predizer estruturas similares a essa estrutura modelo.

No trabalho [Bonetti, 2010], objetivou-se reduzir o tempo computacional do cálculo do termo de Van der Waals do algoritmo proposto em [De Lima, 2006] através da paralelização dos cálculos.

Em [Do Ó e Tinós, 2009], empregou-se uma abordagem similar a deste trabalho, utilizando bases de dados de ângulos conhecidos para gerar as populações iniciais do AG. No entanto, não foram empregadas informações de estruturas secundárias. Um estudo de técnicas de manutenção da diversidade foi realizado, sendo as técnicas de Imigrantes Aleatórios e Hipermutação empregadas. Os resultados mostraram que essas técnicas podem ser úteis para AGs aplicados a PEP. Também foi verificado melhoria dos resultados com ordenamento das bases de dados. 
Em [Schulze-Kremer, 2003b], foram empregados AGs para o problema de PEP com abordagem $a b$ initio. Foram realizados testes para a proteína Crambina e várias estruturas preditas possuíam energia menor que a estrutura nativa. Concluiu-se que a função de fitness não conseguiu avaliar adequadamente as estruturas próximas da nativa. O mesmo ocorreu em [Do Ó e Tinós, 2009] com o peptídeo Met-Encefalina.

A utilização de AGs com modelos Hidrofóbicos-Polares (HP) também tem sido bastante utilizada. No trabalho de [Unger e Moult, 1993], AGs foram empregados no problema de folding com um modelo HP e seu desempenho foi comparado com os métodos convencionais de Monte Carlo e concluiu-se que o desempenho do AG foi superior. Em [Gabriel, 2010], PEP foi utilizado como problema alvo para o desenvolvimento de um AG com modelo HP.

Em [Liu e Tao, 2008], foi proposto o algoritmo genético chamado HPGA/GBX (Hybrid Parallel GA/Guide Blend Crossover) aplicado ao problema de PEP através. Tratase de um AG paralelizado, cuja principal diferença para o AG padrão é o operador decrossover, o qual possui um ponto de corte auto-organizável. A Met-Encefalina foi utilizada como proteína-alvo da predição. Concluiu-se que o AG HPGA/GBX obteve melhores resultados (menor energia potencial) do que outros algoritmos testados, entre eles um DGA (Distributed Genetic Algorithm).

Em [Zhang et al., 2010], foi proposto um algoritmo híbrido que combina AG com Busca Tabu. A Busca Tabu foi empregada no crossover e mutação para guiar a direção da busca pelo espaço conformacional. O algoritmo híbrido foi considerado melhor para o problema de PEP do que o AG convencional. Já em [Jiang et al., 2003], AGs também foram empregados com Busca Tabu, porém apenas no operador de crossover. Também constatou-se que o algoritmo híbrido obteve melhor desempenho que AG convencional.

Em [Custódio et al., 2010], AGs foram empregados juntamente com um abordagem por similaridade baseada em $K$-vizinhos mais próximos (Similarity-based Surrogate Model). Os resultados mostraram que a abordagem por similaridade melhorou a qualidade das soluções obtidas. 


\section{Capítulo 4}

\section{Metodologia}

Neste trabalho, o AG foi implementado (in house) na linguagem $\mathrm{C}++$. Cada indivíduo do AG representa uma possível conformação da proteína de interesse e é representado por um conjunto de ângulos de torção. Bases de ângulos de torção foram utilizadas para gerar os indivíduos iniciais e por dois tipos de mutação, além de imigrantes nas técnicas por imigrantes aleatórios e por similaridade. Dois campos de força foram usados como função de avaliação dos indivíduos, sendo que um deles é coarse-grained, ou seja, utiliza apenas uma sequência de carbonos-alpha para representar a proteína, enquanto que o outro é do tipo full-atom, empregando todos os átomos no modelo. A função de avaliação fornece um fitness para os indivíduos, que é uma medida de energia potencial da conformação. Ressalta-se que, de acordo com o conhecimento da autora, o modelo coarse-grained que foi descrito em [Yap et al., 2008] ainda não foi testado em AGs aplicados ao problema de PEP.

Neste trabalho, uma estratégia foi desenvolvida para inserir conhecimento nos AGs, baseado em alinhamento de estrutura primária. Além disso, a utilização de Imigrantes Aleatórios foi testada em conjunto com esta estratégia como uma tentativa de manter a diversidade em AGs.

Os detalhes da metodologia empregada são apresentados a seguir. A Seção 4.1, aborda as bases de dados de ângulos empregadas; a Seção 4.2, o AG implementado; a Seção 4.3, as funções de avaliação e a Seção 4.4, as proteínas selecionadas para testar os algoritmos.

\subsection{Bases de Dados de Ângulos}

Bases de dados de ângulos foram empregadas, tanto para a cadeia principal, quanto para a cadeia lateral. Elas são utilizadas pelo AG em três ocasiões: a) para gerar a população inicial, b) na construção de imigrantes aleatórios e por similaridade, esse procedimento será melhor explicado na Seção 4.2 e c) em dois tipos de mutação, que são explicados na Seção 4.2.2. 


\subsubsection{Base de Dados da Cadeia Principal}

A base CADB 3.0, utilizada para a cadeia principal, relaciona, para cada aminoácido, os ângulos encontrados em proteínas cujas estruturas tridimensionais foram obtidas através de técnicas de Raios-X e Ressonância Nuclear Magnética [Gopalakrishnan et al., 2007].

A base de ângulos da cadeia principal foi separada em ângulos de $\alpha$-hélice, folha- $\beta$ e uma terceira que contém todos os ângulos, sem distinção entre estruturas secundárias. Essa última, com todos os ângulos é utilizada para gerar todas as regiões da estrutura que não são $\alpha$-hélice ou folha- $\beta$. A base também encontra-se subdividida por aminoácido.

O modelo coarse-grained, que será posteriormente descrito, utiliza as informações de estrutura secundária para calcular o termo de energia do ângulo torção. Uma predição de estrutura secundária é feita, neste trabalho, através do aplicativo PSIPred [Jones, 1999] e esta informação é utilizada para indicar qual base de ângulos da cadeia principal deve ser utilizada para cada aminoácido.

Para facilitar sua utilização, as bases de dados foram aqui organizadas em arquivos binários estruturados, tornando possível acessar uma posição específica no arquivo, sem ter que percorrê-lo. A Figura 4.1 esquematiza o processamento realizado para a base de dados da cadeia principal.

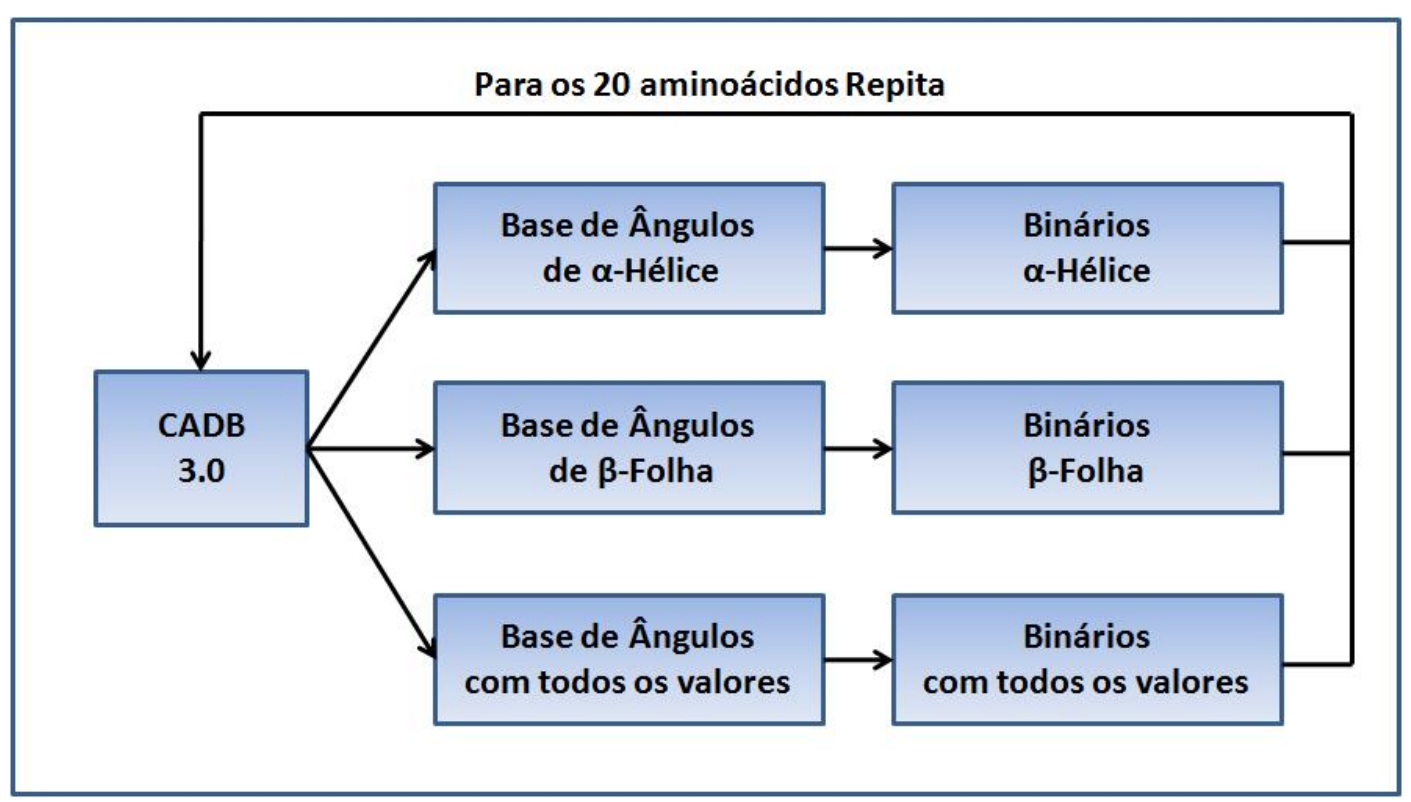

Figura 4.1: Esquema do processamento da base de dados da cadeia principal.

O mesmo procedimento de geração de arquivos binários foi empregado para a base de dados da cadeia lateral utilizada para gerar a população inicial do AG no modelo full-atom. No entanto, como essa base não está dividida de acordo com a estrutura secundária, já que essa informação não é requerida pelo modelo full-atom, mas apenas 
por aminoácido, ela é constituída apenas por 20 arquivos, enquanto que para a cadeia principal existem 60 arquivos (3 para cada aminoácido).

\subsubsection{Base de Dados da Cadeia Lateral}

As bases de dados ou bibliotecas para ângulos da cadeia lateral são frequentemente referidas como bibliotecas de rotâmeros. Um rotâmero corresponde a uma possível conformação de uma cadeia lateral, representada como um conjunto de ângulos qui $\chi$. De acordo com [Dunbrack et al., 2002], existem três tipos de bibliotecas de rotâmeros:

- Independente da cadeia principal

- Dependente da cadeia principal

- Dependente de estrutura secundária

As bibliotecas de rotâmeros independentes da cadeia principal são utilizadas principalmente para refinamento de estruturas obtidas por RNM e raio-X. Contudo, conhecer os possíveis rotâmeros para determinada faixa de ângulos $\phi$ e $\psi$ é uma informação valiosa para o design e predição de estruturas, que é fornecida pelas bibliotecas dependentes da cadeia principal. Quanto as bibliotecas dependentes da estrutura secundária, sua utilização não é aconselhável [Dunbrack et al., 2002] e elas não fornecem uma quantidade de informação maior do que as independentes da cadeia principal.

Neste trabalho, optamos por uma biblioteca de rotâmeros dependente da cadeia principal. Essa biblioteca fornece os rotâmeros de acordo com determinadas faixas de ângulos diedrais médios. Por exemplo, para a os diedrais médios $\phi=-10$ e $\psi=30$ a biblioteca fornece uma lista de rotâmeros ordenados de acordo com uma probabilidade de ocorrência.

\subsection{O AG implementado}

A população inicial do AG foi gerada aleatoriamente, porém respeitando a informação de estruturas secundárias. Cada resíduo da proteína é previamente rotulado como sendo $\alpha$-hélice, folha- $\beta$ ou outro, então, os ângulos da base de dados da cadeia principal são sorteados de acordo com esses rótulos. Desse modo, se um resíduo é classificado como $\alpha$-hélice, seus ângulos $\phi$ e $\psi$ da cadeia principal serão sorteados da base de dados de $\alpha$-hélice e assim por diante. Já para a cadeia lateral, os ângulos $\chi$ com maior probabilidade foram utilizados (modelo full-atom).

Cada indivíduo do AG representa uma possível conformação da proteína. Dessa maneira, um indivíduo é formado por um aminoácido e pelo conjunto de ângulos da cadeia principal obrigatoriamente e pode também possuir os ângulos da cadeia lateral, no caso do modelo full-atom. 
Os indivíduos são avaliados segundo um dado campo de força. Foram utilizados aqui, separadamente, dois campos de força, os quais são descritos na Seção 3.4. Um deles utiliza a cadeia lateral (modelo full-atom) e o outro não (modelo coarse-grained).

Para realizar a avaliação, é necessário converter cada indivíduo, o qual é formado por ângulos de torção, em coordenadas cartesianas, para o campo de força coarsegrained. Esse procedimento foi implementado em $\mathrm{C}++$ seguindo o algoritmo existente no software Tinker [Ponder et al., 1998]. No entanto, para o campo de força full-atom, a rotina do software Tinker foi utilizada, uma vez que a utilização dos ângulos da cadeia lateral aumentaria demasiadamente a complexidade da implementação dessa rotina.

A codificação, os operadores utilizados e as estratégias propostas aqui são descritas a seguir.

\subsubsection{Codificação do AG}

Os indivíduos do AG representam uma possível conformação da proteína a ser predita. Desse modo, um indivíduo (ou cromossomo) é composto por $M$ genes, sendo que cada gene é representado por um conjunto de ângulos de torção $\phi$ e $\psi$ e pelo índice da base de dados correspondente, que pode ser de $\alpha$-hélice, folha- $\beta$ ou da base com todos os ângulos (geral). No caso do modelo full-atom, além dos ângulos de torção da cadeia principal, um gene possui também os ângulos de torção da cadeia lateral $(\chi)$ (dependendo do aminoácido, o número destes ângulos pode variar de zero a cinco) e o índice correspondente na base de dados da cadeia lateral. O número de genes de um indivíduo do AG é igual ao número de aminoácidos da proteína. A Figura 4.2 mostra a codificação do AG para o caso mais geral (modelo full-atom). 


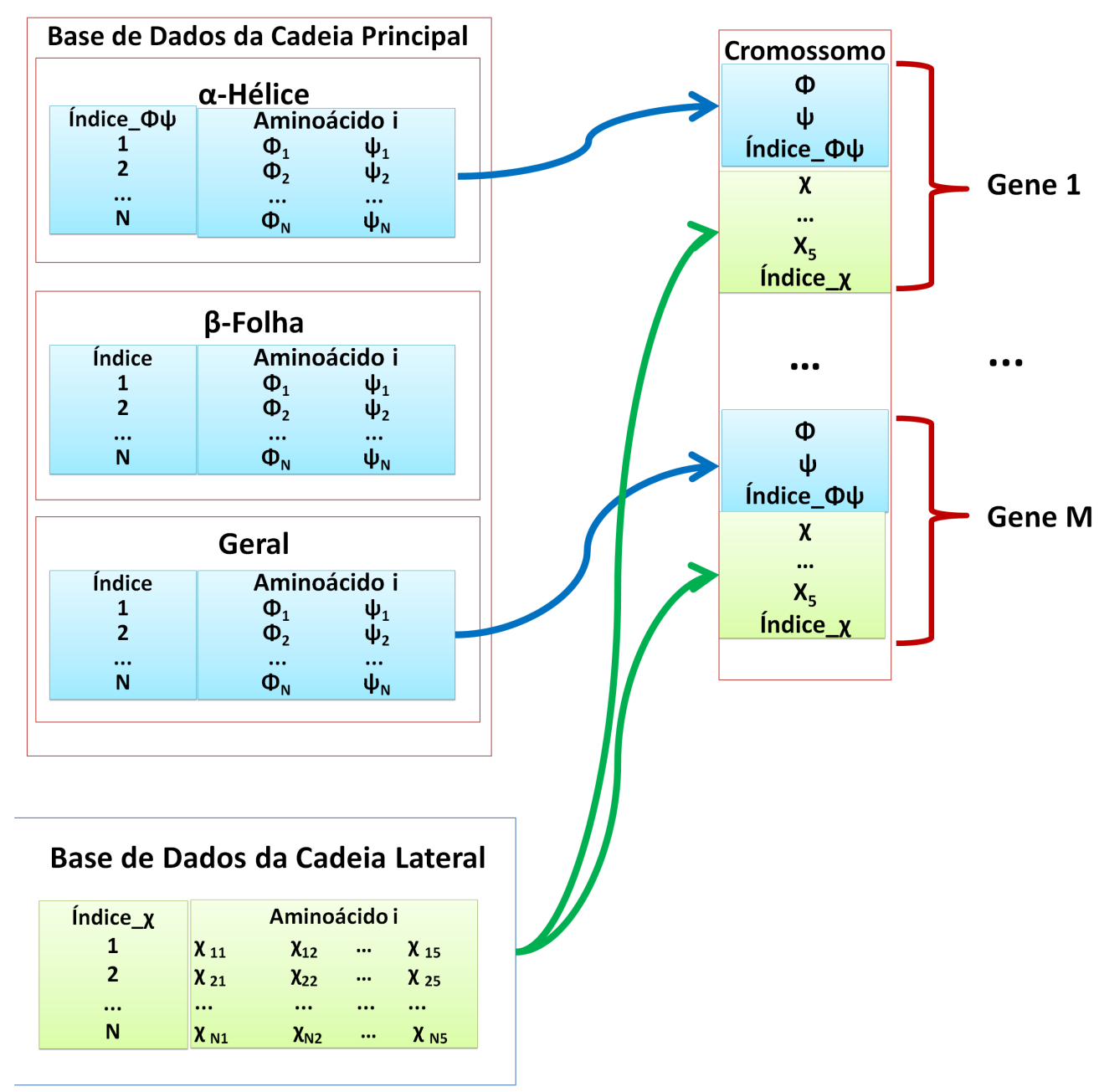

Figura 4.2: Codificação do AG para o caso mais geral (full-atom).

Na Figura 4.2, $N$ representa o número de linhas de um arquivo da base de dados para um aminoácido $i$. Cada gene de um indivíduo do AG é composto pelo conjunto de ângulos da cadeia principal, pelos ângulos da lateral (no caso do modelo full-atom) e seus respectivos índices, que são as posições dos ângulos nos arquivos da base de dados. Os índices são utilizados pelo operador de mutação. Pode-se observar que a base de dados da cadeia principal subdivide-se em $\alpha$-hélice, folha- $\beta$ ou base com todos os ângulos (geral). Já a base da cadeia lateral não é dividida por estrutura secundária e é composta pelos ângulos $\chi$.

\subsubsection{Operadores utilizados}

Os operadores do AG utilizados aqui são:

- Torneio: no qual 3 indivíduos são sorteados e aquele com menor fitness ou energia é selecionado para compor a nova população.

- Elitismo: no qual o melhor indivíduo de cada população, ou seja, aquele com menor fitness, é automaticamente selecionado para compor a próxima população. 
- Crossover: no qual dois indivíduos da população atual são selecionados através de um critério de seleção, no caso, o torneio, e têm seus genes permutados. Optou-se por utilizar o crossover de dois pontos, tradicionalmente utilizado na literatura [De Jong e Spears, 1991].

- Mutação por vizinhança: A mutação deste tipo é feita utilizando o índice para a base de dados de ângulos que é formada por arquivos binários. Assim, dado o índice atual de um aminoácido, por exemplo, $i_{d x}$, os novos valores dos ângulos $\phi, \psi$ da cadeia principal serão os valores correspondentes à posição $i_{d} x \pm z$. $\mathrm{O}$ valor de $z$ é aleatoriamente obtido, com distribuição uniforme, entre \pm 5 , ou seja, pode mudar em até 5 posições para cima ou para baixo. Nessa mutação, os ângulos do aminoácido podem sofrer alterações pequenas, uma vez que a base encontra-se ordenada. Essa mutação também foi utilizada em [Do Ó, 2009]. No caso da cadeia lateral, o ângulo $\chi$ atual é mutado para o mais provável.

- Mutação do índice global: Esta mutação é semelhante à anterior. No entanto, o novo índice pode assumir qualquer posição da base de dados. Ao contrário da outra mutação, esta procura mudar drasticamente o ângulo mutado. Assim como a anterior, essa mutação também foi empregada em [Do Ó, 2009]. No caso da cadeia lateral, o ângulo $\chi$ é mutado aleatoriamente, respeitando o intervalo de $\phi$ e $\psi$ fornecidos.

- Mutação real: Nesta mutação, sorteia-se um ângulo que sofrerá mutação uniforme entre $\pm 5^{\circ}$. Neste tipo de mutação, os ângulos podem acessar valores não pertencentes à base de ângulos. Dessa forma, pode permitir que regiões com uma mesma estrutura secundária, ou com nenhuma, no caso das dobras, sofram alterações que façam com que percam ou mudem de estrutura, o que é interessante se considerarmos que a utilização de preditor para a estrutura secundária introduz erros. Assim, por exemplo, uma região inteira predita como $\alpha$-hélice, mas que na verdade, possui uma dobra em sua extensão, poderá ser alterada caso venha a sofrer uma mutação benéfica, ou seja, que minimize sua energia potencial. Além disso, esta mutação permite que o AG explore regiões de ângulos não presentes nas bases de dados. Ao contrário das anteriores, esta mutação não foi empregada em [Do Ó, 2009].

Cada gene de cada indivíduo possui uma taxa $p_{m}$ que determina se sofrerá ou não mutação, ou seja, se cada ângulo de um aminoácido sofrerá ou não uma mutação. Quando uma mutação ocorre em um dos ângulos de um aminoácido, um dos três tipos de mutação é escolhido com probabilidade de $1 / 3$.

Os tipos de mutação são aplicados à cadeia principal (ou à lateral, no caso da utilização do modelo full-atom, caso em que ocorrem com a mesma probabilidade). A Figura 4.3 mostra o funcionamento do AG. 


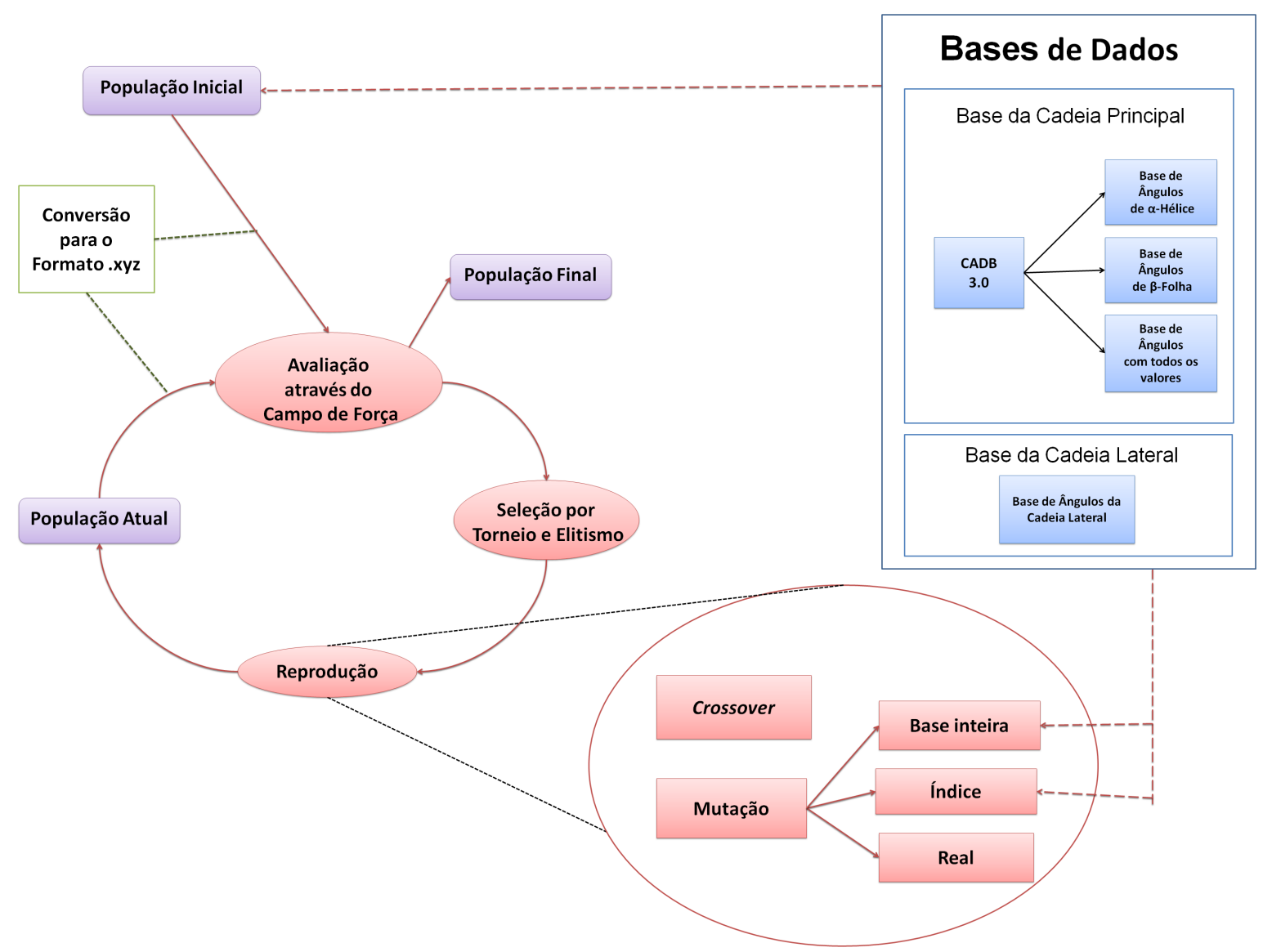

Figura 4.3: Funcionamento do $A G$.

\subsubsection{Estratégias Baseadas em Imigrantes}

A fim de testar o efeito da inserção de similaridade nos AGs, uma estratégia foi criada para gerar indivíduos baseados em alinhamentos simples. Essa estratégia foi chamada de Imigrantes por Similaridade (Seção 4.2.3.2). A estratégia de Imigrantes Aleatórios (Seção 4.2.3.1) também foi empregada, de forma semelhante a que foi utilizada em [Do Ó e Tinós, 2009].

Além disso, uma terceira estratégia (Seção 4.2.3.3) que combina as duas anteriores foi criada e chamada de Imigrantes com Auto-Organização.

\subsubsection{Imigrantes Aleatórios}

Ao longo das gerações, a perda da diversidade é um problema que acontece nas populações de AGs, devido aos operadores de seleção e crossover. Dessa maneira, os indivíduos tendem a tornar-se semelhantes ao melhor indivíduo da população corrente. Isto é chamado de convergência prematura em AGs [Mitchell, 1996]. A estratégia dos imigrantes aleatórios representa uma tentativa de aumentar a diversidade da população. Imigrantes aleatórios foram inicialmente propostos em [Cobb e Grefenstette, 1993] para lidar com problemas de otimização dinâmica. Posteriormente em [Do Ó e Tinós, 
2009], sugeriu-se sua utilização em PEP para inserir diversidade na população como uma tentativa de amenizar o problema da convergência prematura.

A estratégia consiste na criação de indivíduos aleatórios que substituem indivíduos escolhidos aleatoriamente na população. Esses indivíduos, em geral, possuem um valor de aptidão ruim, porém, eventualmente ou quando recombinados com outros, podem gerar soluções boas.

O número de imigrantes inseridos, controlado pela taxa $p_{i A}$ (na qual $p_{i A} .100 \%$ é substituída), também é uma questão importante. Se o número de imigrantes for muito pequeno, eles provavelmente não serão selecionados, por possuírem um valor de aptidão ruim. Contudo, se o número for muito grande, os imigrantes passarão a substituir um quantidade também grande de indivíduos da população que poderão ter fitness melhor que os imigrantes inseridos, diminuindo o número de indivíduos explorando as melhores soluções encontradas na população.

Os indivíduos aleatórios são criados da mesma maneira com que é criada a população inicial do AG, ou seja, obedecendo a predição de estrutura secundária e utilizando ângulos das bases de dados.

\subsubsection{Imigrantes por Similaridade}

Esta estratégia é proposta neste trabalho como uma tentativa de proporcionar a inserção de conhecimento em AGs. Neste caso, sabe-se que a similaridade da estrutura primária tem relação com a similaridade estrutural de uma proteína. Desse modo, optou-se por gerar imigrantes que tivessem estruturas primárias similares a estrutura primária da proteína de interesse.

O procedimento de criação desses imigrantes é realizado da seguinte maneira:

1. Alinhamento simples. O primeiro passo consiste em alinhar a proteína de interesse através da ferramenta de alinhamento simples BLAST [Altschul et al., 1990]. Os parâmetros do algoritmo são mantidos conforme o padrão.

2. Obtenção de estruturas. Em seguida, as estruturas das proteínas retornadas pelo alinhamento são obtidas do banco de dados público do PDB (Protein Data Bank), disponível em http://www.pdb.org. São retornadas no máximo 100 sequências.

3. Conversões. As estruturas no formato PDB são convertidas para ângulos de torção, através de rotinas do software Tinker [Ponder et al., 1998]. Agora, ao invés de coordenadas cartesianas dos átomos, existe uma lista de ângulos de torção para cada aminoácido.

4. Gerar população de similares. Utilizando as informações fornecidas pelo alinhamento (arquivo $x m l$ contendo as regiões de identidade) e os ângulos de torção que foram gerados para cada proteína, seleciona-se apenas os ângulos dos aminoácidos que alinharam. Cada proteína fornecida pelo alinhamento irá compor um 
indivíduo. Os ângulos dos resíduos que não alinharam são sorteados das bases de dados de ângulos.

Por fim, a população de imigrantes é inserida na população ao longo das gerações, do mesmo modo que a estratégia dos imigrantes aleatórios, e está sujeita ao operador crossover. O número de imigrantes por similaridade inseridos em cada geração é controlado pela taxa $p_{i S}$. A seleção dos indivíduos a serem inseridos é feita aleatoriamente.

\subsubsection{Imigrantes com Auto-Organização}

Um dos problemas das duas estratégias acima é que não se sabe qual a quantidade de imigrantes que deve ser inserida. Se um número muito pequeno de imigrantes for inserido, é provável que não haja melhoria e que esses indivíduos se percam na população, não sendo selecionados para gerações posteriores. No entanto, se um número muito grande de imigrantes for inserido, eles poderão substituir indivíduos bons da população, ou seja, aqueles que possuem um fitness melhor que o dos imigrantes, também não ocasionando melhoria. Para solucionar esse problema, foram desenvolvidos os Imigrantes com Auto-Organização, que é uma combinação das duas estratégias anteriores, porém neste caso as taxas de imigrantes se auto-regulam.

No início da simulação, as taxas total de imigrantes (aleatórios e e por similaridade) é definida como sendo $p_{i}$ (ou seja, $p_{i} * 100 \%$ dos indivíduos da população), sendo que $p_{i}=p_{i A}+p_{i S}$, onde $p_{i A}$ é taxa de imigrantes aleatórios e $p_{i S}$ a taxa de imigrantes por similaridade. Desse modo, o número de indivíduos da população normal é iniciado com os $\left(1-p_{i}\right) * 100 \%$ restantes. Então, a cada 50 gerações, verifica-se se o fitness do melhor indivíduo corrente (geração $n$ ) é menor que a do melhor indivíduo da geração $n-50$. Caso não seja, as taxas sofrem uma alteração aleatória entre $\pm 3 \%$. A taxa de imigrantes pode variar entre $30 \%$ e $98 \%$.

Dessa forma, sempre que o fitness da melhor solução atual é o mesmo que a de 50 gerações atrás, o algoritmo muda as taxas para encontrar melhores parâmetros.

\subsection{Funções de Avaliação}

Neste projeto, um modelo CG, descrito em [Yap et al., 2008], foi utilizado para AGs aplicados a PEP. Neste modelo, a informação de estrutura secundária é utilizada como conhecimento a priori para reduzir o espaço de busca. Além disso, também foram feitos testes com um modelo full-atom. As funções de avaliação ou fitness são utilizadas para medir a aptidão (fitness) de cada indivíduo do AG. Neste caso, os indivíduos mais aptos são os que possuem a menor energia potencial, que é calculada por um desses campo de força. Desse modo, são apresentados a seguir conceitos básicos dos dois tipos de campos de força utilizados neste trabalho. 


\subsubsection{Modelo CG}

O modelo CG foi aqui implementado, ao contrário do full-atom (onde foi utilizado uma rotina externa), o que o torna extremamente rápido.

Seguindo a abordagem empregada em [Brown et al., 2003] e [Yap et al., 2008] quando o modelo CG é usado, parâmetros que variam conforme a estrutura secundária são utilizados. Esse tipo de conhecimento ajuda a guiar o espaço de busca. Porém também pode representar um problema, uma vez que pode induzir a erros no processo de busca quando existirem erros nas predições de estrutura secundária. Quando o modelo CG é utilizado, os indivíduos do AG são representados através de uma classe cujos atributos são: aos ângulos da cadeia principal fi $(\phi)$ e psi $(\psi)$ e o seu índice correspondente na base de dados. O modelo minimalista, ou CG, aqui utilizado é baseado naquele descrito em [Yap et al., 2008] e foi calibrado de modo a favorecer que a proteína dobre na estrutura nativa. A grande vantagem de sua utilização é o menor custo computacional, quando comparado a modelos que consideram todos os átomos das proteínas (full atom). Essa vantagem permite aumentar o espaço de conformações explorado, utilizando os recursos computacionais disponíveis [Maupetit et al., 2007].

Nesse modelo, os átomos do carbono de cada aminoácido são utilizados para representar a cadeia principal da proteína. Nessa abordagem, detalhes estruturais dos aminoácidos são desconsiderados.

Conforme expresso pela Equação 4.1, que descreve a Hamiltoniana efetiva utilizada, a energia potencial (E), também chamado aqui de fitness, é calculada através da soma dos termos: Energia dos ângulos de ligação $\left(E_{A L}\right)$, Energia dos ângulos diedrais $\left(E_{A D}\right)$, Energia de van der Waals $\left(E_{V d W}\right)$ e Energia das ligações de hidrogênio $\left(E_{L H}\right)$, ou seja:

$$
E=E_{A L}+E_{A D}+E_{V d W}+E_{L H}
$$

Assim como em [Yap et al., 2008], todas as simulações são efetuadas aqui, em unidades reduzidas. Os valores das energias são apresentados em unidades da constante $\epsilon_{0}$. De acordo com [Guo e Thirumalai, 1996], $\epsilon_{0} \approx 1 \mathrm{Kcal} / \mathrm{mol}$.

Os diferentes termos da Equação 4.1 são apresentados a seguir.

\subsubsection{Energia do Ângulo de Ligação}

A energia do ângulo de ligação é dada por:

$$
E_{A L}=\sum_{i} \frac{1}{2} k_{0}\left(\theta_{i}-\theta_{0}\right)^{2}
$$


sendo $\theta$ o i-ésimo ângulo de ligação, que é o ângulo formado por três carbonos- $\alpha$ consecutivos. Os parâmetros utilizados neste trabalho são $k_{0}=20 \epsilon_{h} / \mathrm{rad}^{2}$ e $\theta_{0}=95^{\circ}$ se o carbono- $\alpha$ em questão pertencer a uma $\alpha$-hélice, ou $\theta_{0}=105^{\circ}$, caso contrário.

\section{Energia $/ \varepsilon_{\mathrm{h}}$}

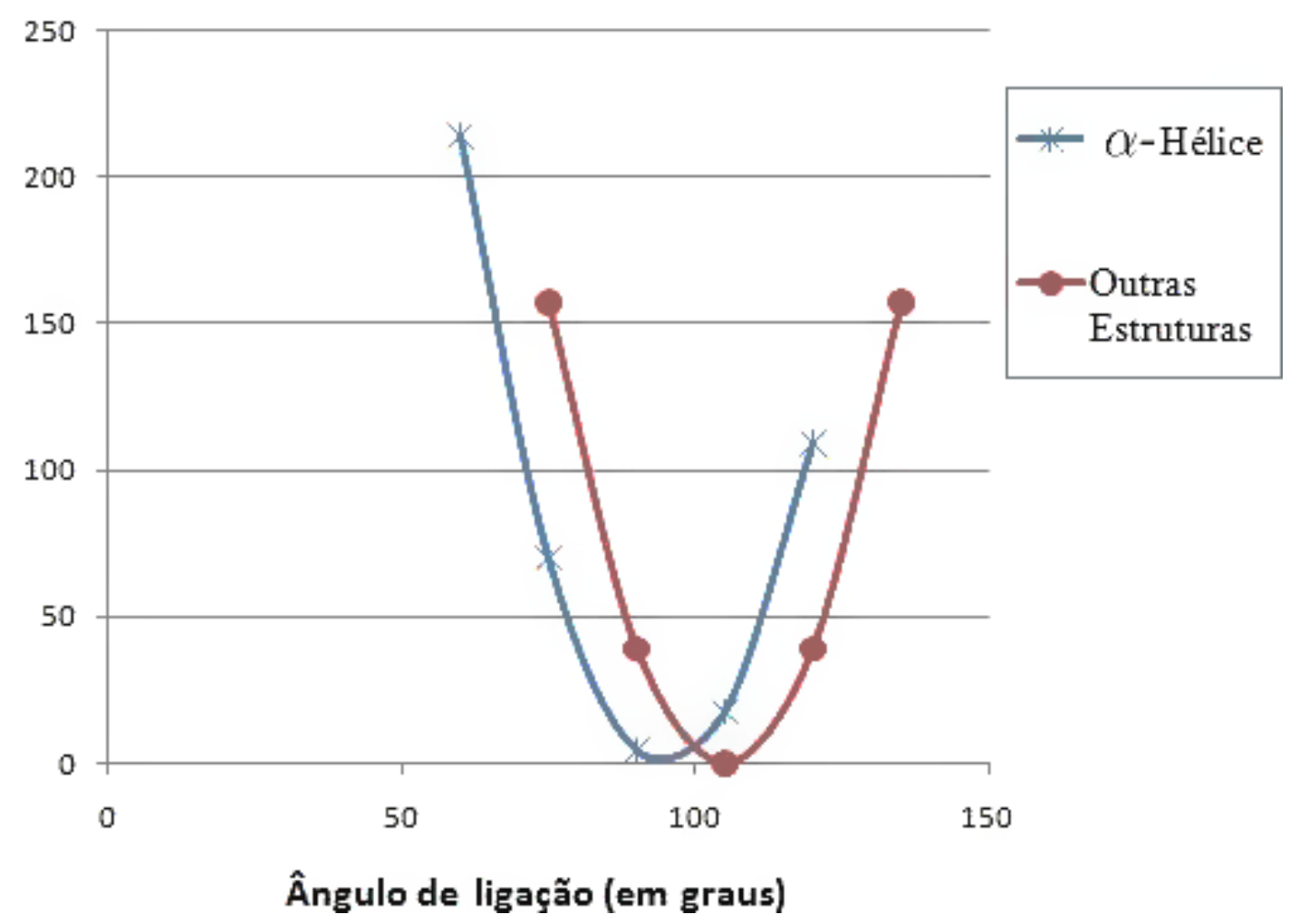

Figura 4.4: Exemplo da energia potencial relacionada com o ângulo de ligação.

A Figura 4.4 mostra a energia do ângulo de ligação para ângulos de $\alpha$-hélice e outras estruturas (Equação 4.2). Pode-se observar que a energia mínima para as $\alpha$-hélices ocorre para o ângulo de $95^{\circ}$, enquanto que para outras estruturas secundárias ocorre em $105^{\circ}$.

\subsubsection{Energia do ângulos de torção}

O ângulo de torção é o ângulo formado entre 4 carbonos- $\alpha$ consecutivos $(X, Y, Z$ e $W)$. Supondo que existam três vetores entre esses quatros carbonos $(\overrightarrow{X Y}, \overrightarrow{Y Z}$ e $\overrightarrow{Z W})$ e que eles formem dois planos, de modo que o vetor $\overrightarrow{Y Z}$ pertença à intersecção dos planos, então o ângulo de torção é o ângulo formado entre os dois planos e é dado pelo ângulo entre seus vetores normais.

Aqui, são utilizadas duas variações da energia do ângulo de torção. A primeira delas, chamada de termo diedral 1 para facilitar o entendimento, foi apresentada em [Yap et al., 2008], é dada por: 
$E_{A D}=\sum_{i} A\left[1+\cos \left(\phi_{i}-\phi_{0}\right)\right]+B\left[1-\cos \left(\phi_{i}-\phi_{0}\right)\right]+C\left[1+\cos 3\left(\phi_{i}+\phi_{0}\right)\right]+D\left[1+\cos \left(\phi+\phi_{0}+\frac{\pi}{4}\right)\right]$

sendo $\phi$ o ângulo de torção do bead $i$. Os parâmetros A, B, C, D e $\phi_{0}$ variam de acordo com o tipo de estrutura formada e são escolhidos a priori [Yap et al., 2008]. As estruturas secundárias podem assumir os seguintes tipos: $\mathrm{H}$ (hélice), $\mathrm{E}$ (estendido ou folha- $\beta$ ), T, P, U ou Q (tipos de dobra ou turn). A Tabela 4.1, descrita em [Yap et al., 2008], mostra os valores dos parâmetros para cada estrutura.

Tabela 4.1: Parâmetros dos vários tipos diedrais [Yap et al., 2008].

\begin{tabular}{cccccc}
\hline \hline Tipo de diedro & $\mathrm{A}\left(\epsilon_{h}\right)$ & $\mathrm{B}\left(\epsilon_{h}\right)$ & $\mathrm{C}\left(\epsilon_{h}\right)$ & $\mathrm{D}\left(\epsilon_{h}\right)$ & $\phi_{0}($ rad $)$ \\
\hline H (Hélice) & 0 & 1,2 & 1,2 & 1,2 & $+0,17$ \\
E (Estendido) & 0,45 & 0 & 0,6 & 0 & $-0,35$ \\
T (Volta) & 0,2 & 0,2 & 0,2 & 0,2 & 0 \\
$\mathrm{P}\left(90^{\circ}\right)$ & 0,36 & 0 & 0,48 & 0 & $+1,57$ \\
$\mathrm{Q}\left(-90^{\circ}\right)$ & 0,36 & 0 & 0,48 & 0 & $-1,57$ \\
$\mathrm{U}\left(0^{\circ}\right)$ & 0,36 & 0 & 0,48 & 0 & $+3,14$
\end{tabular}

A classificação dos aminoácidos de cada proteína é fornecida em [Yap et al., 2008]. Um gráfico típico para energia dos ângulos de torção pode ser visto no gráfico da Figura 4.5.

\section{Energia $/ \varepsilon_{h}$}

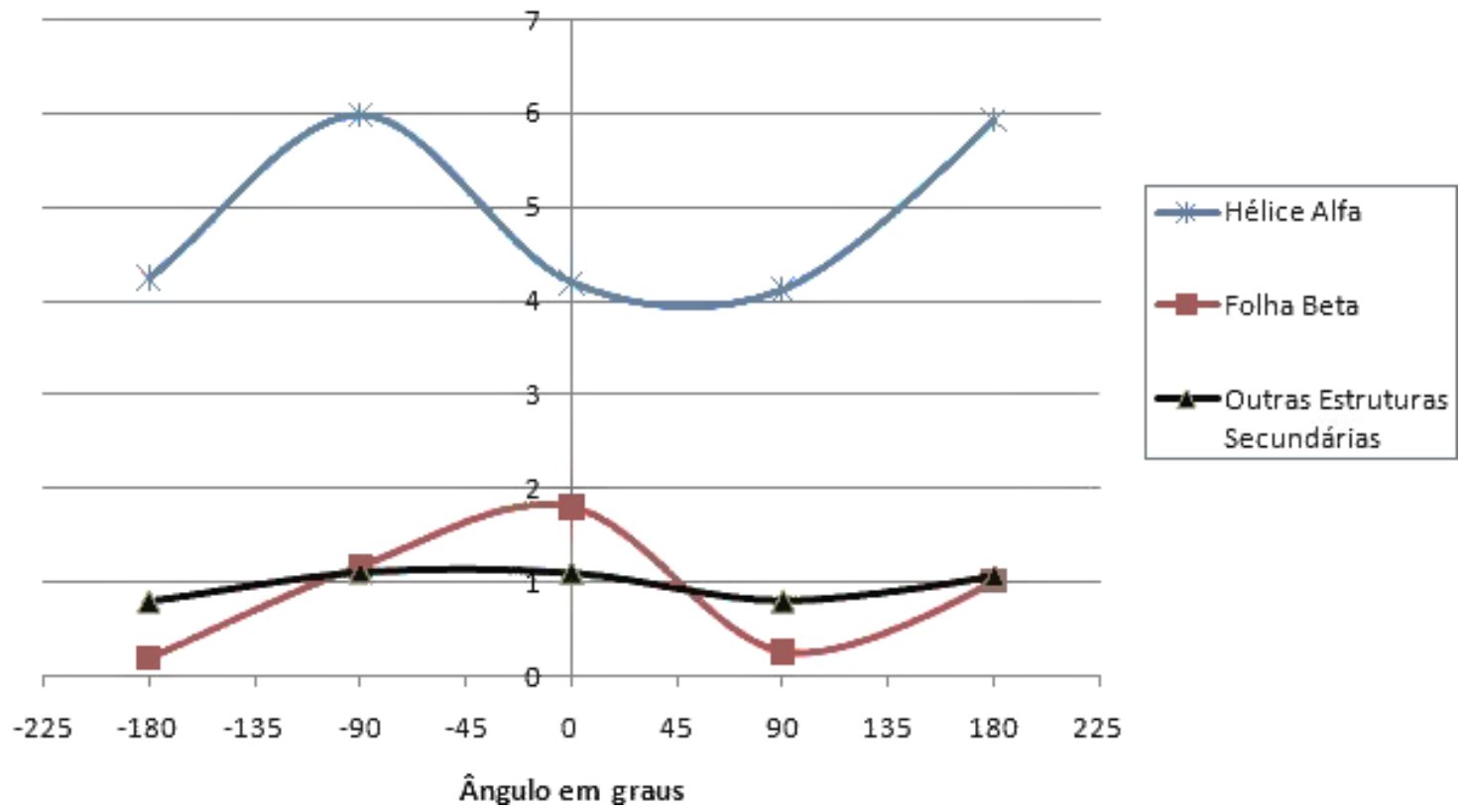

Figura 4.5: Energia dos ângulos diedrais.

A segunda variação da Energia do Ângulo de Torção (Equação 4.4), utilizada aqui 
em alguns testes e chamada de termo diedral 2, foi descrita em um trabalho anterior [Brown et al., 2003], sendo dada por:

$E_{A D}=\sum_{i} A\left[1+\cos \left(\phi_{0}\right)\right]+B\left[1-\cos \left(\phi_{i}\right)\right]+C\left[1+\cos 3\left(\phi_{i}\right)\right]+D\left[1+\cos \left(\phi+\frac{\pi}{4}\right)\right]$

Neste caso, os parâmetros A, B, C e D são dados pela Tabela 4.2 e $\phi_{0}=105^{\circ}$. Podese notar que a estrutura secundária é classificada apenas em: H, E e T. Essa equação foi utilizada na maioria dos experimentos, descritos na Seção 5 , porque o preditor de estrutura secundária utilizado não fornece uma classificação mais específica para regiões de dobra.

Tabela 4.2: Parâmetros dos vários tipos diedrais [Brown et al., 2003].

\begin{tabular}{ccccc}
\hline \hline Tipo de diedro & $\mathrm{A}\left(\epsilon_{h}\right)$ & $\mathrm{B}\left(\epsilon_{h}\right)$ & $\mathrm{C}\left(\epsilon_{h}\right)$ & $\mathrm{D}\left(\epsilon_{h}\right)$ \\
\hline $\mathrm{H}$ (Hélice) & 0 & 1,2 & 1,2 & 1,2 \\
E (Estendido) & 0,9 & 0 & 1,2 & 0 \\
T (Volta) & 0 & 0 & 0,2 & 0 \\
\hline
\end{tabular}

Para essa variação da expressão, as proteínas testadas são classificadas manualmente, utilizando a informação da predição de estrutura secundária.

\subsubsection{Energia de Van der Waals}

O termo de van der Waals, modelado pelo potencial de Lennard-Jones, é dada por:

$$
\left.E_{V d W}=\sum_{i, j \geq i+3}\left[4 \epsilon_{h} S 1\left(\frac{\sigma}{r_{i j}}\right)^{12}-S 2 \frac{\sigma}{r_{i j}}\right)^{6}\right]
$$

sendo que $r_{i j}$ representa a distância entre dois beads $i$ e $j$, neste caso, dois carbonos- $\alpha$ e $\sigma=1,16$. Os valores das energias são dados em unidades da constante $\epsilon_{h}$. Conforme apresentado na Tabela 4.3, a qual foi apresentada em [Yap et al., 2008], cada um dos aminoácidos é classificado de acordo com um tipo de bead, sendo eles: $B$ (atração forte), $V$ (atração fraca), $N$ (repulsão fraca), L (repulsão forte).

Os parâmetros $S 1$ e $S 2$ variam de acordo com as interações $B-B, B-V, V-V, L-L, L-V$, $L-B$ e $N X$ (Tabela 4.4), sendo $X$ de qualquer tipo $(B, L, V$ e $N)$.

De acordo com a Figura 4.6, pode-se observar um gráfico típico da energia de van der Waals para os diferentes tipos de interações. 
Tabela 4.3: Mapeamento [Yap et al., 2008].

\begin{tabular}{cccc}
\hline \hline Amino & Tipo & Amino & Tipo \\
\hline Trp & B & Met & B \\
Gly & N & Asn & L \\
Cys & B & Val & B \\
Ser & N & His & L \\
Leu & B & Ala & V \\
Thr & N & Gln & L \\
Ile & B & Tyr & V \\
Glu & L & Lys & L \\
Phe & B & Pro & N \\
Asp & L & Arg & L
\end{tabular}

Tabela 4.4: Valores para S1 e S2 [Yap et al., 2008].

\begin{tabular}{c|ccccccc}
\hline \hline & B-B & B-V & V-V & L-L & L-V & L-B & N-X \\
\hline S1 & 1,4 & 0,7 & 0,35 & $1 / 3$ & $1 / 3$ & $1 / 3$ & 1 \\
S2 & -1 & -1 & -1 & -1 & -1 & -1 & 0 \\
\hline
\end{tabular}

\section{Energia/ch}

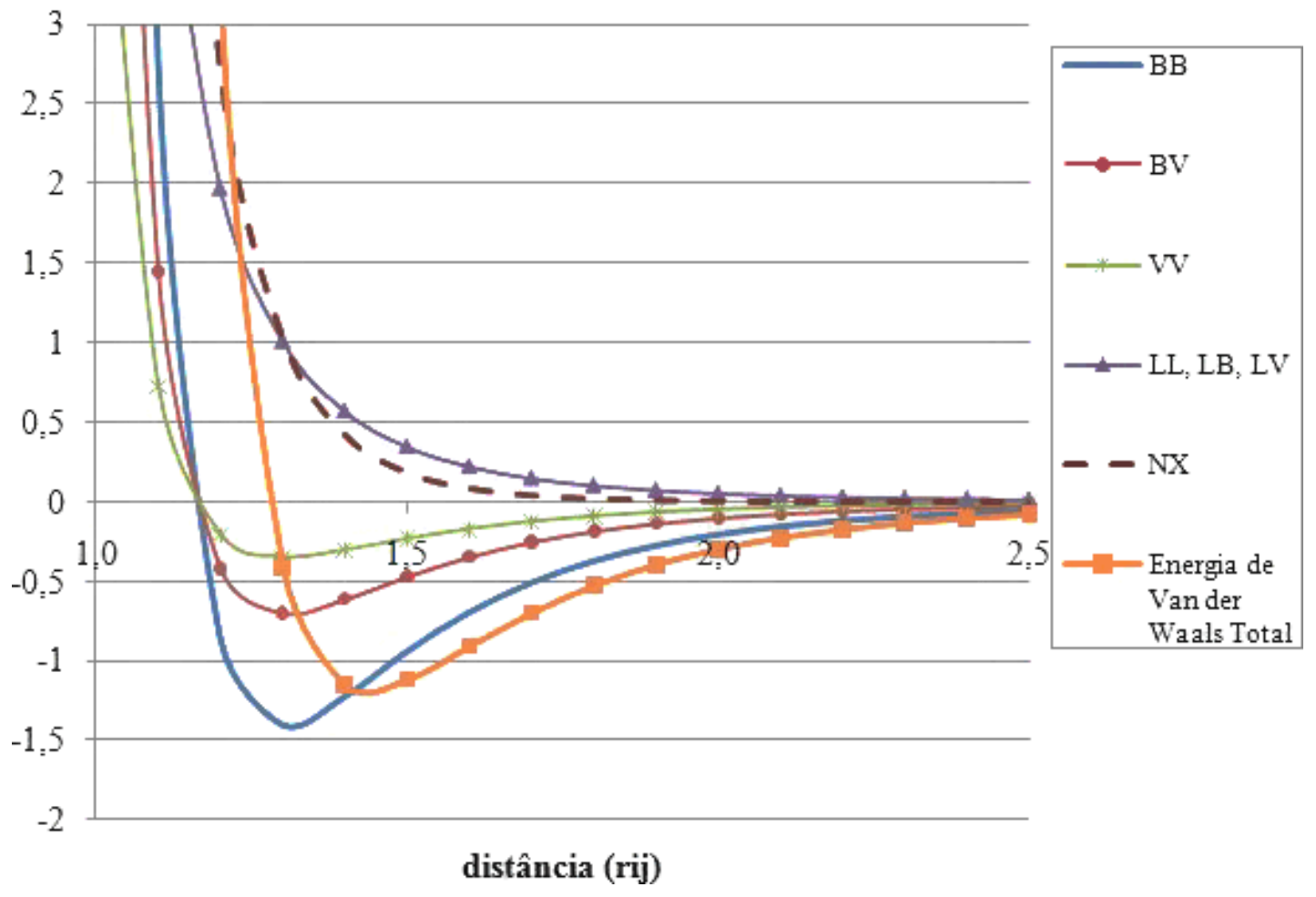

Figura 4.6: Gráfico típico para o termo de van der Waals do potencial de interação.

\subsubsection{Energia das ligações de hidrogênio}

A energia das ligações de Hidrogênio é dada por: 


$$
E_{L H}=\sum_{L H} \epsilon_{L H} F\left(r_{i j}-r_{L H}\right) G\left(\left|\mathbf{t}_{L H, i} \times \mathbf{r}_{i j}\right|-1\right) H\left(\left|\mathbf{t}_{L H, j} \times \mathbf{r}_{i j}\right|-1\right)
$$

na qual:

$$
\begin{gathered}
F\left(r_{i j}-r_{L H}\right)=\exp \left\{\left(\frac{-\left(r_{i j}-r_{L H}\right)^{2}}{\left(\sigma_{L H d i s t}\right)^{2}}\right)\right\} \\
G\left(\left|\mathbf{t}_{L H, i} \times \mathbf{r}_{i j}\right|-1\right)=\exp \left\{\left(\frac{\left|\mathbf{t}_{L H, i} \times \mathbf{r}_{i j}\right|-1}{\left(\sigma_{L H}\right)^{2}}\right)\right\} \\
H\left(\left|\mathbf{t}_{H B, j} \times \mathbf{r}_{i j}\right|-1\right)=\exp \left\{\left(\frac{\left|\mathbf{t}_{L H, j} \times \mathbf{r}_{i j}\right|-1}{\left(\sigma_{L H}\right)^{2}}\right)\right\}
\end{gathered}
$$

sendo que o parâmetro $r_{i j}$ é a distância entre dois beads $i$ e $j$ e o $\mathbf{r}_{i j}$ é o vetor entre esses beads $i$ e $j$. $F$ é uma função gaussiana centrada na distância ideal para a ligação de hidrogênio $\left(r_{L H}\right)$ e $\mathbf{t}_{L H, i}$ e $\mathbf{t}_{L H, j}$ são vetores unitários normais aos planos $(i-1, i$, $i+1)$ e $(j-1, j, j+1)$, respectivamente. A distância ideal para a ligação de hidrogênio utilizada é de $r_{L H}=1,35$ para $\alpha$-hélices e $r_{L H}=1,25$ para folhas- $\beta$. Todos os outros parâmetros são independentes da estrutura secundária e os valores utilizados são: $r_{L H d i s t}=0,5$ e $r_{L H}=0,5$.

Aqui, dependendo da propensão diedral, cada carbono- $\alpha$ assume um dos tipos: $\alpha$ hélice, folha- $\beta$ e nenhum. Para $\alpha$-hélices, o potencial é calculado para cada carbono$\alpha$ cujo terceiro vizinho também pertença a $\alpha$-hélice. Já para folha- $\beta$, o potencial é calculado para cada carbono- $\alpha$ que esteja a um raio de 3 unidades de comprimento de outro que também pertença a folha- $\beta$ [Yap et al., 2008].

\subsubsection{Modelo full-atom}

O segundo campo de força empregado como função de avaliação do AG foi o CHARMM versão 22, descrito em [Brooks et al., 1983b]. A versão utilizada é disponibilizada como padrão pelo software Tinker [Ponder et al., 1998]. A parametrização utilizada foi a padrão fornecida, desse modo a constante dielétrica empregada do modelo é igual a 1 (valor da constante no vácuo). O modelo utiliza todos os átomos da proteína.

A Energia potencial calculada por este campo de força possui as seguintes componentes:

$$
E_{\text {Potencial }}=E C L+E A L+E A T+E U B+E T T+E I+E V d W+E E
$$

sendo:

- ECL: Energia do comprimento de ligação ou estiramento; 
- EAL: Energia do ângulo de ligação ou deformação;

- EAT: Energia torsional (ou do ângulo de torção);

- EUB: Energia de Urey Bradley;

- ETT: Energia torção-torção;

- EI: Energia de torção imprópria;

- EVdW: Energia de van der Waals;

- EE: Energia eletrostática;

Estas componentes são descritas no Apêndice A.

\subsection{Proteínas selecionadas}

As cinco proteínas utilizadas neste trabalho foram selecionadas de acordo com sua complexidade e tamanho e são brevemente apresentadas a seguir.

\subsubsection{Proteína Receptora de Acetilcolina}

A proteína de código PDB: 1A11 (Figura 4.7) foi escolhida devido ao seu tamanho pequeno e por ser formada por uma única $\alpha$-hélice. A proteína é uma receptora de acetilcolina e possui 25 resíduos [Opella et al., 1999].

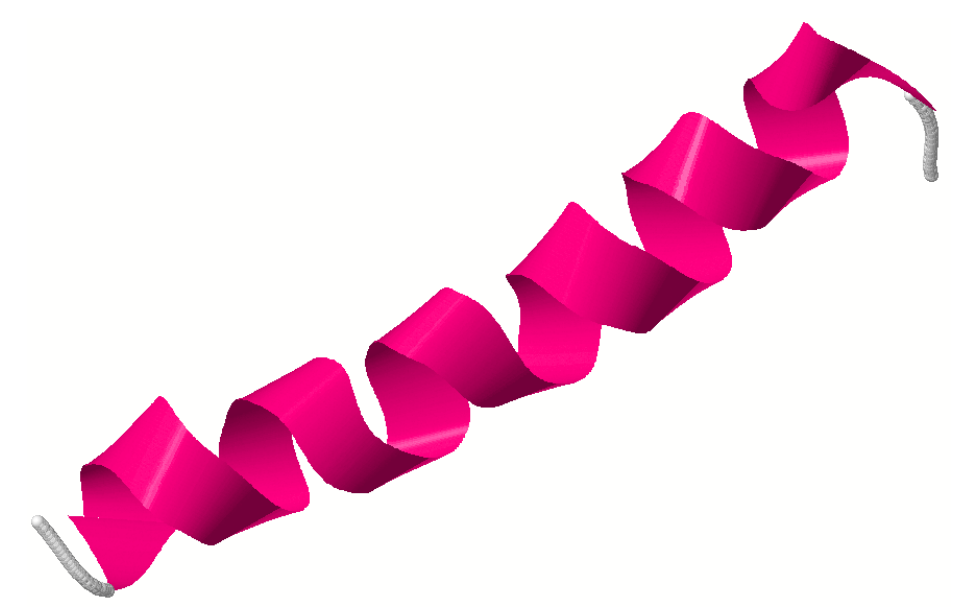

Figura 4.7: Representação da estrutura nativa da proteína 1A11.

Trata-se de uma estrutura proteica simples e foi selecionada justamente por essa razão. Espera-se que os algoritmos testados obtenham bons resultados e não desmontem a $\alpha$ hélice ao longo das gerações.

\subsubsection{Proteína MSI-594}

A proteína MSI-594, cujo código PDB é 2 K98 (Figura 4.8), foi utilizada nos experimentos, devido a sua simplicidade estrutural. É constituído por 24 resíduos de 
aminoácidos e sua estrutura tridimensional consiste basicamente de duas $\alpha$-hélices [Bhunia et al., 2009].

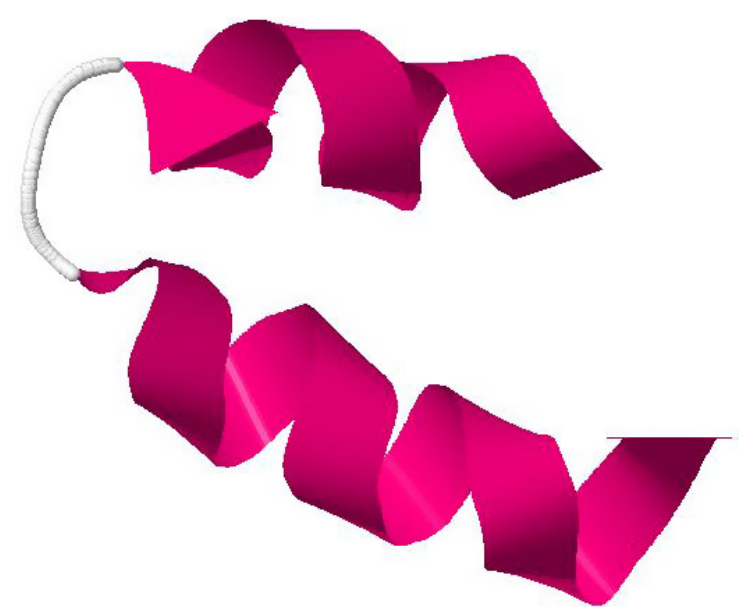

Figura 4.8: Representação da estrutura nativa da Proteína 2 K98.

\subsubsection{Proteína DNA-ligante}

A proteína PDB: 1ENH tem como função ligar-se ao DNA, possuindo $3 \alpha$-hélices e 54 resíduos (Figura 4.9) [Clarke et al., 1994].

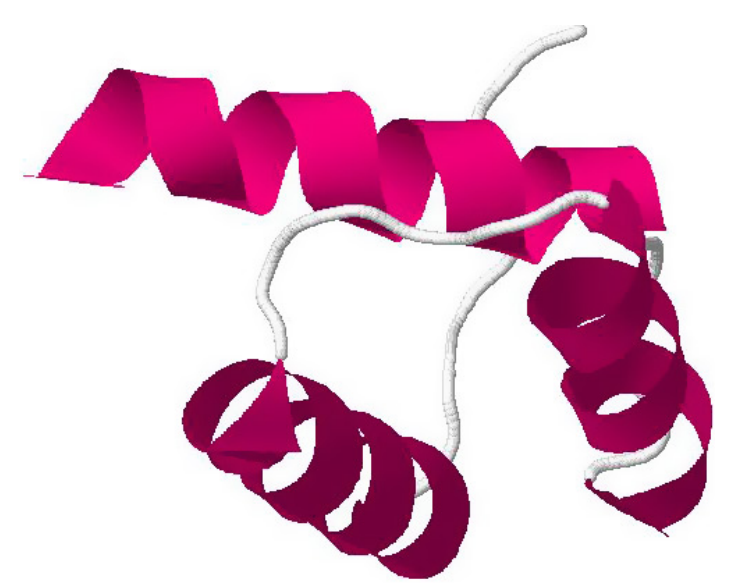

Figura 4.9: Representação da estrutura nativa da proteína 1ENH.

\subsubsection{Proteína G}

A proteína de código PDB: 2GB1 (Figura 4.10), foi empregada em [Yap et al., 2008]. Trata-se da proteína G, uma ligante de imunoglobulina. Ela possui 56 resíduos, sendo constituída por $1 \alpha$-hélice e $4 \beta$-fitas [Gronenborn et al., 1991]. 


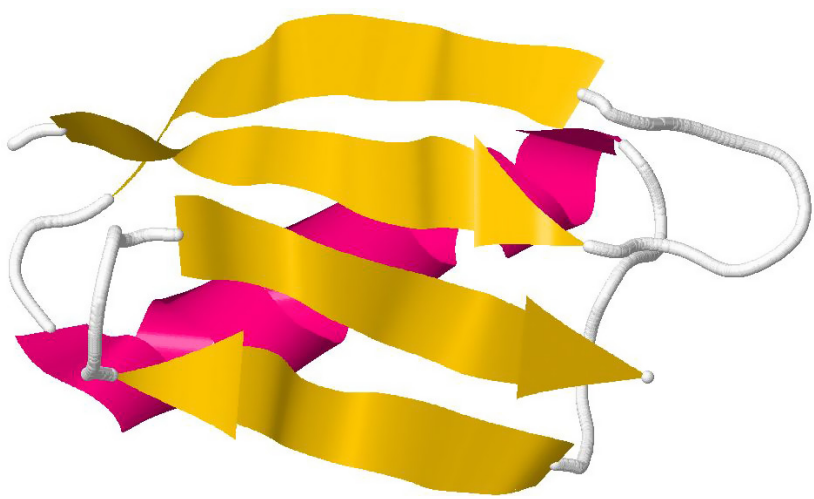

Figura 4.10: Representação da estrutura nativa da proteína $2 G B 1$.

\subsubsection{Proteína Fosfatase}

A proteína de código PDB: 2w4P (Figura 4.11) é uma fosfatase humana e possui 2 $\alpha$-hélices e $5 \beta$-fitas. Foi selecionada por possuir uma estrutura mais complexa que as demais e um número maior de resíduos (99).

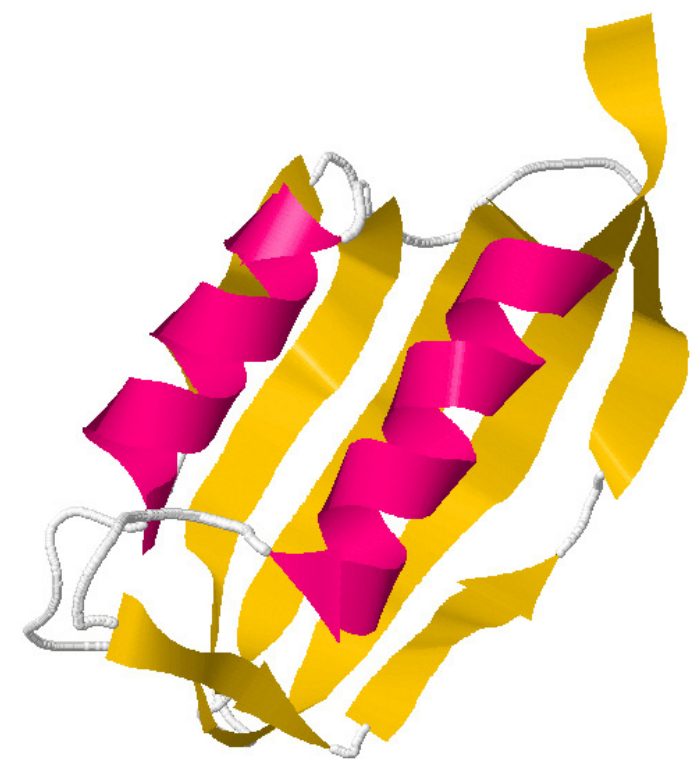

Figura 4.11: Representação da estrutura nativa da proteína $2 W 4 P$. 


\section{Capítulo 5}

\section{Resultados e discussões}

\subsection{Descrição dos experimentos}

Foram realizados experimentos com os seguintes algoritmos:

- AGP: Algoritmo genético padrão;

- AGPA6: Algoritmo genético $\operatorname{com} p_{i A}=0,06$ e $p_{i S}=0$, ou seja, na qual 6\% da população é substituída por imigrantes aleatórios em toda geração;

- AGS6: Algoritmo genético com $p_{i S}=0,06$ e $p_{i A}=0$, ou seja, na qual 6\% da população é substituída por imigrantes por similaridade em toda geração;

- AGAutoOrg: Algoritmo genético com taxas de imigrantes $\left(p_{i}\right)$ auto-organizáveis (ver Seção refsec:iautoorg), iniciado $\operatorname{com} p_{i A}=p_{i S}=0,1$ para imigrantes aleatórios e por Similaridade.

Os resultados foram separados em 2 partes: na primeira delas, foram descritos os experimentos realizados com o modelo $\mathrm{CG}$ e na segunda parte os realizados com modelo full-atom.

Um experimento inicial foi realizado para definir as taxas de mutação e crossover. Este experimento foi executado com a proteína MSI-594 (2K98), por ter o menor número de resíduos (24), para uma mesma semente aleatória e com o mesmo número de gerações igual a 100. Os resultados podem ser observados na Tabela 5.1.

\begin{tabular}{c||ccc}
\multicolumn{1}{c||}{} & \multicolumn{3}{c}{ Crossover } \\
Mutação & $60 \%$ & $70 \%$ & $80 \%$ \\
\hline \hline $5 \%$ & 29,50 & 31,35 & 31,95 \\
$10 \%$ & 33,17 & 27,71 & 25,09 \\
$15 \%$ & $\mathbf{2 4 , 5 7}$ & 29,69 & 27,16
\end{tabular}

Tabela 5.1: Teste de Parâmetros: Energia mínima (do melhor indíviduo) em unidades de $\epsilon_{h}$.

De acordo com o teste de parâmetros, a menor energia foi obtida para a combinação: $60 \%$ de crossover e $15 \%$ de mutação. Esses valores de parâmetros foram adotados 
para todos os experimentos posteriores. Em todos os experimentos deste trabalho, o número de gerações é igual a 100 indivíduos, que é uma escolha comum em AGs de acordo com a literatura.

A fim de comparar os resultados obtidos pelos algoritmos, o teste de Wincoxon SignedRank foi empregado. Esse teste não-paramétrico é utilizado para testar se dois conjuntos de dados são oriundos de distribuições com médias iguais [Garcia et al., 2009]. Ele pode ser utilizado para dados de qualquer distribuição. Nas tabelas referentes às comparações estatísticas, o p-valor do teste não-paramétrico é mostrado. Além disso, a seguinte codificação é utilizada: o símbolo (s) indica que o p-valor é menor que o nível de significância, ou seja, que existe diferença significativa (de acordo com o nível de significância) do algoritmo em questão com o AGP; o símbolo (-) indica que a mediana do algoritmo em questão é maior que a do AGP, enquanto que o símbolo (+) indica que esta mediana é menor que a do AGP (ou seja, o desempenho do algoritmo foi melhor que o do AGP). A linguagem e ambiente de desenvolvimento $\mathrm{R}$ foi utilizado nesses cálculos [Team, 2008]. O nível de significância utilizado foi de 5\%.

Os algoritmos foram executados 10 vezes, ou seja, para 10 sementes aleatórias. Nos experimentos com o modelo CG, foram efetuados alguns testes para determinar um número de gerações razoável. Optou-se por um número de gerações que variasse de acordo com o número de resíduos da proteína, de modo que para as proteínas maiores o número de gerações fosse também maior. Desse modo, o número de gerações utilizado foi inicialmente 200 por resíduo da proteína, valor o qual foi escolhido arbitrariamente. No entanto, esse valor foi aumentado em alguns casos, de acordo com o tamanho da proteína, para melhor avaliação do critério de parada. Desse modo, para cada experimento o número de gerações é informado na respectiva seção.

Nos experimentos com o modelo full-atom, devido ao maior custo computacional, o número de gerações empregados foi de 1000 .

Para se ter uma ideia da diferença entre o custo computacional, quando os modelos CG e full-atom são utilizados, enquanto a execução de 1000 gerações do AGP com o modelo CG e utilizando a proteína 2GB1, de 56 resíduos, demora cerca de 18,30 minutos, a mesma simulação empregando o modelo full-atom leva 24,16 horas em um computador com quatro processadores (Intel $\AA$ Xeon $\AA 2,00 \mathrm{GHz}, 5 \mathrm{~GB}$ de RAM).

A Tabela 5.2 mostra os experimentos realizados.

\begin{tabular}{c||cc} 
Experimento & Modelo & Nome \\
\hline \hline 1 & CG & Sem predição de estrutura secundária \\
\hline 2 & CG & Com predição de estrutura secundária \\
\hline 3 & full-atom & Otimização da cadeia lateral \\
\hline
\end{tabular}

Tabela 5.2: Experimentos realizados.

De forma resumida, o objetivo dos experimentos é: 
- Experimento 1 (Seção 5.2.1): Verificar o comportamento do campo de força descrito em [Yap et al., 2008] para PEP com a codificação fornecida no artigo para a estrutura secundária.

- Experimento 2 (Seção 5.2.2): Testar a utilização do modelo CG, usando um preditor de estrutura secundária, que é uma abordagem mais realista para a PEP. Além disso, testar o desempenho do modelo para mais proteínas.

- Experimento 3 (Seção 5.3.1): Testar se a inserção de conhecimento é importante utilizando o campo de força full-atom e comparar as diferenças para com o modelo CG.

A Seção 5.4 traz a análise dos resultados.

\subsection{Experimentos com o modelo CG}

Nos experimentos 1 e 2, utilizou-se como função de avaliação o modelo descrito na Seção 4.3.1 da metodologia, sendo que somente os ângulos da cadeia principal são utilizados. O artigo [Yap et al., 2008] fornece tanto a parametrização do modelo, que foi apresentada na metodologia, quanto uma classificação para a estrutura secundária da proteína 2GB1. Contudo, diferentemente de quando um aplicativo para predição de estrutura secundária é usado por um preditor, os autores classificam as regiões de dobra em quatro tipos: (T, P, Q e U), como também já foi comentado anteriormente.

No Experimento 1, utilizou-se o termo diedral descrito na Equação 4.3 (termo diedral 1), enquanto que no experimento 2 empregou-se a Equação 4.4 (termo diedral 2), já que o preditor de estrutura secundária foi utilizado. No termo diedral da Equação 4.4, dobras não possuem classificação e são apenas definidas como T (turn). Essa simplificação do termo diedral foi necessária uma vez que o preditor de estrutura secundária empregado, o PSIPred [Jones, 1999], não fornece diferenciação dentro das regiões de dobra. Dessa forma, no Experimento 2, valeu-se de predição de estrutura secundária.

A seguir, são apresentados todos os experimentos feitos para o modelo CG, primeiramente sem predição de estrutura secundária, ou seja, com a classificação fornecida em [Yap et al., 2008], utilizando o termo diedral 1.

\subsubsection{Experimento 1: Modelo CG sem predição de estrutura secundária}

Neste experimento, o número de gerações empregado foi de 200 por resíduo. Neste caso, para a proteína 2GB1, que possui 56 resíduos, o total de gerações foi 11200 .

\subsubsection{Proteína G (2GB1)}

A seguir são apresentados os resultados obtidos utilizando o campo de força CG com os parâmetros de estrutura secundária fornecidos em [Yap et al., 2008] (termo diedral 1). Em negrito estão os menores valores de cada coluna. 


\begin{tabular}{c||cccc}
\multirow{2}{*}{ Algoritmo } & Média \pm Desvio Padrão & $\begin{array}{c}\text { Energia } \epsilon_{h} \\
\text { Mediana }\end{array}$ & Mínimo & Máximo \\
\hline \hline AGP & $59,58 \pm 3,90$ & 59,45 & 53,51 & 66,50 \\
\hline AGA6 & $\mathbf{5 6 , 7 9} \pm 4,72$ & 58,25 & $\mathbf{4 9 , 1 5}$ & $\mathbf{6 3 , 0 7}$ \\
\hline AGS6 & $57,19 \pm 4,33$ & $\mathbf{5 6 , 8 3}$ & 49,91 & 65,84 \\
\hline AGAutoOrg & $60,96 \pm 3,26$ & 61,89 & 54,63 & 64,28 \\
\hline
\end{tabular}

Tabela 5.3: Valores da energia total para a $2 G B 1$ sem predição de estrutura secundária (valores relativos a 10 execuções).

A Tabela 5.3 mostra os valores de energia total de interação (fitness) para a proteína G alcançados pelo melhor indivíduo da última geração do AG em 10 execuções (como em todos os outros experimentos). A menor energia média e a menor mínima foram obtidas pelo AGA6.

\begin{tabular}{c||cccc}
\multirow{2}{*}{ Algoritmo } & Média \pm Desvio Padrão & $\begin{array}{c}\text { RMSD } \AA \\
\text { Mediana }\end{array}$ & Mínimo & Máximo \\
\hline \hline AGP & $17,71 \pm 4,04$ & 16,90 & 13,11 & 26,13 \\
\hline AGA6 & $\mathbf{1 6 , 5 7} \pm 3,16$ & $\mathbf{1 6 , 1 9}$ & 12,70 & $\mathbf{2 1 , 6 9}$ \\
\hline AGS6 & $19,44 \pm 4,54$ & 18,76 & $\mathbf{1 2 , 1 0}$ & 26,68 \\
\hline AGAutoOrg & $18,26 \pm 4,43$ & 18,57 & 12,18 & 27,63 \\
\hline
\end{tabular}

Tabela 5.4: $R M S D$ para a 2GB1 sem predição de estrutura secundária.

A Tabela 5.4 mostra os valores de RMSD para o Experimento 1 com a proteína 2GB1. Pode-se observar que o menor RMSD foi 12,10 ̊ para o algoritmo AGS6.

O teste estatístico de Wilcoxon, para verificar se houve diferença estatística entre os valores de energias obtidos pelos algoritmos, é apresentado a seguir.

\begin{tabular}{c||ccc} 
& \multicolumn{3}{c}{ p-valor } \\
& AGA6 & AGS6 & AGAutoOrg \\
\hline \hline AGP & $0,2324(+)$ & $0,1934(+)$ & $0,3750(-)$
\end{tabular}

Tabela 5.5: Teste Estatístico para a $2 G B 1$.

De acordo com a Tabela 5.5, não foi verificada diferença significativa entre o AGP e os demais algoritmos. Contudo, o AGS6 e o AGA6 possuem medianas menores que o AGP.

A Figura 5.1 mostra a energia mínima média, que é a média sobre 10 execuções da energia do melhor indivíduo, ao longo das gerações. Já a Figura 5.2 mostra a média dos RMSDs dos melhores indivíduos, que não necessariamente é o menor RMSD na última geração. 


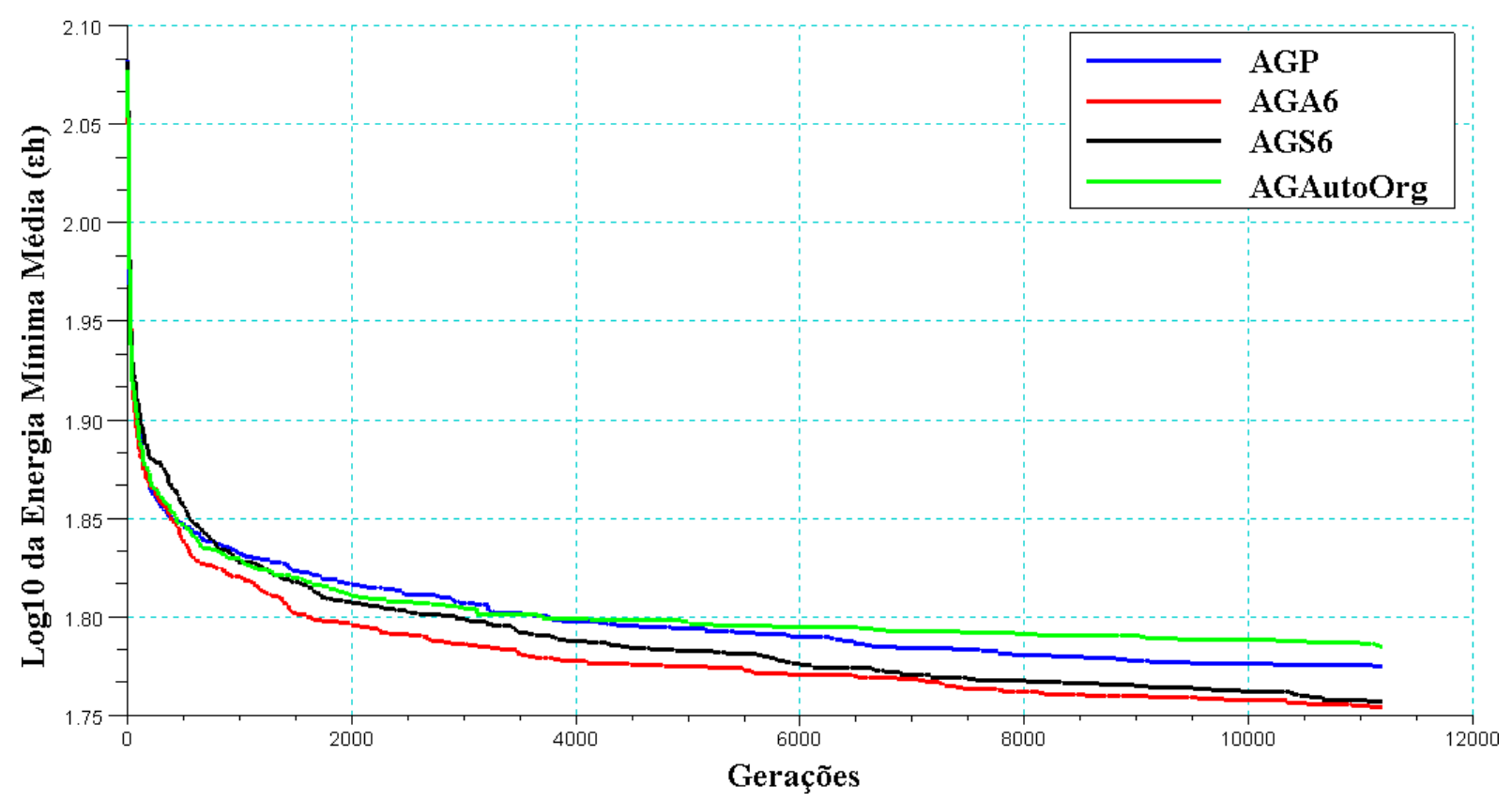

Figura 5.1: Média dos fitness mínimos (ou seja, obtidos pelo melhor indivíduo da população corrente) ao longo das gerações para a $2 G B 1$ sem predição de estrutura secundária.

De acordo com o gráfico da Figura 5.1, pode-se observar que o AGA6 obteve a menor energia mínima média. Também pode-se notar que a curva de energia ainda decresce ligeiramente. $\mathrm{O}$ desempenho do algoritmo foi analisado de acordo com o critério de parada, neste caso ao final das 11200 gerações.

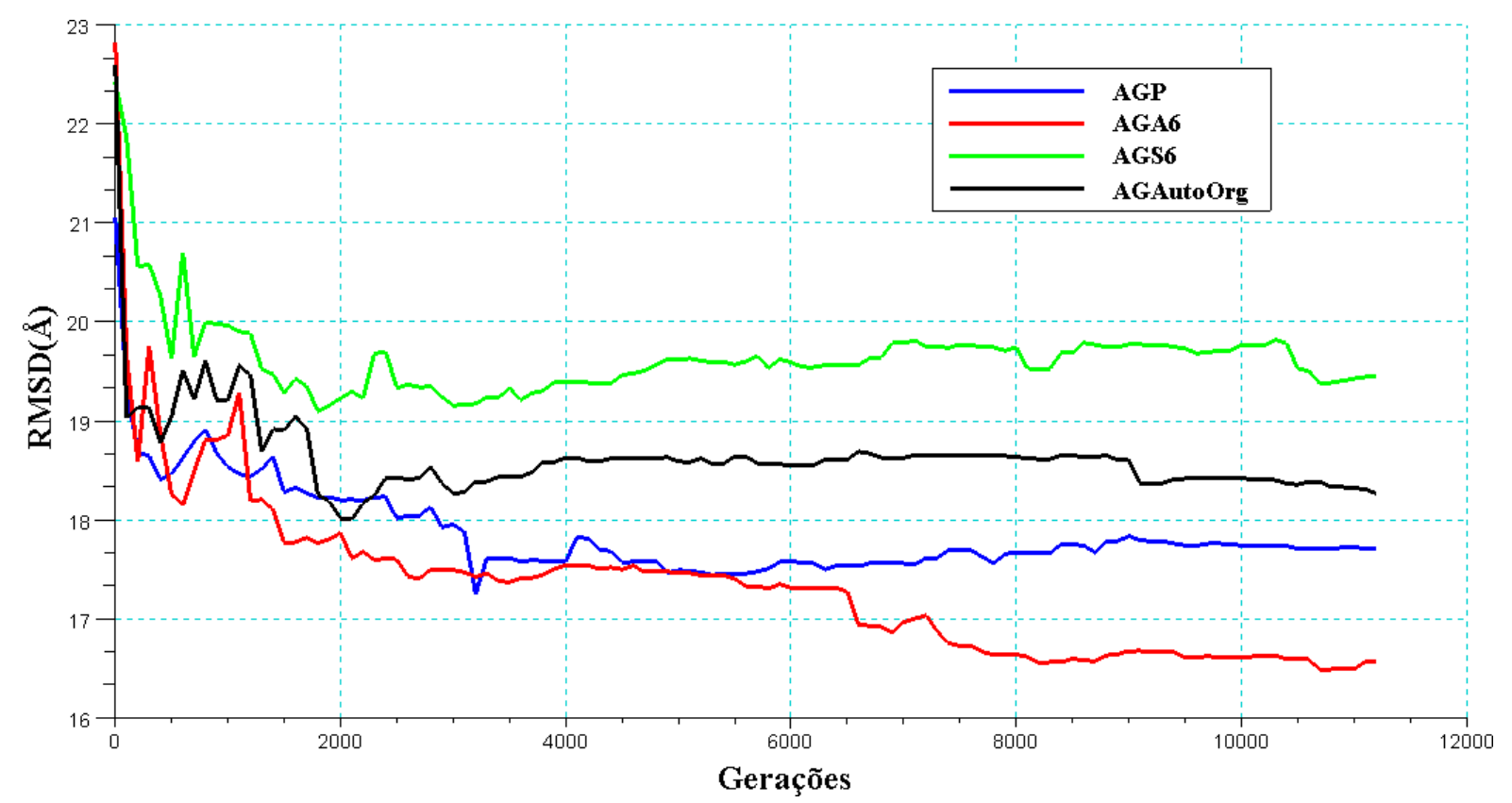

Figura 5.2: Média dos fitness mínimos ao longo das gerações para a $2 G B 1$ sem predição de estrutura secundária.

A Figura 5.2, mostra que o AGA6 também obteve o maior decréscimo no RMSD, principalmente a partir da geração 6000, o que indica que a inserção de diversidade 
pelos imigrigantes aleatórios está sendo importante.

A Figura 5.3 mostra as estruturas com menor energia e com menor RMSD geradas.

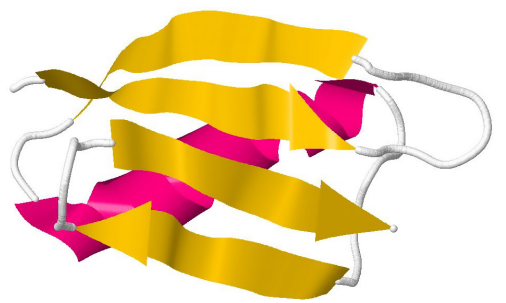

(a) Nativa $\left(161,11 \epsilon_{h}\right)$

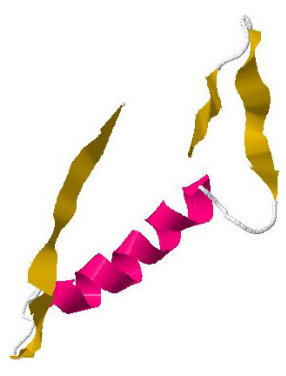

(b) Menor Energia $\left(49,15 \epsilon_{h}\right)$

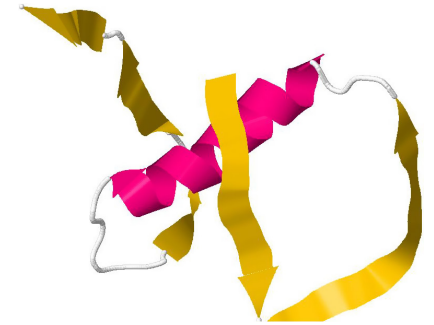

(c) Menor RMSD $\left(56,03 \epsilon_{h}\right)$

Figura 5.3: Estruturas preditas de menor energia e menor RMSD para a 2GBI- sem predição de estrutura secundária.

Na Figura 5.3, pode-se observar discordância das estruturas preditas com a estrutura na $2 \mathrm{~GB} 1$, principalmente nas folhas- $\beta$ que não foram formadas. No entanto, nota-se maior facilidade do modelo em manter as $\alpha$-hélices.

\subsubsection{Experimento 2: Modelo CG com predição de estrutura secundária}

Nos experimentos apresentados aqui, utilizou-se a predição de estrutura secundária do PSIPred [Jones, 1999]. Neste caso, a região de dobra (turn) não é subdividida em outras categorias para o cálculo da energia do ângulo de torção, uma vez que o preditor não oferece esse tipo de informação. Assim, o termo diedral 2 (Equação 4.4) é utilizado ao invés do termo diedral 1 (Equação 4.3).

Neste experimento, o número de gerações utilizados foi 500 gerações por resíduo para as proteínas maiores (2GB1, 1ENH E 2W4P), 400 por resíduo para a 1 A11 e 200 por resíduo para $2 \mathrm{~K} 98$.

\subsubsection{Receptora de Acetilcolina (1A11)}

A seguir são apresentados os resultados para a proteína PDB:1A11.

\begin{tabular}{c||cccc}
\multirow{2}{*}{ Algoritmo } & Média \pm Desvio Padrão & Energia $\epsilon_{h}$ \\
& Mediana & Mínimo & Máximo \\
\hline \hline AGP & $24,82 \pm 0,74$ & 24,78 & 23,59 & 26,03 \\
\hline AGA6 & $\mathbf{2 3 , 9 6} \pm 1,00$ & $\mathbf{2 3 , 7 1}$ & 22,93 & 26,14 \\
\hline AGS6 & $24,60 \pm 0,68$ & 24,78 & 22,92 & $\mathbf{2 5 , 2 4}$ \\
\hline AGAutoOrg & $24,45 \pm 1,14$ & 24,30 & $\mathbf{2 2 , 8 6}$ & 26,75 \\
\hline
\end{tabular}

Tabela 5.6: Valores da energia total para a $1 A 11$.

A Tabela 5.6 mostra que a menor energia média foi obtida pelo AGA6 enquanto que a mínima foi obtida pelo AGAutoOrg. 


\begin{tabular}{c||cccc}
\multirow{2}{*}{ Algoritmo } & Média \pm Desvio Padrão & $\begin{array}{c}\text { RMSD } \AA \\
\text { Mediana }\end{array}$ & Mínimo & Máximo \\
\hline \hline AGP & $1,91 \pm 0,51$ & $\mathbf{1 , 7 4}$ & $\mathbf{1 , 3 0}$ & 2,82 \\
\hline AGA6 & $1,98 \pm 0,22$ & 2,02 & 1,56 & $\mathbf{2 , 2 0}$ \\
\hline AGS6 & $\mathbf{1 , 8 7} \pm 0,29$ & 1,84 & 1,41 & 2,29 \\
\hline AGAutoOrg & $1,98 \pm 0,49$ & 2,09 & 1,37 & 2,68 \\
\hline
\end{tabular}

Tabela 5.7: RMSD para a 1A11.

A Tabela 5.7 mostrou que o menor RMSD médio foi obtido para o AGS6 e o RMSD mínimo foi para o AGP. Os valores máximos de RMSD obtidos foram menores que 3 Å. Na Tabela 5.8, o teste estatístico de Wilcoxon é apresentado.

\begin{tabular}{c||ccc} 
& \multicolumn{3}{c}{ p-valor } \\
& AGA6 & AGS6 & AGAutoOrg \\
\hline \hline AGP & $0,0840(+)$ & $0,4316(-)$ & $0,5566(+)$
\end{tabular}

Tabela 5.8: Teste estatístico para a 1A11.

De acordo com a Tabela 5.8, pode-se concluir que não foi verificada diferença significativa para o nível de significância de $5 \%$ entre os algoritmos.

As Figuras 5.4 e 5.5 apresentam o comportamento da energia mínima média e do RMSD médio do melhor indivíduo, ao longo das gerações.

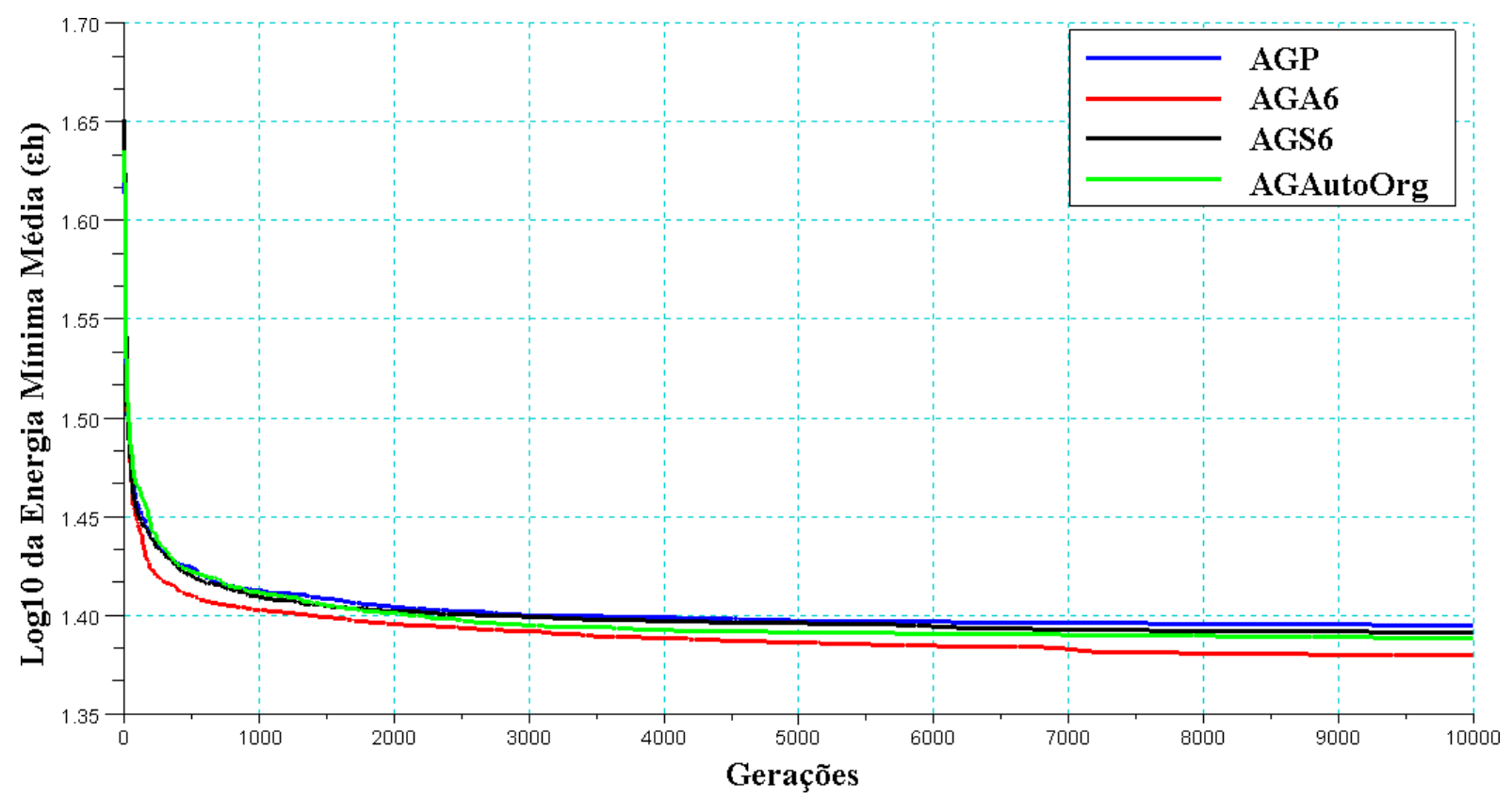

Figura 5.4: Média dos fitness mínimos ao longo das gerações para a $1 A 11$ sem predição de estrutura secundária.

As curvas da Figura 5.4 decrescem mais acentuadamente no começo do experimento, sendo que a partir de então o decréscimo é pequeno. Isso ocorre porque a proteína é 
pequena, de modo que os algoritmos conseguem encontrar soluções boas mais rapidamente no espaço de busca.

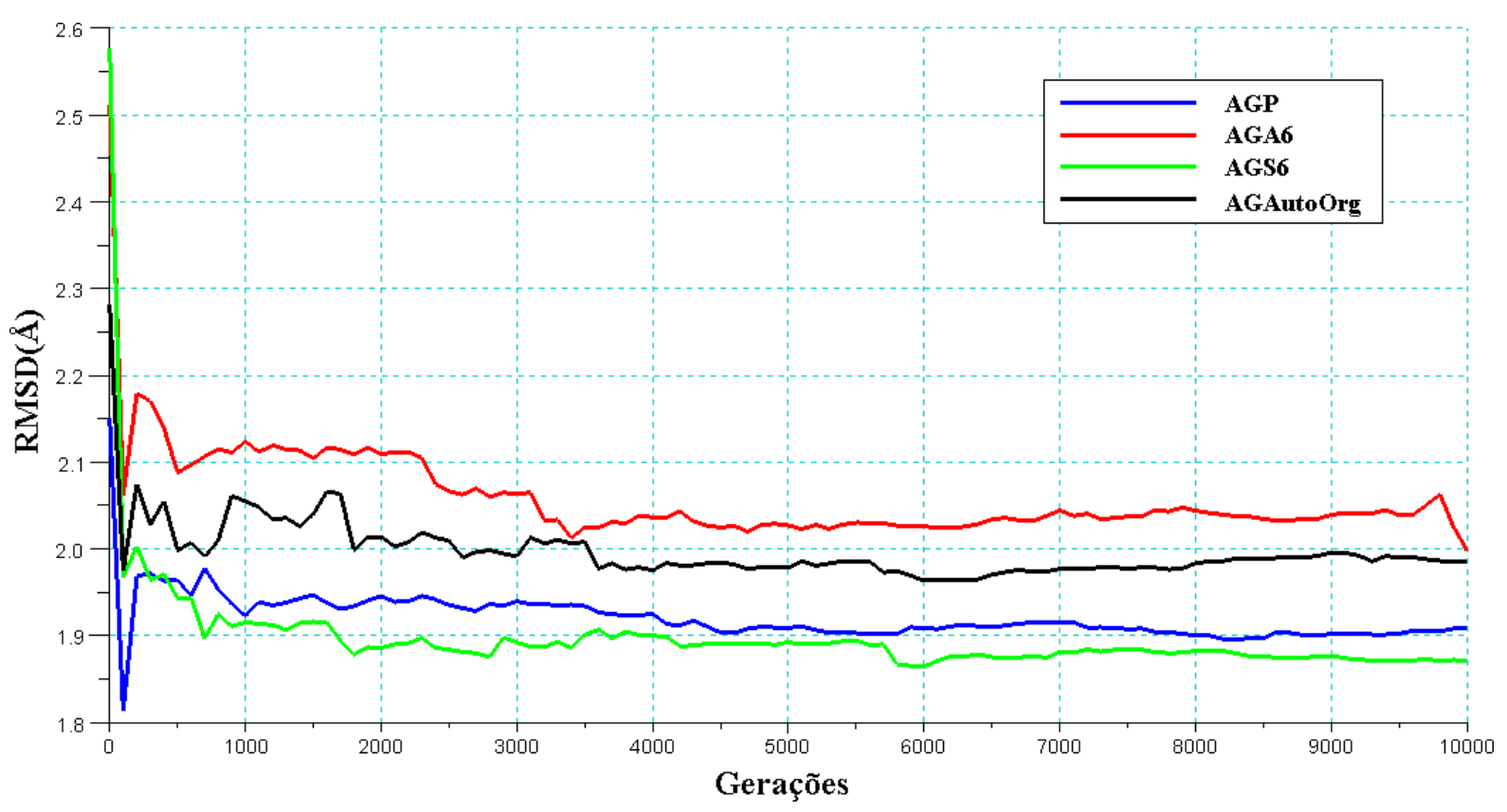

Figura 5.5: Média dos RMSDs mínimos ao longo das gerações para a 1A11 sem predição de estrutura secundária.

As curvas de RMSDs médios da Figura 5.5 mostram um decréscimo mais acentuado do RMSD no início da simulação. Depois, as estruturas se estabilizam em torno de pontos ótimos.

A Figura 5.6 mostra as estruturas geradas com menor energia e com menor RMSD, respectivamente. Pode-se perceber que as estruturas preditas são similares à nativa. Observa-se ainda que o modelo CG usado facilita a construção das $\alpha$-hélices. Contudo, esse resultado já era esperado, uma vez que o modelo emprega informação de estrutura secundária.

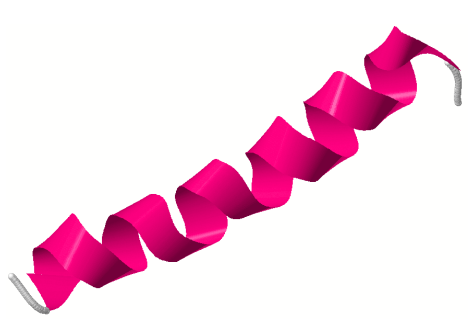

(a) Nativa $\left(58,13 \epsilon_{h}\right)$

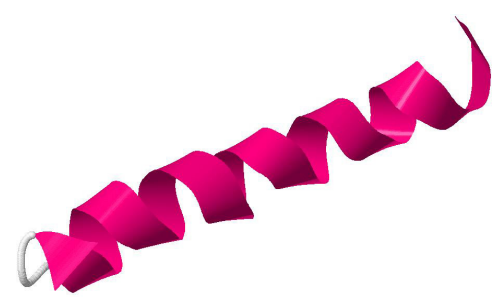

(b) Menor energia $\left(22,86 \epsilon_{h}\right)$

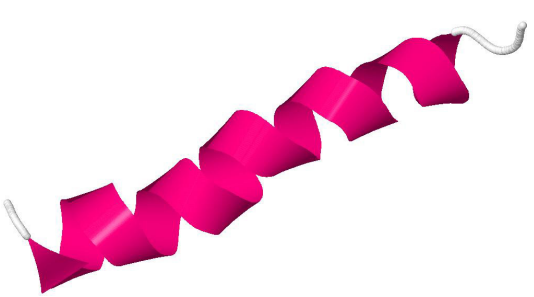

(c) Menor RMSD $\left(25,20 \epsilon_{h}\right)$

Figura 5.6: Estruturas preditas de menor energia e menor RMSD para a 1A11.

O comportamento das taxas de imigrantes do AGAutoOrg, a energia e o RMSD, para a primeira execução, são apresentados a seguir. 


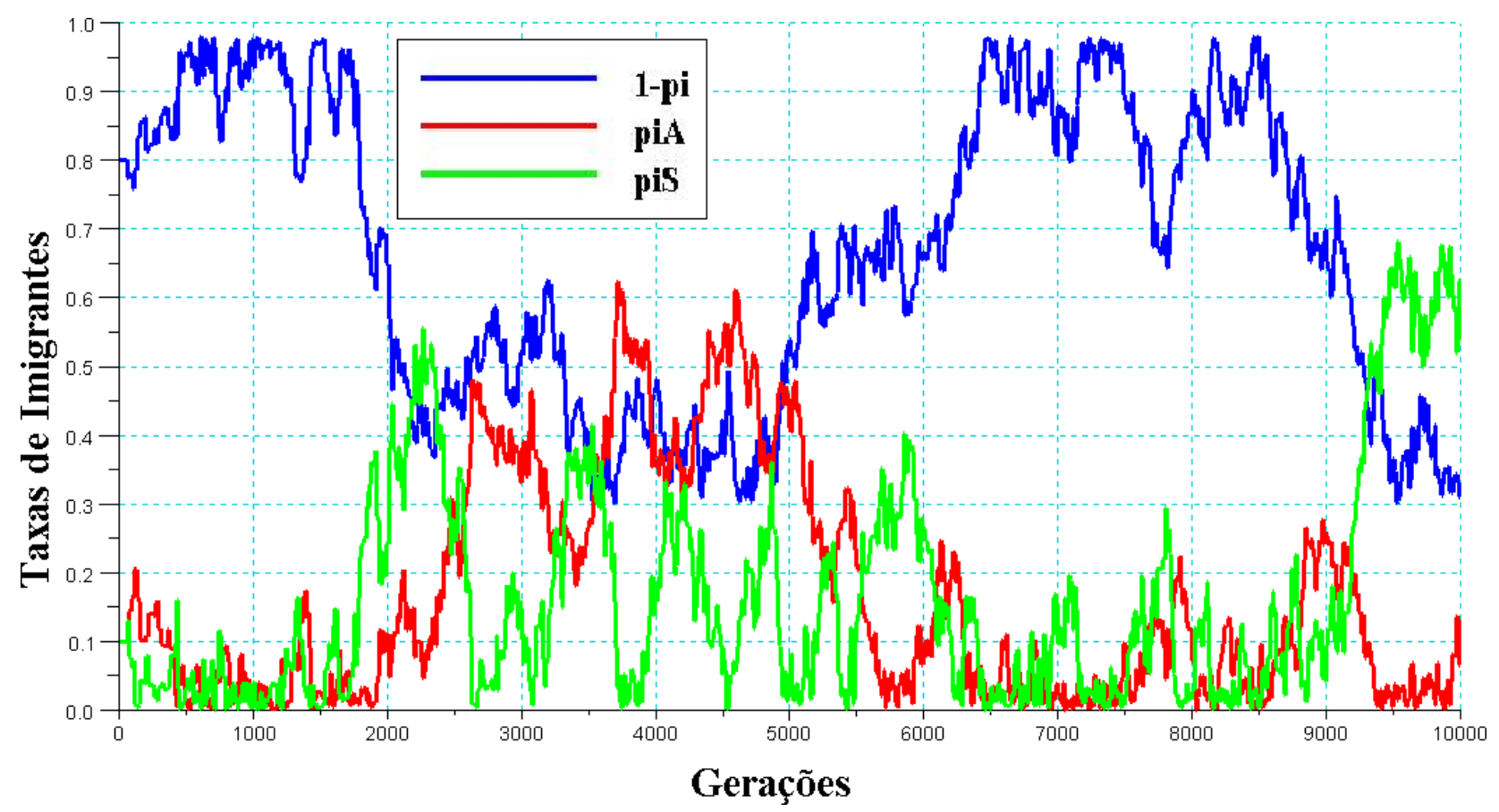

Figura 5.7: Variação das taxas de imigrantes $\left(p_{i A}, p_{i S} e 1-p_{i}\right)$ para a 1A11.

A Figura 5.7 mostra que as taxas variaram de modo que no fim da simulação, 31,9\% dos indivíduos pertenciam a população normal, 3,9\% era imigrantes aleatórios e 64,1\% imigrantes por similaridade.

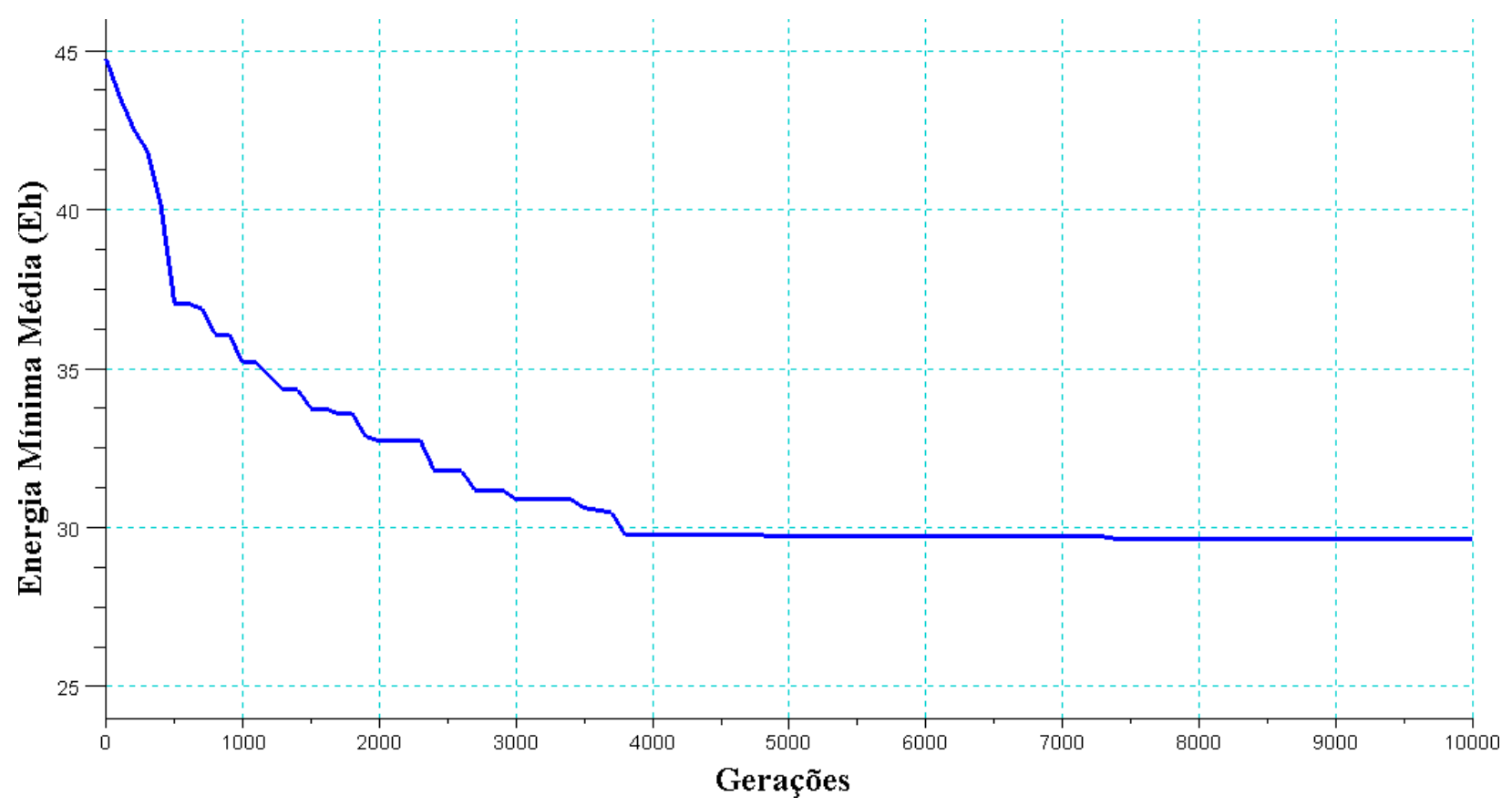

Figura 5.8: Energia para a primeira execução do AGAutoOrg. 


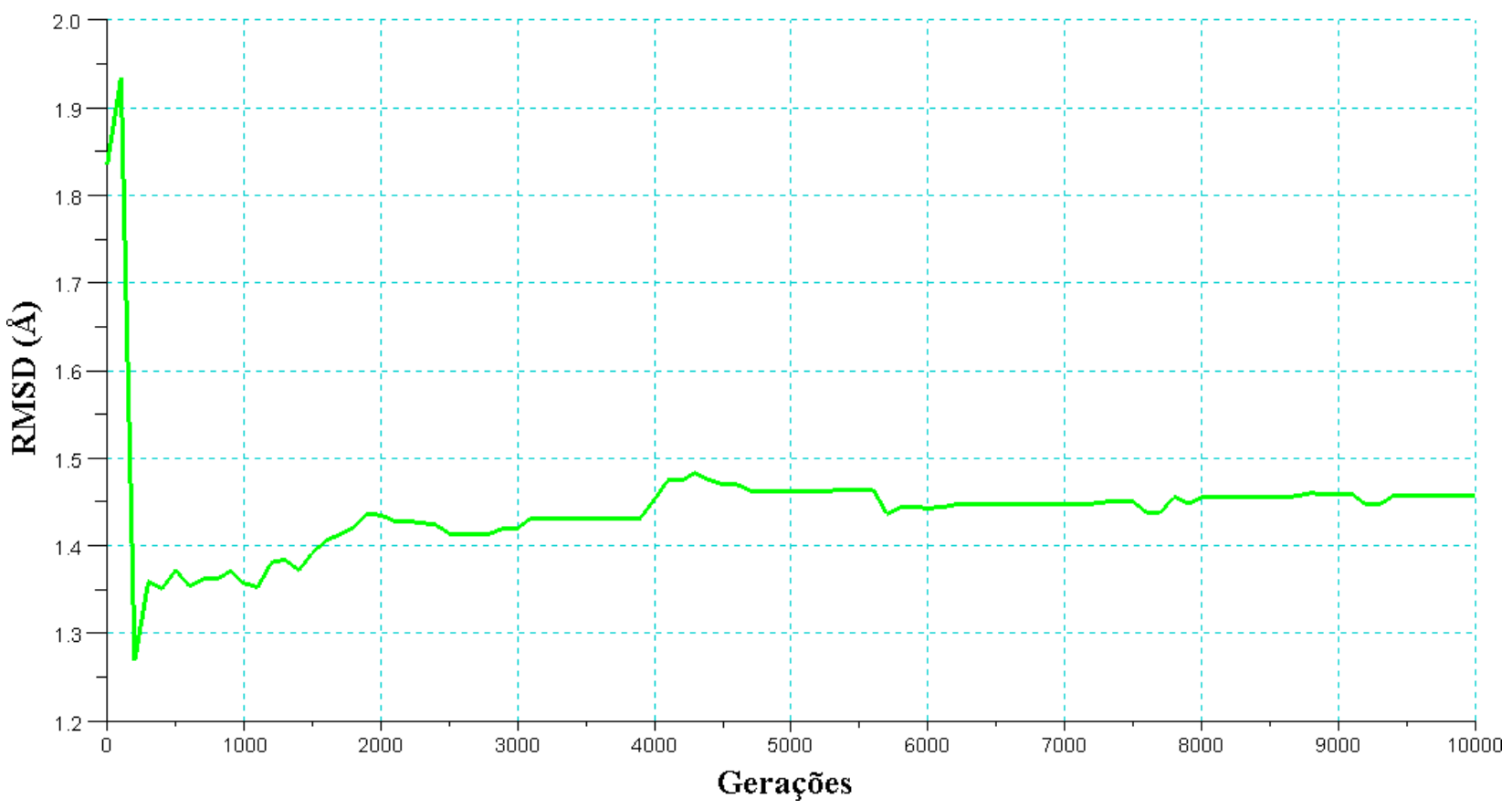

Figura 5.9: RMSD para a primeira execução do AGAutoOrg.

A Figura 5.8 mostra que a energia decresce ao longo das gerações para esta execução. Os platôs existentes são responsáveis pelas mudanças no gráfico da Figura 5.7, uma vez que as taxas de imigrantes mudam sempre que a melhor solução permanece inalterada após 50 gerações. Já o RMSD (Figura 5.9) decresce no início da simulação e depois se estabiliza. 


\subsubsection{Proteína MSI-594 (2K98)}

Os resultados de energia e RMSD obtidos para proteína 2K98 são exibidos nas tabelas 5.9 e 5.10 .

\begin{tabular}{c||cccc}
\multirow{2}{*}{ Algoritmo } & Média \pm Desvio Padrão & $\begin{array}{c}\text { Energia } \epsilon_{h} \\
\text { Mediana }\end{array}$ & Mínimo & Máximo \\
\hline \hline AGP & $\mathbf{3 7 , 1 0} \pm 1,41$ & $\mathbf{3 7 , 4 2}$ & 34,44 & 38,97 \\
\hline AGA6 & $37,95 \pm 0,85$ & 37,87 & 36,79 & 39,31 \\
\hline AGS6 & $37,31 \pm 2,84$ & 37,84 & $\mathbf{2 6 , 3 6}$ & 40,92 \\
\hline AGAutoOrg & $37,72 \pm 0,68$ & 37,74 & 36,53 & $\mathbf{3 8 , 8 7}$ \\
\hline
\end{tabular}

Tabela 5.9: Valores da energia total para a $2 \mathrm{~K} 98$.

A Tabela 5.9 mostra que a menor energia média foi obtida pelo AGP e a menor mínima pelo AGS6.

\begin{tabular}{c||cccc}
\multirow{2}{*}{ Algoritmo } & Média \pm Desvio Padrão & $\begin{array}{c}\text { RMSD } \\
\text { Mediana }\end{array}$ & Mínimo & Máximo \\
\hline \hline AGP & $5,93 \pm 0,42$ & $\mathbf{6 , 0 8}$ & 5,17 & $\mathbf{6 , 5 0}$ \\
\hline AGA6 & $6,30 \pm 0,19$ & 6,27 & 6,12 & 6,78 \\
\hline AGS6 & $\mathbf{5 , 8 4} \pm 1,07$ & 6,25 & $\mathbf{2 , 9 5}$ & 6,54 \\
\hline AGAutoOrg & $6,40 \pm 0,22$ & 6,32 & 6,16 & 6,69 \\
\hline
\end{tabular}

Tabela 5.10: $R M S D$ para a $2 K 98$.

A Tabela 5.10 mostra que o menor RMSD médio e o menor mínimo foram obtidos para o AGS6. Neste caso, o RMSD mínimo também foi consideravelmente pequeno $(2,95 \AA)$ e bastante inferior ao alcançado pelos outros algoritmos, o que mostra o benefício de se usar as informações de similaridade.

A Tabela 5.11 mostra o teste de Wincoxon para a 2 K98.

\begin{tabular}{|c|c|c|c|}
\hline & AGA6 & $\begin{array}{c}\mathrm{p} \text {-valor } \\
\text { AGS6 }\end{array}$ & AGAutoOrg \\
\hline$\overline{\mathrm{AGP}}$ & 0,0273 (s-) & $0,7695(-)$ & $0,4316(-)$ \\
\hline
\end{tabular}

Tabela 5.11: Teste estatístico para a $2 K 98$.

De acordo com a Tabela 5.11, pode-se dizer que existe diferença significativa entre o AGP e o AGA6, sendo que conforme a Tabela 5.9, o AGA6 possui energia mediana maior que o AGP.

As Figuras 5.10 e 5.11 mostram os gráficos da energia e RMSD médios. 


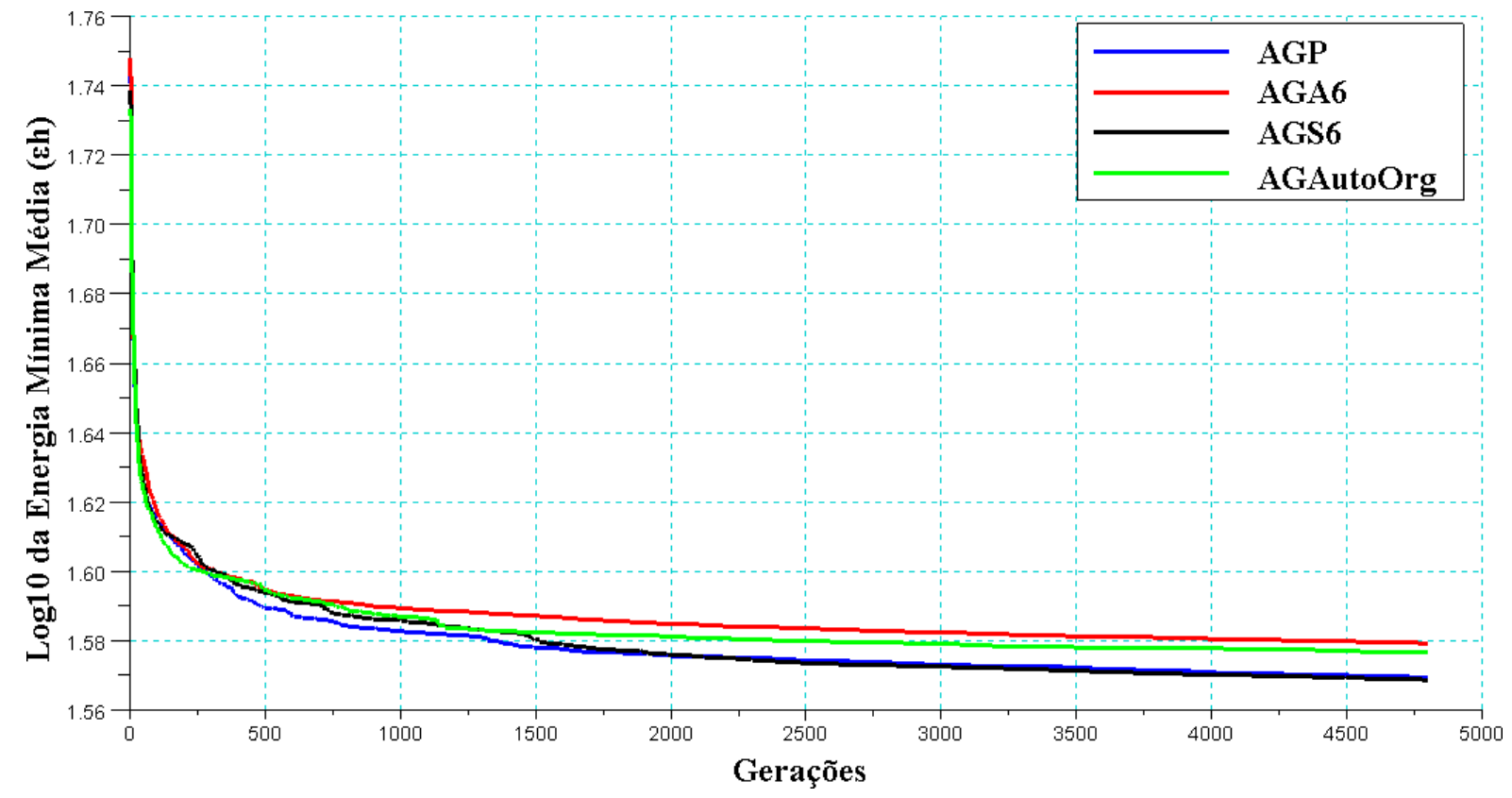

Figura 5.10: Média dos fitness mínimos ao longo das gerações para a $2 K 98$.

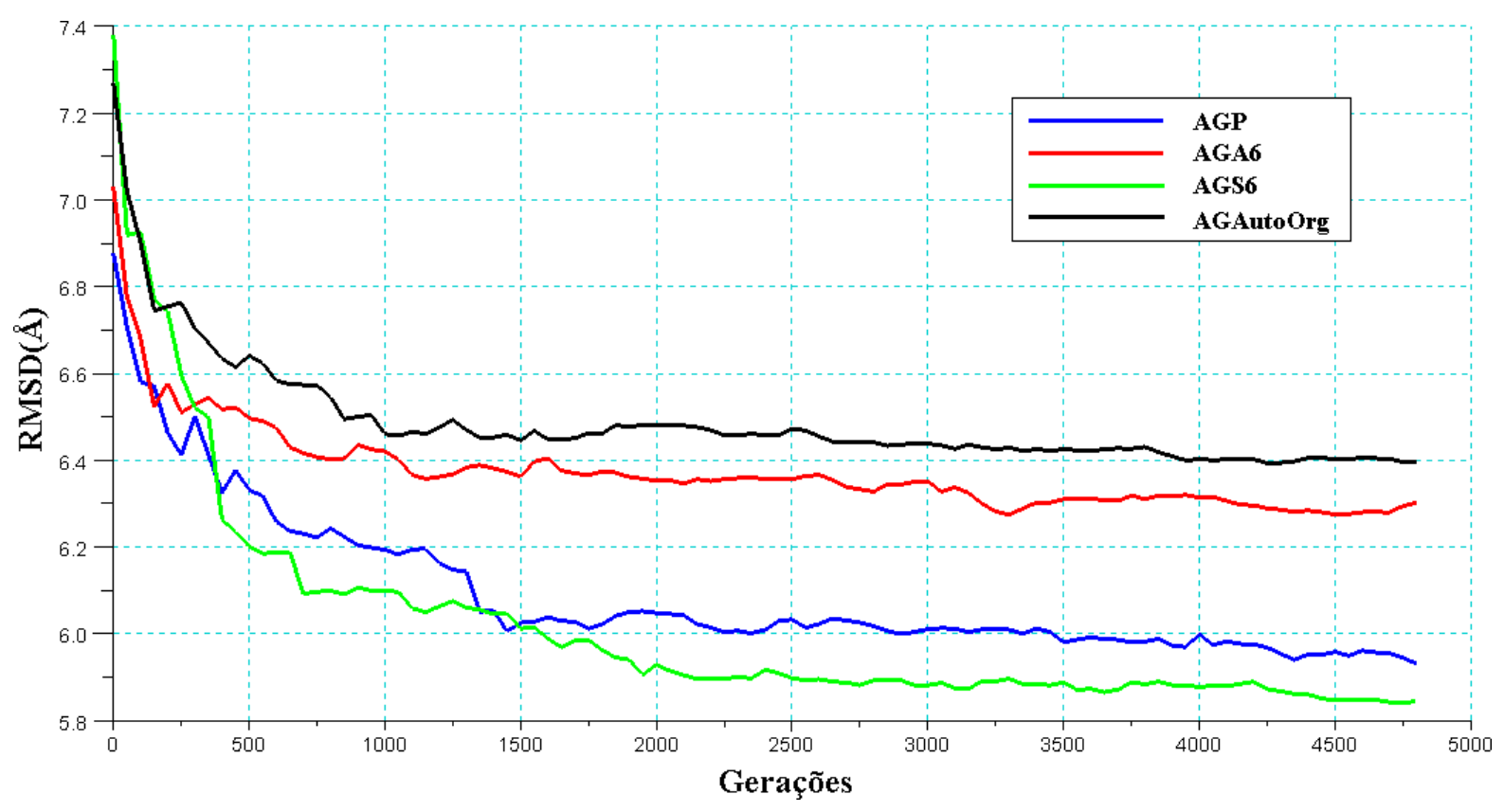

Figura 5.11: Média dos RMSDs ao longo das gerações para a $2 K 98$.

Os RMSDs da Figura 5.11 decaem ao longo do tempo, sendo que todos os algoritmos apresentam curvas próximas. 


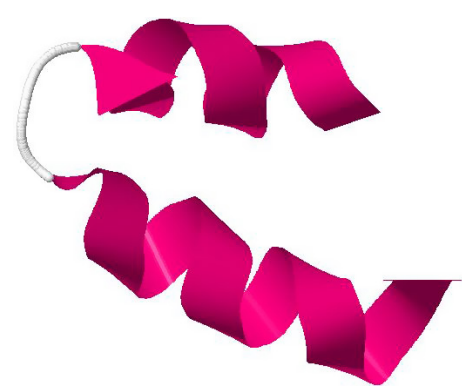

(a) Nativa $\left(60,61 \epsilon_{h}\right)$

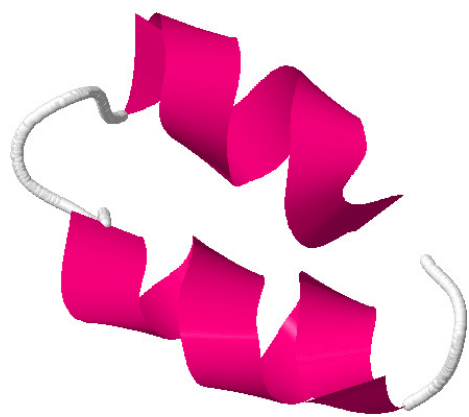

(b) Menor energia $\left(26,36 \epsilon_{h}\right)$

Figura 5.12: Estrutura predita de menor e energia e menor RMSD para a $2 K 98$.

A Figura 5.12 mostra as estruturas nativa e predita, sendo que a estrutura de menor energia e menor RMSD, nesse caso, são correspondentes e semelhantes à nativa.

O comportamento das taxas de imigrantes do AGAutoOrg, a energia e o RMSD, para a primeira execução, são apresentadas a seguir.

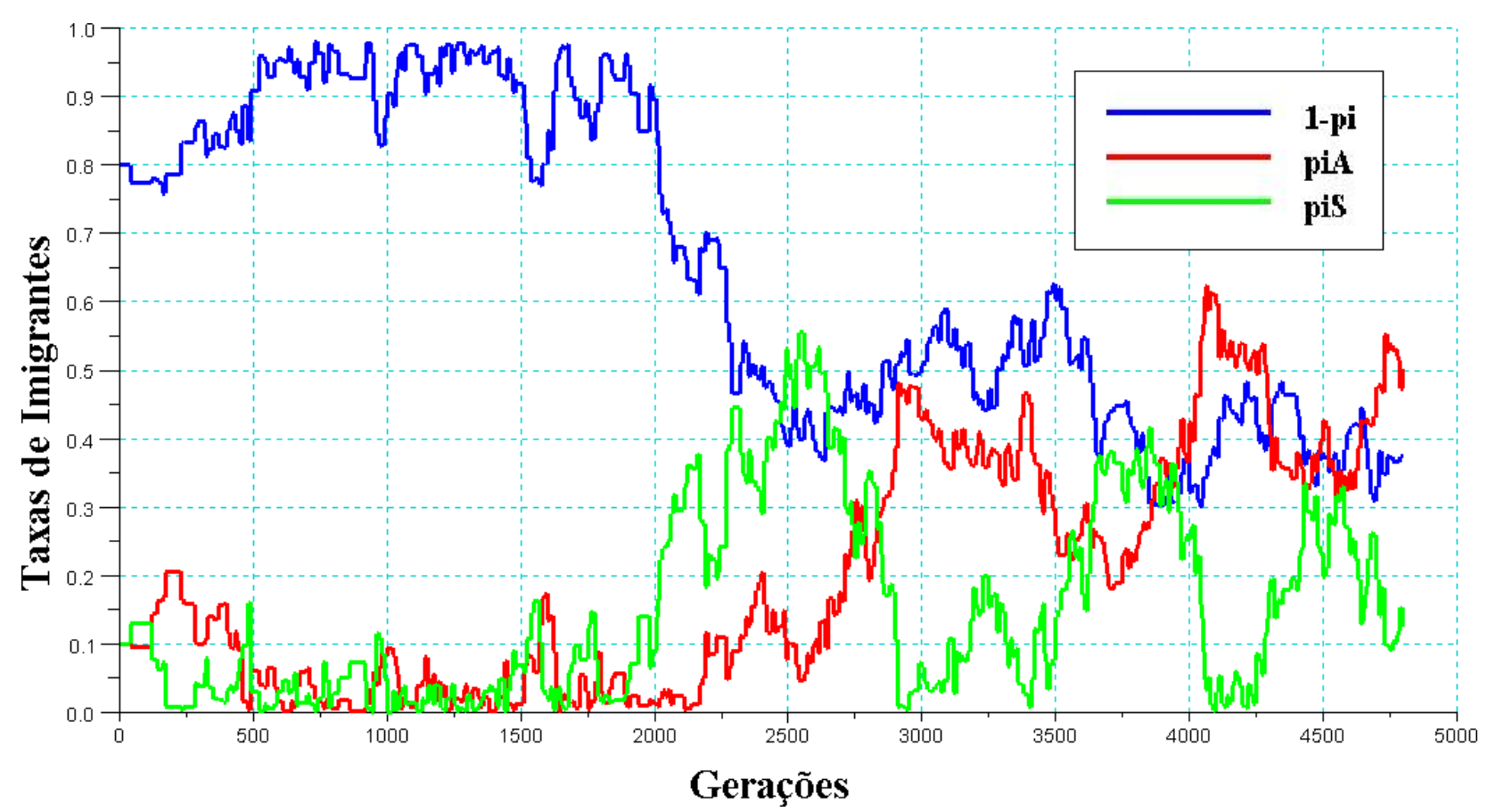

Figura 5.13: Variação das taxas de imigrantes para a 2 K98.

A Figura 5.13 mostra que as taxas variaram de modo que no fim da simulação, 37,2\% dos indivíduos pertenciam a população normal, 50,2\% eram imigrantes aleatórios e $12,5 \%$ imigrantes por similaridade. 


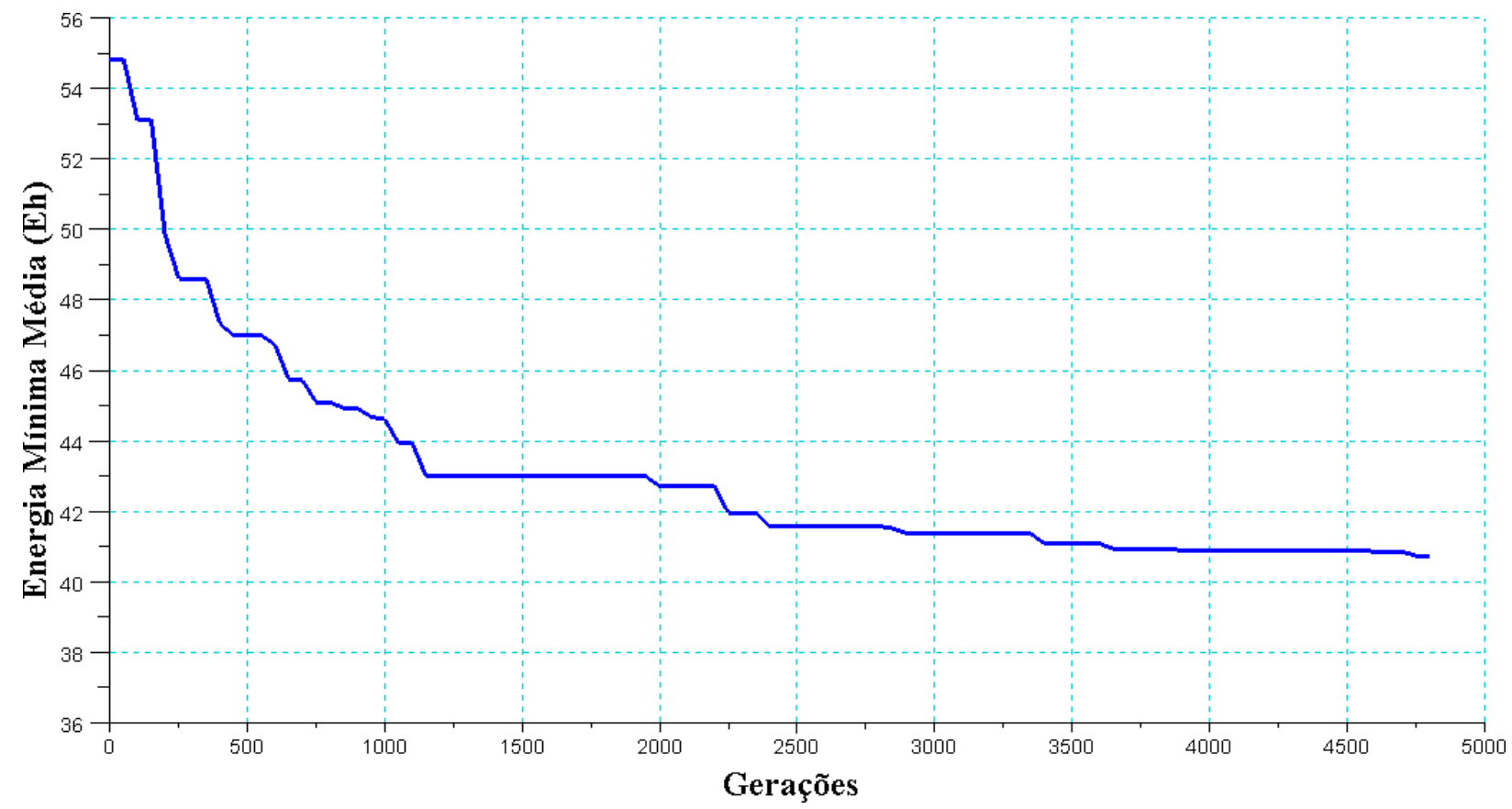

Figura 5.14: Energia para a primeira execução do AGAutoOrg.

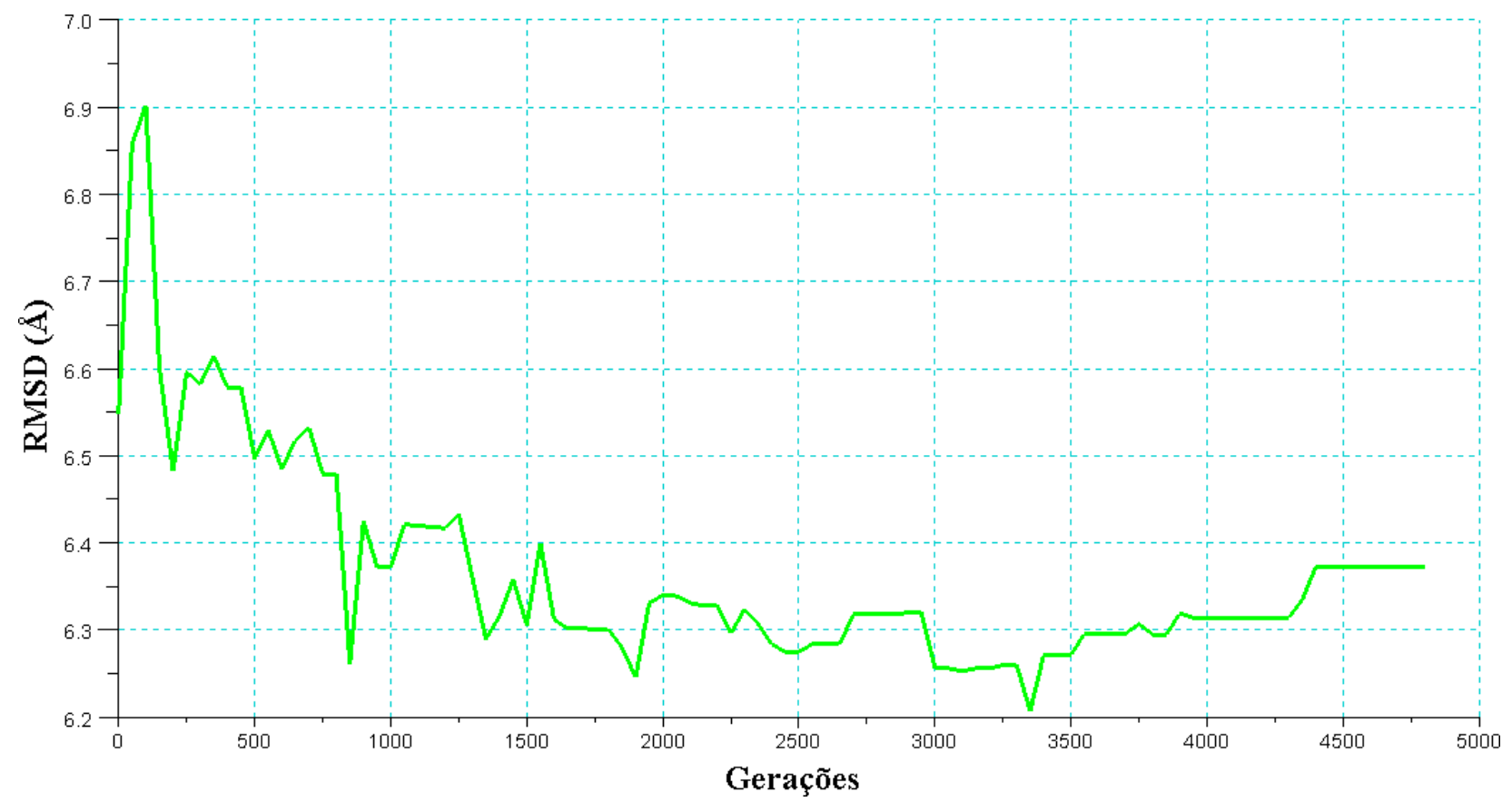

Figura 5.15: RMSD para a primeira execução do AGAutoOrg. 


\subsubsection{Proteína DNA-ligante (1ENH)}

Os resultados para a proteína 1ENH são exibidos a seguir.

\begin{tabular}{c||cccc}
\multirow{2}{*}{ Algoritmo } & Média \pm Desvio Padrão & $\begin{array}{c}\text { Energia } \epsilon_{h} \\
\text { Mediana }\end{array}$ & Mínimo & Máximo \\
\hline \hline AGP & $67,42 \pm 3,93$ & 68,30 & 61,30 & $\mathbf{7 3 , 1 6}$ \\
\hline AGA6 & $68,81 \pm 3,63$ & $\mathbf{6 8 , 1 8}$ & 64,46 & 74,05 \\
\hline AGS6 & $\mathbf{6 7 , 2 8} \pm 6,21$ & 68,54 & $\mathbf{5 5 , 8 5}$ & 76,61 \\
\hline AGAutoOrg & $69,59 \pm 4,64$ & 69,34 & 64,74 & 79,18 \\
\hline
\end{tabular}

Tabela 5.12: Valores da energia total para a 1ENH.

A Tabela 5.12 mostra que o menor valor de energia média e mínima foram obtidos pelo AGS6.

\begin{tabular}{c||cccc}
\multirow{2}{*}{ Algoritmo } & Média \pm Desvio Padrão & $\begin{array}{c}\text { RMSD } \\
\text { Mediana }\end{array}$ & Mínimo & Máximo \\
\hline \hline AGP & $\mathbf{1 2 , 5 3} \pm 4,19$ & 11,25 & $\mathbf{8 , 8 8}$ & 22,07 \\
\hline AGA6 & $13,66 \pm 4,56$ & $\mathbf{1 1 , 1 2}$ & 8,94 & 21,60 \\
\hline AGS6 & $13,03 \pm 2,33$ & 12,37 & 9,24 & $\mathbf{1 6 , 9 3}$ \\
\hline AGAutoOrg & $14,26 \pm 3,56$ & 13,36 & 11,08 & 22,50 \\
\hline
\end{tabular}

Tabela 5.13: RMSD para a $1 E N H$.

A Tabela 5.13 mostra que o menor RMSD médio e mínimo foi obtido pelo AGP, sendo que o menor RMSD foi de 8,88 ̊. O teste de Wilcoxon é apresentado na Tabela 5.14. Em [Hamelryck et al., 2006], um modelo escondido de Markov (Hidden Markov model (HMM)) foi testado para PEP com e sem a utilização de informações da estrutura secundária. O menor RMSD obtido para a 1ENH foi de 1,7 Å. Já em [Li et al., 2008], técnicas de biblioteca de fragmentos, HMM, clusterização e refinamento são empregadas para obter predições. O menor RMSD obtido também para a 1ENH foi de 1,81 A. Nestes dois trabalhos, a PEP não é utilizada apenas como um problema para estudo de algoritmos, mas sim como o objetivo principal, destaca-se também que em ambos foi utilizado conhecimento do problema.

Em [Do Ó, 2009], onde AGs foram aplicados ao problema de PEP com abordagem $a b$ initio, sem empregar conhecimento do problema. O menor RMSD obtido para a 1ENH foi de $30,67 \AA$.

\begin{tabular}{c||ccc} 
& \multicolumn{3}{c}{ p-valor } \\
& AGA6 & AGS6 & AGAutoOrg \\
\hline \hline AGP & $0,2324(+)$ & $0,7695(-)$ & $0,3223(-)$
\end{tabular}

Tabela 5.14: Teste estatístico para a $1 E N H$. 
O teste de Wilcoxon exibido pela Tabela 5.14 mostra que não houve diferença estatística entre os algoritmos.

As curvas de energia e RMSD médios são exibidas nas Figuras 5.16 e 5.17.

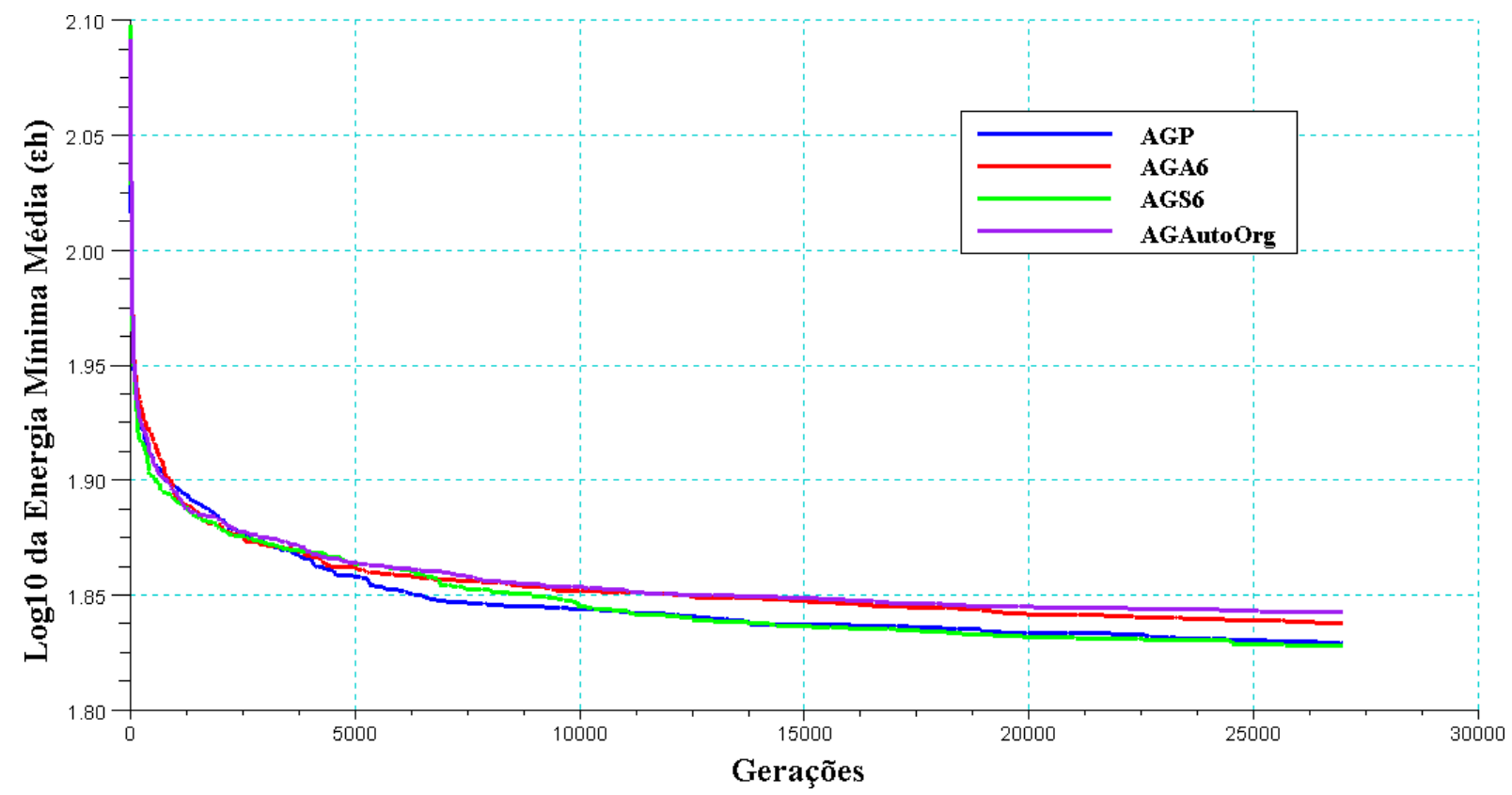

Figura 5.16: Média dos fitness mínimos ao longo das gerações para a 1ENH.

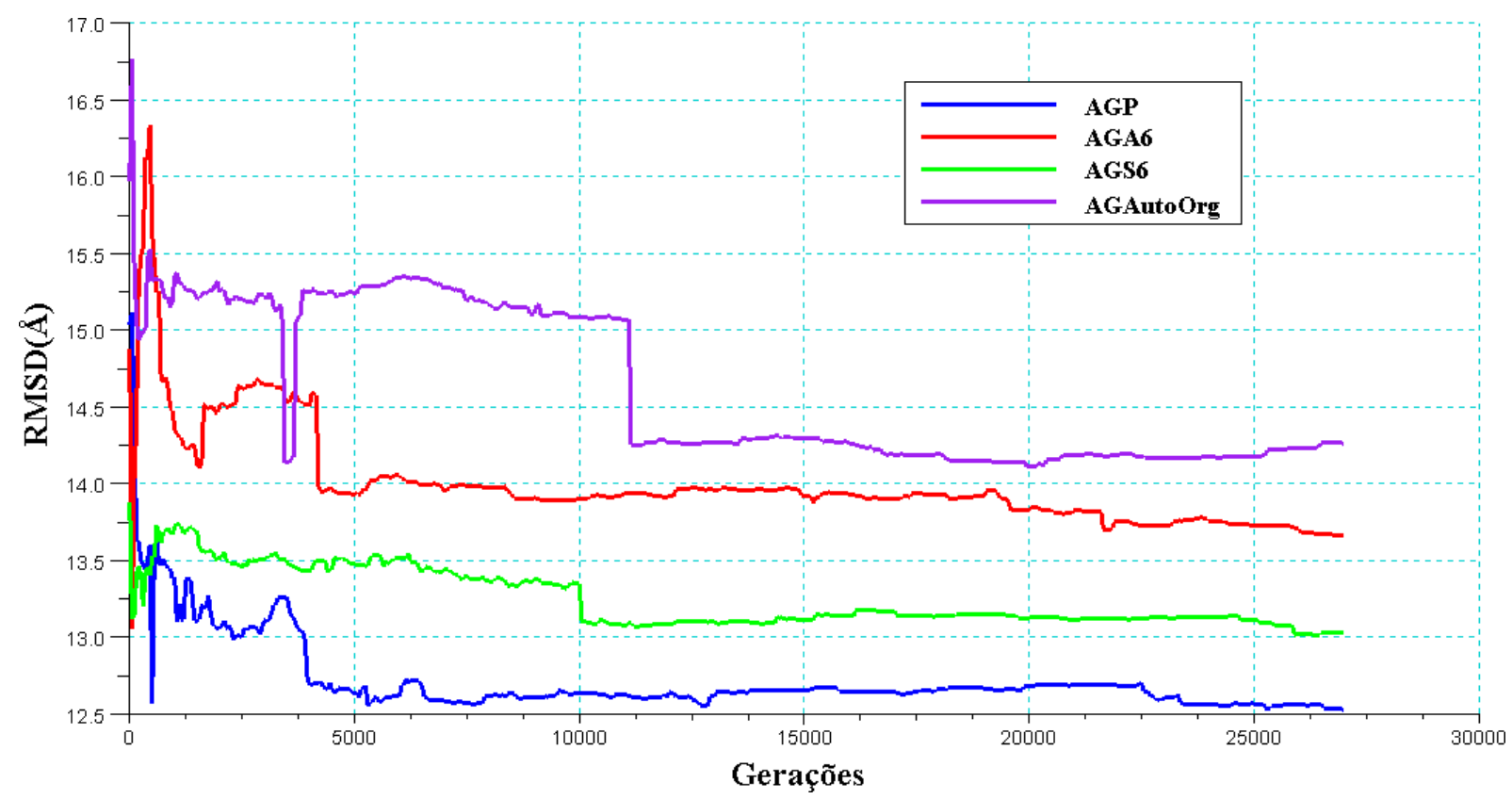

Figura 5.17: Média dos RMSDs mínimos ao longo das gerações para a 1ENH.

Já a Figura 5.17 mostra que as curvas do RMSD decresceram no início, mas não apresentam decaimento considerável no final do experimento. Porém, aparentemente as energias ainda não se estabilizaram.

A Figura 5.18 apresenta as estruturas preditas para a 1ENH. 


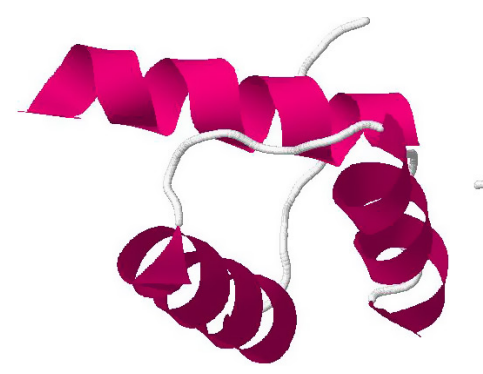

(a) Nativa $\left(108,20 \epsilon_{h}\right)$

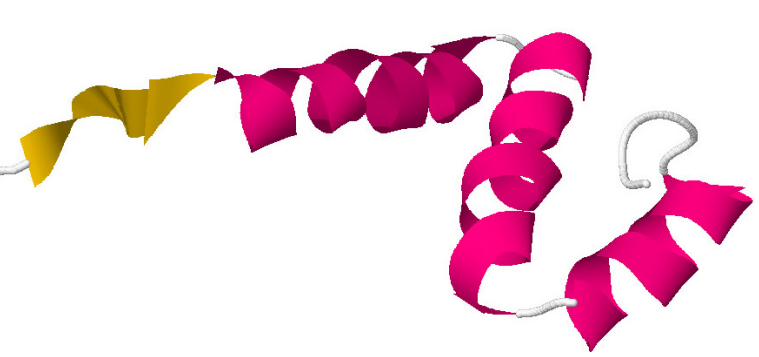

(b) Menor energia $\left(55,85 \epsilon_{h}\right)$

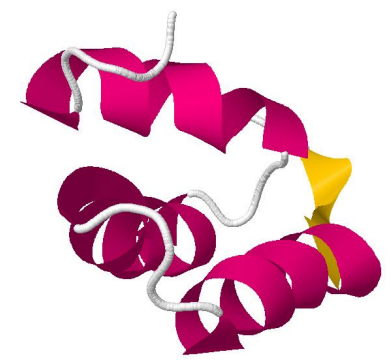

(c) Menor RMSD $(63,86$ $\left.\epsilon_{h}\right)$

Figura 5.18: Estruturas preditas de menor e energia e menor RMSD para a 1ENH.

Pode-se observar pela Figura 5.18, que as estruturas preditas mantem as hélices, porém as regiões de dobras discordam da estrutura nativa, para a estrutura de menor energia.

O comportamento das taxas de imigrantes do AGAutoOrg, a energia e o RMSD, para a primeira execução, são apresentadas a seguir.

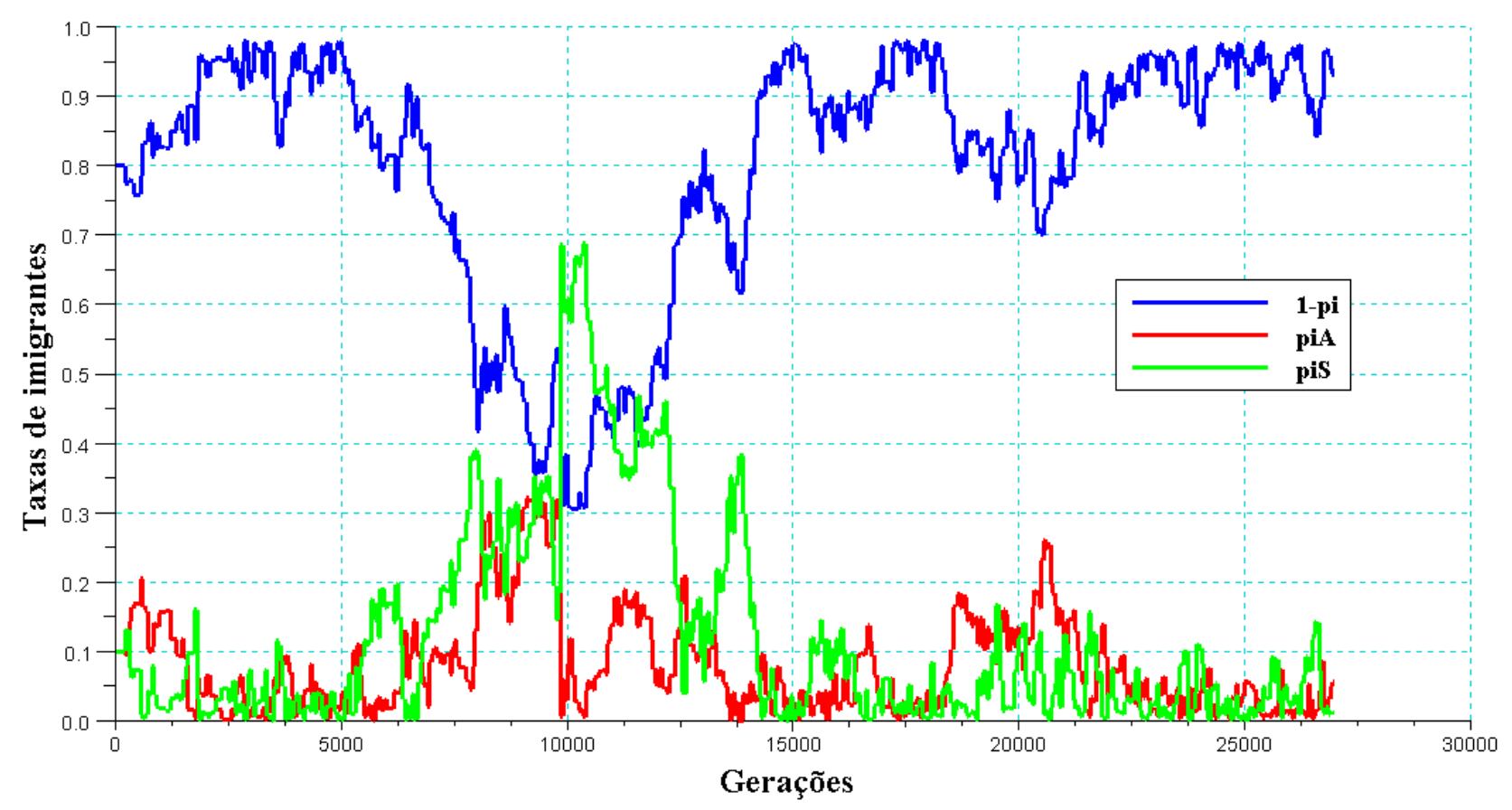

Figura 5.19: Variação das taxas de imigrantes para a 1ENH.

Na Figura 5.19 $\left(1-p_{i}\right)$ é a taxa de indivíduos da população normal; $p_{i A}$, a taxa de imigrantes aleatórios e a $p_{i S}$, a taxa de imigrantes por similaridade. Lembrando que $p_{i}=p_{i A}+p_{i S}$. As taxas variaram de modo que no fim da simulação, 98,85\% dos indivíduos pertenciam a população normal, 0,89\% eram imigrantes aleatórios e 2,26\% imigrantes por similaridade. 


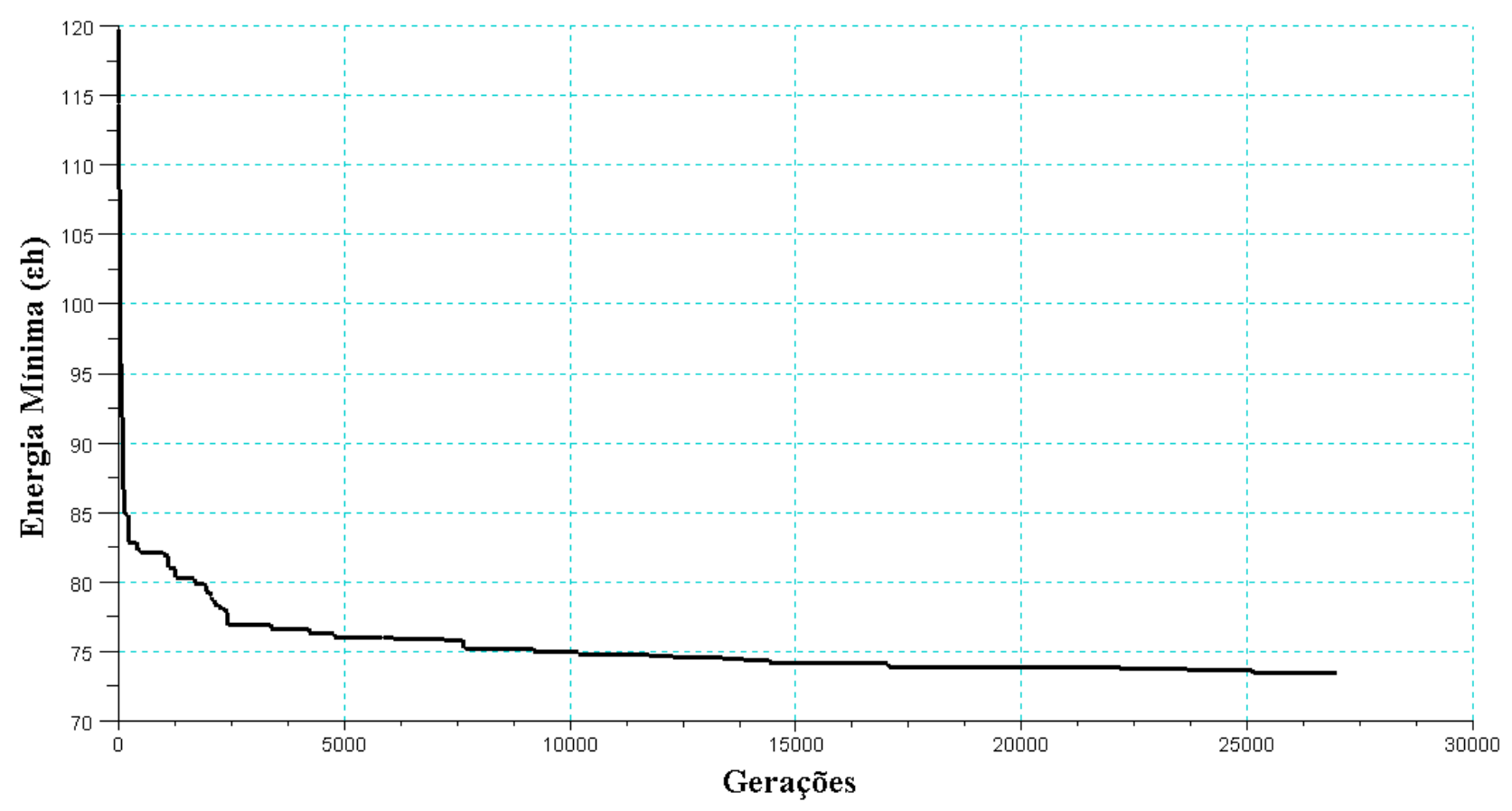

Figura 5.20: Energia para a primeira execução do AGAutoOrg da 1ENH.

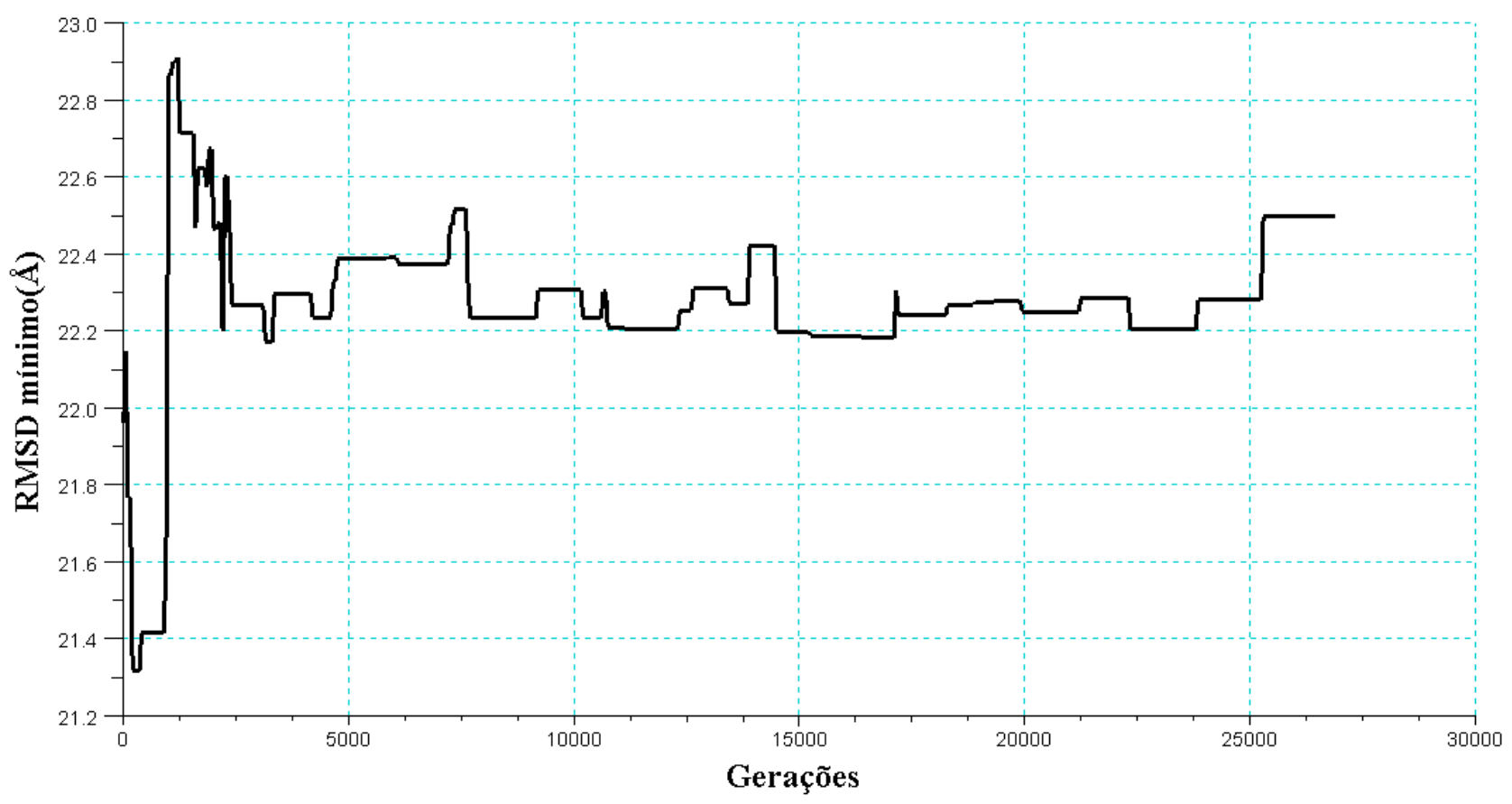

Figura 5.21: RMSD para a primeira execução do AGAutoOrg da 1ENH.

As figuras 5.20 e 5.21 mostram que, em geral, energia e RMSD caem ao longo das gerações. 


\subsubsection{Proteína G (2GB1)}

Os resultados obtidos para a $2 \mathrm{~GB} 1$ podem ser vistos a seguir.

\begin{tabular}{c||cccc}
\multirow{2}{*}{ Algoritmo } & Média \pm Desvio Padrão & $\begin{array}{c}\text { Energia } \epsilon_{h} \\
\text { Mediana }\end{array}$ & Mínimo & Máximo \\
\hline \hline AGP & $\mathbf{5 0 , 6 3} \pm 3,69$ & $\mathbf{4 9 , 9 5}$ & 43,32 & $\mathbf{5 7 , 1 3}$ \\
\hline AGA6 & $51,36 \pm 5,73$ & 52,55 & $\mathbf{4 1 , 6 1}$ & 59,42 \\
\hline AGS6 & $51,03 \pm 4,67$ & 51,22 & 43,80 & 59,96 \\
\hline AGAutoOrg & $57,29 \pm 3,82$ & 57,40 & 49,13 & 62,91 \\
\hline
\end{tabular}

Tabela 5.15: Valores da energia total para a 2GB1 com PES.

A Tabela 5.15 mostra os resultados obtidos para a 2GB1 no Experimento 2. Notase que a menor média foi alcançada pelo AGP, enquanto que a energia mínima foi alcançada pelo AGA6.

\begin{tabular}{|c|c|c|c|c|}
\hline Algoritmo & Média \pm Desvio Padrão & $\begin{array}{l}\text { RMSD } \AA \\
\text { Mediana }\end{array}$ & Mínimo & Máximo \\
\hline AGP & $15,00 \pm 1,71$ & 14,86 & 12,37 & 19,08 \\
\hline AGA6 & $15,13 \pm 2,62$ & 15,50 & 11,86 & 19,88 \\
\hline AGS6 & $\mathbf{1 4 , 5 9} \pm 1,51$ & 14,38 & 11,27 & 16,92 \\
\hline AGAutoOrg & $15,27 \pm 3,22$ & 13,64 & 12,09 & 21,12 \\
\hline
\end{tabular}

Tabela 5.16: $R M S D$ para a 2GB1 com predição de estrutura secundária.

Conforme apresentado na Tabela 5.16, é possível observar que o menor RMSD médio e o mínimo foi obtido pelo AGS6. O menor RMSD obtido foi de 11,27. Os Experimentos 1 e 2 foram feitos com números diferentes de gerações, contudo, cabe ressaltar que mesmo com a utilização do preditor, quando o mesmo número de gerações é considerado, o Experimento 2 obteve resultados compatíveis aos alcançados no Experimento 1.

Em [Hamelryck et al., 2006], a proteína 2GB1 também foi testada e o RMSD mínimo obtido foi 4,9 Å. Já em [Li et al., 2008], o menor RMSD obtido também para a 2GB1 foi de 2,18 ̊. Em um terceiro trabalho [Simons et al., 1997a], que também utilizou bibliotecas de fragmentos e empregou recozimento simulado, foram obtidos RMSDs em torno de $6 \AA$ A. Os três trabalhos citados evidenciam a importância da inserção de conhecimento em PEP.

\begin{tabular}{c||ccc} 
& \multicolumn{3}{c}{$\begin{array}{c}\text { p-valor } \\
\text { AGA6 }\end{array}$} \\
& AGS6 & AGAutoOrg \\
\hline \hline AGP & $0,9219(-)$ & $0,8457(-)$ & $0,0039(\mathrm{~s}-)$
\end{tabular}

Tabela 5.17: Teste estatístico para 2GB1 no Experimento 2. 
A Tabela 5.17 apresenta o teste de Wilcoxon para este experimento. Nota-se que houve diferença significativa entre o AGP e AGAutoOrg, sendo que o AGAutoOrg obteve a maior mediana.

As Figuras 5.22 e 5.23 mostram a energia mínima média e o RMSD mínimo médio ao longo das gerações, respectivamente.

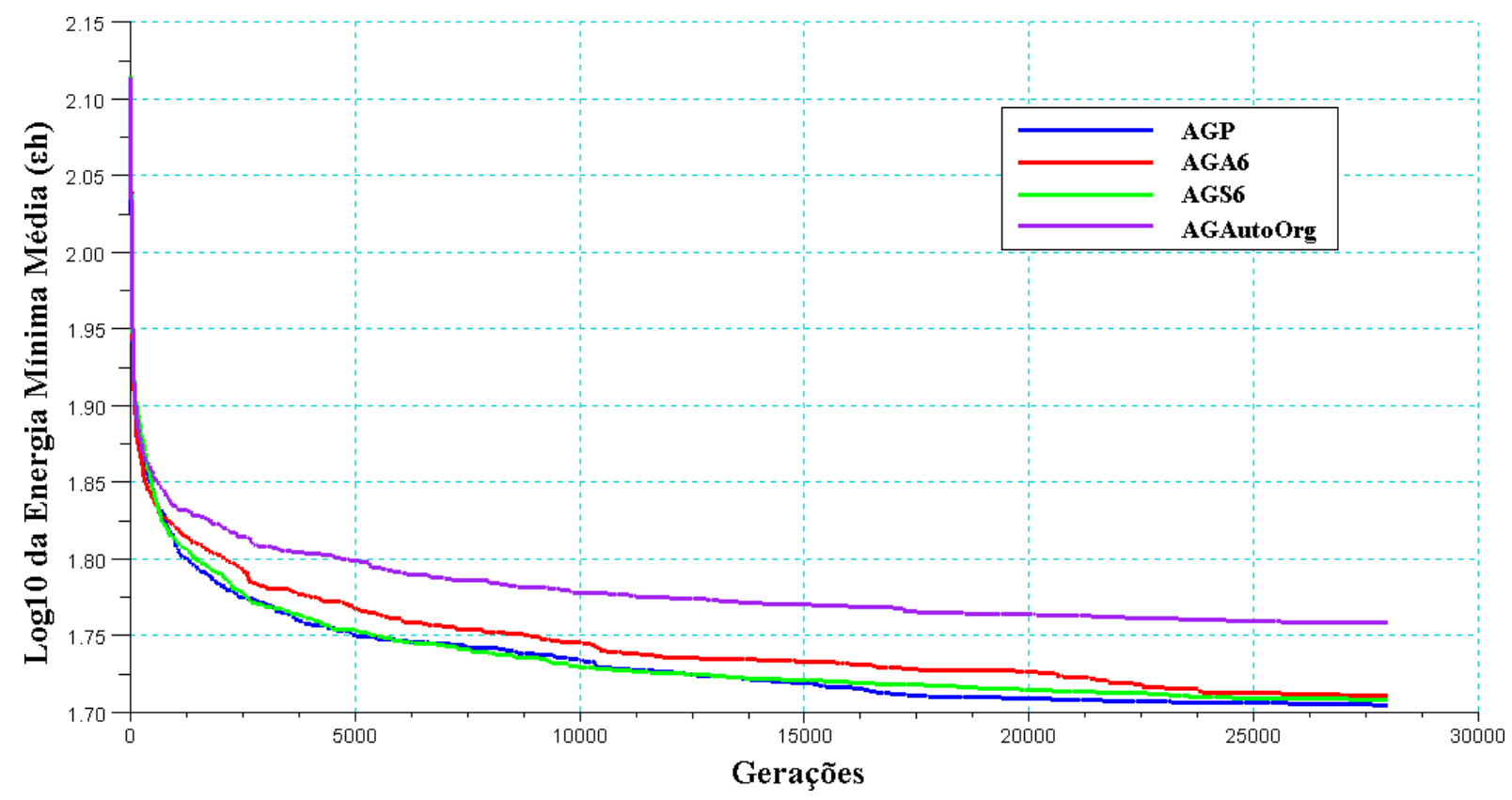

Figura 5.22: Média dos fitness mínimos ao longo das gerações para a $2 G B 1$ com predição de estrutura secundária.

A curva da Figura 5.22 mostra que as energias mínimas médias ainda estão decrescendo ao longo das gerações. Contudo, esse decréscimo é menor próximo ao final do experimento. 


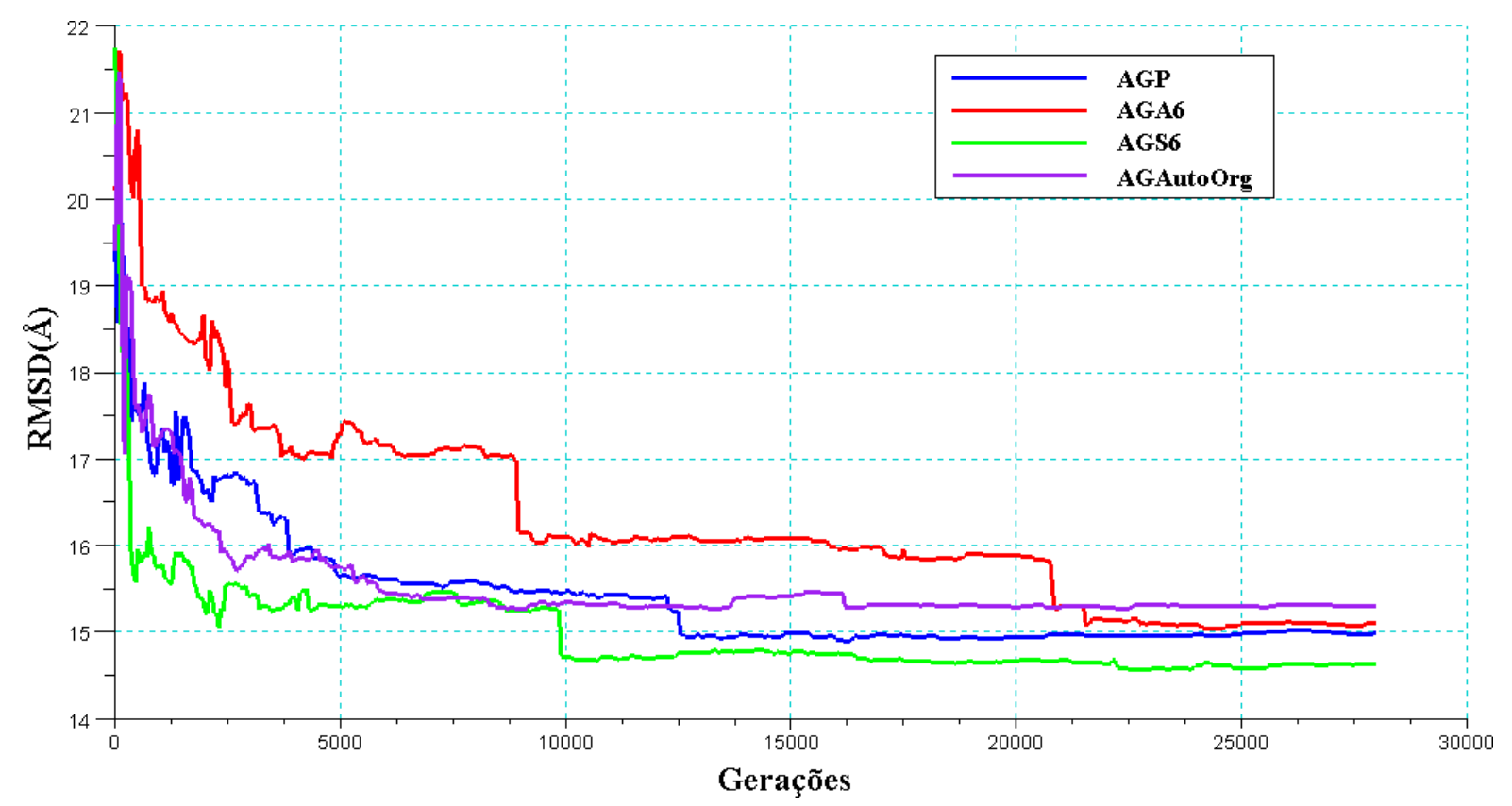

Figura 5.23: Média dos RMSDs do melhor indivíduo ao longo das gerações para a 2GB1 com predição de estrutura secundária.

Quanto ao RMSD da Figura 5.23, é possível verificar que, em média, o RMSD decresce ao longo das gerações, sendo que o AGS6 apresentou decrescimento mais notável.

A Figura 5.24 mostra algumas das estruturas preditas para este experimento.

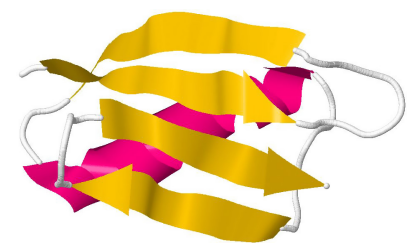

(a) Nativa $\left(160,56 \epsilon_{h}\right)$

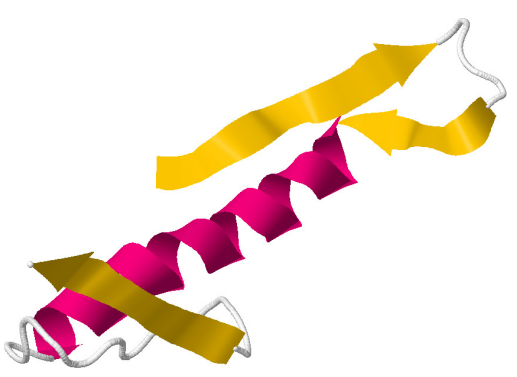

(b) Menor energia $\left(41,61 \epsilon_{h}\right)$

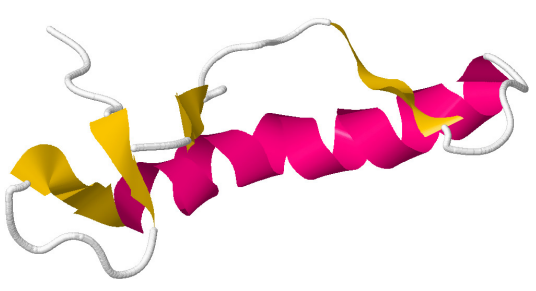

(c) Menor RMSD $\left(48,99 \epsilon_{h}\right)$

Figura 5.24: Estruturas preditas de menor e energia e menor RMSD para a 2GB1, com predição de estrutura secundária.

Pode-se observar, nas estruturas preditas na Figura 5.24, que as folhas- $\beta$ não se formaram adequadamente.

A seguir é exibido o gráfico que apresenta a variação das taxas de imigrantes para o algoritmo AGAutoOrg para a primeira execução. Estes gráficos são importantes para o entendimento do comportamento do algoritmo. Também são exibidos os gráficos da energia mínima e do RMSD mínimo para esta execução. 


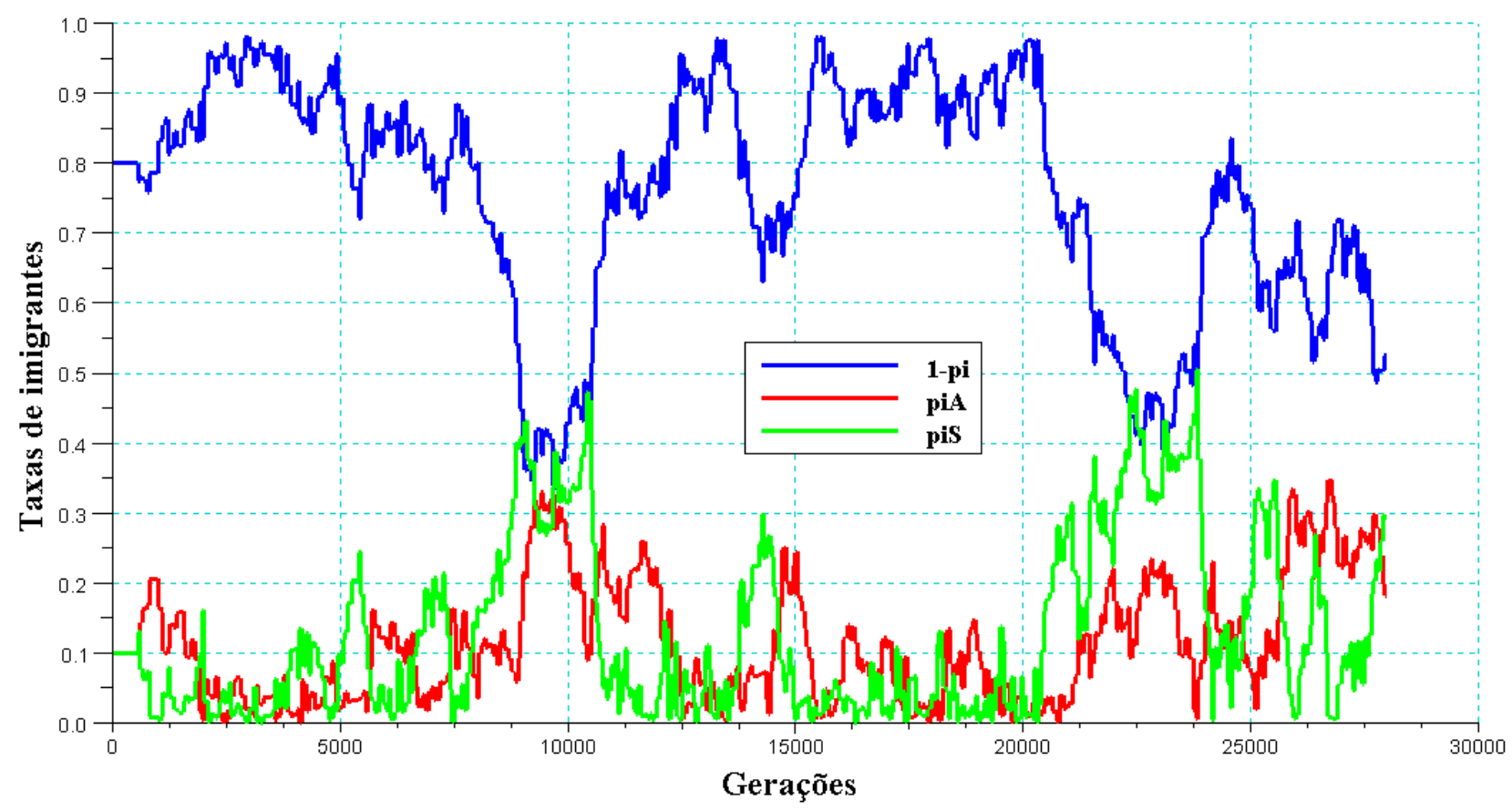

Figura 5.25: Variação das taxas de imigrantes para a $2 G B 1$.

Na Figura 5.25, pode-se observar que as taxas variaram de modo que, no fim da simulação 52,97\% dos indivíduos pertenciam a população normal, 11,64\% eram imigrantes aleatórios e 35,38\% imigrantes por similaridade.

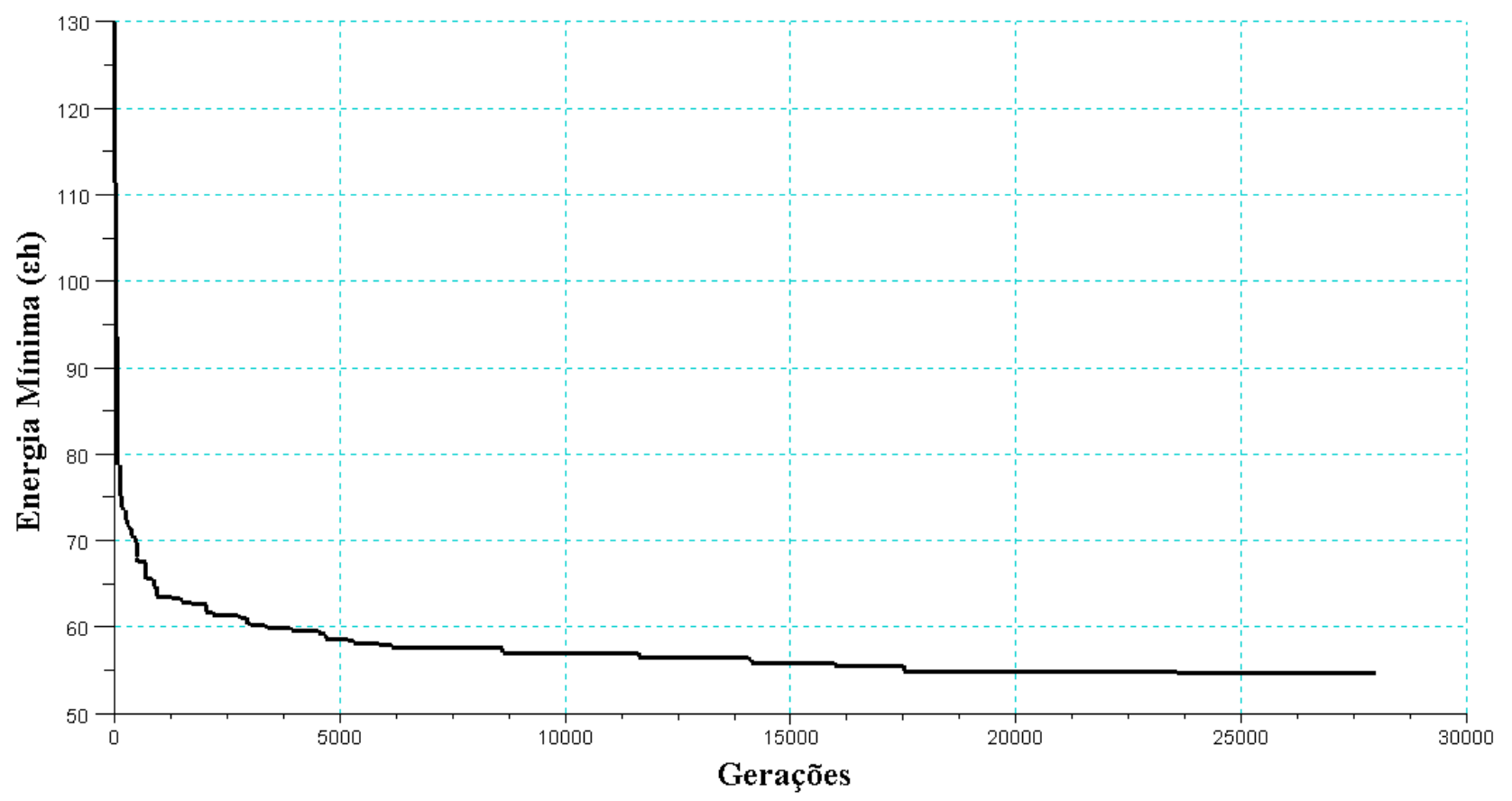

Figura 5.26: Energia para a primeira execução do AGAutoOrg. 


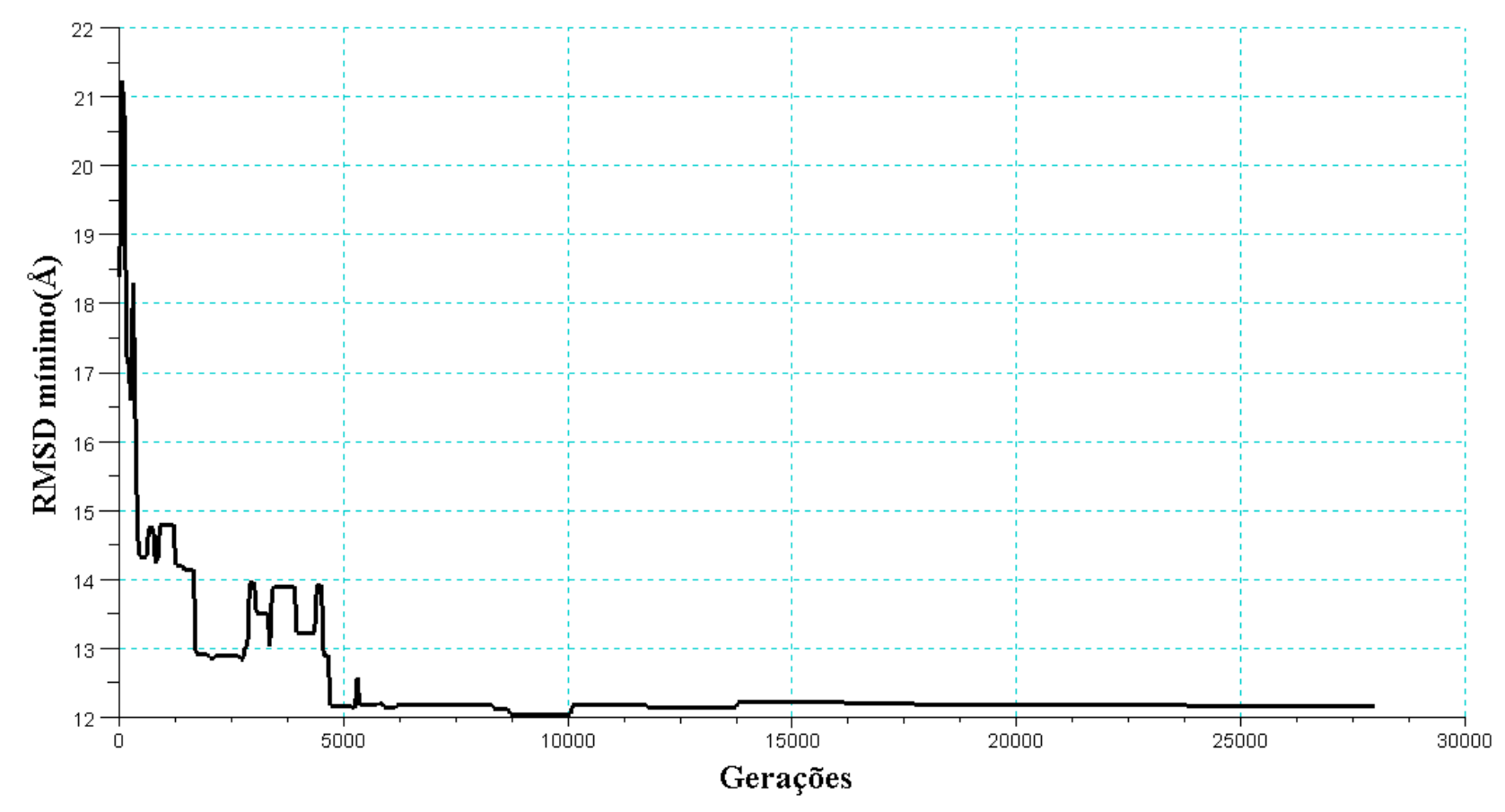

Figura 5.27: RMSD para a primeira execução do AGAutoOrg.

A Figura 5.26 mostra a energia mínima para a primeira execução do AGAutoOrg. Os platôs existentes são responsáveis pelas mudanças no gráfico da Figura 5.25, uma vez que as taxas de imigrantes mudam sempre que a melhor solução permanece inalterada após 50 gerações.

Já a Figura 5.27 mostra o RMSD para a primeira execução. Neste caso, como a relação a menor energia nem sempre representa o menor RMSD, é mais difícil estabelecer uma relação direta entre as figuras 5.27 e 5.25 . No entanto, uma queda brusca no RMSD pode corresponder a uma mudança benéfica nas taxas de imigrantes, o que seria extremamente útil.

\subsubsection{Proteína Fosfatase (2W4P)}

Os resultados para a proteína 2W4P são exibidos a seguir.

\begin{tabular}{c||cccc}
\multirow{2}{*}{ Algoritmo } & Média \pm Desvio Padrão & Energia $\epsilon_{h}$ \\
& Mediana & Mínimo & Máximo \\
\hline \hline AGP & $8,88 \mathrm{E}+01 \pm 6,82 \mathrm{E}+00$ & $8,92 \mathrm{E}+01$ & $7,86 \mathrm{E}+01$ & $9,80 \mathrm{E}+01$ \\
\hline AGA6 & $8,68 \mathrm{E}+01 \pm 6,92 \mathrm{E}+00$ & $8,70 \mathrm{E}+01$ & $7,58 \mathrm{E}+01$ & $9,66 \mathrm{E}+01$ \\
\hline AGS6 & $8,54 \mathrm{E}+01 \pm 6,41 \mathrm{E}+00$ & $8,47 \mathrm{E}+01$ & $7,38 \mathrm{E}+01$ & $\mathbf{9 , 3 2 E + 0 1}$ \\
\hline AGAutoOrg & $\mathbf{8 , 4 6 E + 0 1 ~} \pm 6,71 \mathrm{E}+00$ & $\mathbf{8 , 4 4 E + 0 1}$ & $\mathbf{7 , 3 0 E + 0 1}$ & $9,50 \mathrm{E}+01$ \\
\hline
\end{tabular}

Tabela 5.18: Valores da energia total para a $2 W 4 P$.

A Tabela 5.18 mostra que o menor valor médio de energia e menor mínimo foram obtidos pelo AGAutoOrg. 


\begin{tabular}{c||cccc}
\multirow{2}{*}{ Algoritmo } & Média \pm Desvio Padrão & $\begin{array}{c}\text { RMSD } \\
\text { Mediana }\end{array}$ & Mínimo & Máximo \\
\hline \hline AGP & $24,86 \pm 6,89$ & 24,18 & $\mathbf{1 6 , 2 6}$ & 40,37 \\
\hline AGA6 & $22,80 \pm 2,99$ & 22,41 & 18,48 & $\mathbf{2 9 , 3 9}$ \\
\hline AGS6 & $25,30 \pm 6,52$ & 23,52 & 16,94 & 36,39 \\
\hline AGAutoOrg & $\mathbf{2 2 , 5 3} \pm 5,95$ & $\mathbf{2 0 , 7 8}$ & 17,78 & 37,32 \\
\hline
\end{tabular}

Tabela 5.19: $R M S D$ para a $2 W 4 P$.

A Tabela 5.19 mostra que o menor RMSD médio foi obtido pelo AGAutoOrg e menor mínimo pelo AGP. O teste de Wilcoxon é apresentado na Tabela 5.20.

\begin{tabular}{c||ccc} 
& \multicolumn{3}{c}{ p-valor } \\
& AGA6 & AGS6 & AGAutoOrg \\
\hline \hline AGP & $0,6953(+)$ & $0,4922(+)$ & $0,2324(+)$
\end{tabular}

Tabela 5.20: Teste estatístico para a $2 W 4 P$.

O teste de Wilcoxon exibido pela Tabela 5.20 mostra que não houve diferença estatística entre os algoritmos. Contudo, as medianas do AGA6, AGS6 e AGAutoOrg foram menores que a mediana do AGP.

As curvas de energia e RMSD médios são exibidas nas Figuras 5.28 e 5.29.

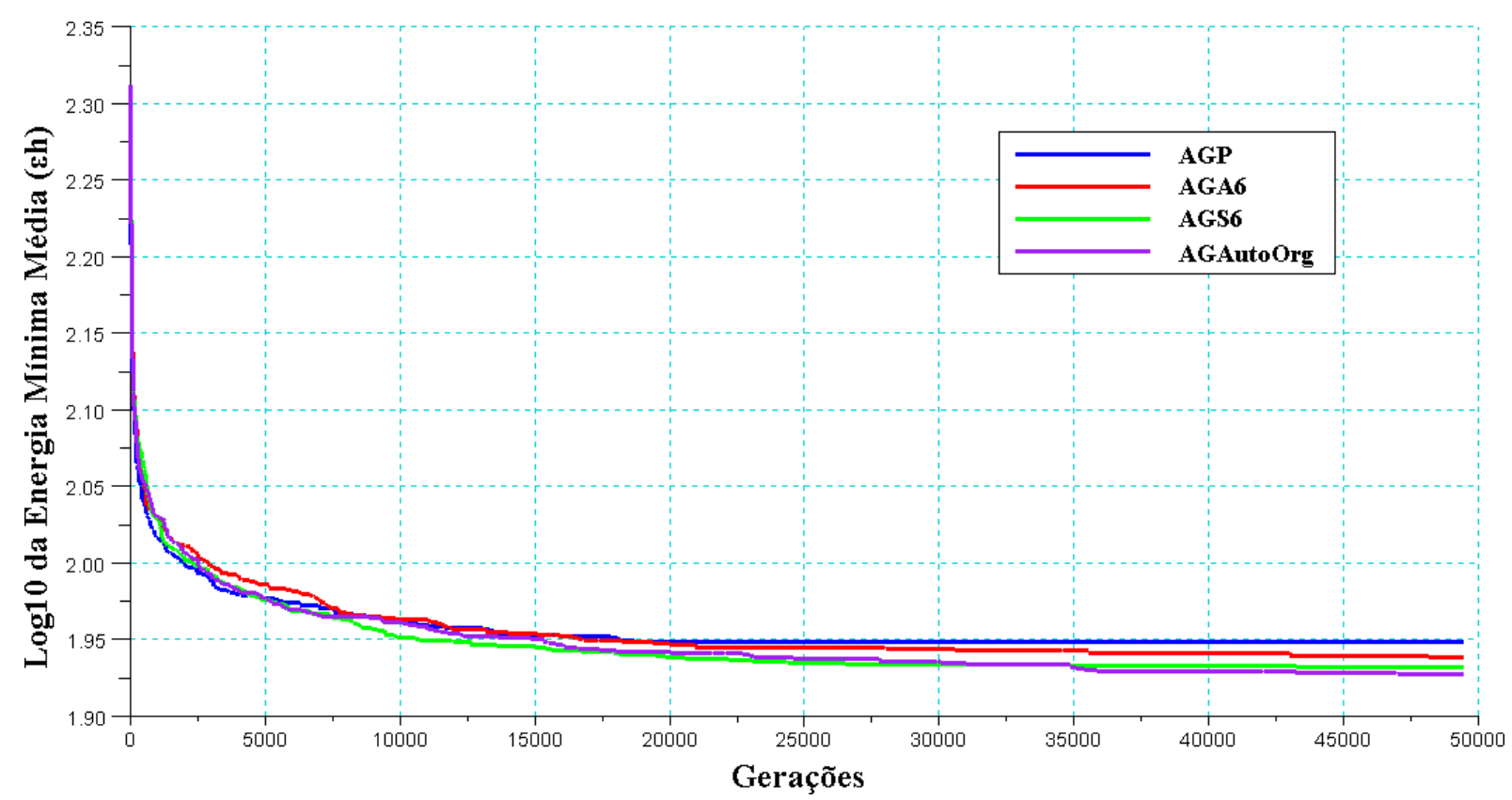

Figura 5.28: Média dos fitness mínimos ao longo das gerações para a $2 W 4 P$.

A Figura 5.28 mostra que as curvas de energia média ainda estão decrescendo. 


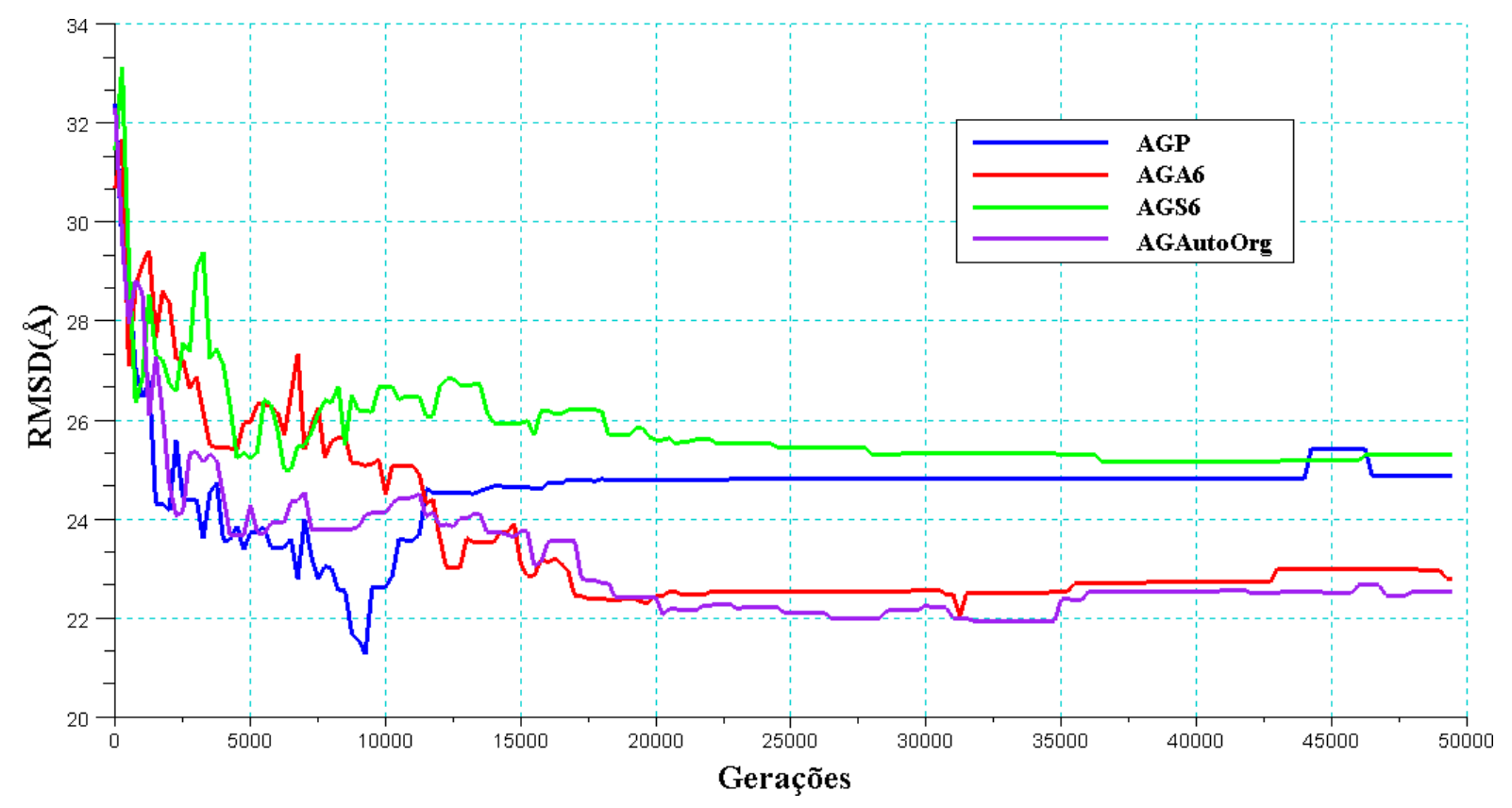

Figura 5.29: Média dos RMSDs mínimos ao longo das gerações para a $2 W 4 P$.

Já a Figura 5.29 mostra que as curvas do RMSD decresceram no início, mas não apresentam decaimento considerável no final do experimento.

A Figura 5.30 apresenta as estruturas preditas para a 2W4P.

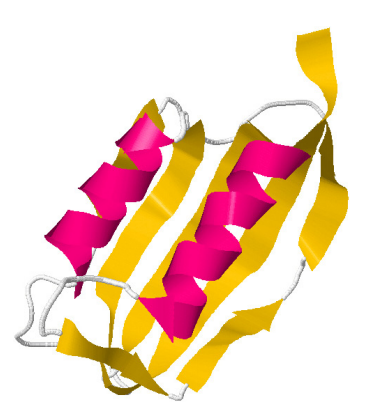

(a) Nativa ( 2,04E+02

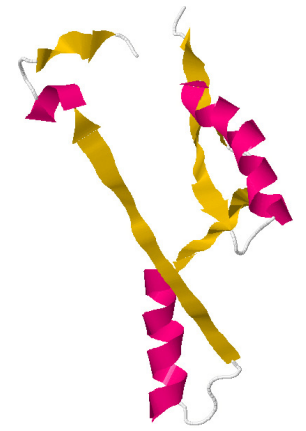

(b) Menor Energia $\left(7,30 \mathrm{E}+01 \epsilon_{h}\right)$

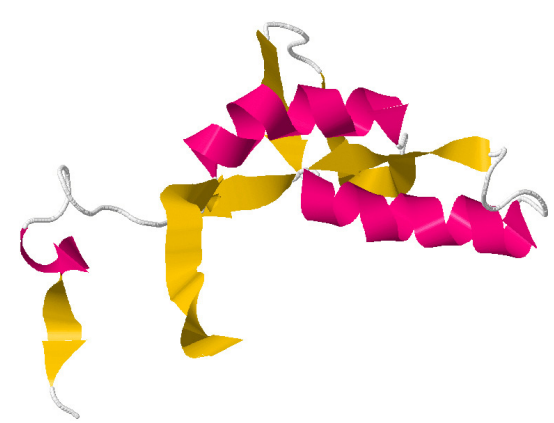

(c) Menor RMSD $\left(8,09 \mathrm{E}+01 \epsilon_{h}\right)$ $\left.\epsilon_{h}\right)$

Figura 5.30: Estruturas preditas de menor energia e menor RMSD para a $2 W 4 P$.

Pode-se observar pela Figura 5.30, que as estruturas preditas apresentam fitas- $\beta$ distantes umas das outras, formando conformações pouco compactas.

O comportamento das taxas de imigrantes do AGAutoOrg, a energia e o RMSD, para a primeira execução, são apresentadas a seguir. 


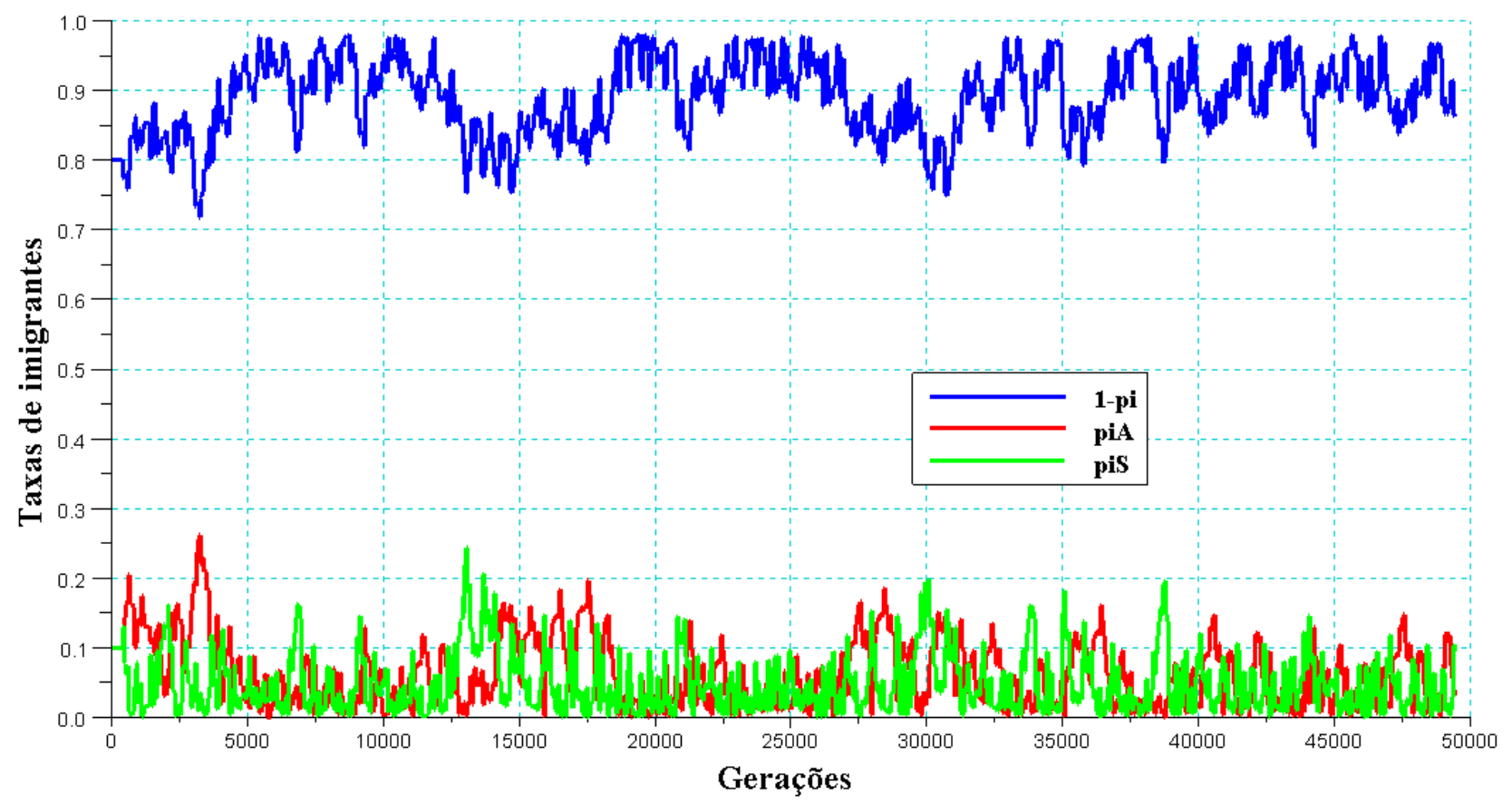

Figura 5.31: Variação das taxas de imigrantes para a $2 W 4 P$.

A Figura 5.31 mostra que as taxas variaram de modo que no fim da simulação, $86,80 \%$ dos indivíduos pertenciam a população normal, 3,92\% era imigrantes aleatórios e 9,28\% imigrantes por similaridade.

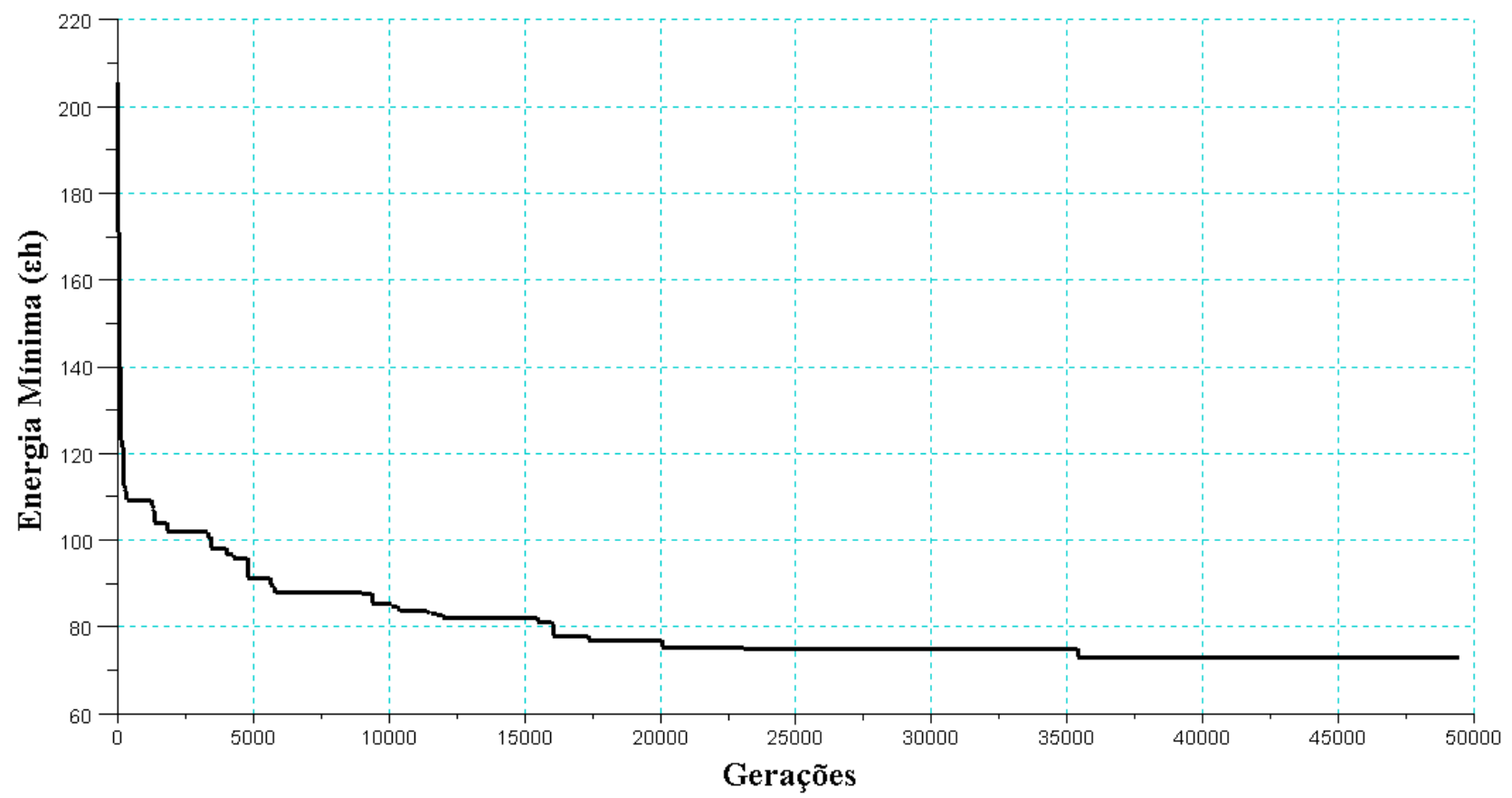

Figura 5.32: Energia para a primeira execução do AGAutoOrg. 


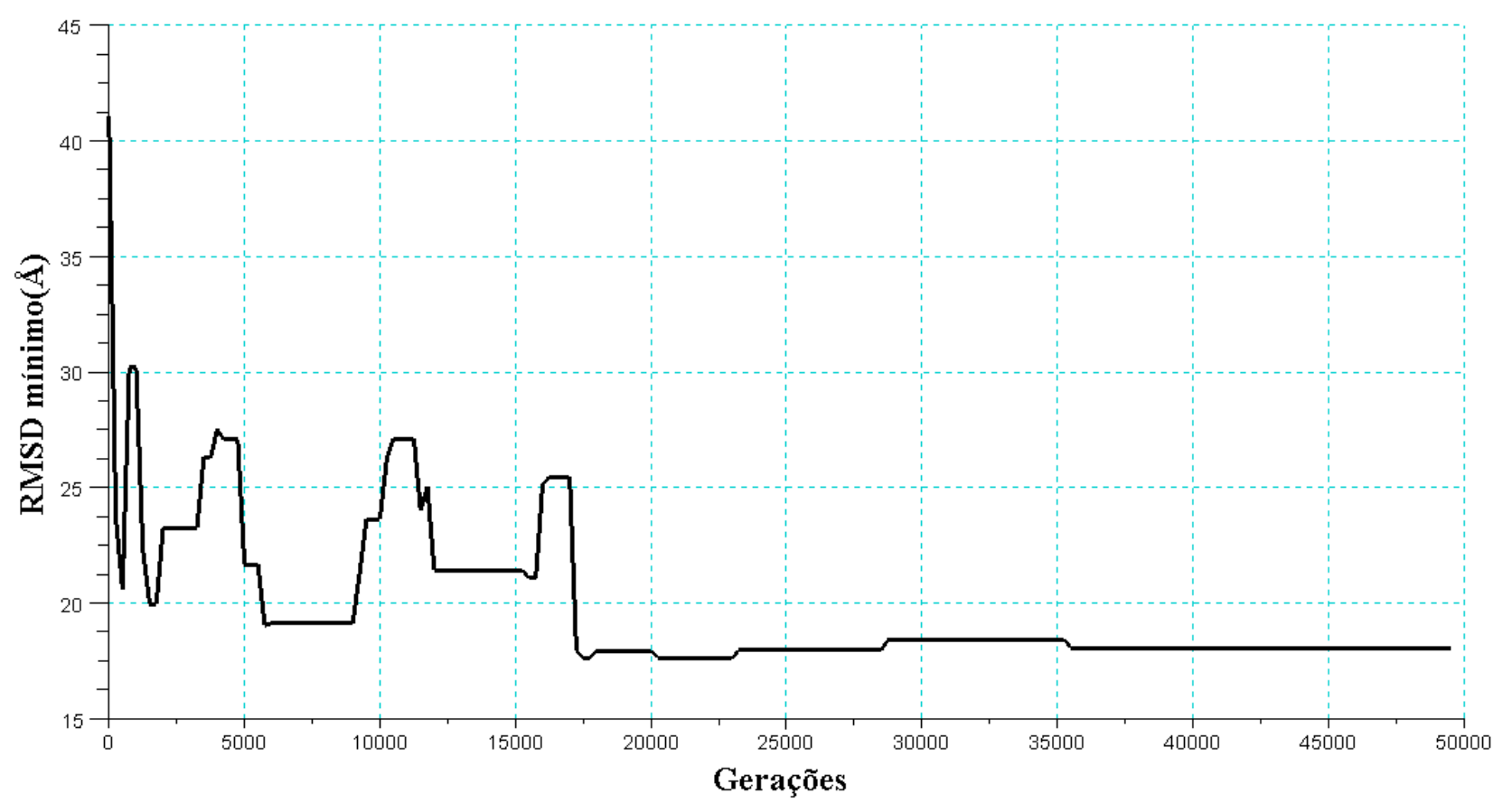

Figura 5.33: RMSD para a primeira execução do AGAutoOrg.

As Figuras 5.32 e Figura 5.33 mostram que, em geral, energia e RMSD caem ao longo das gerações. 


\subsection{Experimentos com o modelo Full-atom}

Devido ao maior custo computacional do modelo full-atom, todos os experimentos desta subseção foram realizados com número de gerações igual a 1000.

Para comparar as componentes de energia produzidas pelos dois modelos, foram realizados testes utilizando a estrutura nativa e a predita (pelo Experimento 2).

\begin{tabular}{c|cc} 
Componente & $\begin{array}{c}\text { Energia kcal/mol } \\
\text { 2GB1 Nativa }\end{array}$ & AGP Última Geração (Experimento 2) \\
\hline \hline ECL & 117,61 & 33,53 \\
\hline EAL & 46,52 & 63,10 \\
\hline EUB & 13,96 & 4,02 \\
\hline EI & 0,02 & 1,78 \\
\hline EAT & 185,36 & 69,15 \\
\hline ETT & $-10,26$ & $-16,33$ \\
\hline EVdW & 125,73 & 2448684,50 \\
\hline EE & $-211,95$ & $-222,67$ \\
\hline ETotal & 267,0 & 2448751,91 \\
\hline
\end{tabular}

Tabela 5.21: Termos de energia empregando o CHARMM22 para a $2 G B 1$.

A Tabela 5.21 mostra as componentes de energia empregando o CHARMM22. Foram analisadas a estrutura nativa da 2GB1 e o melhor indivíduo da última geração do AGP para o Experimento 2. Pode-se observar que a diferença mais significativa ocorre entre os termos de Van der Waals, que são muito altos nas proteínas preditas. Isso pode ser explicado devido ao fato de que no modelo CG a cadeia lateral da proteína não é levada em conta para o cálculo da energia potencial. Assim, imigrantes gerados por similaridade terão em geral, valores altos de fitness devido ao componente de Van der Waals. Dessa forma, optou-se por realizar uma otimização simplificada das cadeias laterais ao invés de gerá-las aleatoriamente.

\subsubsection{Experimento 3: Otimização da cadeia lateral}

A otimização da cadeia lateral foi realizada, empregando-se o AGP e o modelo fullatom com o CHARMM22. Neste caso, porém, empregou-se o indivíduo mais similar da população de similaridade (o primeiro retornado pelo algoritmo de alinhamento). O algoritmo foi alterado de modo a não permitir alterações na cadeia principal, mas apenas na lateral. Os operadores e os parâmetros foram mantidos. Dessa maneira, foi gerada uma população de indivíduos por similaridade, cuja cadeia principal era sempre igual e a cadeia lateral iniciada aleatoriamente. Foram realizados testes com uma população de 20 indivíduos. Por fim, a cadeia lateral do melhor indivíduo foi copiada para todos os demais indivíduos da população gerada através de similaridade. A Tabela 5.22 mostra as energias obtidas. O número de gerações foi 10000. 


\begin{tabular}{c||ccc}
\multirow{2}{*}{ Experimento } & Energia melhor indivíduo & $\begin{array}{c}\text { Energia kcal/mol } \\
\text { Média da população }\end{array}$ & Máximo da população \\
\hline \hline 1A11 & 175915 & $3,19 \mathrm{e}+16$ & $3,19 \mathrm{e}+17$ \\
\hline 2K98 & 330326 & $7,51 \mathrm{e}+17$ & $1,50 \mathrm{e}+19$ \\
\hline 1ENH & 809019 & $3,72 \mathrm{e}+14$ & $4,15 \mathrm{e}+15$ \\
\hline 2GB1 & $3,75 \mathrm{e}+06$ & $1,24 \mathrm{e}+15$ & $1,37 \mathrm{e}+16$ \\
\hline 2W4P & $4,73 \mathrm{e}+07$ & $9,39 \mathrm{e}+18$ & $1,88 \mathrm{e}+20$ \\
\hline
\end{tabular}

Tabela 5.22: Valores da energia total para otimização da cadeia lateral.

A Tabela 5.22 mostra que a energia mínima total para as proteínas com folhas- $\beta$ é maior do que a das proteínas com $\alpha$-hélices apenas.

A Tabela 5.23 mostra o termo de van der Waals para as estruturas nativas e para as preditas da primeira e da última geração do experimento de otimização. Pode-se observar que houve um decréscimo significativo dos valores graças a otimização da cadeia lateral.

\begin{tabular}{|c|c|c|c|}
\hline Componente & Nativa & $\begin{array}{l}\text { Termo de VdW kcal/mol } \\
\text { AGP Primeira Geração }\end{array}$ & AGP Última Geração \\
\hline 1A11 & 125,71 & $\overline{5} 5,55 \mathrm{e}+11$ & 175818 \\
\hline $2 \mathrm{~K} 98$ & 101,47 & $9,63 \mathrm{e}+10$ & 329379 \\
\hline $1 \mathrm{ENH}$ & 3,01 & $1,82 \mathrm{e}+13$ & 809854 \\
\hline 2GB1 & 177,40 & $9,22 \mathrm{e}+13$ & $3,75 e+06$ \\
\hline 2W4P & $-200,43$ & $7,07 e+12$ & $4,73 e+07$ \\
\hline
\end{tabular}

Tabela 5.23: Termos de Energia no experimento de otimização da cadeia lateral.

De acordo com a Tabela 5.23, observa-se que houve maior decréscimo de energia para as proteínas que possuem apenas $\alpha$-hélices.

A seguir serão apresentados os experimentos para as cinco proteínas testadas. A otimização também foi utilizada apenas para as populações de indivíduos similares.

\subsubsection{Proteína Receptora de Acetilcolina (1A11)}

Neste experimento, com a proteína 2GB1, a otimização da cadeia lateral foi empregada na população de similaridade, a qual é utilizada pelos algoritmos que empregam similaridade. A população inicial desse experimento foi iniciada aleatoriamente, assim como nos experimentos anteriores.

Os resultados para a 1A11 são apresentados a seguir.

A Tabela 5.24 mostra que a menor média foi obtida pelo AGA6, enquanto que a energia mínima foi obtida pelo AGP.

A Tabela 5.25 exibe os RMSDs obtidos. As menores médias foram obtidas para os algoritmos que empregam similaridade. O RMSD mínimo foi obtido para o AGAutoOrg. 


\begin{tabular}{c||cccc}
\multirow{2}{*}{ Algoritmo } & Média \pm Desvio Padrão & Energia kcal/mol \\
& Mediana & Mínimo & Máximo \\
\hline \hline AGP & $2,72 \mathrm{E}+03 \pm 2,12 \mathrm{E}+03$ & $2,28 \mathrm{E}+03$ & $\mathbf{5 , 8 5 E + 0 2}$ & $7,16 \mathrm{E}+03$ \\
\hline AGA6 & $\mathbf{2 , 3 4 E + 0 3} \pm 1,28 \mathrm{E}+03$ & $\mathbf{2 , 1 1 E + 0 3}$ & $9,22 \mathrm{E}+02$ & $\mathbf{4 , 4 4 E + 0 3}$ \\
\hline AGS6 & $4,28 \mathrm{E}+03 \pm 2,56 \mathrm{E}+03$ & $5,49 \mathrm{E}+03$ & $7,15 \mathrm{E}+02$ & $7,25 \mathrm{E}+03$ \\
\hline AGAutoOrg & $5,81 \mathrm{E}+03 \pm 1,16 \mathrm{E}+03$ & $5,94 \mathrm{E}+03$ & $4,09 \mathrm{E}+03$ & $7,38 \mathrm{E}+03$ \\
\hline
\end{tabular}

Tabela 5.24: Valores da energia total para 1A11.

\begin{tabular}{c||cccc}
\multirow{2}{*}{ Algoritmo } & Média \pm Desvio Padrão & $\begin{array}{c}\text { RMSD A } \\
\text { Mediana }\end{array}$ & Mínimo & Máximo \\
\hline \hline AGP & $5,70 \pm 1,57$ & 5,17 & 4,16 & 8,52 \\
\hline AGA6 & $6,54 \pm 1,81$ & 6,39 & 4,39 & 8,76 \\
\hline AGS6 & $\mathbf{4 , 1 4} \pm 0,75$ & $\mathbf{3 , 9 6}$ & 3,30 & $\mathbf{5 , 4 5}$ \\
\hline AGAutoOrg & $4,22 \pm 0,87$ & 4,02 & $\mathbf{3 , 1 2}$ & 6,19 \\
\hline
\end{tabular}

Tabela 5.25: RMSD para a $1 A 11$.

As Figuras 5.34 e 5.35 mostram as curvas médias de energia e RMSD.

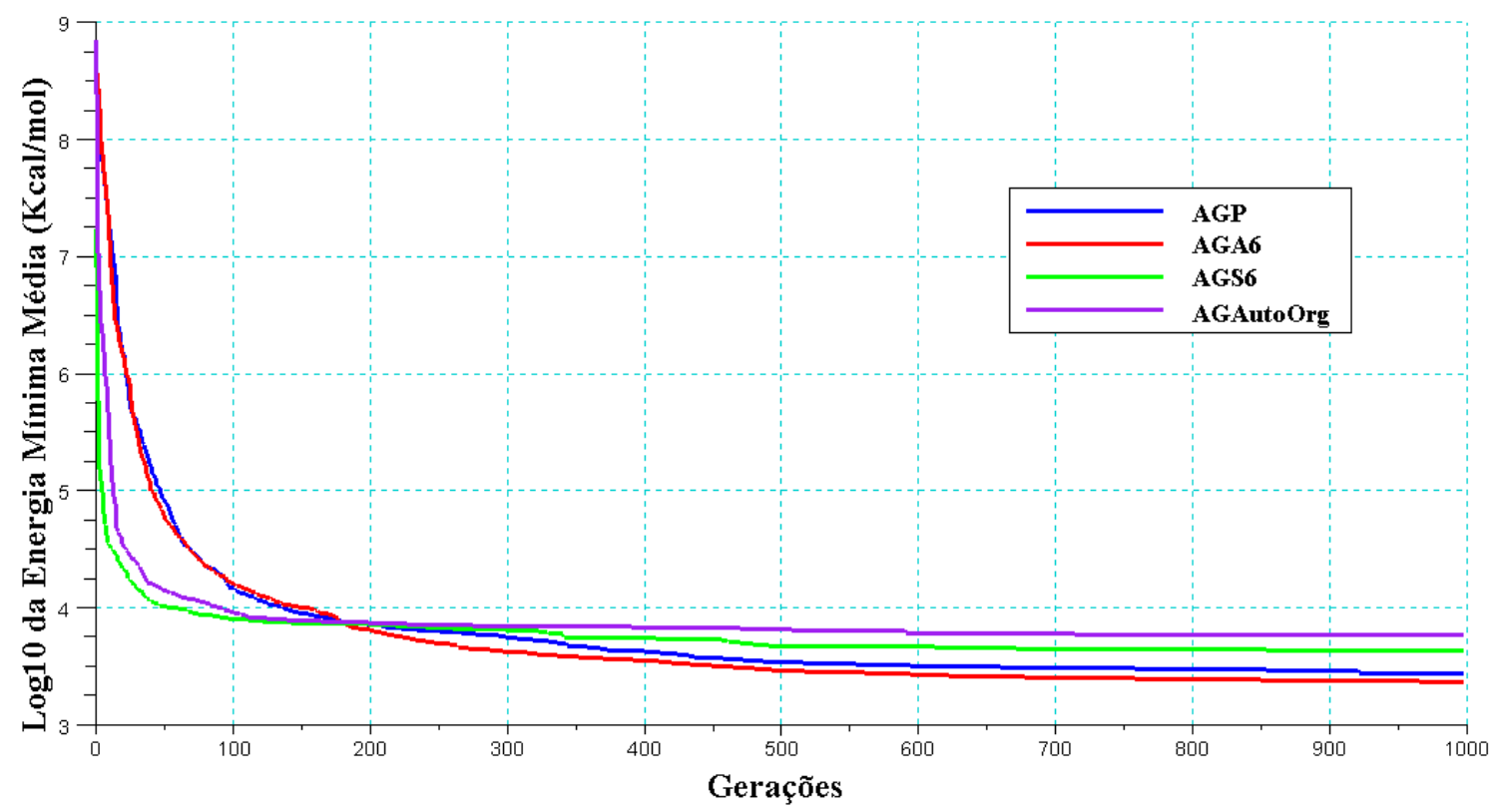

Figura 5.34: Média dos fitness mínimos ao longo das gerações para a 1 A11 com modelo full-atom.

De acordo com a Figura 5.34 podemos observar que energia decai consideravelmente ao longo das gerações e parece se estabilizar no final. 


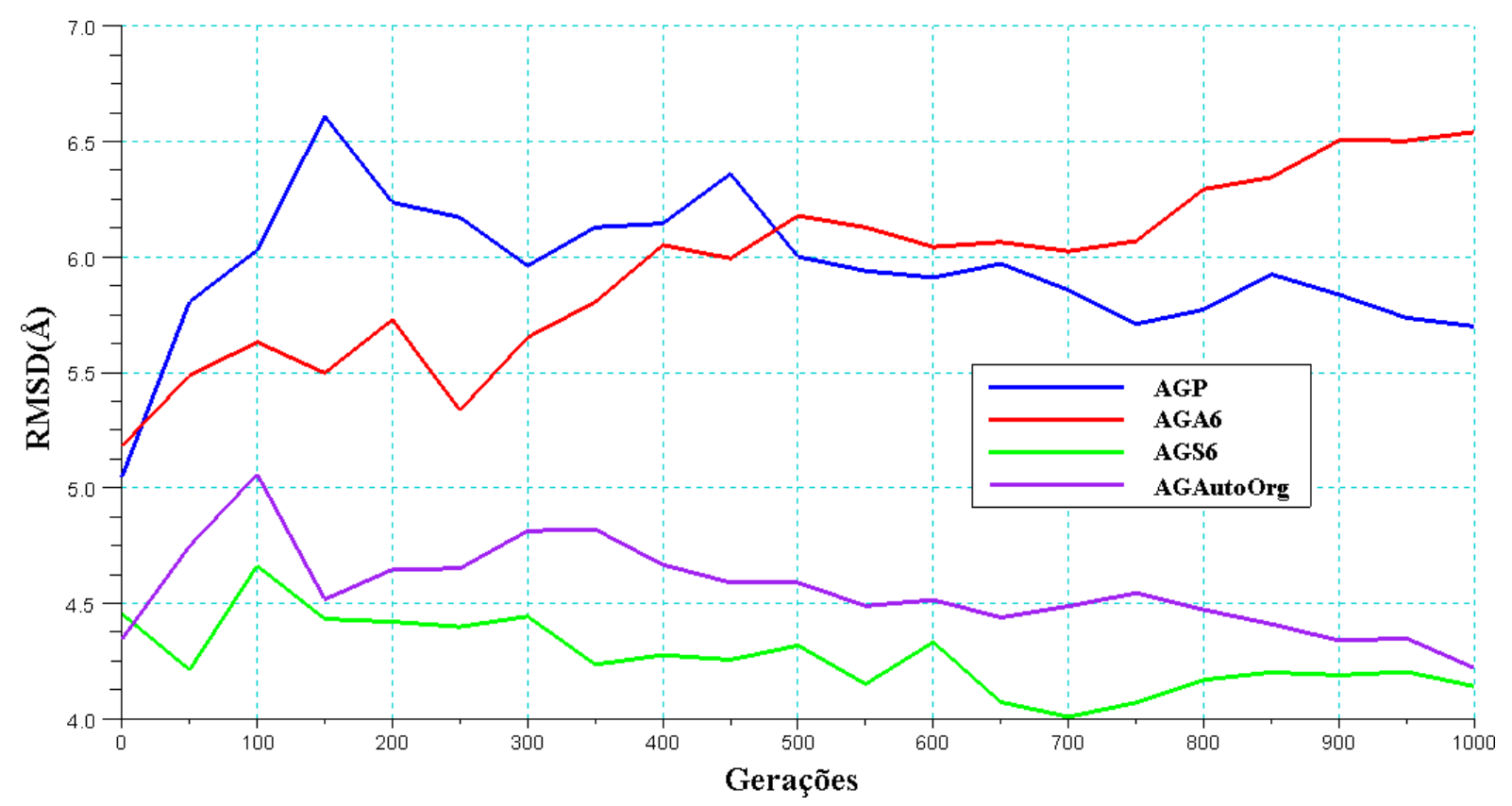

Figura 5.35: Média dos RMSDs ao longo das gerações para a 1 Al1 com modelo full-atom.

O teste estatístico de Wilcoxon é mostrado na Tabela 5.26.

\begin{tabular}{c||ccc} 
& \multicolumn{3}{c}{ p-valor } \\
& AGA6 & AGS6 & AGAutoOrg \\
\hline \hline AGP & $0,5566(+)$ & $0,1934(-)$ & $0,0059(-)$
\end{tabular}

Tabela 5.26: Teste de Wilcoxon para a 1A11 com modelo full-atom.

De acordo com a Tabela 5.26, podemos observar que houve diferença significativa entre os algoritmos AGP e AGAutoOrg, porém o AutoOrg obteve pior desempenho, apresentando uma maior mediana.

A Figura 5.36 mostra as estruturas com menor energia e com menor RMSD geradas. Podemos observar que a hélice sofreu quebras ao longo da estrutura em todas as estruturas geradas.

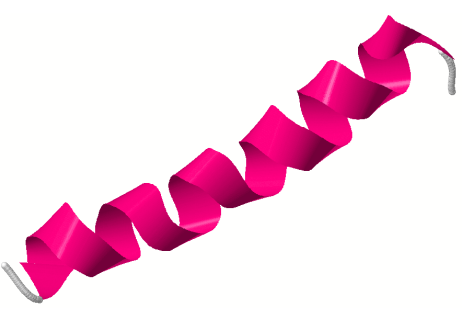

(a) Nativa $(1,26 \mathrm{E}+02 \mathrm{kcal} / \mathrm{mol})$

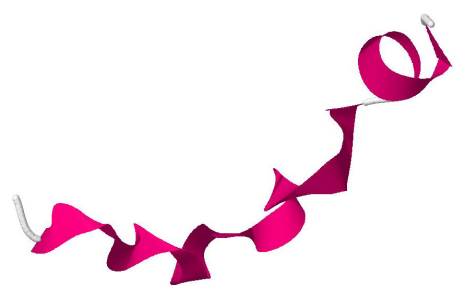

(b) Menor Energia $(5,85 \mathrm{E}+02$ $\mathrm{kcal} / \mathrm{mol})$

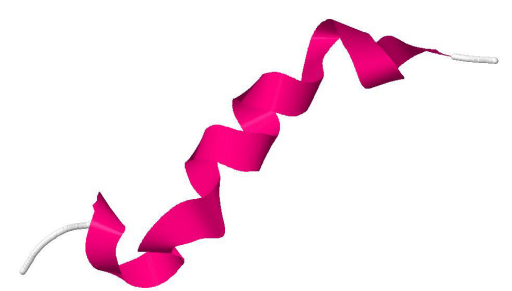

(c) Menor RMSD (4,52E+03 $\mathrm{kcal} / \mathrm{mol})$

Figura 5.36: Estruturas preditas de menor energia e menor RMSD para a 1 Al1 com modelo full-atom. 


\subsubsection{MSI-594 (2K98)}

O experimento com a proteína $2 \mathrm{~K} 98$ é apresentado a seguir.

\begin{tabular}{c||cccc}
\multirow{2}{*}{ Algoritmo } & Média \pm Desvio Padrão & $\begin{array}{c}\text { Energia kcal/mol } \\
\text { Mediana }\end{array}$ & Mínimo & Máximo \\
\hline \hline AGP & $3,48 \mathrm{E}+03 \pm 2,11 \mathrm{E}+03$ & $3,69 \mathrm{E}+03$ & $1,10 \mathrm{E}+03$ & $6,32 \mathrm{E}+03$ \\
\hline AGA6 & $3,09 \mathrm{E}+03 \pm 1,81 \mathrm{E}+03$ & $2,91 \mathrm{E}+03$ & $1,27 \mathrm{E}+03$ & $\mathbf{5 , 3 0 E}+\mathbf{0 3}$ \\
\hline AGS6 & $3,79 \mathrm{E}+03 \pm 1,60 \mathrm{E}+03$ & $3,84 \mathrm{E}+03$ & $\mathbf{1 , 0 9 E}+\mathbf{0 3}$ & $6,01 \mathrm{E}+03$ \\
\hline AGAutoOrg & $\mathbf{2 , 4 7 E + 0 3} \pm 1,91 \mathrm{E}+03$ & $\mathbf{1 , 3 3 E + 0 3}$ & $1,17 \mathrm{E}+03$ & $5,61 \mathrm{E}+03$ \\
\hline
\end{tabular}

Tabela 5.27: Energias para a $2 \mathrm{~K} 98$ com modelo full-atom.

A Tabela 5.27 mostra que a menor energia média foi obtida pelo AGA6 e a mínima pelo AGS6.

\begin{tabular}{c||cccc}
\multirow{2}{*}{ Algoritmo } & Média \pm Desvio Padrão & $\begin{array}{c}\text { RMSD } \AA \\
\text { Mediana }\end{array}$ & Mínimo & Máximo \\
\hline \hline AGP & $5,80 \pm 1,28$ & $\mathbf{5 , 3 8}$ & $\mathbf{4 , 1 8}$ & 7,55 \\
\hline AGA6 & $\mathbf{5 , 6 7} \pm 0,86$ & 5,58 & 4,61 & $\mathbf{7 , 1 9}$ \\
\hline AGS6 & $6,56 \pm 0,96$ & 6,46 & 5,14 & 8,42 \\
\hline AGAutoOrg & $6,30 \pm 1,05$ & 6,17 & 4,64 & 8,18 \\
\hline
\end{tabular}

Tabela 5.28: $R M S D$ para a $2 K 98$ com modelo full-atom.

De acordo com a Tabela 5.28, o menor RMSD médio foi obtido para o AGA6, enquanto que o menor mínimo foi obtido para o AGP.

As Figuras 5.37 e 5.38 apresentam as energias e RMSDs médios.

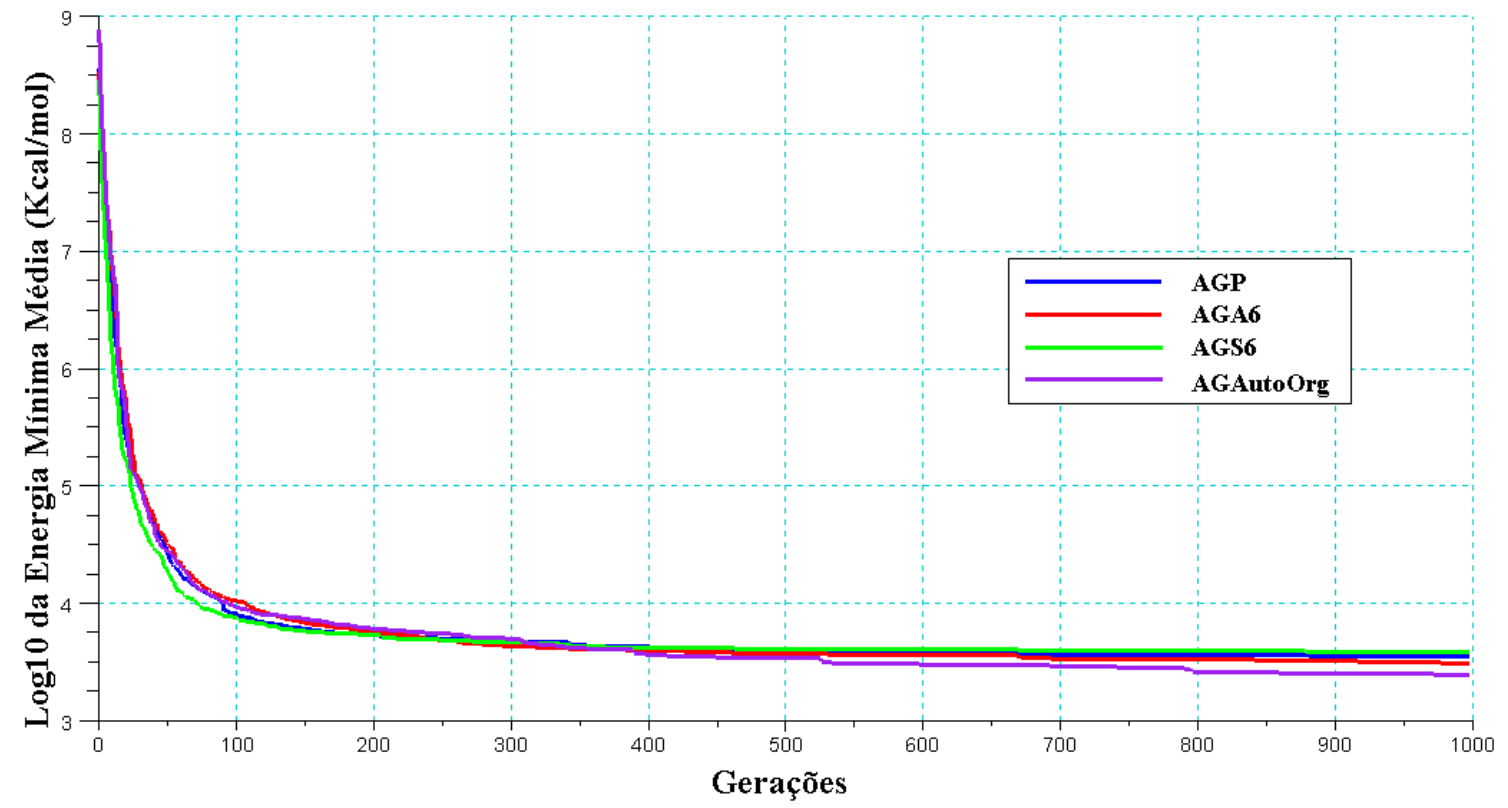

Figura 5.37: Média dos fitness mínimos ao longo das gerações para a 2 K98 com modelo full-atom. 


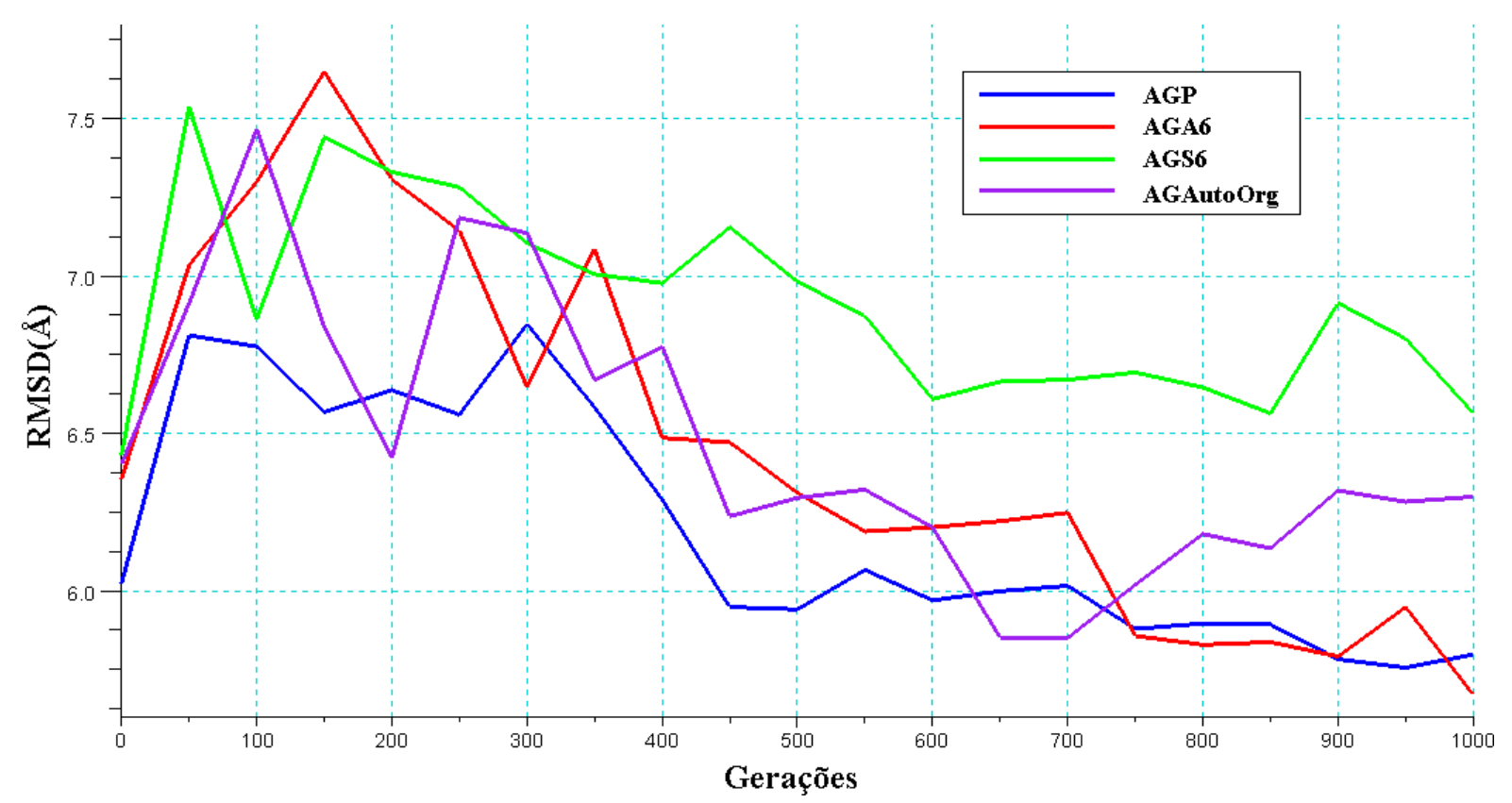

Figura 5.38: Média dos RMSDs ao longo das gerações para a $2 \mathrm{~K} 98$ com modelo full-atom.

O teste estatístico de Wilcoxon é mostrado na Tabela 5.29.

\begin{tabular}{c||ccc}
\multicolumn{1}{c||}{} & \multicolumn{3}{c}{ p-valor } \\
& AGA6 & AGS6 & AGAutoOrg \\
\hline \hline AGP & $1(-)$ & $1(+)$ & $0,2324(+)$
\end{tabular}

Tabela 5.29: Teste de Wilcoxon para a 2 K98 com modelo full-atom.

De acordo com a Tabela 5.29, podemos observar que não houve diferença significativa entre os algoritmos.

A Figura 5.39 mostra as estruturas com menor energia e com menor RMSD geradas.

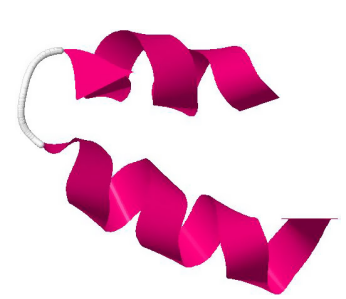

(a) Nativa $(1,01 \mathrm{E}+02$ $\mathrm{kcal} / \mathrm{mol}$ )

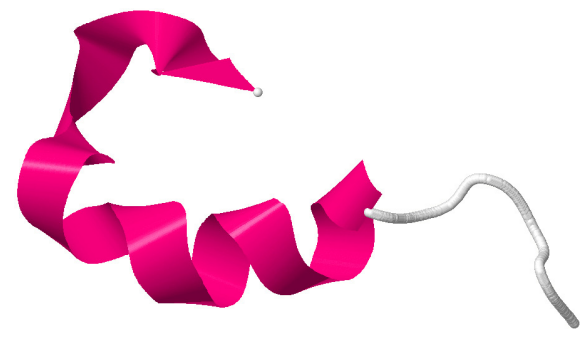

(b) Menor Energia (1,09E+03 kcal/mol)

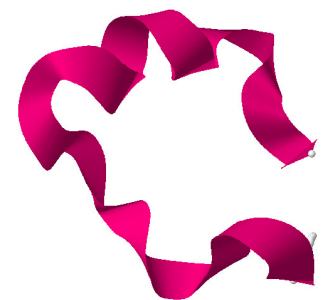

(c) Menor RMSD $(3,60 \mathrm{E}+03 \mathrm{kcal} / \mathrm{mol})$

Figura 5.39: Estruturas preditas de menor energia e menor RMSD para a 2 K98 com modelo full-atom. 


\subsubsection{DNA-Ligante (1ENH)}

A seguir o experimento com a proteína 1ENH é apresentado.

\begin{tabular}{c||cccc}
\multirow{2}{*}{ Algoritmo } & Média \pm Desvio Padrão & $\begin{array}{c}\text { Energia kcal/mol } \\
\text { Mediana }\end{array}$ & Mínimo & Máximo \\
\hline \hline AGP & $7,14 \mathrm{E}+04 \pm 3,71 \mathrm{E}+04$ & $5,52 \mathrm{E}+04$ & $2,30 \mathrm{E}+04$ & $\mathbf{1 , 3 4 E + 0 5}$ \\
\hline AGA6 & $8,18 \mathrm{E}+04 \pm 4,31 \mathrm{E}+04$ & $7,60 \mathrm{E}+04$ & $4,11 \mathrm{E}+04$ & $1,80 \mathrm{E}+05$ \\
\hline AGS6 & $\mathbf{4 , 0 4 E + 0 4} \pm 2,82 \mathrm{E}+04$ & $\mathbf{2 , 9 0 E + 0 4}$ & $\mathbf{1 , 8 8 E + 0 4}$ & $1,09 \mathrm{E}+05$ \\
\hline AGAutoOrg & $5,19 \mathrm{E}+04 \pm 2,33 \mathrm{E}+04$ & $4,57 \mathrm{E}+04$ & $2,45 \mathrm{E}+04$ & $9,39 \mathrm{E}+05$ \\
\hline
\end{tabular}

Tabela 5.30: Energias para a 1ENH com modelo full-atom.

A Tabela 5.30 mostra que a menor energia média e mínima foram obtidas pelo AGS6.

\begin{tabular}{c||crrc}
\multirow{2}{*}{ Algoritmo } & Média \pm Desvio Padrão & $\begin{array}{c}\text { RMSD } \AA \\
\text { Mediana }\end{array}$ & Mínimo & Máximo \\
\hline \hline AGP & $19,71 \pm 3,04$ & 19,76 & 14,67 & 25,50 \\
\hline AGA6 & $18,60 \pm 4,30$ & $\mathbf{1 8 , 1 7}$ & $\mathbf{1 2 , 3 1}$ & 25,85 \\
\hline AGS6 & $\mathbf{1 8 , 1 7} \pm 3,51$ & 18,37 & 12,55 & 23,43 \\
\hline AGAutoOrg & $18,55 \pm 2,92$ & 19,01 & 13,36 & $\mathbf{2 3 , 3 6}$ \\
\hline
\end{tabular}

Tabela 5.31: RMSD para a 1ENH com modelo full-atom.

Segundo a Tabela 5.31, o menor RMSD médio foi obtido para o AGS6, enquanto que o menor mínimo foi obtido para o AGA6. No entanto, os valores foram altos em geral.

As Figuras 5.40 e 5.41 apresentam as energias e RMSDs médios.

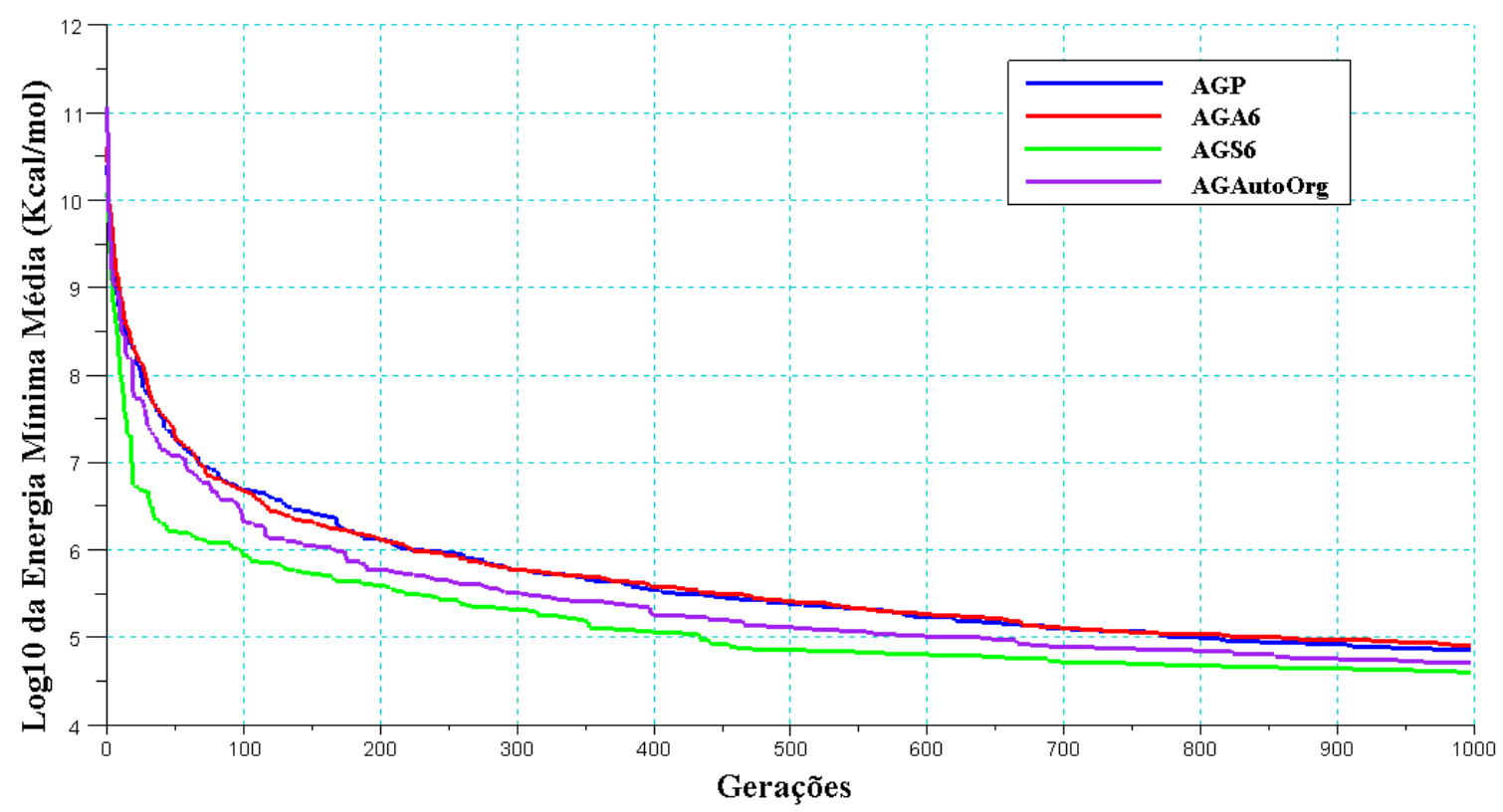

Figura 5.40: Média dos fitness mínimos ao longo das gerações para a 1ENH com modelo full-atom. 


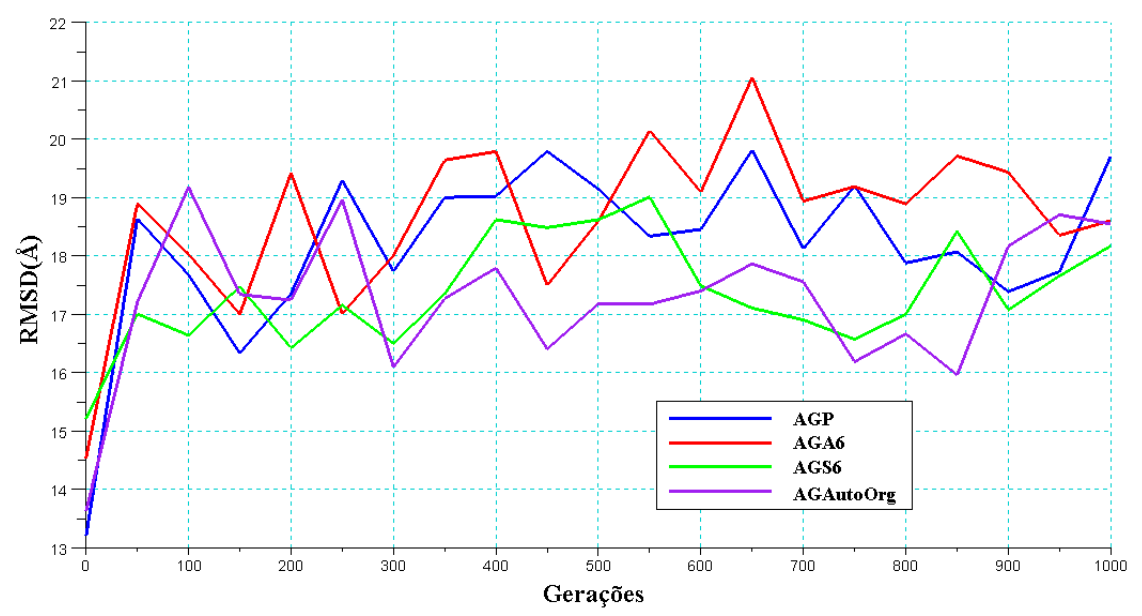

Figura 5.41: Média dos RMSDs ao longo das gerações para a 1ENH com modelo full-atom.

O teste estatístico de Wilcoxon é mostrado na Tabela 5.32.

\begin{tabular}{|c|c|c|c|}
\hline & AGA6 & $\begin{array}{c}\text { p-valor } \\
\text { AGS6 }\end{array}$ & AGAutoOrg \\
\hline$\overline{\mathrm{AGP}}$ & $0,8457(-)$ & $0,08398(+)$ & $0,1934(+)$ \\
\hline
\end{tabular}

Tabela 5.32: Teste de Wilcoxon para a 1ENH com modelo full-atom.

De acordo com a Tabela 5.32, podemos observar que não houve diferença significativa entre os algoritmos.

A Figura 5.42 mostra as estruturas com menor energia e com menor RMSD geradas.

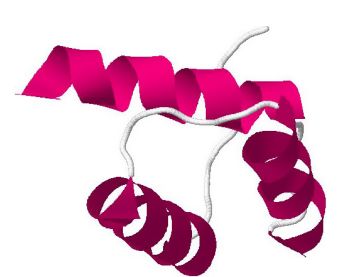

(a) Nativa $(3,01 \mathrm{kcal} /-$ mol)

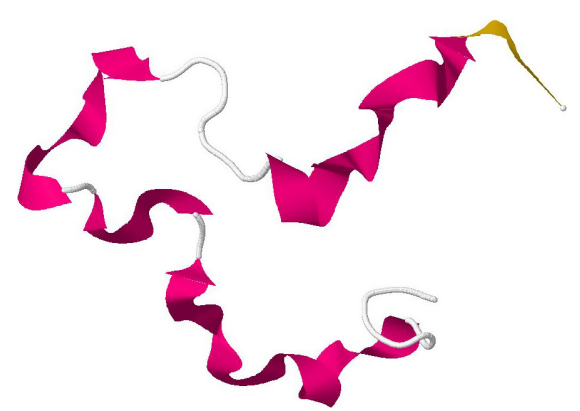

(b) Menor Energia $(1,88 \mathrm{E}+04 \mathrm{kcal} /-$ mol)

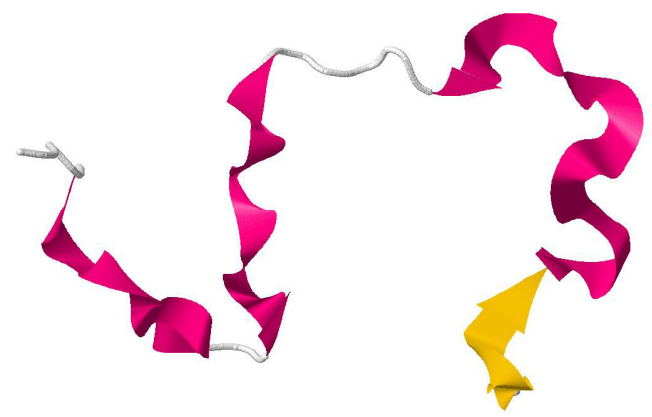

(c) Menor RMSD $(1,80 \mathrm{E}+05 \mathrm{kcal} / \mathrm{mol})$

Figura 5.42: Estruturas preditas de menor e Energia e menor RMSD para a 1ENH com modelo full-atom.

Podemos observar, na Figura 5.42, discordância entre as estruturas preditas e a nativa. 


\subsubsection{Proteína G (2GB1)}

Os resultados para a 2GB1 são apresentados a seguir.

\begin{tabular}{c||cccc}
\multirow{2}{*}{ Algoritmo } & Média \pm Desvio Padrão & $\begin{array}{c}\text { Energia kcal/mol } \\
\text { Mediana }\end{array}$ & Mínimo & Máximo \\
\hline \hline AGP & $2,82 \mathrm{E}+04 \pm 1,20 \mathrm{E}+04$ & $2,75 \mathrm{E}+04$ & $\mathbf{8 , 3 9 E + 0 3}$ & $5,48 \mathrm{E}+04$ \\
\hline AGA6 & $5,62 \mathrm{E}+04 \pm 6,09 \mathrm{E}+04$ & $3,85 \mathrm{E}+04$ & $2,45 \mathrm{E}+04$ & $2,27 \mathrm{E}+05$ \\
\hline AGS6 & $\mathbf{2 , 2 2 E + 0 4} \pm 6,07 \mathrm{E}+03$ & $\mathbf{2 , 2 2 E + 0 4}$ & $1,20 \mathrm{E}+04$ & $\mathbf{3 , 3 5 E + 0 4}$ \\
\hline AGAutoOrg & $2,39 \mathrm{E}+04 \pm 7,70 \mathrm{E}+03$ & $2,27 \mathrm{E}+04$ & $1,19 \mathrm{E}+04$ & $3,87 \mathrm{E}+04$ \\
\hline
\end{tabular}

Tabela 5.33: Energias para a 2GB1 com modelo full-atom.

A Tabela 5.33 mostra que a menor energia média foi obtida pelo AGS6, enquanto que a energia mínima foi obtida para o AGP.

\begin{tabular}{c||cccc}
\multirow{2}{*}{ Algoritmo } & Média \pm Desvio Padrão & $\begin{array}{c}\text { RMSD } \\
\text { Mediana }\end{array}$ & Mínimo & Máximo \\
\hline \hline AGP & $\mathbf{1 9 , 4 7} \pm 5,01$ & $\mathbf{1 8 , 6 8}$ & $\mathbf{1 2 , 9 7}$ & 28,40 \\
\hline AGA6 & $20,26 \pm 2,31$ & 20,02 & 16,22 & $\mathbf{2 3 , 8 4}$ \\
\hline AGS6 & $19,61 \pm 2,31$ & 19,69 & 15,90 & 23,88 \\
\hline AGAutoOrg & $20,17 \pm 4,18$ & 19,71 & 16,06 & 26,40 \\
\hline
\end{tabular}

Tabela 5.34: RMSD para a 2GB1 com modelo full-atom.

Segundo a Tabela 5.34, o menor RMSD médio, assim como o mínimo foram obtidos para o AGP. No entanto os valores foram altos em geral.

As figuras 5.43 e 5.44 apresentam as energias e RMSDs médios.

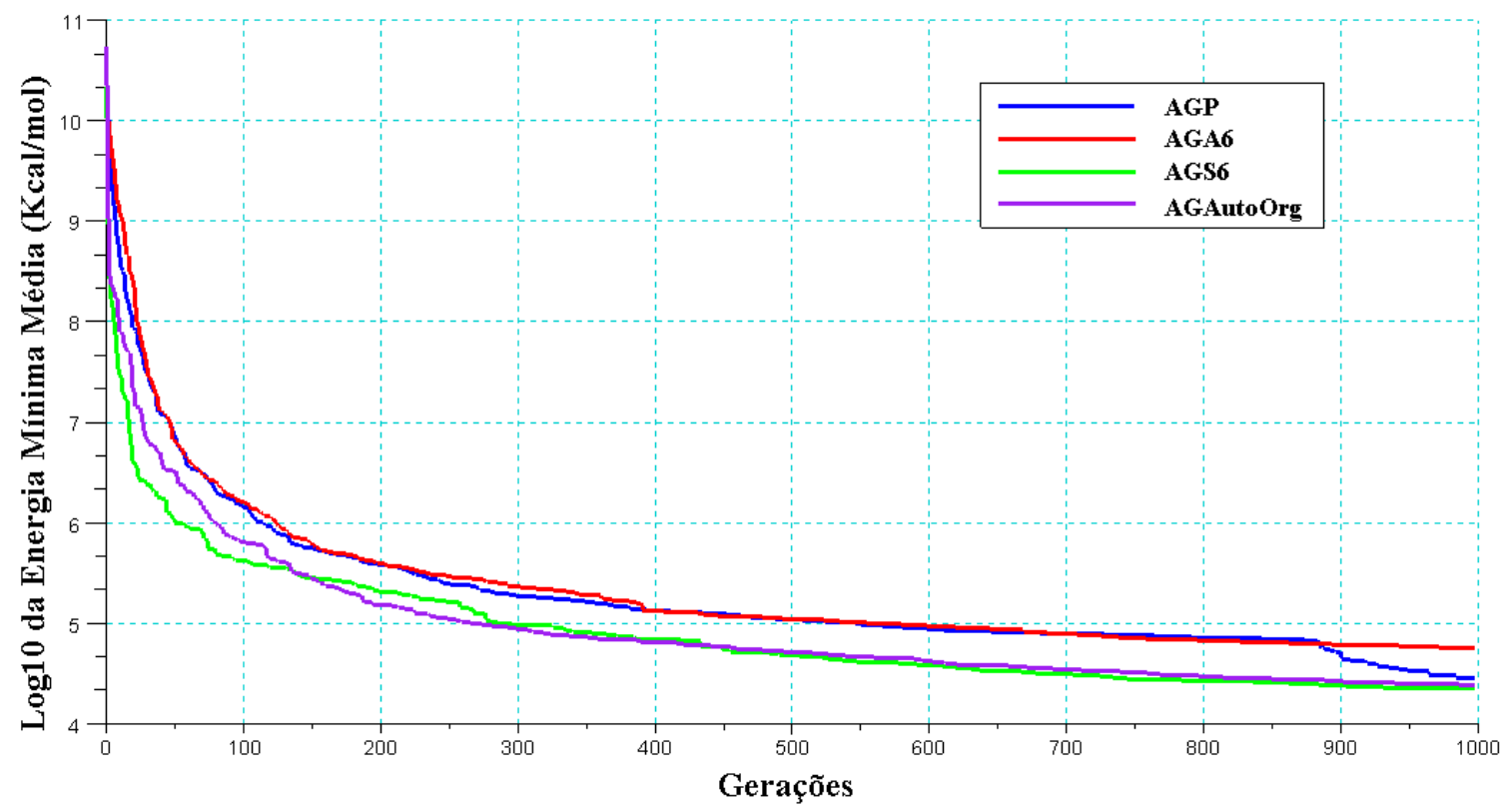

Figura 5.43: Média dos fitness mínimos ao longo das gerações para a 2GB1 para o modelo full-atom. 
De acordo com a Figura 5.43, nota-se que a energia apresenta queda acentuada no início da simulação.

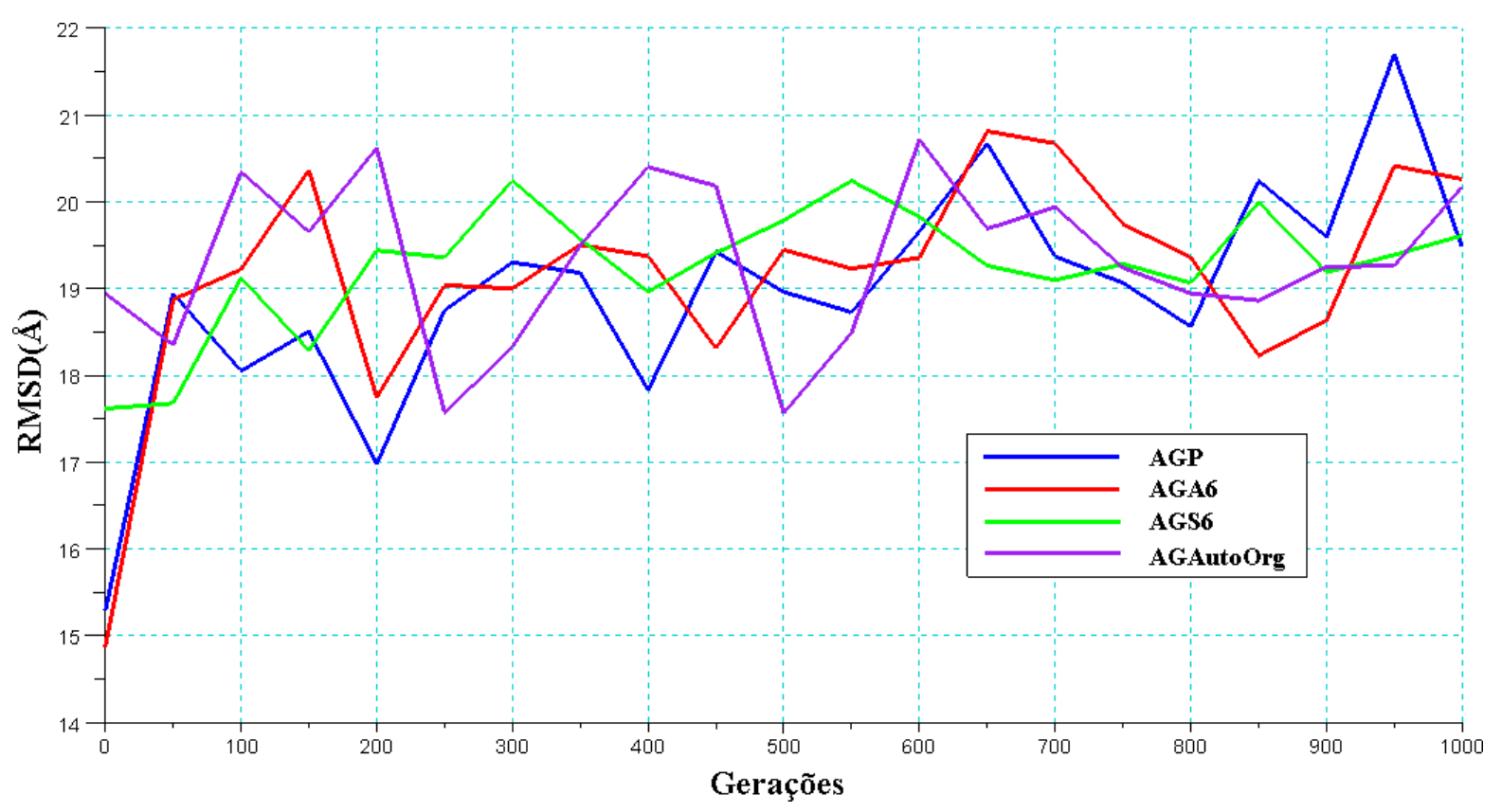

Figura 5.44: Média dos RMSDs ao longo das gerações para a 2GB1 para o modelo full-atom.

O teste estatístico de Wilcoxon é mostrado na Tabela 5.35.

\begin{tabular}{c||ccc} 
& \multicolumn{3}{c}{ p-valor } \\
& AGA6 & AGS6 & AGAutoOrg \\
\hline \hline AGP & $0.1055(-)$ & $0.3223(+)$ & $0.2324(+)$
\end{tabular}

Tabela 5.35: Teste de Wilcoxon para a 2GB1 com modelo full-atom.

De acordo com a Tabela 5.35, podemos observar que não houve diferença significativa entre os algoritmos.

A Figura 5.45 mostra as estruturas com menor energia e com menor RMSD geradas.

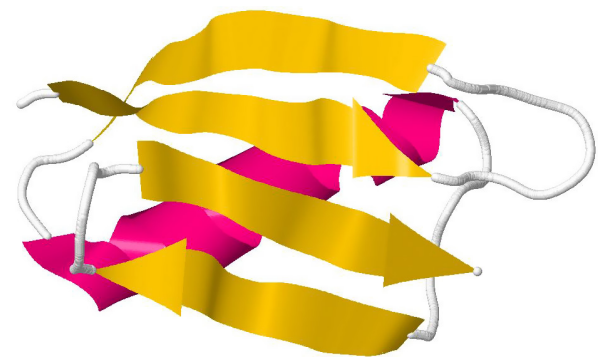

(a) Nativa $(1,77 \mathrm{E}+02 \mathrm{kcal} / \mathrm{mol})$

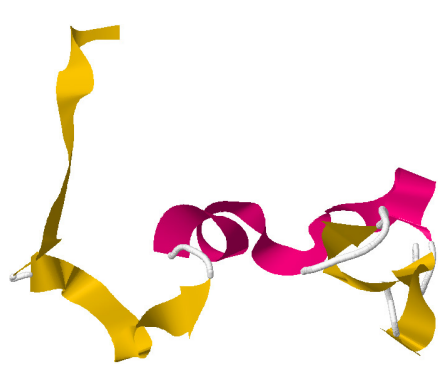

(b) Menor Energia $(8,39 \mathrm{E}+3$ $\mathrm{kcal} / \mathrm{mol}$ )

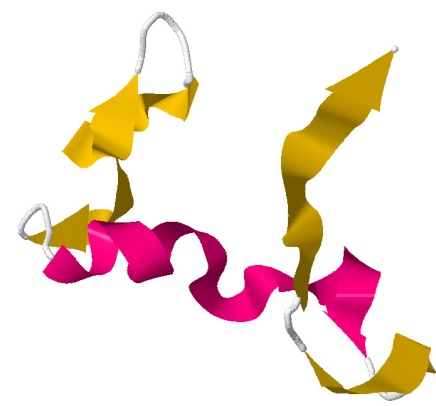

(c) Menor RMSD $(2,61 \mathrm{E}+04$ $\mathrm{kcal} / \mathrm{mol}$ )

Figura 5.45: Estruturas preditas de menor e energia e menor RMSD para a 2GB1 com modelo full-atom. 
Na Figura 5.45 podemos observar discordância entre as estruturas preditas e a nativa.

O comportamento das taxas de imigrantes do AGAutoOrg, a energia e o RMSD, para a primeira execução, são apresentadas a seguir.

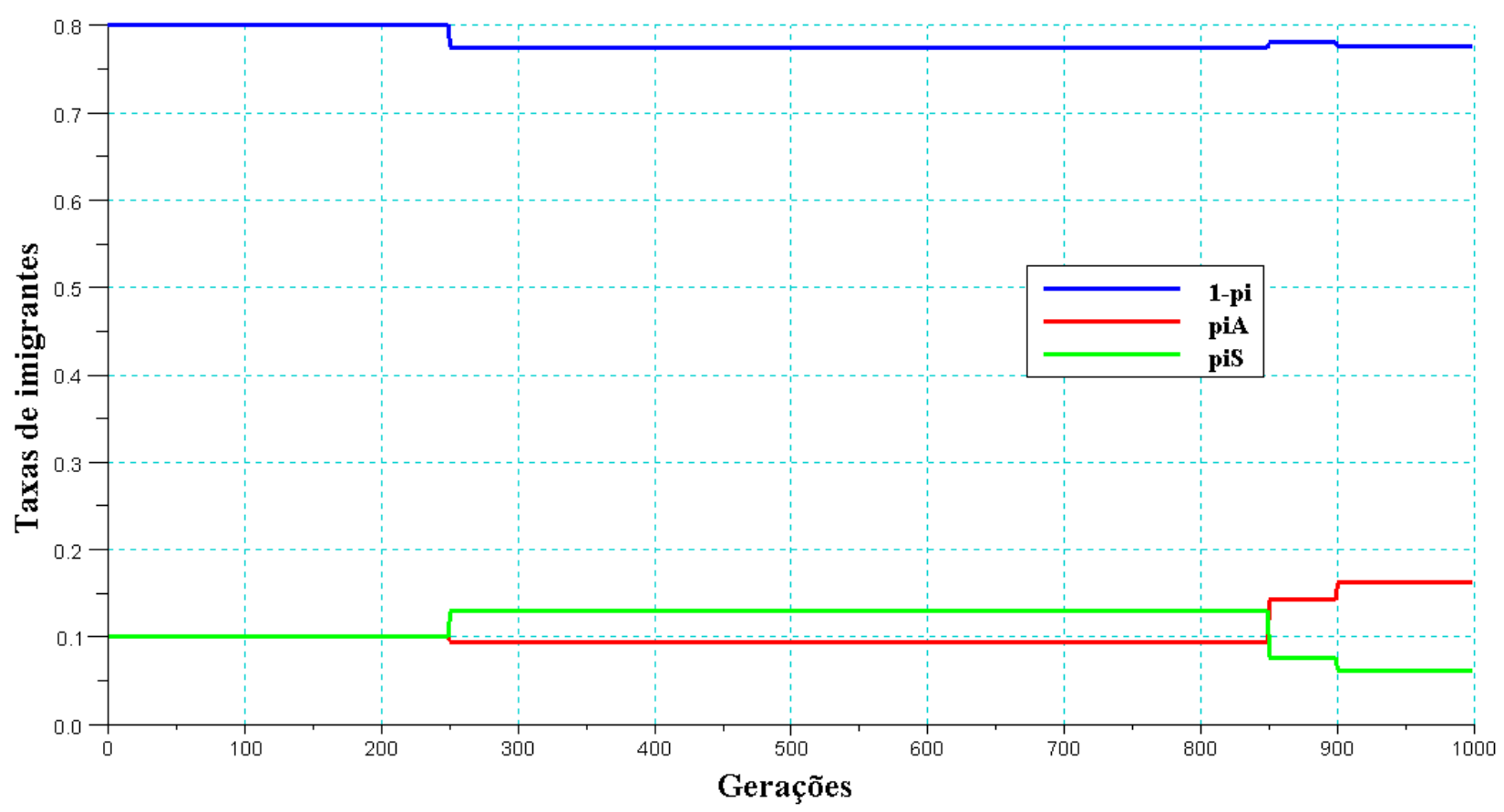

Figura 5.46: Variação das taxas de imigrantes para a $2 G B 1$.

A Figura 5.46 mostra que as taxas ao final da simulação são $77,52 \%$ população, $16,28 \%$ imigrantes aleatórios e $6,19 \%$ por similaridade.

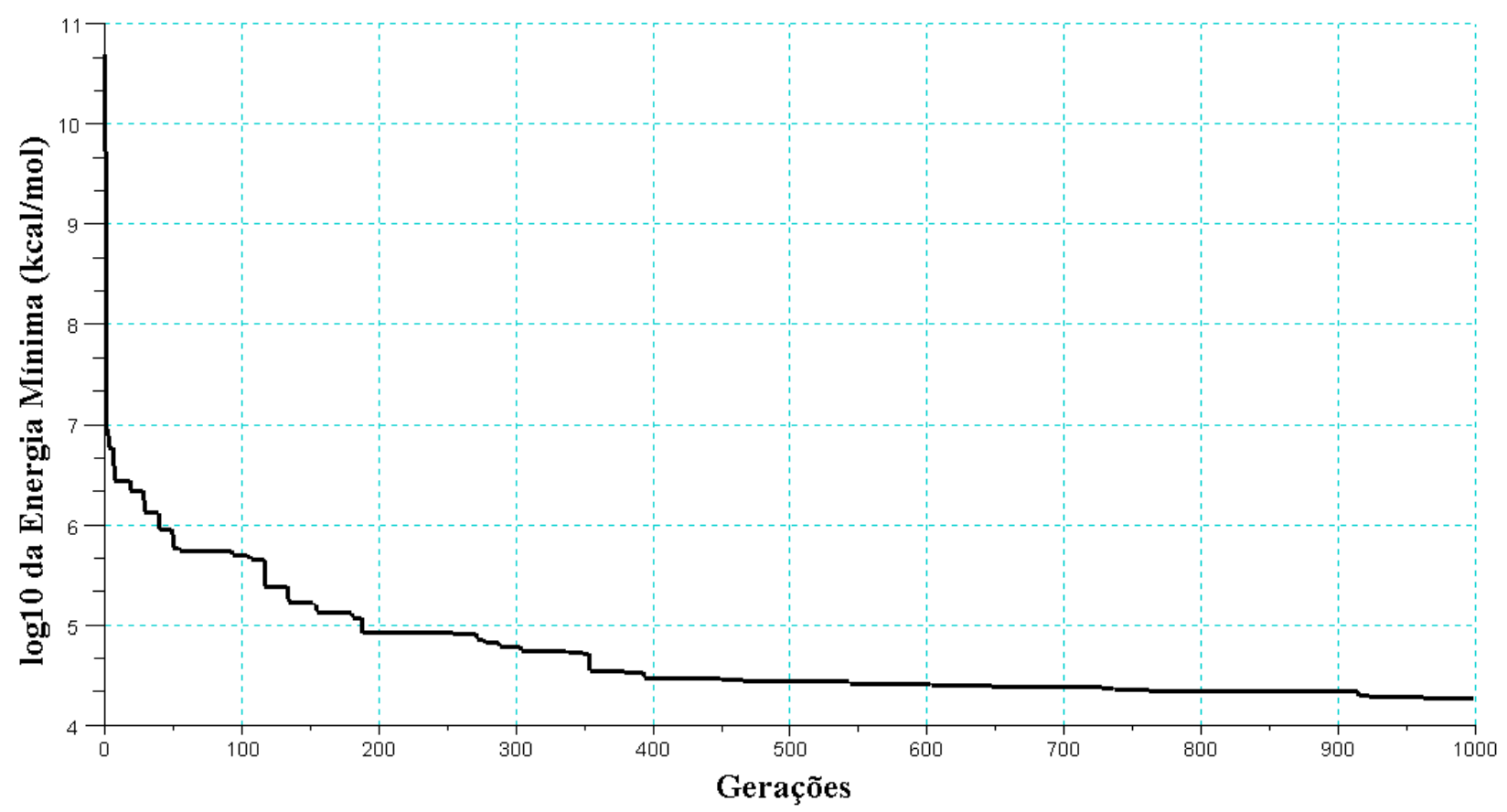

Figura 5.47: Energia para a primeira execução do AGAutoOrg. 


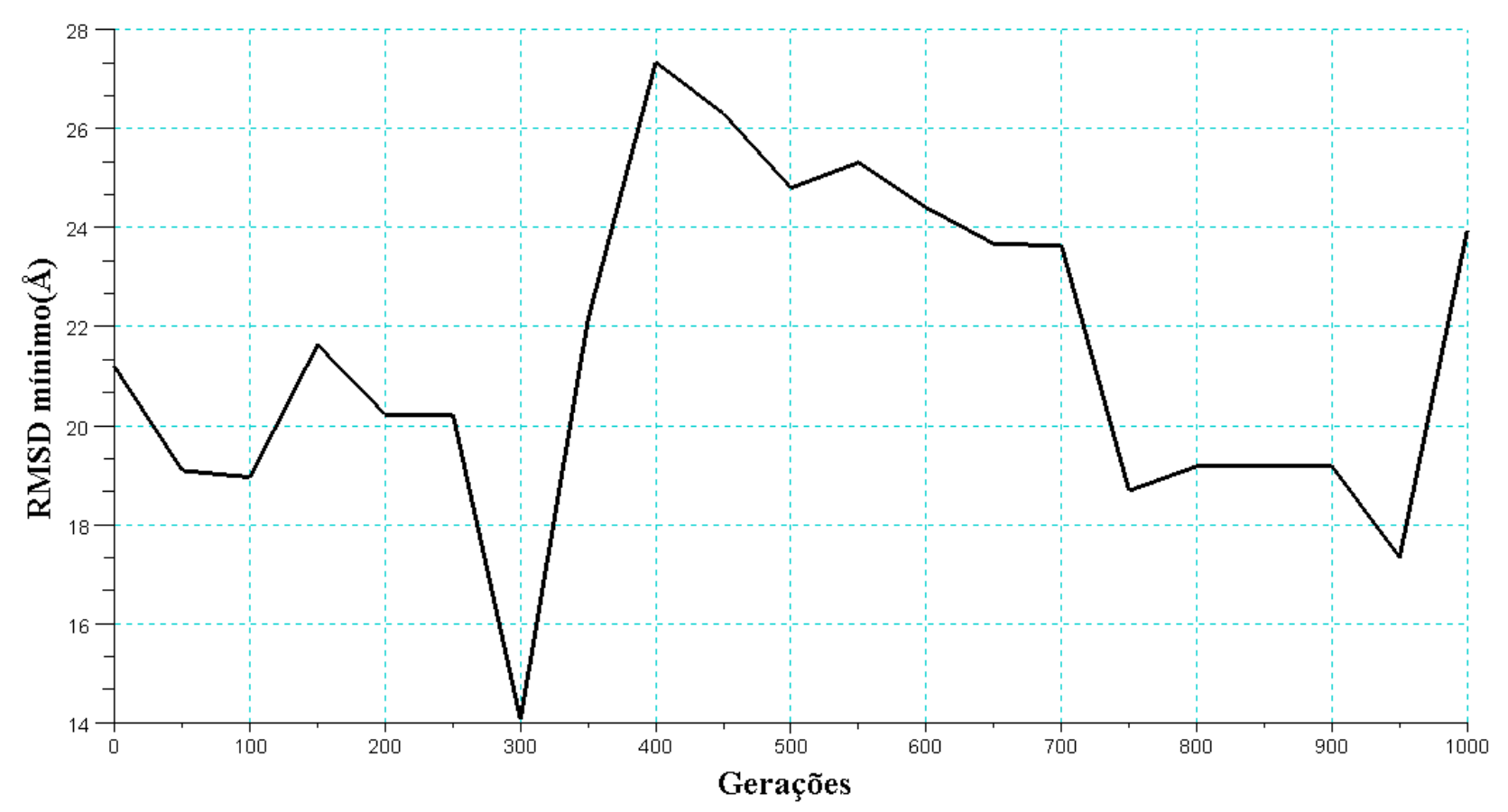

Figura 5.48: RMSD para a primeira execução do AGAutoOrg.

\subsubsection{Proteína Fosfatase (2W4P)}

A seguir os resultados para a proteína 2W4P.

\begin{tabular}{c||cccc}
\multirow{2}{*}{ Algoritmo } & Média \pm Desvio Padrão & $\begin{array}{c}\text { Energia kcal/mol } \\
\text { Mediana }\end{array}$ & Mínimo & Máximo \\
\hline \hline AGP & $3,20 \mathrm{E}+06 \pm 4,39 \mathrm{E}+06$ & $1,98 \mathrm{E}+06$ & $8,70 \mathrm{E}+05$ & $1,54 \mathrm{E}+07$ \\
\hline AGA6 & $1,76 \mathrm{E}+06 \pm 1,03 \mathrm{E}+06$ & $\mathbf{1 , 3 9 E}+\mathbf{0 6}$ & $5,73 \mathrm{E}+05$ & $4,04 \mathrm{E}+06$ \\
\hline AGS6 & $6,01 \mathrm{E}+06 \pm 3,45 \mathrm{E}+06$ & $5,28 \mathrm{E}+06$ & $2,38 \mathrm{E}+06$ & $1,31 \mathrm{E}+07$ \\
\hline AGAutoOrg & $\mathbf{1 , 6 7 E + 0 6} \pm 1,03 \mathrm{E}+06$ & $1,63 \mathrm{E}+06$ & $\mathbf{1 , 8 4 E + 0 5}$ & $\mathbf{3 , 2 1 E + 0 6}$ \\
\hline
\end{tabular}

Tabela 5.36: Energias para a 2 W4P com modelo full-atom.

A Tabela 5.36 mostra que a energia mínima e média foi obtida pelo AGAutoOrg.

\begin{tabular}{c||cccc}
\multirow{2}{*}{ Algoritmo } & \multirow{4}{*}{ Média \pm Desvio Padrão } & $\begin{array}{c}\text { RMSD } \\
\text { Mediana }\end{array}$ & Mínimo & Máximo \\
\hline \hline AGP & $30,90 \pm 4,31$ & 30,48 & 24,65 & 40,26 \\
\hline AGA6 & $32,57 \pm 5,91$ & 31,80 & 22,62 & 42,81 \\
\hline AGS6 & $29,12 \pm 6,08$ & 29,23 & $\mathbf{2 1 , 0 5}$ & 40,91 \\
\hline AGAutoOrg & $\mathbf{2 8 , 3 5} \pm 4,28$ & $\mathbf{2 7 , 8 5}$ & 22,92 & $\mathbf{3 4 , 0 6}$ \\
\hline
\end{tabular}

Tabela 5.37: $R M S D$ para a $2 W 4 P$ com modelo full-atom.

Segundo a Tabela 5.37, o menor RMSD médio foi obtido para o AGAutoOrg, enquanto que o menor mínimo foi obtido para o AGS6. No entanto, os valores obtidos foram consideravelmente altos. 
As Figuras 5.49 e 5.50 apresentam as energias e RMSDs médios.

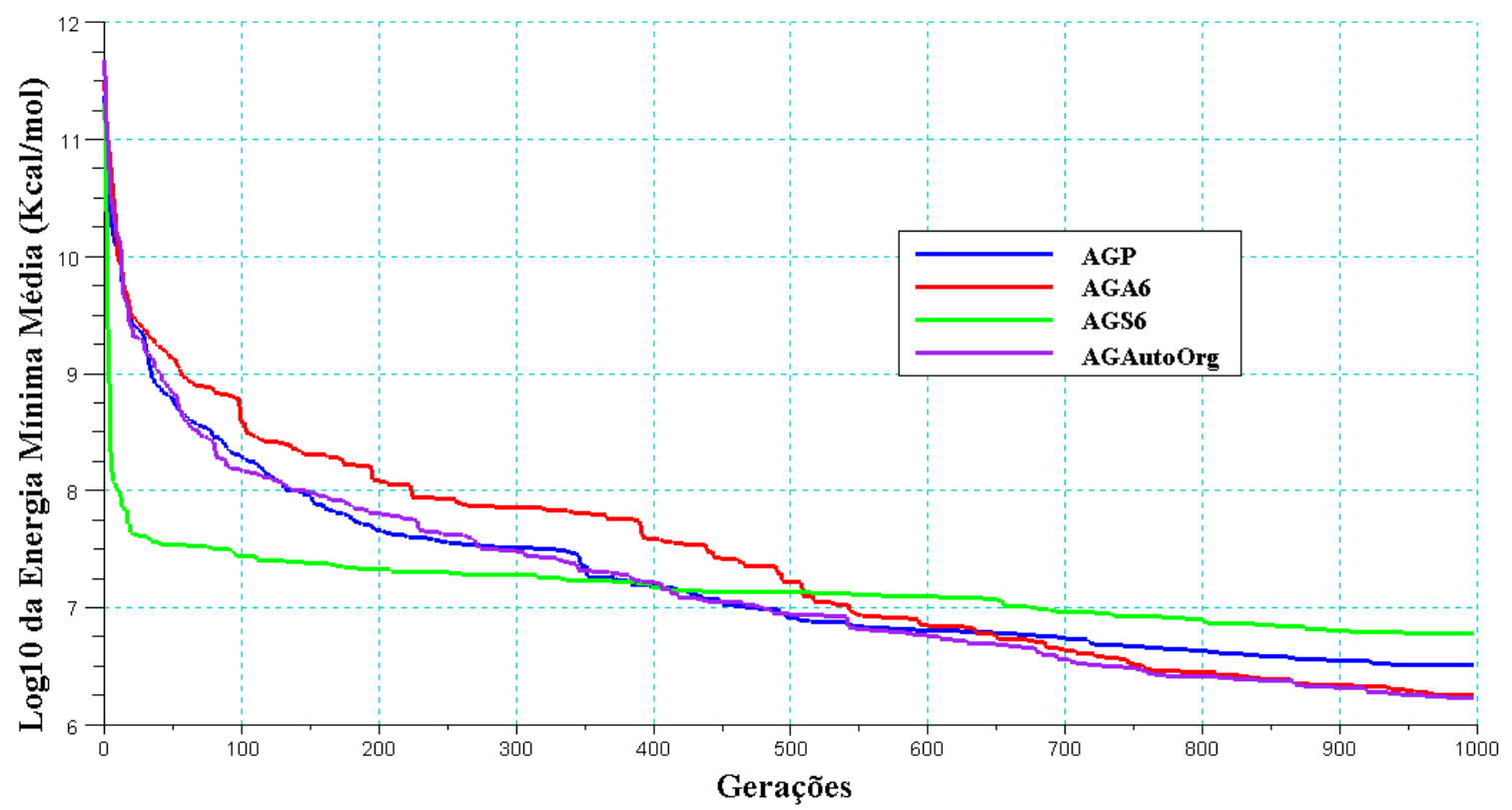

Figura 5.49: Média dos fitness mínimos ao longo das gerações para a 2 W4P com modelo full-atom.

De acordo com a Figura 5.49, observa-se que a energia decai constantemente ao longo das gerações.

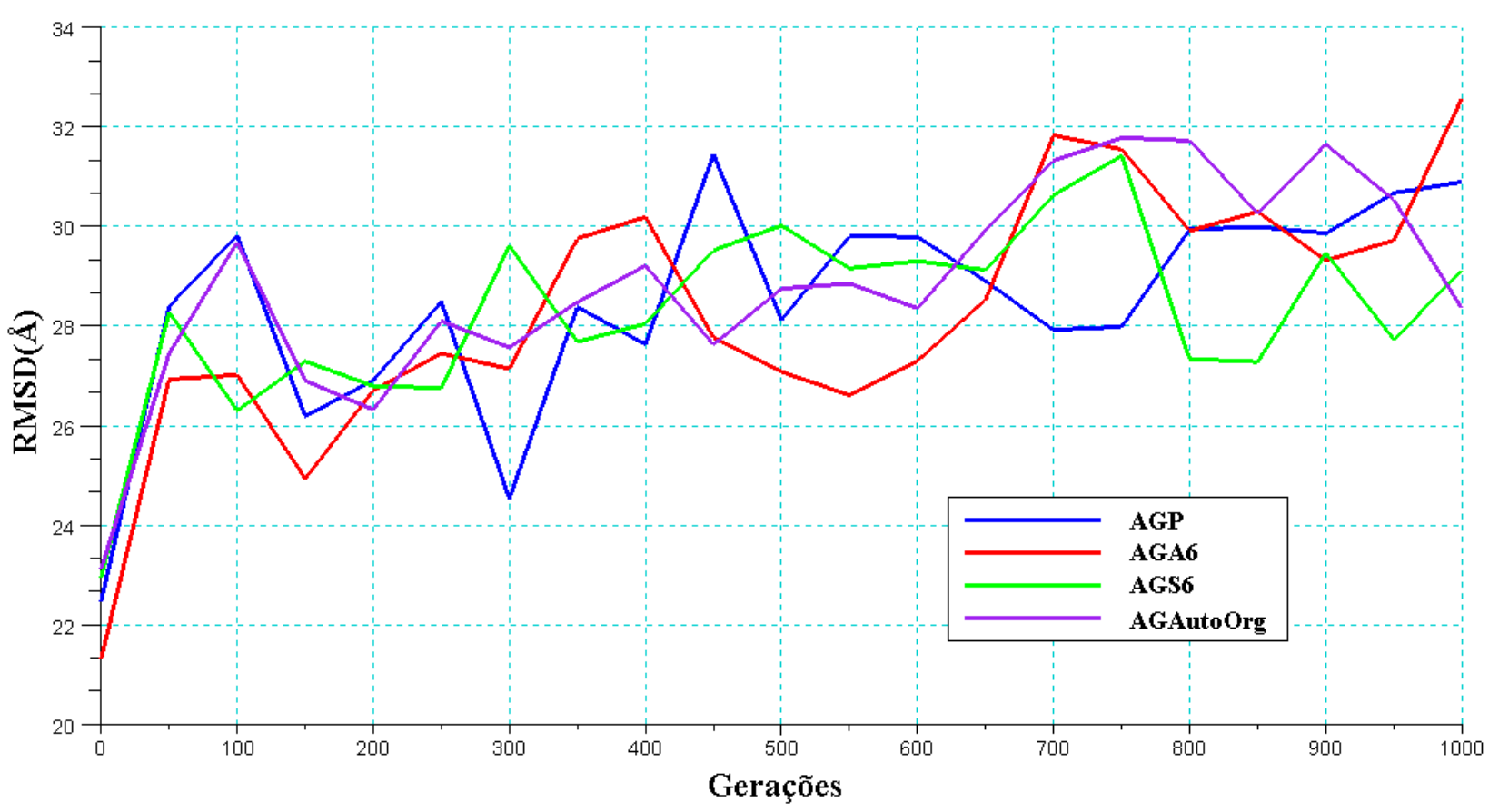

Figura 5.50: Média dos RMSDs ao longo das gerações para a 2W4P com modelo full-atom.

O teste estatístico de Wilcoxon é mostrado na Tabela 5.38.

De acordo com a Tabela 5.38, podemos observar que não houve diferença significativa entre os algoritmos. 


\begin{tabular}{|c|c|c|c|}
\hline & AGA6 & $\begin{array}{c}\text { p-valor } \\
\text { AGS6 }\end{array}$ & AGAutoOrg \\
\hline AGP & $0.6250(-)$ & $0.0644(+)$ & $0.5566(+)$ \\
\hline
\end{tabular}

Tabela 5.38: Teste de Wilcoxon para a 2 W4P com modelo full-atom.

A Figura 5.51 mostra as estruturas com menor energia e com menor RMSD geradas.

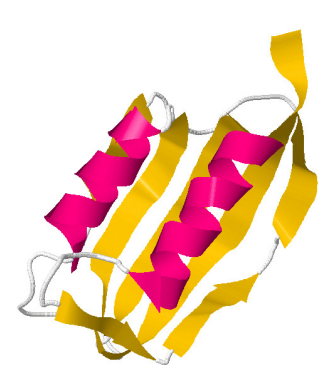

(a) Nativa ($2,00 \mathrm{E}+02 \mathrm{kcal} / \mathrm{mol})$

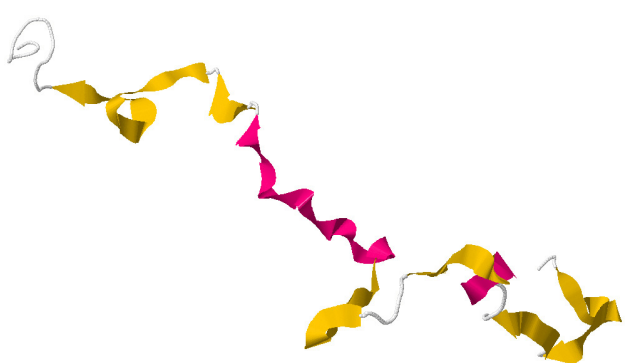

(b) Menor Energia $(1,84 \mathrm{E}+05 \mathrm{kcal} / \mathrm{mol})$

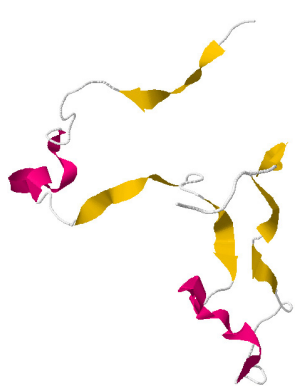

(c) Menor RMSD $(8,44 \mathrm{E}+06 \mathrm{kcal} / \mathrm{mol})$

Figura 5.51: Estruturas preditas de menor energia e menor RMSD para a $2 W 4 P$ com modelo full-atom.

Na Figura 5.51 podemos observar discordância entre as estruturas preditas e a nativa. Neste caso, a energia da 2W4P nativa foi de $-200,43 \mathrm{Kcal} / \mathrm{mol}$, de 1,84E+05 Kcal/mol para a estrutura de menor energia e de $8,44 \mathrm{E}+06 \mathrm{Kcal} / \mathrm{mol}$ para a estrutura de menor RMSD.

O comportamento das taxas de imigrantes do AGAutoOrg, a energia e o RMSD, para a primeira execução, são apresentadas a seguir. 


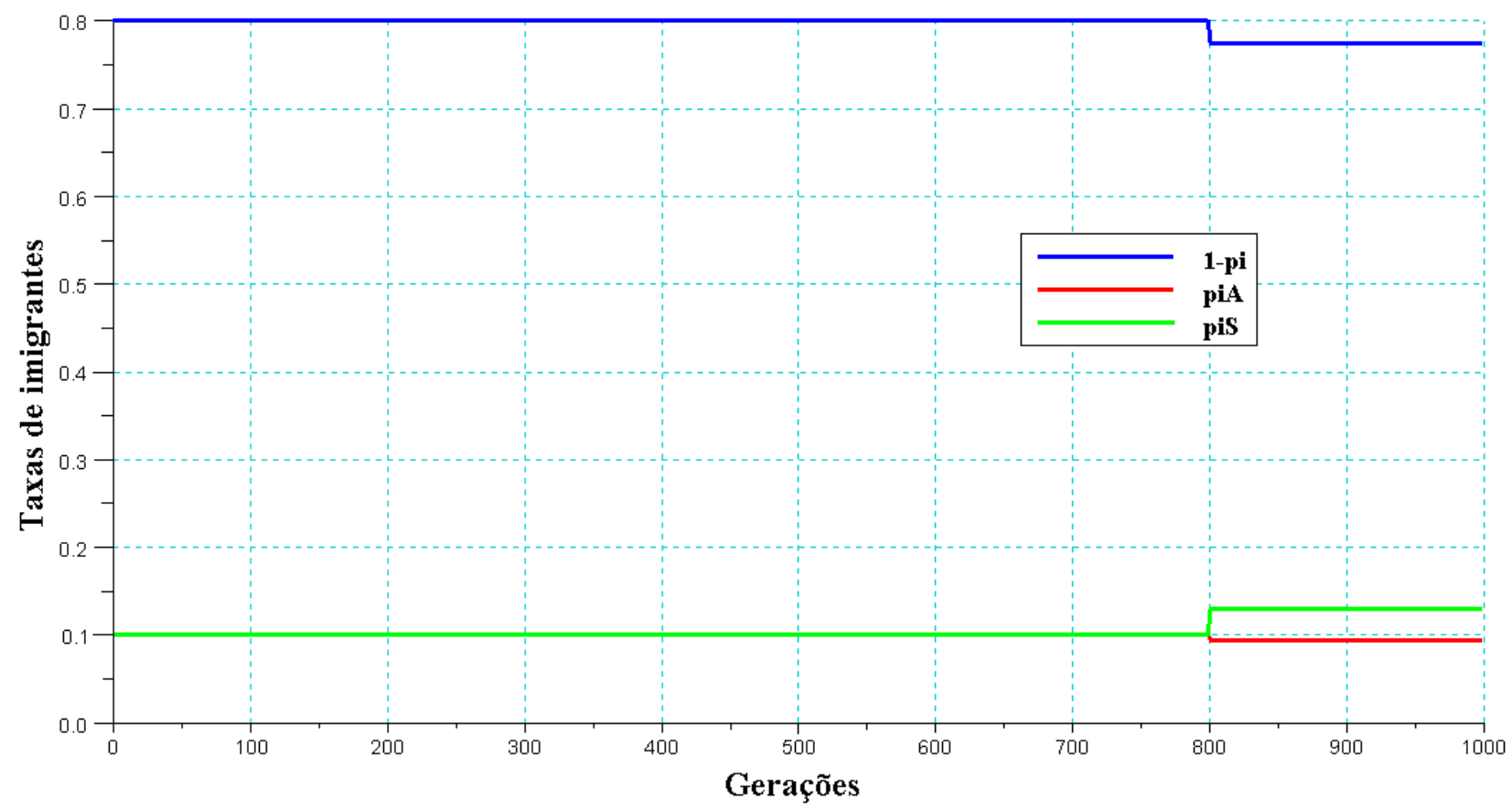

Figura 5.52: Variação das taxas de imigrantes para a $2 W 4 P$.

A Figura 5.46 mostra que as taxas ao final da simulação são $78,05 \%$ população, $14,33 \%$ imigrantes aleatórios e 7,62\% por similaridade.

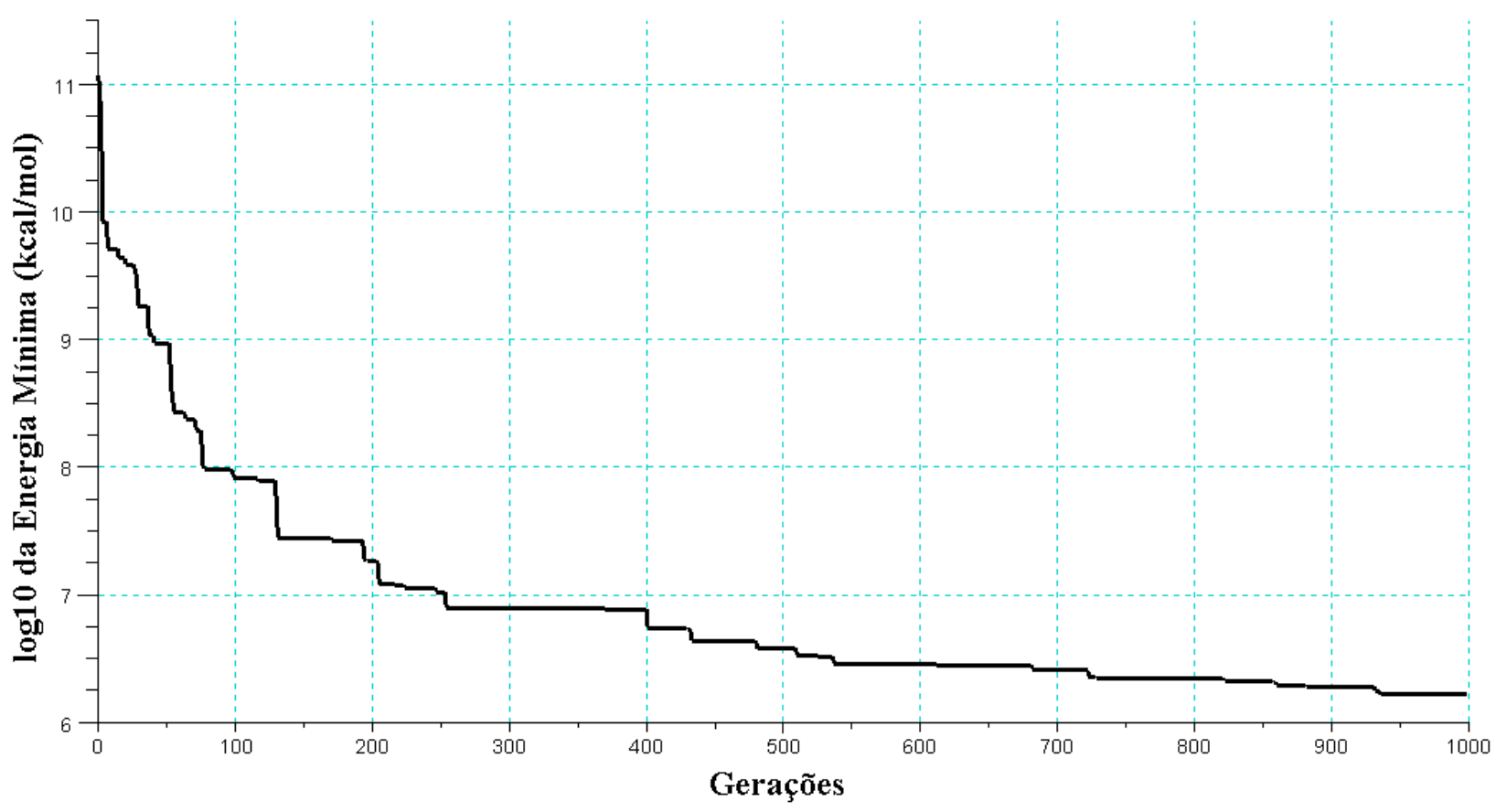

Figura 5.53: Energia para a primeira execução do AGAutoOrg. 


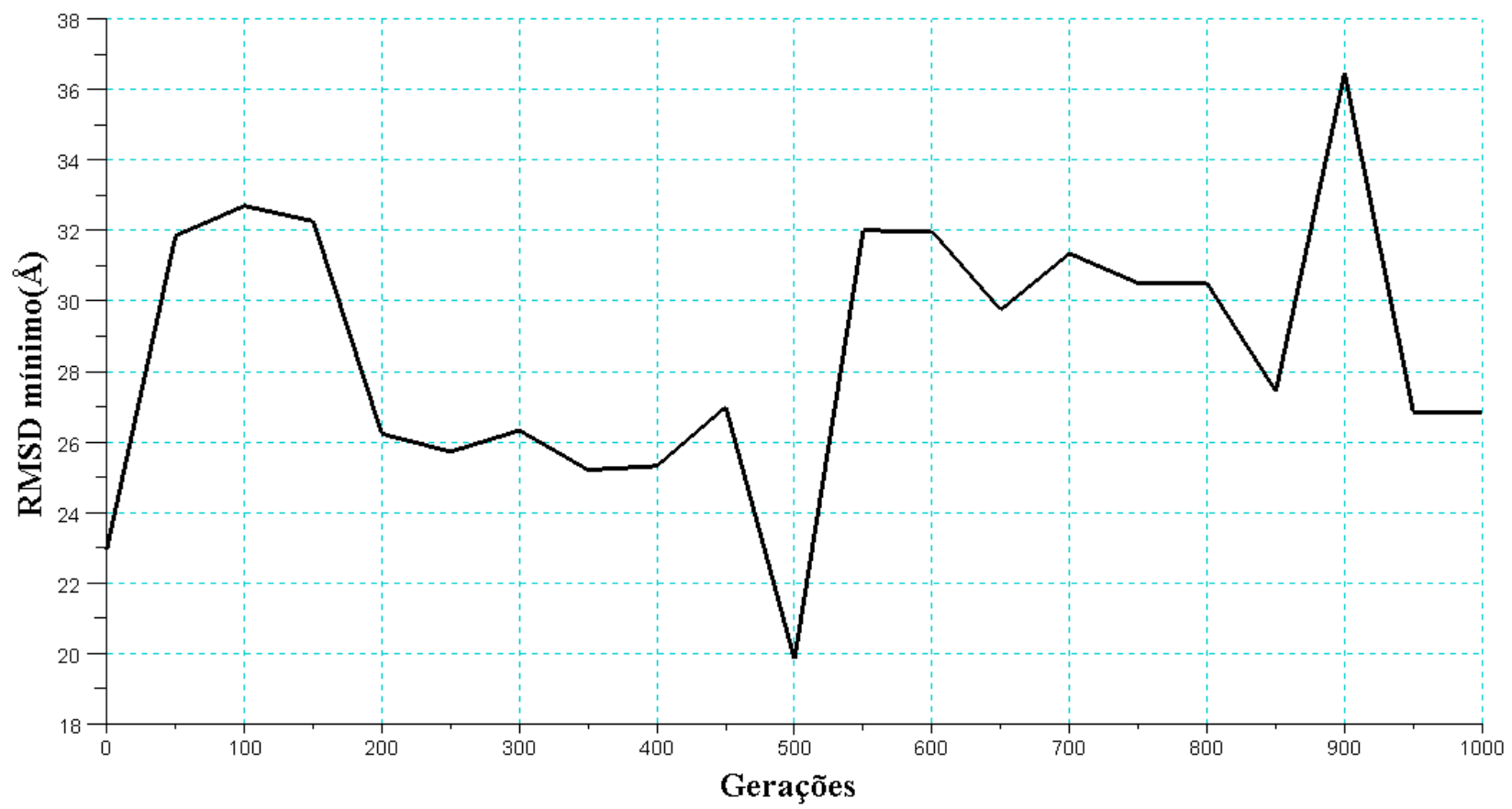

Figura 5.54: RMSD para a primeira execução do AGAutoOrg. 


\subsection{Análise dos resultados obtidos}

Nesta seção os experimentos serão analisados inicialmente separadamente, e posteriormente em conjunto.

\subsubsection{Experimento 1}

Este experimento foi realizado para verificar o comportamento do campo de força $\mathrm{CG}$ descrito em [Yap et al., 2008] para PEP via AGs com a codificação fornecida no artigo para a estrutura secundária. Essa codificação classifica as regiões de dobra em quatro tipos (T, P, Q e U), tornando-as mais rígidas.

Nos resultados obtidos, a menor energia mediana foi obtida pelo AGS6 e a menor energia mínima e média foi obtida pelo o AGA6, enquanto que o menor RMSD também foi obtido pelo AGS6. Contudo não foi verificada diferença estatística significativa entre o AGP e os demais algoritmos para nível de significância de 5\%.

As estruturas geradas apresentam as fitas- $\beta$ desalinhadas e separadas sem formar folhas. Em [Yap et al., 2008], este modelo foi utilizado para o dobramento proteico e obteve estruturas semelhantes à nativa. Contudo, deve-se considerar que as simulações, neste caso, iniciam-se de conformações próximas da nativa.

O principal problema encontrado na utilização do modelo CG (Experimentos 1 e 2) foi sua dificuldade de distinguir entre algumas estruturas distantes da estrutura nativa. A Tabela 5.39 evidencia essa característica.

\begin{tabular}{c|cc} 
Componente & $\begin{array}{c}\text { Energia } \epsilon_{h} \\
\text { 1A11 Nativa }\end{array}$ & AGP Última Geração (Exp. 2) \\
\hline \hline EAL & 4,39 & 2,63 \\
\hline EAD & 58,27 & 49,08 \\
\hline EVdW & $-8,27$ & $-25,71$ \\
\hline EPh & 3,74 & 0,25 \\
\hline ETotal & 58,13 & 26,24 \\
\hline
\end{tabular}

Tabela 5.39: Termos de Energia para a $1 A 11$ pelo modelo $C G$.

A Tabela 5.39 mostra que os termos de energia obtidos pelo modelo CG para a proteína predita são todos menores que os observados para a proteína nativa, neste caso a 1A11. O mesmo comportamento foi observado para todas as proteínas testadas.

Essa característica do modelo CG é um problema para a estratégia de inserção de similaridade, uma vez que as estruturas similares podem apresentar energia maior em algumas soluções obtidas pelo AGP. Dessa forma, os imigrantes gerados por similaridade se perdem ao longo das gerações, não auxiliando no processo de busca. Esse problema acaba incidindo no desempenho dos algoritmos que utilizam a similaridade. 
Esses resultados concordam com a afirmação contida em [Tozzini, 2005], de que modelos de 1 bead, frequentemente, possuem dependência da configuração inicial, devido a dificuldade de representar características mais gerais dos aminoácidos com poucos parâmetros. Essa dependência faz com que os modelos de 1 bead possuam um viés em direção à configuração inicial.

Em suma, o Experimento 1 (e mesmo o Experimento 2) evidenciou essa dependência da configuração inicial do modelo CG, pois, partindo de conformações geradas aleatoriamente e considerando o protocolo de simulação adotado neste trabalho, não se obteve estruturas com RMSD pequeno, assim como aquelas obtidas em [Yap et al., 2008] partindo de uma configuração próxima da nativa. O menor RMSD obtido no Experimento 1 foi de 12,10 ̊, enquanto que em [Yap et al., 2008] obteve-se um RMSD de $3,0 \AA$.

\subsubsection{Experimento 2}

No Experimento 2, optou-se por utilizar predição de estrutura secundária, uma vez que a codificação empregada no Experimento 1, a qual foi fornecida em [Yap et al., 2008] não estava disponível para todas as proteínas, isso porque os preditores de estrutura secundária normalmente não classificam por tipos as regiões de dobras. Usar um preditor é um precedente mais realista, já que, obviamente, em proteínas em que a PEP deve ser empregada, não se conhece $a$ priori a estrutura secundária.

Observando os Experimentos 1 e 2, podemos notar que para a 2GB1, mesmo utilizando um preditor de estrutura secundária, os resultados obtidos foram compatíveis.

A similaridade do alinhamento de cada proteína que pode ser expresso pelo score e e-value do algoritmo Blast. Na Tabela 5.40 são exibidos os valores máximos obtidos.

\begin{tabular}{c||cc} 
Proteína & Score & $e$-value \\
\hline \hline 1A11 & 78,7 & $2 \mathrm{e}-16$ \\
2K98 & 73,2 & $1 \mathrm{e}-14$ \\
1ENH & 108 & $8 \mathrm{e}-25$ \\
2GB1 & 113 & $2 \mathrm{e}-26$ \\
2W4P & 204 & $1 \mathrm{e}-53$
\end{tabular}

Tabela 5.40: Máximo Score e e-value obtidos pelo Blast para as proteínas utilizadas.

Observa-se pela Tabela 5.40 que o Score máximo encontrado é maior para as proteínas maiores. A proteína que possui menor Score máximo é a 2 K98.

Os resultados obtidos no Experimento 2 são sintetizadas nas tabelas a seguir, onde pode-se observar o ranking das melhores medianas (Tabela 5.41) e dos melhores RMSDs (Tabela 5.42) de acordo com a proteína. Desse modo, cada algoritmo recebeu uma pontuação de 1 até 4 , onde 1 representa que ele obteve a melhor mediana e 4 a pior mediana. 


\begin{tabular}{|c|c|c|c|c|}
\hline \multirow[t]{2}{*}{ Proteína } & \multicolumn{3}{|c|}{ Algoritmos } & \multirow[b]{2}{*}{ AGAutoOrg } \\
\hline & AGP & AGA6 & AGS6 & \\
\hline 1A11 & 3 & $\overline{1}$ & 4 & 2 \\
\hline $2 \mathrm{~K} 98$ & 1 & 4 & 3 & 2 \\
\hline $1 \mathrm{ENH}$ & 2 & 1 & 3 & 4 \\
\hline 2GB1 & 1 & 3 & 2 & 4 \\
\hline $2 \mathrm{~W} 4 \mathrm{P}$ & 4 & 3 & 2 & 1 \\
\hline
\end{tabular}

Tabela 5.41: Ranking dos algoritmos com CG que obtiveram menor energia mediana no Experimento 2.

Conforme já discutido no Experimento 1, a dificuldade do modelo CG em distinguir conformações distantes da nativa ocasiona a perda dos indivíduos gerados por similaridade. Neste Experimento 2, em geral, não foi verificada a diferença estatística significativa entre os algoritmos.

A Tabela 5.41 mostra que, com exceção da 2W4P, a maior proteína, para as demais proteínas os algoritmos que obtiveram a melhor mediana (posição 1 no ranking) foram sempre o AGP ou AGA6. Já para a 2W4P, a situação se inverte e as melhores mediana foram obtidas pelos algoritmos que utilizam similaridade AGS6 e AGAutoOrg.

\begin{tabular}{|c|c|c|c|c|}
\hline \multirow[t]{2}{*}{ Proteína } & \multicolumn{3}{|c|}{ Algoritmos } & \multirow[b]{2}{*}{ AGAutoOrg } \\
\hline & AGP & AGA6 & AGS6 & \\
\hline 1A11 & 1 & 4 & 3 & 2 \\
\hline 2K98 & 2 & 3 & 1 & 4 \\
\hline $1 \mathrm{ENH}$ & 1 & 2 & 3 & 4 \\
\hline 2GB1 & 4 & 2 & 1 & 3 \\
\hline $2 \mathrm{~W} 4 \mathrm{P}$ & 1 & 4 & 2 & 3 \\
\hline
\end{tabular}

Tabela 5.42: Ranking dos algoritmos com CG que obtiveram menor RMSD no Experimento 2.

De acordo com a Tabela 5.42, os menores RMSDs foram obtidos pelo AGP e pelo AGS6. Essa discordância com a Tabela 5.41 mostra que as estruturas de menor energia não são as de menor RMSD.

\subsubsection{Experimento 3}

O Experimento 3 foi realizado com o modelo full-atom e foram adicionadas as cadeias laterais aumentando o número de variáveis do problema. Para que se pudesse empregar as mesmas populações geradas por similaridade, foi realizada uma otimização da cadeia lateral nos indivíduos obtidos por similaridade.

O ranking dos algoritmos que obtiveram melhores medianas e mínimos pode ser visto nas Tabelas 5.43 e 5.44 a seguir.

A Tabela 5.43 mostra que, no caso do modelo full-atom, os algoritmos AGA6, AGS6 e AGAutoOrg obtiveram as melhores medianas, ao contrário do que ocorreu para o 


\begin{tabular}{c||cccc}
\multicolumn{1}{c||}{ Proteína } & \multicolumn{5}{c}{$\begin{array}{c}\text { Algoritmos } \\
\end{array}$} & AGP & AGA6 & AGS6 & AGAutoOrg \\
\hline \hline 1A11 & 2 & $\mathbf{1}$ & 3 & 4 \\
2K98 & 4 & 2 & 3 & $\mathbf{1}$ \\
1ENH & 3 & 4 & $\mathbf{1}$ & 2 \\
2W4P & 3 & $\mathbf{1}$ & 4 & 2 \\
2GB1 & 3 & 4 & $\mathbf{1}$ & 2
\end{tabular}

Tabela 5.43: Ranking dos algoritmos com full-atom que obtiveram menor Energia no Experimento 3.

modelo CG. Isso ocorre, porque ao contrário do modelo CG, a distinção entre as conformações mais distantes da nativa é mais clara e as energias das estruturas preditas geradas pelo modelo são maiores que a energia da estrutura nativa quando avaliada pelo mesmo.

\begin{tabular}{|c|c|c|c|c|}
\hline \multirow[t]{2}{*}{ Proteína } & \multicolumn{3}{|c|}{ Algoritmos } & \multirow[b]{2}{*}{ AGAutoOrg } \\
\hline & AGP & AGA6 & AGS6 & \\
\hline $1 \mathrm{~A} 11$ & 3 & 4 & 2 & 1 \\
\hline 2K98 & 1 & 2 & 4 & 3 \\
\hline $1 \mathrm{ENH}$ & 4 & 1 & 2 & 3 \\
\hline $2 \mathrm{~W} 4 \mathrm{P}$ & 4 & 2 & 1 & 3 \\
\hline 2GB1 & 1 & 4 & 2 & 3 \\
\hline
\end{tabular}

Tabela 5.44: Ranking dos algoritmos com full-atom que obtiveram menor RMSD no Experimento 3.

Quanto aos RMSDs mínimos mostrados na Tabela 5.44, o AGAutoOrg obteve o menor RMSD apenas uma vez. Sendo que quanto aos demais algoritmos as posições encontram-se relativamente distribuídas.

No entanto, se considerarmos as primeiras e segundas posições, ou seja, valor 1 e 2 , podemos observar que o AGS6 não obteve as melhores colocações no ranking apenas para a 2K98, que é a proteína de menor score máximo (Ver Tabela 5.40).

Os imigrantes aleatórios (AGA6) são úteis, pois conseguem, eventualmente, inserir diversidade na população, o que é útil para fugir de ótimos locais. Neste caso, o AGA6 obteve duas segundas posições e uma primeira.

Observa-se também que os imigrantes por similaridade (AGS6) foram úteis especialmente nas estruturas maiores e com maior score no alinhamento. Quanto ao AGAutoOrg, seu desempenho inferior ao AGS6 pode ser explicado devido ao pequeno número de gerações empregado no experimento, que não é suficiente para que o algoritmo altere as taxas de forma benéfica.

\subsubsection{Comparação entre os experimentos}

Comparando os experimentos com e sem predição de estrutura secundária, pode-se observar que os que utilizaram o preditor obtiveram RMSDs compatíveis e as estru- 
turas preditas aparentam estar mais dobradas. No entanto, também deve se considerar que o número de gerações foi diferente. Uma das hipóteses para explicar esse resultado é que a classificação interna dos turns empregada por [Yap et al., 2008] deixa as estruturas mais rígidas, enquanto que a empregada em [Brown et al., 2003] permite maior flexibilidade, facilitando a dobra.

Quanto aos experimentos 2 e 3, observou-se que os RMSDs obtidos pelo modelo CG foram menores do que os obtidos pelo modelo full-atom. O menor custo computacional do modelo full-atom permitiu que um número maior de gerações fosse executado.

O AGS6 obteve os melhores resultados, considerando primeiros e segundos lugares, para a proteína $2 \mathrm{~GB} 1$ em ambos os modelos e para a proteína $2 \mathrm{~W} 4 \mathrm{P}$ para o modelo CG. Essas duas proteínas obtiveram maior score máximo no alinhamento (Tabela 5.40). Dessa forma, a inserção de similaridade foi útil.

Para ambos os modelos a predição de folhas- $\beta$ não ocorreu. No caso do modelo $\mathrm{CG}$, a distância entre os beads é grande e não ocasiona a formação de pontes de hidrogênio. Assim, a contribuição do termo ponte de hidrogênio é pequeno na equação de energia do modelo CG.

Os algoritmos AGA6 e AGAutoOrg obtiveram bons resultados para a 1A11, considerando ambos os modelos, o que indica que os imigrantes aleatórios foram úteis neste caso.

O AGAutoOrg, não obteve os resultados esperados em alguns casos, principalmente para o modelo CG. No caso do modelo full-atom, pode-se argumentar que o número de gerações foi insuficiente para houvesse mudanças benéficas das taxas, pois ocorreram alterações das taxas apenas para a 2GB1 e 2W4P. Nas demais proteínas as taxas não se alteraram durante a execução. Quando ao modelo CG, a estratégia auto-organizável, em geral, não foi boa. Uma possível explicação é que melhorar a diversidade não está sendo útil neste caso e o algoritmo está obtendo melhores resultados ao explorar a solução atual (AGP). Contudo, também deve-se ressaltar que, no caso do modelo CG, a inserção de similaridade (AGAutoOrg e AGS6) não obteve melhores resultados devido a dificuldade do modelo de avaliar soluções distantes da nativa, permitindo que algumas vezes indivíduos gerados na população inicial possuam energias menores que indivíduos similares à conformação nativa.

\subsubsection{Tempo Computational}

A seguir serão apresentados alguns gráficos referentes ao tempo computacional. Contudo, não será possível comparar todos os experimentos para todas as proteínas, já que os computadores utilizados possuíam configurações diferentes. Desse modo, serão exibidos apenas as comparações possíveis.

As Figuras 5.55 e 5.56 referem-se ao tempo computacional gasto pelo AGP, na exe- 
cução de 1000 gerações, para ambos os modelos e para as proteínas 1ENH (54 resíduos) e 2GB1 (56 resídudos), em um computador com quatro processadores (Intel $\mathbb{R}$

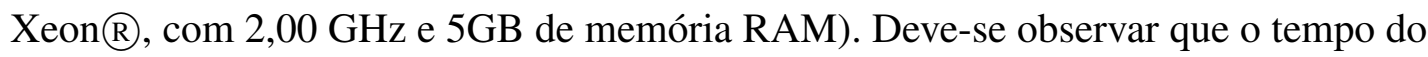
modelo CG está representado em minutos e o do full-atom em horas.

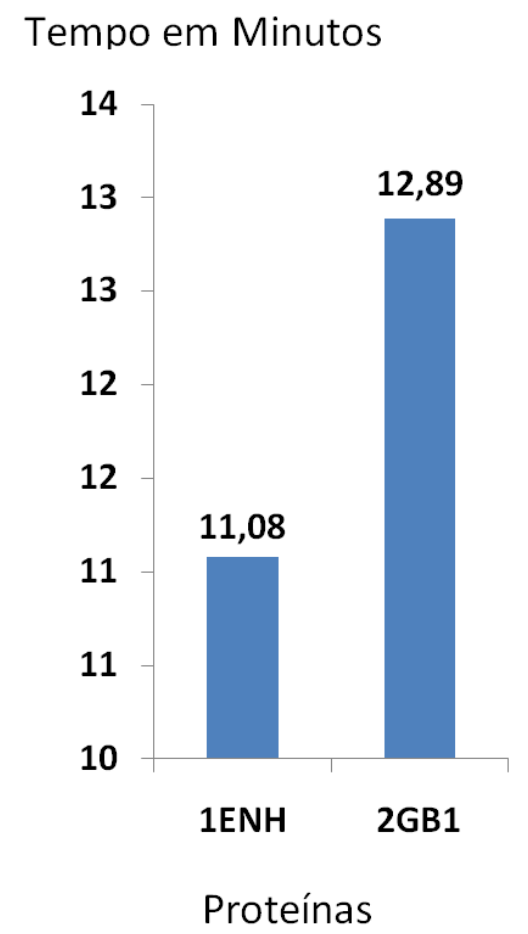

Figura 5.55: Tempo computacional gasto pelo o modelo CG para as proteínas $1 E N H$ e $2 G B 1$.

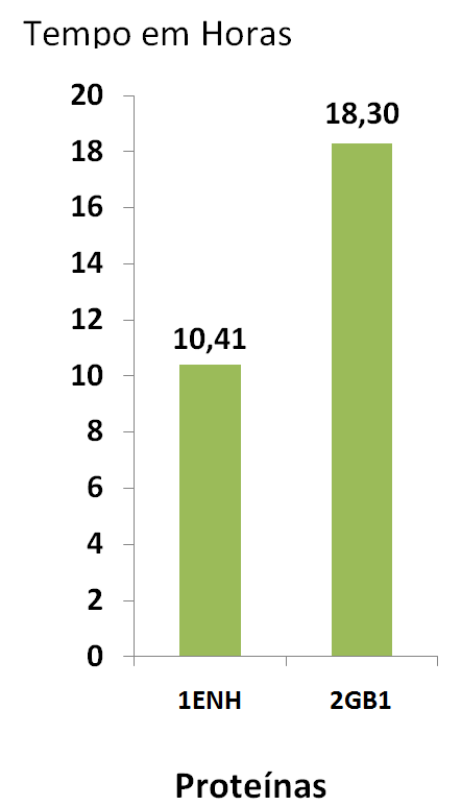

Figura 5.56: Tempo computacional gasto pelo o modelo full-atom para as proteínas 1ENH e 2 GB1.

Nas Figuras 5.55 e 5.56, observa-se que à medida que o tamanho da proteína cresce, 
neste caso, em apenas um resíduo, o tempo computacional gasto pelo CG cresce mais lentamente (1,81 minutos) do que para ofull-atom (7,89 horas).

A proteína 2W4P, de 99 resíduos, demorou em média 23,96 minutos em um computador com 8 processadores ( Intel@ Core $^{T M}$ i7 com 2,676 GHz e 3GB de memória RAM).

Conforme já citado, o baixo custo computacional do modelo CG permitiu que se realizasse simulações com um número de gerações muito maior do que o modelo full-atom, justificando sua escolha. 


\section{Capítulo 6}

\section{Conclusões}

Neste trabalho, foram realizados experimentos a fim de testar a inserção de conhecimento através de imigrantes, os quais foram gerados a partir de alinhamentos da sequência proteica primaria ou aleatoriamente. Esses experimentos empregaram um modelo CG, até então utilizado apenas no dobramento proteico. Por fim, também foram realizados testes para um modelo do tipo full-atom a fim de que fosse possível comparar os resultados obtidos com o modelo CG.

Considerando o protocolo de simulação utilizado neste trabalho, o modelo CG não foi capaz de distinguir adequadamente entre a estrutura nativa de uma proteína e uma estrutura mais distante, sendo assim, a estrutura nativa e estruturas próximas possuem energia maior do que proteínas desenoveladas. Esses resultados concordam com a afirmação contida em [Tozzini, 2005], de que modelos de 1 bead, frequentemente, possuem dependência da configuração inicial, devido a dificuldade de representar características mais gerais dos aminoácidos com poucos parâmetros. Essa dependência, faz com que os modelos de 1 bead possuam um viés em direção a configuração inicial. No caso do modelo CG, aqui utilizado, existe uma dependência adicional do conhecimento da estrutura secundária.

Esse viés do modelo CG, faz com que o AGP encontre soluções, muitas vezes, melhores que os demais algoritmos, mesmo diante da inserção de indivíduos gerados por similaridade. Isso ocorre porque as estruturas similares nem sempre apresentam energia menor que as estruturas geradas aleatoriamente, fazendo com que as informações geradas pela similaridade com estruturas conhecidas se percam ao longo das gerações. Contudo, o modelo CG é interessante por auxiliar na formação de estruturas secundárias e para realizar a busca mais "grosseira" no espaço de soluções.

Nos experimentos realizados com o modelo full-atom, em geral, não houve diferença estatística entre os algoritmos, porém os algoritmos que empregam similaridade obtiveram as melhores energias mais frequentemente.

Um dos problemas encontrados foi a necessidade de otimizar as cadeias laterais. A otimização utilizada foi bastante simples, empregando apenas um indivíduo da popu- 
lação. Outra estratégia seria otimizar todas as cadeias laterais dos indivíduos similares e para todas as proteínas, porém o custo computacional seria muito alto. Assim, os indivíduos similares, mesmo com a cadeia lateral otimizada, possuem uma energia alta, o que pode justificar o fato de não ter sido encontrada diferença estatística entre os algoritmos. Isso ocorre porque ao serem inseridos na população, esses indivíduos com energias altas se perdem e não são selecionados para as próximas gerações. Como os indivíduos da população de similares podem sofrer crossover antes de serem inseridos, esse operador eventualmente produz indivíduos com energias melhores, o que justifica a obtenção de energias menores pelos algoritmos que empregam similaridade em vários casos.

Em resumo, a inserção de similaridade foi útil e eventualmente produziu as melhores soluções em termos de energia e RMSD, sendo que isso ocorreu de forma mais expressiva para o modelo full-atom. A inserção de imigrantes aleatórios também mostrou-se útil em alguns casos, quando a obtenção de uma diversidade maior foi importante, produziu também as melhores soluções.

Futuramente uma questão que poderia ser abordada é a continuação dos experimentos obtidos através do CG com o modelo full-atom. Assim, o modelo CG realizaria a busca de forma mais grosseira e posteriormente o modelo full-atom refinaria as soluções. A combinação de modelos mais grosseiros com modelos mais detalhistas é uma estratégia que tem sido utilizada em diversos trabalhos de predição com sucesso, pode-se citar o preditor do ROSETTA [Raman et al., 2009], que já foi discutido aqui. Outras melhorias poderão ser realizadas nos algoritmos para reduzir o custo computacional. Uma melhoria interessante seria a paralelização do AG, uma vez que é sabido que AGs podem ser paralelizados com certa facilidade devido a suas características [Cantú-Paz, 1998; Muhlenbein, 1991; Stender, 1993].

Além disso, a estratégia desenvolvida para a criação de imigrantes por similaridade poderia ser aplicada e testada para modelagem comparativa. 


\section{Apêndice A}

\section{Função de avaliação para o modelo full-atom}

A energia potencial calculada pelo campo de força full-atom possui as seguintes componentes:

$$
E_{\text {Potencial }}=E C L+E A L+E A T+E U B+E T T+E I+E V d W+E E \text { (A.1) }
$$

sendo:

- ECL: Energia do Comprimento de Ligação;

- EAL: Energia do Ângulo de Ligação;

- EAT: Energia do Ângulo de Torção;

- EUB: Energia de Urey Bradley;

- ETT: Energia Torção-Torção;

- EI: Energia Imprópria;

- EVdW: Energia de Van der Waals;

- EE: Energia Eletrostática;

As componentes são descritas a seguir.

No CHARMM22, cada átomo recebe um número como codificação. A codificação empregada, que foi extraída do arquivo de parametrização, pode ser vista na Figura A.1, a qual é empregada nas demais seções. 


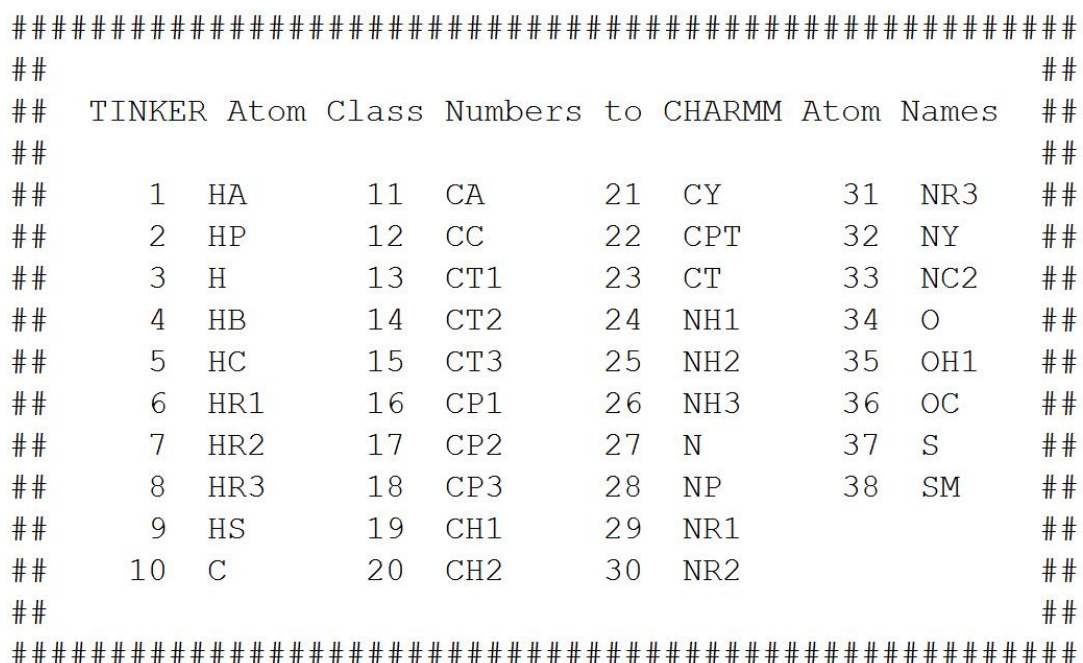

Figura A.1: Codificação dos átomos do CHARMM22.

\section{A.1 Energia do Comprimento de Ligação (ECL)}

A energia potencial para o comprimento de ligação pode ser descrita eficientemente pelo potencial de Morse, cuja equação é dada por:

$$
E_{C L}=K_{e}\left(1-\exp \left\{-a\left(r-r_{0}\right)\right\}\right)^{2}
$$

sendo $K_{e}$ a altura do potencial de mínima energia, $a=\omega \sqrt{\frac{\mu}{2 K_{e}}}$, sendo $\mu$ a massa reduzida e $\omega$ é a frequência de vibração da ligação, $r_{0}$ o comprimento de ligação de referência e $r$ o comprimento de ligação.

Contudo, o potencial de Morse não é frequentemente utilizado em campos de força uma vez que, por necessitar de três parâmetros, não é computacionalmente eficiente. Desse modo, a energia potencial do comprimento de ligação, cuja variação depende da distância entre os átomos da ligação, é modelada pela Lei de Hooke, cuja equação é dada por:

$$
E_{A L}=\frac{k}{2}\left(r-r_{0}\right)^{2}
$$

sendo $k$ a constante de comprimento de ligação e $r_{0}$ o comprimento de ligação padrão. Consultando o arquivo com a parametrização para o CHARMM22, encontra-se uma seção contendo os parâmetros utilizados para o calculo da Energia do comprimento de ligação. A Figura A.2 mostra um trecho deste arquivo de parâmetros. 


\begin{tabular}{|c|c|c|c|c|c|}
\hline & \#\# \# & \# \# \# \# \# & \# \# \# \# \# \# \# \# \# \# \# & \# \# \# \# \# \# \# \# \# & \\
\hline & \#\# & & & & \#\# \\
\hline & \#\# & Bond & Stretching & Parameters & \#\# \\
\hline & \#\# & & & & $\# \#$ \\
\hline & \#\#\# \# & \#\#\#\#\#\# & \#\# \# \# \# \# \#\# \# \# \# \# & \# \# \# \# \# \# \# \# \# \# \# \# & \#\#\# \# \\
\hline bond & & 1 & 10 & 330.00 & 1.1000 \\
\hline bond & & 1 & 11 & 340.00 & 1.0830 \\
\hline bond & & 1 & 12 & 317.13 & 1.1000 \\
\hline bond & & 1 & 13 & 309.00 & 1.1110 \\
\hline bond & & 1 & 14 & 309.00 & 1.1110 \\
\hline bond & & 1 & 15 & 322.00 & 1.1110 \\
\hline bond & & 1 & 17 & 309.00 & 1.1110 \\
\hline bond & & 1 & 18 & 309.00 & 1.1110 \\
\hline
\end{tabular}

Figura A.2: Trecho do arquivo de parâmetros do CHARMM22, contendo alguns parâmetros do comprimento de ligação.

De acordo com a Figura A.2 podemos observar a seção Bond Stretching Parameters, cujas colunas 1 e 2 correspondem ao código do átomo. Já as colunas 3 e 4 correspondem a constante de comprimento de ligação e comprimento de ligação padrão, respectivamente. O gráfico da Figura A.3 foi construído utilizando os valores da primeira linha de parâmetros que corresponde a ligação entre os átomos chamados HA e C (códigos 1 e 10), sendo o valor do comprimento de ligação padrão $r_{0}$ de $1,1 A^{\circ}$, enquanto que a constante $k$ é de $330 \mathrm{Kcal} * A^{\circ} / \mathrm{mol}$.

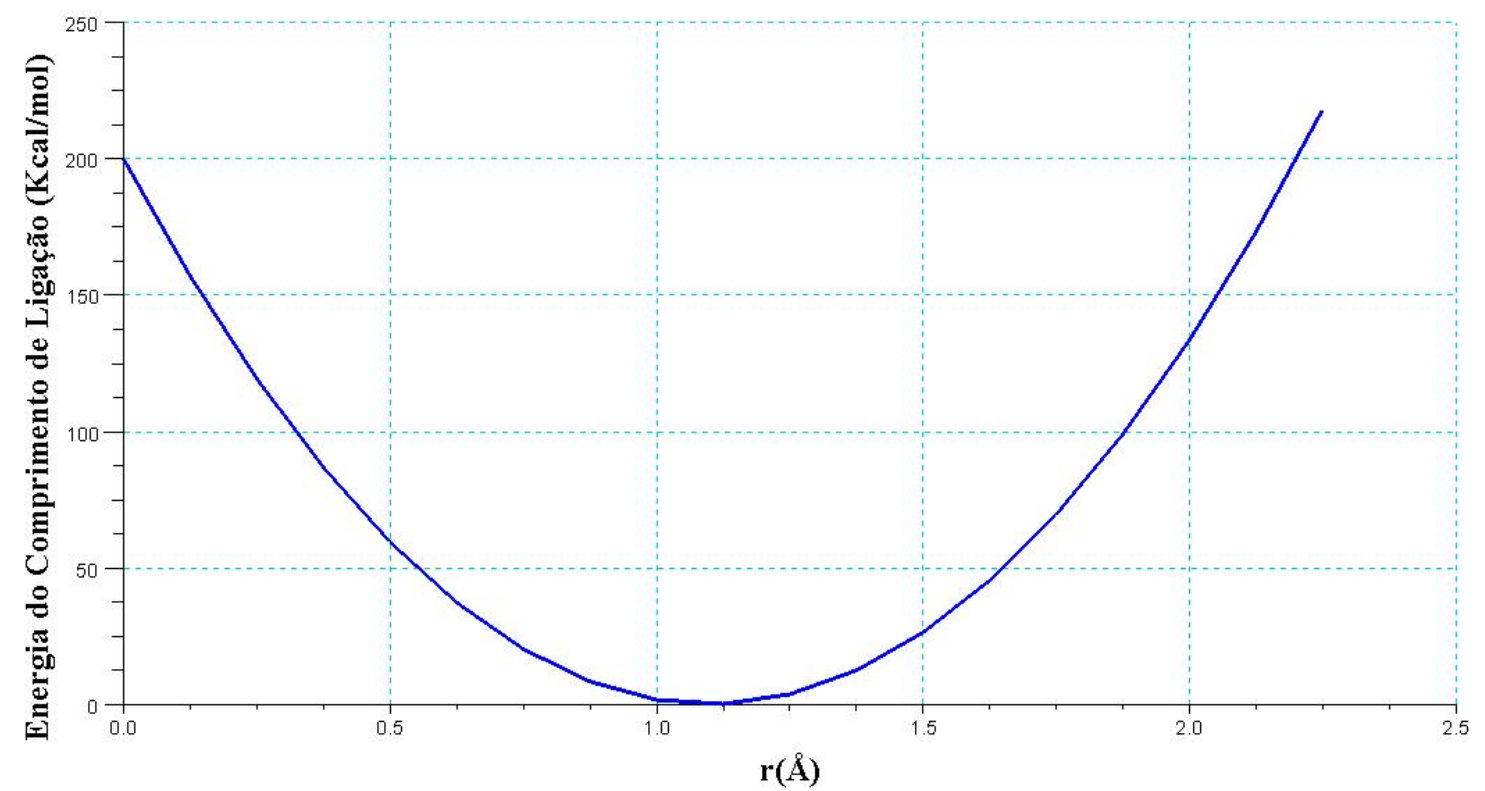

Figura A.3: Energia do Comprimento de Ligação. 


\section{A.2 Energia do Ângulo de Ligação (EAL)}

A Energia do Ângulo de Ligação baseada na Lei de Hooke é similar àquela mostrada na Seção 4.3.1. No caso full-atom, porém a expressão é calculada para todos os ângulos de ligação da molécula e não somente para os Carbono- $\alpha$. Deste modo, os parâmetros variam conforme cada tripla de átomos que possuem um ângulo de ligação e não de acordo com estrutura secundária como no caso CG.

$$
E_{A L}=\frac{k_{0}}{2}\left(\theta-\theta_{0}\right)^{2}
$$

sendo $k_{0}$ a constante do ângulo de ligação e $\theta_{0}$ o ângulo de ligação de referência.

No arquivo de parametrização do CHARMM22, encontra-se os parâmetros utilizados para cada tripla de átomos (Figura A.4).

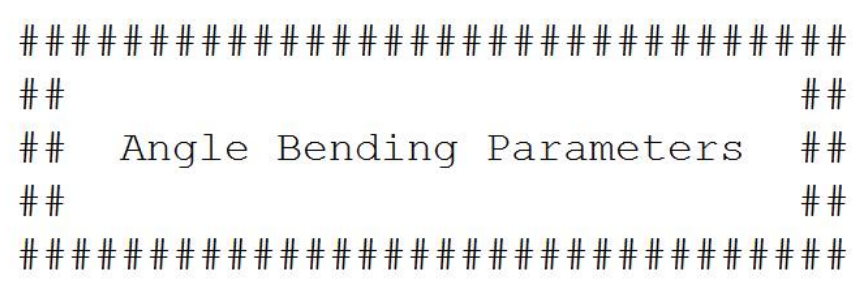

$\begin{array}{lrrrrr}\text { angle } & 3 & 10 & 34 & 50.00 & 121.70 \\ \text { angle } & 13 & 10 & 24 & 80.00 & 116.50 \\ \text { angle } & 13 & 10 & 27 & 20.00 & 112.50 \\ \text { angle } & 13 & 10 & 34 & 80.00 & 121.00 \\ \text { angle } & 14 & 10 & 24 & 80.00 & 116.50 \\ \text { angle } & 14 & 10 & 27 & 20.00 & 112.50 \\ \text { angle } & 14 & 10 & 34 & 80.00 & 121.00\end{array}$

Figura A.4: Fragmento do arquivo de parâmetros do CHARMM22 contendo alguns parâmetros do ângulo de ligação.

$\mathrm{Na}$ Figura A.4, as colunas 2, 3 e 4 representam o código dos átomos que formam o ângulo de ligação, enquanto que as colunas 5 e 6 representam a constante do ângulo de ligação e o ângulo de referência respectivamente. A primeira linha corresponde, portanto, ao ângulo formado entre os átomos $\mathrm{H}, \mathrm{C}$ e $\mathrm{O}$, onde $k_{0}=50,0\left(\mathrm{Kcal}^{\circ} / \mathrm{mol}\right)$ e $\theta_{0}=127,70^{\circ}$. A Figura A.5 mostra o gráfico correspondente a essa primeira linha de parâmetros. 


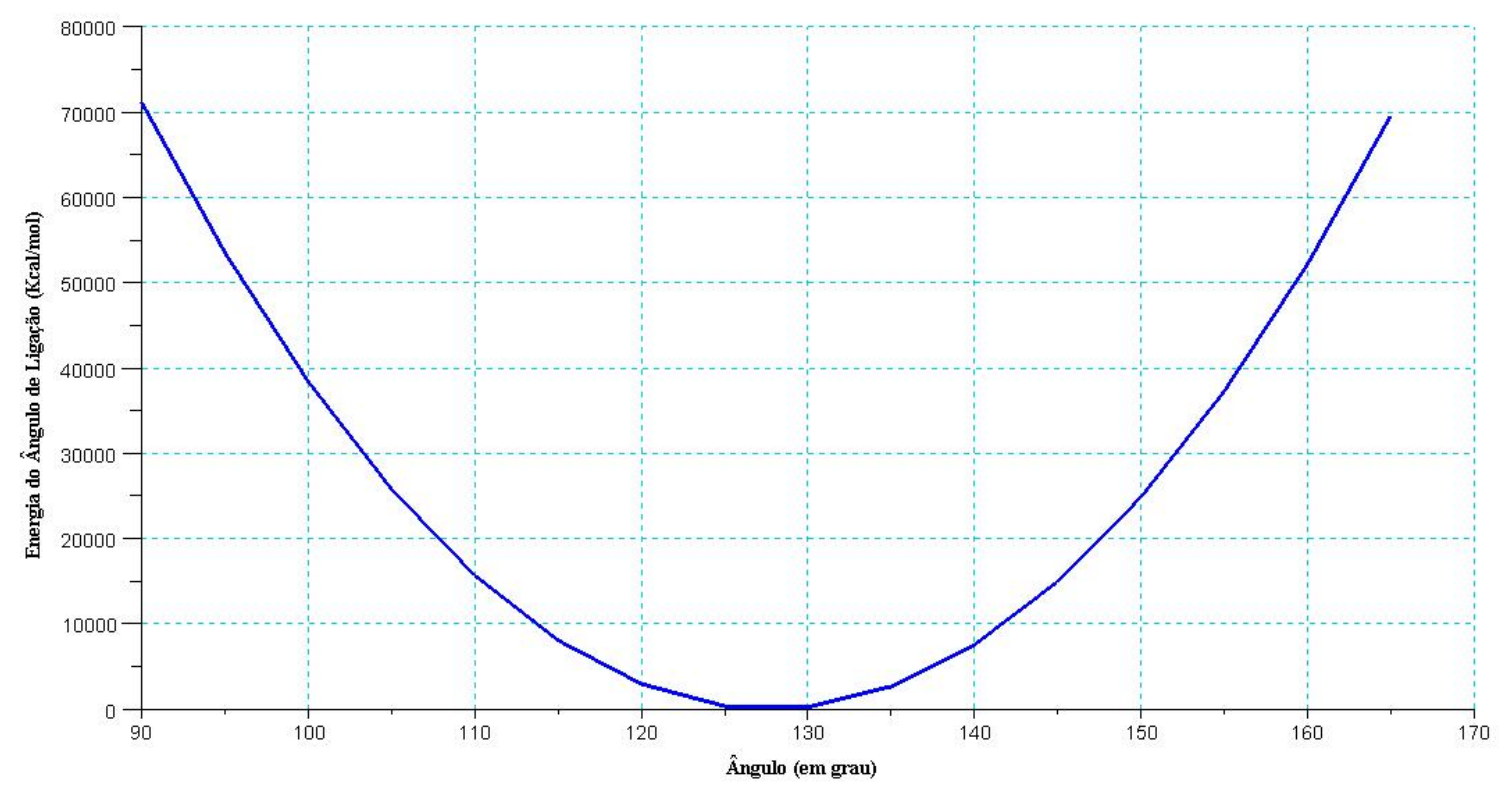

Figura A.5: Energia do Ângulo de Ligação.

\section{A.3 Energia do Ângulo de Torção (EAT)}

O ângulo de torção é formado entre quatro átomos $(\mathrm{C}, \mathrm{C}-\alpha, \mathrm{N}$ e C). A EAT representa a energia de rotação ao redor de uma ligação covalente. As energias do comprimento de ligação e do ângulo de ligação precisam alcançar valores muito altos para provocar alterações estruturais [Leach, 2001]. Já a energia do ângulo de torção juntamente com as interações não ligadas proporcionam as maiores variações de energia.

A expressão que representa a EAT é dada por:

$$
E_{A T}=\sum_{n=0}^{N} \frac{K_{\omega}}{2}[1+\cos (n \omega-\gamma)]
$$

sendo $K_{\omega}$ a constante de energia do ângulo de torção, $\omega$ o ângulo diedral, $n$ o número de fases e $\gamma$ o ângulo de fase.

A Figura A.6 mostra um fragmento do cabeçalho do arquivo do CHARMM22 relativo a esta componente. 


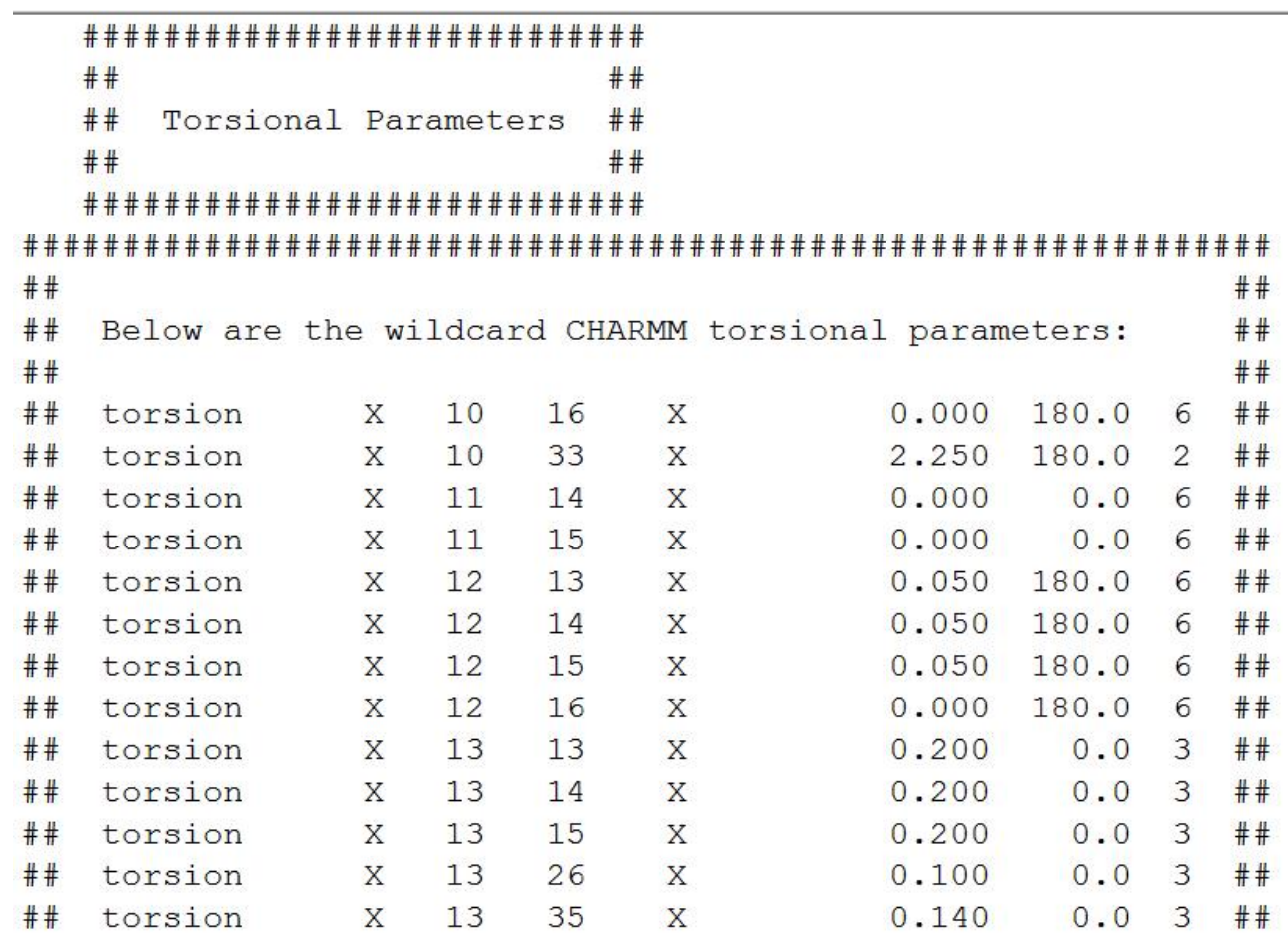

Figura A.6: Fragmento do arquivo de parâmetros do CHARMM22 contendo alguns parâmetros de torção.

O fragmento da Figura A.6 mostra alguns dos parâmetros utilizados para o cálculo da EAT. Essa seção é chamada de wildcard porque alguns dos códigos dos átomos aparecem mascarados com um $\mathrm{X}$, indicando que eles podem ser substituídos por qualquer átomo. As colunas 3 e 4 mostram o código dos átomos conforme mostrado anteriormente na Figura A.1. As colunas 6, 7 e 8, respectivamente, correspondem: a constante do ângulo de torção (kcal/mol), ângulo de torção de referência (em grau) e a multiplicidade, que fornece o número de mínimos que a função assume em $360^{\circ}$. A Figura A.7 mostra o comportamento da EAT para alguns valores retirados do fragmento da Figura A.6. 


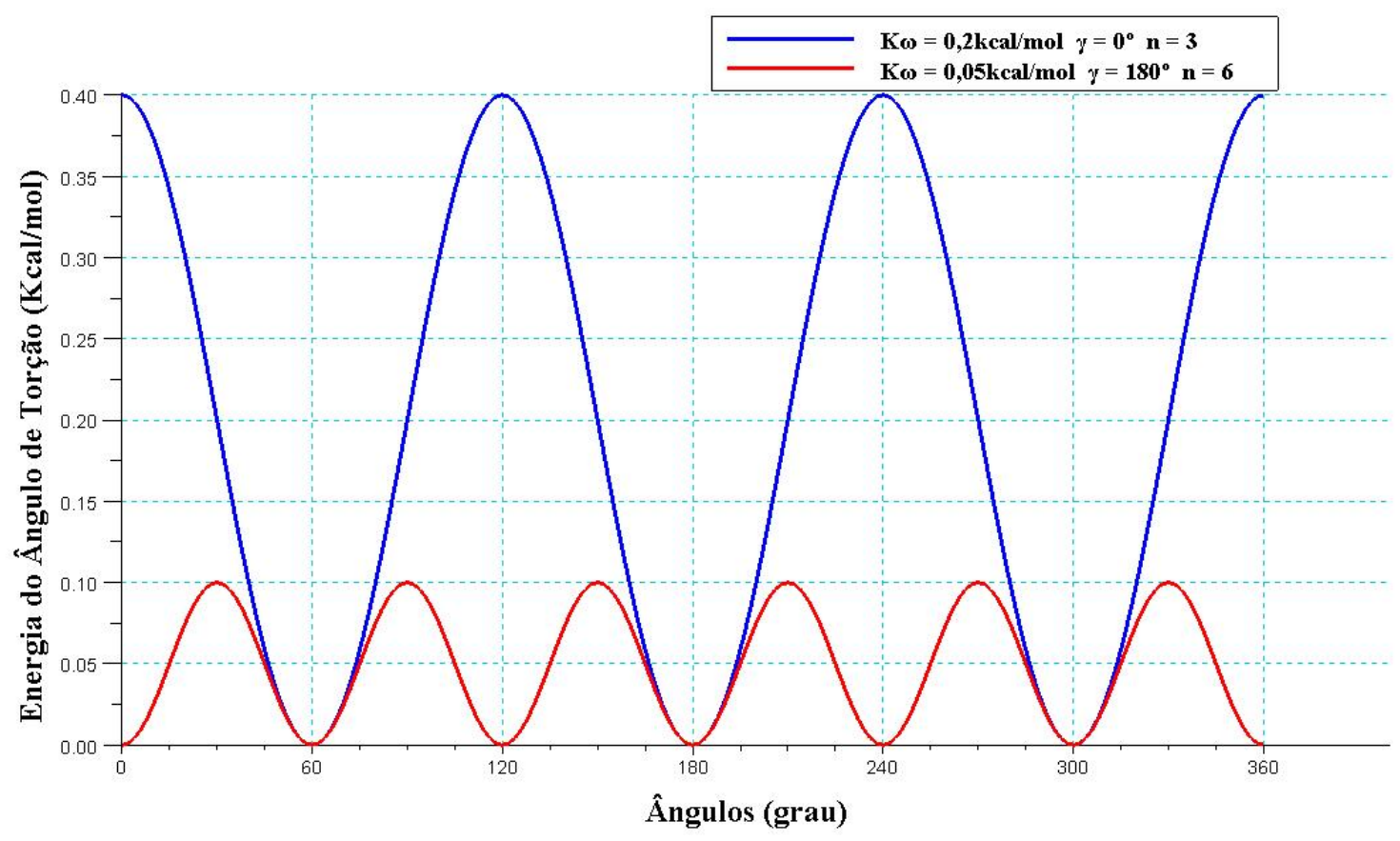

Figura A.7: Energia do ângulo de torção.

\section{A.4 Energia de Urey-Bradley (EUB)}

A Energia de Urey-Bradley (EUB) é a energia de interação de um átomo $i$ com seu vizinho $i+3$, também chamada interação atômica 1,3 [Brooks et al., 1990]. O termo também é representado como uma aproximação harmônica baseada na Lei de Hooke:

$$
E_{U B}=\frac{k_{U B}}{2}\left(s-s_{0}\right)^{2}
$$

sendo $k_{U B}$ a constante harmônica de Urey-Bradley, $s$ a distância da interação atômica $1,3 \AA$ e $s_{0}$ a distância padrão desta interação. A Figura A.8 mostra um fragmento do cabeçalho do arquivo do CHARMM22 referente aos parâmetros utilizados para o cálculo da EUB. 


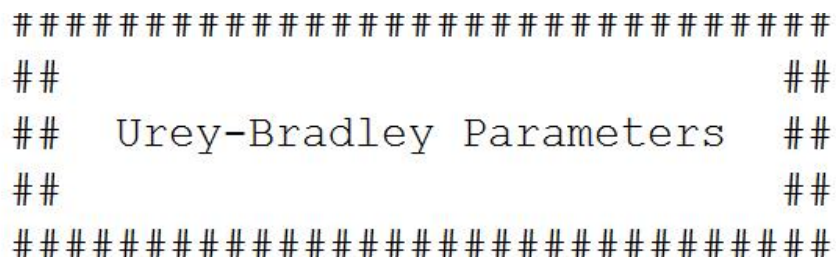

$\begin{array}{lrrrrr}\text { ureybrad } & 33 & 10 & 33 & 90.00 & 2.3642 \\ \text { ureybrad } & 1 & 11 & 11 & 25.00 & 2.1525 \\ \text { ureybrad } & 1 & 11 & 21 & 25.00 & 2.1730 \\ \text { ureybrad } & 1 & 11 & 32 & 25.00 & 2.1770 \\ \text { ureybrad } & 2 & 11 & 11 & 22.00 & 2.1525 \\ \text { ureybrad } & 2 & 11 & 21 & 25.00 & 2.1730 \\ \text { ureybrad } & 2 & 11 & 22 & 22.00 & 2.1460 \\ \text { ureybrad } & 2 & 11 & 32 & 25.00 & 2.1770 \\ \text { ureybrad } & 11 & 11 & 11 & 35.00 & 2.4162 \\ \text { ureybrad } & 21 & 11 & 32 & 25.00 & 2.2400 \\ \text { ureybrad } & 1 & 12 & 25 & 50.00 & 1.9800\end{array}$

Figura A.8: Fragmento do arquivo de parâmetros do CHARMM22 contendo alguns parâmetros de UreyBradley.

\section{A.5 Energia Torção-Torção (ETT)}

Esse termo representa uma correção para os ângulos de torção $\phi$ e $\psi$. Segundo [Mackerell Jr et al., 2004], trata-se corrigir um o efeito de correlação de elétrons do Diagrama de Ramachandran e no CHARMM22 isso é feito para os aminoácidos: alanina, glicina e prolina. Esse termo, é referido como CMAP (energy correction map ou dihedral crossterms) e é dado por:

$$
f(\phi, \psi)=\sum_{i=1}^{4} \sum_{i=1}^{4} c_{i j}\left(\frac{\phi-\phi_{L}}{\Delta_{\phi}}\right)^{i-1}\left(\frac{\psi-\psi_{L}}{\Delta_{\psi}}\right)^{j-1}
$$

sendo $c_{i j}$ o coeficiente de interpolação bicúbica, $\phi$ e $\psi$ os ângulos de torção, $\phi_{L}$ e $\psi_{L}$ os ângulos de torção de referência e $\Delta_{\phi}$ e $\Delta_{\psi}$ as derivadas parciais de $f(\phi, \psi)$.

\section{A.6 Energia Imprópria (EI)}

A Energia Imprópria é a energia devido a distorções e deformações dos ângulos de torção. Segundo [Leach, 2001], isso ocorre devido à presença de ligações- $\pi$ que se maximizam com geometria coplanar, podendo fazer com que átomos sejam deslocados para fora do plano. O termo Energia Imprópria é usado para manter a geometria sem essas deformações. Esse termo, assim como parte dos demais, é também representado como uma aproximação harmônica, cuja expressão é dada por: 


$$
E_{\text {Imp }}=\frac{k_{i m p}}{2}\left(\varphi-\varphi_{0}\right)^{2}
$$

sendo $k_{i m p}$ a constante harmônica da Energia Imprópria, $\varphi_{0}$ o ângulo de torção impróprio e $\varphi_{0}$ o seu valor de referência.

\section{A.7 Energia de Van der Waals}

As nuvens de elétrons de átomos não carregados, quando muito próximas, podem influenciar umas as outras. Desse modo, alterações de posição dos elétrons podem produzir dípolos temporários, ocasionando atração fraca entre os átomos [Lehninger et al., 2005]. Como os núcleos dos átomos encontram-se próximos, suas nuvens elétricas se repelem. Assim, a Energia de Van der Waals é um balanço entre essas forças de atração e repulsão.

Uma forma popular de se modelar a Energia de Van der Waals é através do potencial de interação de Lennard-Jones, dado por:

$$
E V d W=\sum_{V d W} \epsilon\left[\left(\frac{R_{m_{i n} i j}}{r_{i j}}\right)^{12}\left(\frac{R_{m_{i n} i j}}{r_{i j}}\right)^{6}\right]
$$

sendo $\epsilon$ o parâmetro correspondente à profundidade do vale da função Lennard-Jones e $R_{\text {min }_{i j}}$ a distância mínima de Lennard-Jones.

\section{A.8 Energia Eletrostática (EE)}

O termo Energia Eletrostática modela as interações eletrostáticas ou de carga entre um par de átomos da proteína, sendo baseado na Lei de Coulomb e representado como [MacKerell Jr et al., 1998].

$$
E E=\sum_{i j} \frac{q_{i} q_{j}}{\epsilon_{1} r_{i j}}
$$

sendo $q_{i}$ e $q_{j}$ as carga atômicas, $\epsilon_{1}$ a constante dielétrica e $r_{i j}$ a distância entre as duas cargas $q_{i}$ e $q_{j}$. 

APÊNDICE A 


\title{
Referências Bibliográficas
}

\author{
Alberts et al.(2006) B. Alberts, D. Bray, A. Johnson, J. Lewis, M. Raff, K. Roberts, \\ e P. Walter. Fundamentos da biologia celular. Porto Alegre: Artmed, páginas 630- \\ 631. Citado na pág. 5, 7, 13
}

Altschul et al.(1990) S.F. Altschul, W. Gish, W. Miller, E.W. Myers, e D.J. Lipman. Basic local alignment search tool. Journal of molecular biology, 215(3):403-410. ISSN 0022-2836. Citado na pág. 34

Bhunia et al.(2009) A. Bhunia, A. Ramamoorthy, e S. Bhattacharjya. Helical hairpin structure of a potent antimicrobial peptide msi-594 in lipopolysaccharide micelles by nmr spectroscopy. Chemistry - A European Journal, 15:2036-2040. Citado na pág. 43

Bonetti(2010) D.R.F. Bonetti. Aumento da eficiência do cálculo da energia de van der waals em algoritmos genéicos para predição de estruturas de proteínas (2010). enhance the van der waals energy efficiency calculi in genetic algorithms for protein structure prediction. Mestrado em ciências da computação e matemática computacional, Instituto de Ciências Matemáticas e de Computação (ICMC), Universidade de São Paulo (USP), São Carlos. Citado na pág. 1, 25

Branden et al.(1991) C. Branden, J. Tooze, et al. Introduction to protein structure, volume 17. Garland Publishing New York. Citado na pág. 5, 7

Brooks et al.(1983a) B. R. Brooks, R. E. Bruccoleri, B. D. Olafson, D. J. States, S. Swaminathan, e M. Karplus. Charmm: A program for macromolecular energy, minimization, and dynamics calculations. Journal Of Computational Chemistry, 4: 187-217. Citado na pág. 21

Brooks et al.(1983b) B.R. Brooks, R.E. Bruccoleri, B.D. Olafson, et al. Charmm: A program for macromolecular energy, minimization, and dynamics calculations. Journal of Computational Chemistry, 4(2):187-217. Citado na pág. 41

Brooks et al.(1990) C.L. Brooks, M. Karplus, e B.M. Pettitt. Proteins: a theoretical perspective of dynamics, structure and thermodynamics. Wiley-Interscience. Citado na pág. 103

Brown et al.(2003) S. Brown, N.J. Fawzi, e T. Head-Gordon. Coarse-grained sequences for protein folding and design. Proceedings of the National Academy of Sciences of the United States of America, 100(19):10712. Citado na pág. Xvii, 36, 39, 92

Cantú-Paz(1998) E. Cantú-Paz. A survey of parallel genetic algorithms. Calculateurs paralleles, reseaux et systems repartis, 10(2):141-171. Citado na pág. 96 
Clarke et al.(1994) N.D. Clarke, C.R. Kissinger, J. Desjarlais, G.L. Gilliland, e C.O. Pabo. Structural studies of the engrailed homeodomain. Protein Science, 3(10): 1779-1787. ISSN 1469-896X. Citado na pág. 43

Cobb e Grefenstette(1993) H. G. Cobb e J. J. Grefenstette. Genetic algorithms for tracking changing environments. Em Proceedings of the 5th International Conference on Genetic Algorithms, páginas 523-530, San Francisco, CA, USA. Morgan Kaufmann Publishers Inc. ISBN 1-55860-299-2. URL http://portal.acm.org/ citation.cfm? $\mathrm{id}=645513.657576$. Citado na pág. 33

Contreras-Moreira et al.(2005) B. Contreras-Moreira, I. Ezkurdia, M.L. Tress, e A. Valencia. Empirical limits for template-based proteinnext term structure previous termprediction:next term the casp5 example. Febs Letters, 579(5):1203-1207. Citado na pág. 15

Cooper et al.(2003) L. R. Cooper, D. W. Corne, e M. J. C. Crabbe. Use of a novel hillclimbing genetic algorithm in protein folding simulations. Computational Biology and Chemistry, 27(6):575 - 580. Citado na pág. 1, 2

Custódio et al.(2010) F.L. Custódio, H.J.C. Barbosa, e L.E. Dardenne. Full-atom ab initio protein structure prediction with a genetic algorithm using a similarity-based surrogate model. Em IEEE Congress on Evolutionary Computation (CEC), páginas 1-8. ISBN 978-1-4244-6909-3. Citado na pág. 26

Das et al.(2007a) R. Das, B. Qian, S. Raman, R. Vernon, J. Thompson, P. Bradley, S. Khare, M.D. Tyka, D. Bhat, D. Chivian, et al. Structure prediction for casp7 targets using extensive all-atom refinement with rosetta home. Proteins: Structure, Function, and Bioinformatics, 69(S8):118-128. ISSN 1097-0134. Citado na pág. 18

Das et al.(2007b) R. Das, B. Qian, S. Raman, R Vernon, T. Thompson, P Bradley, S. Khare, M. D. Tyka, D Bhat, D Chivian, D. E. Kim, W. H. Sheffler, L. Malmström, A. M. Wollacott, C. Wang, I andre, e D. Baker. Structure prediction for casp7 targets using extensive all-atom refinement with rosettahome. Proteins: Structure, Function, and Bioinformatics, 69(1-3):118-128. Citado na pág. 18

Davis et al.(2003) A.M. Davis, S.J. Teague, e G.J. Kleywegt. Application and limitations of x-ray crystallographic data in structure-based ligand and drug design. Angew. Chem. Int. Ed, 42(24):2718-36. Citado na pág. 12

De Jong e Spears(1991) K. De Jong e W. Spears. An analysis of the interacting roles of population size and crossover in genetic algorithms. Parallel problem solving from nature, páginas 38-47. Citado na pág. 32

De Lima et al.(2007) T. W. De Lima, R. A. Faccioli, P. H. R. Gabriel, A. C. B. Delbem, e I. N. Da Silva. Evolutionary approach to protein structure prediction with hydrophobic interactions. Em Gecco 07: Proceedings Of The 9th Annual Conference On Genetic and Evolutionary Computation, páginas 425-425, New York, Ny, Usa. Acm. ISBN 978-1-59593-697-4. Citado na pág. 1

De Lima(2006) T.W. De Lima. Algoritmos evolutivos para predição de estruturas de proteínas. Mestrado em ciências da computação e matemática computacional, Instituto de Ciências Matemáticas e de Computação (ICMC), Universidade de São Paulo (USP), São Carlos. Citado na pág. 25 
Dill(2010) Group Dill. Funil de energia livre. Internet (Visitada Em 31/01/2010), 2010. Url: Http://www.Dillgroup.Ucsf.Edu/. Citado na pág. xiii, 12

Do Ó e Tinós(2009) V. T. Do Ó e R. Tinós. Diversity control in genetic algorithms for protein structure prediction. Em Nos Anais Do Xxix Congresso Da Sociedade Brasileira De Computação (Csbc 2009) Vii Encontro Nacional De Inteligência Artificial (Enia 2009), páginas 727-737. Citado na pág. 25, 26, 33

Do Ó(2009) V. T. do Do Ó. Técnicas de controle da diversidade de populações em algoritmos genéticos para determinação de estruturas de proteínas. Mestrado em física aplicada a biologia e medicina, Faculdade de Filosofia, Ciências e Letras de Ribeirão Preto (FFCLRP), Universidade de São Paulo (USP), Ribeirão Preto. Citado na pág. $1,2,32,59$

Dunbrack et al.(2002) R.L. Dunbrack et al. Rotamer libraries in the 21 st century. Current opinion in structural biology, 12(4):431-440. ISSN 0959-440X. Citado na pág. 29

Faccioli et al.(2007) R.A. Faccioli, I.N. da Silva, A.C. Junior, e I.N. da Silva. Algoritmo híbrido multi-objetivo para predição de estrutura terciária de proteínas. Mestrado em ciências da computação e matemática computacional, Instituto de Ciências Matemáticas e de Computação (ICMC), Universidade de São Paulo (USP), São Carlos. Citado na pág. 1, 25

Gabriel(2010) P.H.R. Gabriel. Algoritmos evolutivos e modelos simplificados de proteínas para predição de estruturas terciárias. Mestrado em ciências da computação e matemática computacional, Instituto de Ciências Matemáticas e de Computação (ICMC), Universidade de São Paulo (USP), São Carlos. Citado na pág. 1, 26

Garcia et al.(2009) S. Garcia, D. Molina, M. Lozano, e F. Herrera. A study on the use of non-parametric tests for analyzing the evolutionary algorithms behaviour: a case study on the cec 2005 special session on real parameter optimization. Journal of Heuristics, 15(6):617-644. ISSN 1381-1231. Citado na pág. 46

Goldberg(1989) D.E. Goldberg. Genetic algorithms in search, optimization, and machine learning. Addison-wesley. ISBN 0201157675. Citado na pág. 22

Gopal et al.(2009) S. M. Gopal, K. Klenin, e W. Wenzel. Template-free protein structure prediction and quality assessment with an all-atom free-energy model. Proteins: Structure, Function, and Bioinformatics, 77:330-342. Citado na pág. 18

Gopalakrishnan et al.(2007) K. Gopalakrishnan, S. S. Sheik, e C. V. Ranjani. Conformational angles database (cadb-3.0). Protein and Peptide Letters, 14(7):665 668. Citado na pág. 28

Gronenborn et al.(1991) A.M. Gronenborn, D.R. Filpula, N.Z. Essig, A. Achari, M. Whitlow, P.T. Wingfield, e GM Clore. A novel, highly stable fold of the immunoglobulin binding domain of streptococcal protein g. Science, 253(5020):657661. ISSN 0036-8075. Citado na pág. 43

Guo e Thirumalai(1996) Z. Guo e D. Thirumalai. Kinetics and thermodynamics of folding of a de novo designed four-helix bundle protein. Journal of molecular biology, 263(2):323-343. ISSN 0022-2836. Citado na pág. 36 
Hamelryck et al.(2006) T. Hamelryck, J.T. Kent, e A. Krogh. Sampling realistic protein conformations using local structural bias. PLoS Comput. Biol, 2(9):e131. Citado na pág. 59, 63

Haupt e Haupt(1998) R. L. Haupt e S. E. Haupt. Practical genetic algorithms. John Wiley \& Sons, Inc., New York, NY, USA. ISBN 047-1188735. Citado na pág. 21, 22

Herráez(2006) A. Herráez. Biomolecules in the computer: Jmol to the rescue. Biochemistry and Molecular Biology Education, 34(4):255-261. ISSN 1539-3429. Citado na pág. 8

Hoque et al.(2011) Md Tamjidul Hoque, Madhu Chetty, Andrew Lewis, e Abdul Sattar. Twin removal in genetic algorithms for protein structure prediction using low-resolution model. IEEE/ACM Trans. Comput. Biol. Bioinformatics, 8: 234-245. ISSN 1545-5963. doi: http://dx.doi.org/10.1109/TCBB.2009.34. URL http://dx.doi.org/10.1109/TCBB.2009.34. Citado na pág. 1

Isaev(2004) A. Isaev. Introduction to mathematical methods in bioinformatics. Springer Verlag. ISBN 3540219730. Citado na pág. 17

Jiang et al.(2003) T. Jiang, Q. Cui, G. Shi, e S. Ma. Protein folding simulations of the hydrophobic-hydrophilic model by combining tabu search with genetic algorithms. Journal Of Chemical Physics, 119(8):4592 - 4596. Citado na pág. 1, 26

Jones(1999) D.T. Jones. Protein secondary structure prediction based on positionspecific scoring matrices1. Journal of molecular biology, 292(2):195-202. ISSN 0022-2836. Citado na pág. 28, 47, 50

Jorgensen e Tirado-Rives(1988) W. L. Jorgensen e J. Tirado-Rives. The opls potential functions for proteins. energy minimizations for crystals of cyclic peptides and crambin. Computer Physics Communications, 110(6):1657-1666. Citado na pág. 21

Kaczanowski e Zielenkiewicz(2010) S. Kaczanowski e P. Zielenkiewicz. Why similar protein sequences encode similar three-dimensional structures? Theoretical Chemistry Accounts: Theory, Computation, and Modeling (Theoretica Chimica Acta), 125:643-650. ISSN 1432-881X. URL http://dx.doi.org/10.1007/ s00214-009-0656-3. 10.1007/s00214-009-0656-3. Citado na pág. 16

Karplus et al.(1998) K. Karplus, C. Barrett, e R. Hughey. Hidden markov models for detecting remote protein homologies. Bioinformatics, 14(10):846. Citado na pág. 20

Karplus et al.(2003) K. Karplus, R. Karchin, J. Draper, J. Casper, Y. MandelGutfreund, M. Diekhans, e R. Hughey. Combining local-structure, fold-recognition, and new fold methods for protein structure prediction. Proteins-Structure Function and Genetics, 53(6):491-496. Citado na pág. 20

Khimasia e Coveney(1997) M.M. Khimasia e Coveney. Protein structure prediction as a hard optimization problem: The genetic algorithm approach. Arxiv Physics E-Prints. Citado na pág. 12

Kleywegt(2006) G.J. Kleywegt. Crystallographic refinement of ligand complexes. Acta Crystallographica Section D: Biological Crystallography, 63(1):94-100. ISSN 0907-4449. Citado na pág. 12 
Kryshtafovych et al.(2007) A. Kryshtafovych, K. Fidelis, e J. Moult. Progress from casp6 to casp7. Proteins: Structure, Function, and Bioinformatics, 69:194-207. Citado na pág. 18

Leach(2001) A. R. Leach. Molecular Modelling: Principles and Applications. Pearson Education Ema, 2nd edition edição. Citado na pág. 1, 6, 16, 17, 101, 104

Lehninger et al.(2005) A. L. Lehninger, D. L. Nelson, e M. M. Cox. Lehninger Principles Of Biochemistry. New York: Freeman, 4th edition edição. Citado na pág. 5, $6,7,10,11,13,105$

Levinthal(1969) C. Levinthal. Mossbauer spectroscopy in biological systems. Em Proceedings of a Meeting held at Allerton House, página 22. University of Illinois Press. Citado na pág. 11

Li et al.(2008) S.C. Li, D. Bu, J. Xu, e M. Li. Fragment-hmm: A new approach to protein structure prediction. Protein Science, 17(11):1925-1934. ISSN 1469-896X. Citado na pág. 59, 63

Liang e Wong(2001) F. Liang e W. H. Wong. Evolutionary monte carlo for protein folding simulations. Journal Of Chemical Physics, 115(7):3374 - 3380. Citado na pág. 1

Liu e Tao(2008) Y. Liu e L. Tao. Protein structure prediction based on an improved genetic algorithm. Em Bioinformatics and Biomedical Engineering, 2008. ICBBE 2008. The 2nd International Conference on, páginas 577 -580. doi: 10.1109/ICBBE.2008.140. Citado na pág. 26

Lodish et al.(2003) H. Lodish, A. Berk, P. Matsudaira, C. A. Kaiser, M. Krieger, M. P. Scott, L. Zipursky, e J. Darnell. Molecular Cell Biology. Wh Freeman, 5th edition edição. Citado na pág. 5

Luenberger e Ye(2008) D.G. Luenberger e Y. Ye. Linear and nonlinear programming. Springer Verlag. ISBN 0387745025. Citado na pág. 22

MacKerell Jr et al.(1998) AD MacKerell Jr, D. Bashford, M. Bellott, RL Dunbrack Jr, JD Evanseck, MJ Field, S. Fischer, J. Gao, H. Guo, S. Ha, et al. All-atom empirical potential for molecular modeling and dynamics studies of proteins. J. Phys. Chem. $B, 102(18): 3586-3616$. Citado na pág. 105

Mackerell Jr et al.(2004) A.D. Mackerell Jr, M. Feig, e C.L. Brooks III. Extending the treatment of backbone energetics in protein force fields: limitations of gas-phase quantum mechanics in reproducing protein conformational distributions in molecular dynamics simulations. Journal of computational chemistry, 25(11):1400-1415. ISSN 1096-987X. Citado na pág. 104

Marrink et al.(2007) S. J. Marrink, H. J. Risselada, S. Yefimov, D. P. Tieleman, e A. H. Vries. The MARTINI force field: coarse grained model for biomolecular simulations. Journal of Physical Chemistry B-Condensed Phase, 111(27):78127824. Citado na pág. 21

Martí-Renom et al.(2003) M.A. Martí-Renom, A.C. Stuart, A. Fiser, R. Sánchez, F. Melo, e A. Šali. Comparative protein structure modeling of genes and genomes. Annual review of biophysics and biomolecular structure, 29(1):291. Citado na pág. 16 
Maupetit et al.(2007) J. Maupetit, P. Tuffery, e P. Derreumaux. A coarse-grained protein force field for folding and structure prediction. Proteins: Structure, Function, and Bioinformatics, 69(2):394-408. Citado na pág. 36

Mitchell(1996) M. Mitchell. An Introduction To Genetic Algorithms. Mit Press, Cambridge, Ma, Usa. ISBN 0-262-13316-4. Citado na pág. 21, 33

Moult et al.(2009) J. Moult, K. Fidelis, A. Kryshtafovych, Rost B., e A. Tramontano. Critical assessment of methods of protein structure prediction round viii. Proteins: Structure, Function, and Bioinformatics, 77:1-4. Citado na pág. 15

Muhlenbein(1991) H. Muhlenbein. Evolution in time and space-the parallel genetic algorithm. Em Foundations of genetic algorithms. Citeseer. Citado na pág. 96

Nugent et al.(2011) T. Nugent, S. Ward, e D.T. Jones. The mempack alpha-helical transmembrane protein structure prediction server. Bioinformatics. ISSN 13674803. Citado na pág. 1

Opella et al.(1999) S. J. Opella, F. M. Marassi, J. J. Gesell, A. P. Valente, Y. Kim, M. Oblatt-Montal, e M. Montal. Structures of the $\mathrm{m} 2$ channel-lining segments from nicotinic acetylcholine and nmda receptors by nmr spectroscopy. Nat. Struct. Biol., 6:374 - 379. Citado na pág. 42

Pearlman et al.(1995) D. A. Pearlman, D. A. Case, J. W. Caldwell, e W. S. Ross. Amber, a package of computer programs for applying molecular mechanics, normal mode analysis, molecular dynamics and free energy calculations to simulate the structural and energetic properties of molecules. Computer Physics Communications, 91:1-41. Citado na pág. 21

Pedersen e Moult(1996) J. T. Pedersen e J. Moult. Genetic algorithms for protein structure prediction. Current Opinion In Structural Biology, 6(2):227 - 231. Citado na pág. 1

Pevsner(2009) J. Pevsner. Bioinformatics and functional genomics. Blackwell Pub. ISBN 0470085851. Citado na pág. 16

Ponder et al.(1998) J.W. Ponder et al. Tinker: software tools for molecular design. Department of Biochemistry and Molecular Biophysics, Washington University School of Medicine, St. Louis, MO. Citado na pág. 30, 34, 41

Raman et al.(2009) S. Raman, R. Vernon, J. Thompson, M. Tyka, R. Sadreyev, J. Pei, D. Kim, E. Kellogg, F. DiMaio, O. Lange, et al. Structure prediction for casp8 with all-atom refinement using rosetta. Proteins: Structure, Function, and Bioinformatics, 77(S9):89-99. ISSN 1097-0134. Citado na pág. 18, 19, 96

Roy et al.(2010) A. Roy, A. Kucukural, e Y. Zhang. I-tasser: a unified platform for automated protein structure and function prediction. Nature protocols, 5(4):725738. ISSN 1754-2189. Citado na pág. 19

Schulze-Kremer(2003a) S. Schulze-Kremer. Application Of Evolutionary Computation To Protein Folding. Springer-Verlag New York, Inc., New York, Ny, Usa. ISBN 3-540-43330-9. Citado na pág. 1, 2 
Schulze-Kremer(2003b) S. Schulze-Kremer. Application of evolutionary computation to protein folding with specialized operators. Em Evolutionary computation in bioinformatics. Morgan Kaufmann Pub. Citado na pág. 26

Scott et al.(1999) W. R. P. Scott, H. Hunenberger, I. G. Tironi, A. E. Mark, S. R. Billeter, J. Fennen, A. E. Torda, T. Huber, P. Kruger, e W. F. Van Gunsteren. The gromos biomolecular simulation program package. Journal of Physical Chemistry A, 103:3596-3607. Citado na pág. 21

Shi et al.(2001) J. Shi, T.L. Blundell, e K. Mizuguchi. Fugue: sequence-structure homology recognition using environment-specific substitution tables and structuredependent gap penalties1. Journal of Molecular Biology, 310(1):243-257. Citado na pág. 19

Simons et al.(1997a) K.T. Simons, C. Kooperberg, E. Huang, e D. Baker. Assembly of protein tertiary structures from fragments with similar local sequences using simulated annealing and bayesian scoring functions1. Journal of Molecular Biology, 268(1):209-225. ISSN 0022-2836. Citado na pág. 63

Simons et al.(1997b) K.T. Simons, C. Kooperberg, E. Huang, e D. Baker. Assembly of protein tertiary structures from fragments with similar local sequences using simulated annealing and bayesian scoring functions. Journal of molecular biology, 268(1):209-225. Citado na pág. 19

Soding(2005) J. Soding. Protein homology detection by hmm-hmm comparison. Bioinformatics, 21(7):951. Citado na pág. 20

Stender(1993) J. Stender. Parallel genetic algorithms: theory and applications. Ios Pr Inc. Citado na pág. 96

Takeshi et al.(2008) N. S. Takeshi, C. Hikmet, e S. Masaki. A coarse-grained langevin molecular dynamics approach to de novo protein structure prediction. Biochemical and Biophysical Research Communications, 369:500-506. Citado na pág. 18

Team(2008) R. Team. R: A language and environment for statistical computing. $R$ Foundation for Statistical Computing Vienna Austria ISBN, 3(10). ISSN 1600-0706. Citado na pág. 46

Tozzini(2005) V. Tozzini. Coarse-grained models for proteins. Current opinion in structural biology, 15(2):144-150. ISSN 0959-440X. Citado na pág. 89, 95

Unger(2004) R. Unger. Genetic algorithms aproach for protein structure prediction. Structure and Bonding, 110:153-175. Citado na pág. 1, 2

Unger e Moult(1993) R. Unger e J. Moult. Genetic algorithms for protein folding simulations. Journal Of Molecular Biology, 231(1):75 - 81. Citado na pág. 1, 2, 26

Unizar(2010) Unizar. Ângulos diedrais. Internet (Visitada Em 31/01/2010), 2010. Url: Http://www.unizar.es/. Citado na pág. xiii, 8

Voet e Voet(2003) D. Voet e J. G. Voet. Bioquímica. Porto Alegre: Artes Médicas, 3rd edition edição. Citado na pág. $7,8,11$ 
Wu e Zhang(2007) S. Wu e Y. Zhang. Lomets: a local meta-threading-server for protein structure prediction. Nucleic acids research, 35(10):3375. Citado na pág. 19, 20

Xu e Xu(2000) Y. Xu e D. Xu. Protein threading using prospect: design and evaluation. Proteins: Structure, Function, and Bioinformatics, 40(3):343-354. Citado na pág. 20

Yap et al.(2008) E. Yap, N. L. Fawzi, e T. Head-Gordon. A coarse-grained alphacarbon protein model with anisotropic hydrogen-bonding. Proteins: Structure, Function, and Bioinformatics, 70(3):626-638. Citado na pág. xvii, 2, 21, 27, 35, 36, $37,38,39,40,41,43,47,88,89,92$

Zhang et al.(2010) X. Zhang, T. Wang, H. Luo, J. Yang, Y. Deng, J. Tang, e M. Yang. $3 \mathrm{~d}$ protein structure prediction with genetic tabu search algorithm. BMC Systems Biology, 4(Suppl 1):S6. ISSN 1752-0509. doi: 10.1186/1752-0509-4-S1-S6. URL http://www.biomedcentral.com/1752-0509/4/S1/S6. Citado na pág. 1, 26

Zhang(2008) Y. Zhang. I-tasser server for protein 3d structure prediction. BMC Bioinformatics, 9(1):40. Citado na pág. 1, 17, 18

Zhang e Skolnick(2004) Y. Zhang e J. Skolnick. Automated structure prediction of weakly homologous proteins on a genomic scale. Proceedings Of The National Academy Of Sciences Of The United States Of America, 101(20):7594-7599. Citado na pág. 18

Zhou e Zhou(2004) H. Zhou e Y. Zhou. Single-body residue-level knowledge-based energy score combined with sequence-profile and secondary structure information for fold recognition. Proteins Structure Function and Bioinformatics, 55(4):10051013. Citado na pág. 20

Zhou e Zhou(2005) H. Zhou e Y. Zhou. Fold recognition by combining sequence profiles derived from evolution and from depth-dependent structural alignment of fragments. Proteins, 58(2):321. Citado na pág. 20 